\title{
Using wind fields from a high resolution atmospheric model for simulating snow dynamics in mountainous terrain
}

Dissertation der Fakultät für Geowissenschaften der

Ludwig-Maximilians-Universität zu München

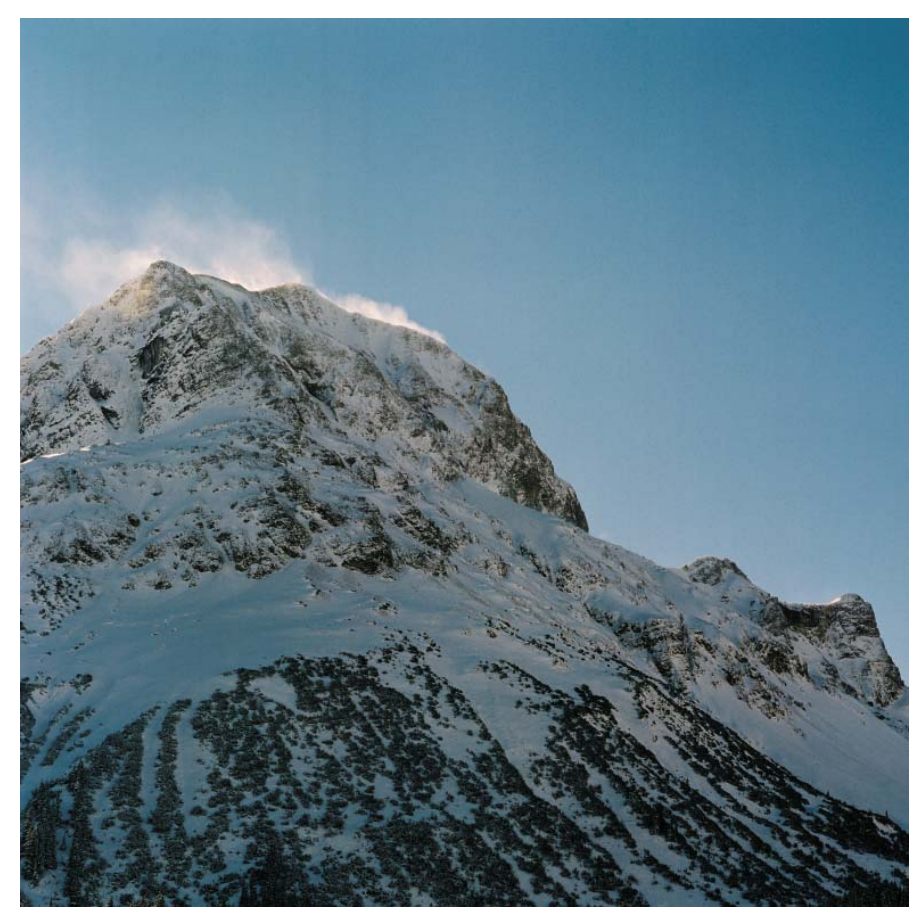

vorgelegt von:

Matthias Bernhardt

aus München

Eingereicht im Juli 2008 
Gähds ned übern Berg, gähds außn rum, awa weida geh muaß.

(Bayerische Weisheit) 
1. Gutachter:

Prof. Dr. Wolfram Mauser

2. Gutachter:

Prof. Dr. Michael Kuhn

Tag der mündlichen Prüfung: 27.10.2008 


\section{Zusammenfassung}

Der Einfluss der Schneedecke auf die Hydrologie Alpiner Einzugsgebiete ist weithin bekannt und in der Literatur eindrucksvoll beschrieben. Saisonale Schneedecken fungieren als temporäre Speicher für den Niederschlag. Das gebundene Wasser wird den Fließgewässern verzögert als Schmelzwasser zugeführt und bestimmt damit zumindest zeitweise deren Abflusshöhe und -menge. Die Modellierung von mengenmäßigem Inhalt und räumlicher Ausdehnung des Schneespeichers ist hilfreich für die Quantifizierung der vorhandenen Wasserressourcen und für die Bestimmung des Zeitpunkts, zu dem die gespeicherten Wassermengen verfügbar werden. Die Intensität der Schneeschmelze hängt dabei, neben der absoluten räumlichen Lage, auch von der räumlichen Heterogenität der Schneedecke ab. In der vorliegenden Arbeit wurde der Einfluss von wind-induzierten Schneetransportprozessen auf die Heterogenität der Alpinen Schneedecke untersucht. Als Testgebiet wurde der Nationalpark Berchtesgaden ausgewählt. Dieses Testgebiet kann aufgrund seiner hohen

Reliefenergie als ideal für die durchgeführten Untersuchungen gelten, da Schneetransportprozesse hier besonders effektiv sind. Die Instrumentierung des Parks ist im Hinblick auf die verfügbaren meteorologischen Stationen außerordentlich gut. Darüber hinaus liegen flächendeckende Informationen über die Geländehöhe und die Vegetation in Form eines hoch aufgelösten (10m) Geographischen Informationssystems (GIS) vor. Für den Untersuchungszeitraum (Wintersaison 2003/2004 und 2004/2005, jeweils gerechnet von August bis Juli) liegen Daten von 5 meteorologischen Stationen, einer Feldkampagne und zwei Landsat ETM+ Bildern vor.

Windinduzierter Schneetransport wird in der Literatur häufig als der bestimmende Prozess für die Heterogenität der Schneedecken in gebirgigen Gebieten angesehen. In starkem Kontrast zu der diesem Prozess zugestandenen Bedeutung, steht die Anzahl der Veröffentlichungen, die die numerische Untersuchung der Effektivität desselben zum Inhalt haben. Das liegt vor allem in der Tatsache begründet, dass die Berechnung von qualitativ hochwertigen Windfeldern in gebirgigem Terrain bis heute nahezu unmöglich ist. Diese allerdings sind von zentraler Bedeutung, um quantitative Aussagen über die Richtung der Verlagerung von Schneemengen zu treffen, und um die entsprechenden Erosions- wie Akkumulationsgebiete 
zu lokalisieren. Für eine möglichst genaue Charakterisierung der Windfelder im Untersuchungsgebiet wurden in der vorliegenden Arbeit physikalisch basierte Windfelder mit Hilfe des PSU-NCAR MM5 Atmosphärenmodells berechnet. Diese wurden im Anschluss in dem etablierten Schneemodell SnowModel als Antrieb für die Schneetransportroutine (SnowTran-3D) verwendet.

Da eine direkte Kopplung von Atmosphärenmodell und Schneemodell unter den heute gegebenen technischen Voraussetzungen zu einer unrealistisch hohen Modell-Laufzeit geführt hätte, wurde eine alternative Methode gewählt: die Windfelder wurden separat berechnet und eine Bibliothek repräsentativer Windfelder für das Untersuchungsgebiet erzeugt. Die zeitliche Synchronisation zwischen Windfeldbibliothek und Schneemodell wurde über das operationelle, mesoskalige Wettervorhersage-Modell des Deutschen Wetterdienstes (DWD), das Lokalmodell hergestellt. Dies wurde aufgrund der Tatsache möglich, dass bestimmte Modellausgaben von Lokalmodell und MM5 im 700 hPa Niveau vergleichbar sind. Um das richtige Windfeld für einen Schneemodellzeitschritt aus der zuvor erzeugten MM5 Windfeldbibliothek auszuwählen, wurden mittlere Windvektoren der MM5 Windfelder mit mittleren Vektoren der entsprechenden Lokalmodell Windfelder verglichen. So wurde es möglich, zu jedem Modellzeitschritt des Lokalmodells (eine Stunde) ein MM5 Windfeld zu selektieren und im Schneemodel anzuwenden.

Die generierten MM5 Windfelder haben eine räumliche Auflösung von 200m. Für eine prinzipielle Überprüfung der Funktionalität des Schneemodels in Verbindung mit einer MM5 Windfeldbibliothek, wurden erste Schneemodelläufe auf der 200m Skala initialisiert. Die zugehörigen Ergebnisse waren plausibel und bestätigten die Anwendbarkeit der Kombination von Schneemodell und MM5 Windfeldern. Die Schneewasseräquivalentverteilung im Gebiet wurde durch die Applikation der MM5 Windfelder weniger abhängig von der allgemeinen niederschlagsbedingten Zunahme des Schneewasseräquivalents mit der Höhe. Ein Zusammenhang mit der Exposition des Geländes konnte nun auch aufgezeigt werden. Zudem konnten Transportprozesse über die Bergkämme hinweg simuliert werden. Eine Intensitätszunahme aller Transportterme unter Anwendung der MM5 Windfelder im Vergleich zu interpolierten Windfeldern konnte ebenfalls festgestellt werden. Die Ergebnisse 
auf der 200m Skala machten deutlich, dass für eine ausreichende und tiefgreifende Beschreibung und Validierung von Schneetransportprozessen ein feineres Modellgrid erforderlich ist. Als Konsequenz wurden die MM5 Windfelder auf eine Auflösung von 30m skaliert. Durch die Skalierungsprozedur konnte eine bessere Korrelation zwischen Stationsmessungen und MM5 Ergebnissen erreicht werden. Die resultierenden 30m Windfelder wurden für hochauflösende 30m Schneemodellläufe genutzt, die auf der Basis von Ergebnissen der durchgeführten Feldkampagnen und Fernerkundungsdaten validiert werden konnten. Auch hier konnte nachgewiesen werden, dass die unter Verwendung der MM5 Windfeldbibiliothek generierten Resultate von höherer Validität waren, als die Ergebnisse die mit Hilfe von interpolierten Windfeldern erzeugt wurden.

Im Weiteren wurden die Modellergebnisse anhand ausgewählter Resultate diskutiert. Es konnte gezeigt werden, dass die Effektivität von Transportprozessen unter 1800m ü. NN. zu vernachlässigen ist und ab 2200m ü. NN. stark zunimmt. Zudem konnte unter Nutzung der MM5 Windfelder der Transport von Schnee auf vergletscherte Flächen modelliert werden. Hohe modellierte Sublimationsraten an den Gipfeln wurden diskutiert und ihre Wichtigkeit im Bezug auf die alpine Wasserbilanz aufgezeigt. Im Ganzen konnte nachgewiesen werden, dass die Einbindung von Ergebnisdaten von Atmosphärenmodellen zu einer deutlichen Verbesserung der Beschreibung der Prozesse an der Erdoberfläche führt.

In einem letzten Schritt wurden die Ergebnisse der hochaufgelösten Schneemodellläufe genutzt, um die Schneedeckenheterogenität im Gebiet zu parametrisieren. Ziel war es, eine Möglichkeit aufzuzeigen, die generierte kleinskalige Information auch für regionale Landoberflächenmodelle nutzbar $\mathrm{zu}$ machen. Infolgedessen wurde eine einfach zu implementierende Routine für regionale Modelle vorgestellt, die die subskalige Beschreibung der Schneedeckenheterogenität erlaubt. Dies kann in entsprechendem Relief zu einer Verbesserung der Energie- und Feuchteflüsse in regionalen Modellen und damit zu einer akkurateren Beschreibung der Ablationsperiode der Schneedecke und der Abflussgenerierung führen. 


\section{Abstract}

It is widely known that the snow cover has a major influence on the hydrology of Alpine watersheds. Snow acts as temporal storage for precipitation during the winter season. The stored water is later released as snowmelt and represents an important component of water supply for the downstream population of large mountain-foreland river systems worldwide. Modelling the amount and position of the snow water stored in the headwater catchments helps to quantify the available water resources and to estimate the timing of their release. The presented work investigates wind induced snow transport processes which are considered to be crucial for the snow distribution in Alpine catchments. In contradiction to the importance that is attributed to this process, there are only a few studies available which have quantified the transport intensities on the catchment scale. This can be attributed to the fact that the even today not much is known about the spatial characteristics of wind fields which are the driving force for snow transport processes. The presented thesis tries to overcome this lack of information by using physically based wind fields predicted by an atmospheric model (PSU_NCAR MM5 model) for the modelling of the snow cover (simulated by SnowModel). All of the used models are described in great detail in the literature, validated in many different regions, and can be seen as applicable with regard to the goal of this work. As snow transport processes are particularly important on a comparatively small scale a numerical inclusion of the responsible processes into regional models is inadequate. Hence, while this study itself mainly uses smaller scale physically based models, a parameterisation scheme is presented at the end of this thesis that is able to incorporate its main findings into larger scale models.

All of the presented work was carried out at the Berchtesgaden National Park. The site is highly appropriate because of the extremely rough terrain and the good accessibility. Furthermore, the instrumentation of the area is comparatively good and the data sources (GIS, field campaign data) are excellent. The thesis deals with the winter seasons (August - July) 2003/2004 and 2004/2005. For this period, data of 5 meteorological stations, 1 field campaign and two Landsat ETM+ images were available. 
As mentioned before, physically based wind fields were used as input for the snow transport modelling. An operational coupling between atmospheric model and snow transport model was not pursued because of the high computational costs of the atmospheric model. Thus, a library of representative wind fields was produced in advance and linked to the snow transport model via operational German weather service Lokalmodell results. This becomes possible because of the comparability of a MM5 model layer with one of the Lokalmodell model layers. To link the wind field library to the snow model all of the predicted MM5 wind fields were characterised by information available from the Lokalmodell. This enable an easy detection of the MM5 wind field which is closest to the real climatic wind conditions at any Lokalmodell time step (1 hour).

The produced MM5 wind fields have a spatial resolution of 200 meters. As an initial check if the snow cover simulation of SnowModel in association with the wind field library delivers adequate results with respect to the snow distribution, model runs were first carried out at the $200 \mathrm{~m}$ scale. An analysis of the results showed that the coupled routine delivers acceptable results. It could be seen that with the use of the MM5 wind fields, the snow cover becomes more anisotropic and that transport processes over crests as well as sublimation processes are predicted to become more intensive. Nevertheless, a higher resolution was needed to quatify the effects and to validate the results.

In a subsequent step the MM5 wind fields were downscaled to a $30 \mathrm{~m}$ resolution. The downscaling procedure lead to a better agreement between modelled and measured wind speeds. The resulting 30m wind fields were used for high resolution model runs which were validated on the basis of the field campaign and remotely sensed data. A comparison with model runs using wind fields interpolated from station data showed that the runs performed with the MM5 wind fields deliver more consistent and comprehensible results.

Subsequently, the validity of the model is discussed on the basis of selected results. High resolution model results indicated that snow transport processes are effective at high elevations but virtually negligible for regions below of $1800 \mathrm{~m}$ a.s.l.. Furthermore, it could be seen that the correct estimation of snow transport from the surrounding areas to glaciers becomes possible by using the MM5 wind fields. Very high modelled sublimation rates at the 
mountains crests are discusses with respect to their importance on the water balance. Furthermore, the influence of preferential snow deposition and snow slides which were not numerically predicted in this work were discusses. Additionally, the applicability of atmospheric model results as input for land-surface models could be confirmed.

In a final step a model scheme is presented that would make the generated information available for regional scale models. This model parameterization scheme which is based on the modelled 30m snow water equivalent distribution within the test area was used for this area. The scheme allows for a quick and simple description of the subscale snow heterogeneity in regional scale models. This can lead to considerable model improvements with respect to the description of the energy and moisture fluxes to and from the surface. An accurate description of these fluxes is essential for an accurate simulation of the melt period and, therefore, for an acceptable calculation of the runoff generation in larger scale models. 


\section{Preface}

The presented work was realized within the framework of GLOWA_Danube a project of the German Ministry for Education and Research $(b m b+f)$. The goal of the work was to investigate how wind induced snow transport processes can influence the Alpine snow cover and how the effects can be implemented in SVAT schemes.

The work was carried out at the Department of Geography within the workgroup of Prof. Dr. Wolfram Mauser. Prof. Dr. Mauser gave me the chance to join his group after my Diploma and he also had the fundamental idea for this thesis, which was, to couple a library of MM5 wind fields with a snow transport routine. Additionally, I would like to thank him for his permanent support (in regard to specialist knowledge, the excellent environment, the possibility to travel to workshops and finally to organise the Alpine*Snow*Workshop together with (Dr. Ulrich Strasser) and his feeling for the workgroup which has generated the best imaginable work climate at the institute. Furthermore, he gave me the chance to gain first experiences in teaching.

I greatly acknowledge the fruitful collaboration with Dr. Glen Liston of the Cooperative Institute for Research in the Atmosphere (CIRA) Colorado State University. He supported me by providing me with the source code of his models and answered any question in an unbelievable time and detail.

At the institute I would like to thank Dr. Ulrich Strasser for his support and interest in this work. The cooperation with him was inspiring and characterized by open discussions inside the institute or at the Steinheil.

I would also like to thank Tobias Hank and Thomas Marke my office roommates. We had a very special work atmosphere, characterized by very useful discussions.

Dr. Günther Zängl has supported me with his infinite knowledge about MM5 and supported me at every time of my work.

I would like to thank Dr. Stefan Pohl for his expertise which has helped to improve this work and for the fruitful discussions. 
My cordial thanks go to all of my dear colleagues which gave me a lot of support during the last years. They are in alphabetical order: Dominik Aulehner, Heike Bach, Ludwig Braun, Marco Braun, Andrea Ebner, Rainer Efinger, Heidi Escher-Vetter, Vera Erfurth, Khaled Haider, Christoph Heinzeller, Jochen Henkel, Ingo Keding, Lorenz Köppl, Alexander Löw, Ralf Ludwig (viva FCB), Stefanie Mayer, Christian Michelbach, Markus Muerth, Susan Niebergall, Natascha Oppelt, Monika Prasch, Renate Santl, Roswitha Stolz, Monika Tepfenhart, Michael Vogel, Daniel Waldmann, Ruth Weidinger.

The Berchtesgaden National Park Administration supported me with field campaign data and offered free access to all required data. Helmut Franz which has coordinated all of this work should be explicitly mentioned here.

Last but not least I would like to thank my family and my girlfriend Daniela Funk who supported me during the last weeks of my work and who has improved the thesis by her work at the institute. 


\section{Table of contents}

\section{Chapter 1 Introduction}

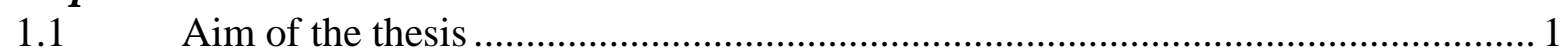

$1.2 \quad$ Introduction and methodology ………………................................................

1.2.1 The snow cover an important land surface feature ............................................... 2

1.2.2 Snow cover modelling ....................................................................................... 5

1.2.3 Model approach of the presented work .............................................................. 8

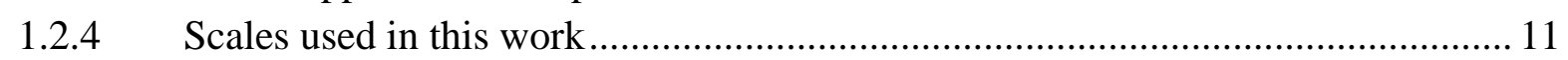

$1.3 \quad$ Test Sites and field measurements ...................................................................... 13

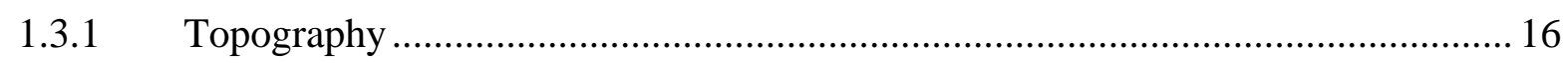

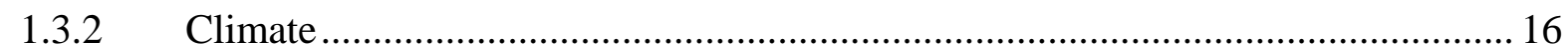

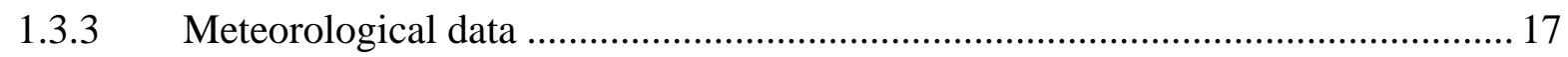

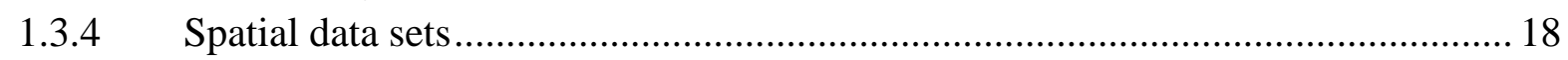

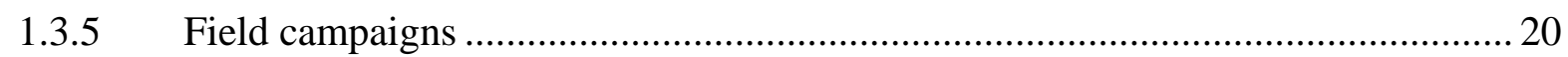

\section{Chapter 2 Model descriptions}

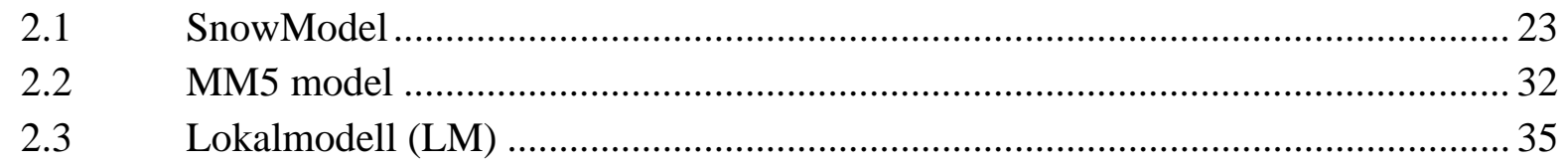

\section{Chapter 3 Meteorological fields}

3.1 Interpolation of meteorological parameters, capabillities and limitations............... 37

3.2 Calculation of wind fields in mountainous terrain................................................. 40

3.2.1 Theoretical background ........................................................................................ 43

3.2.2 Comparison of interpolated and modelled wind fields ........................................... 47

3.3 Creation and synchronisation of a MM5 predicted wind field library....................53

\section{Chapter 4 Snow transport modelling}

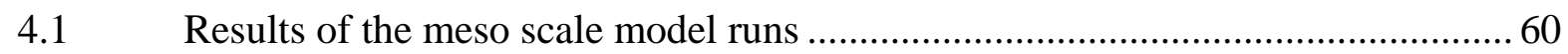

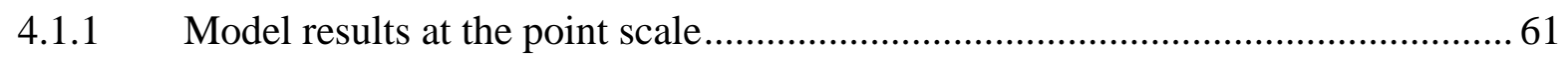

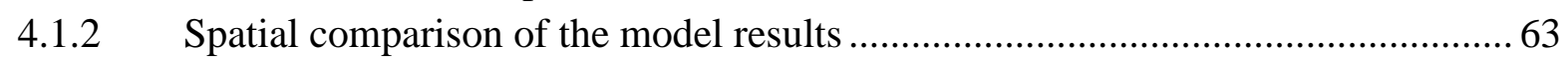

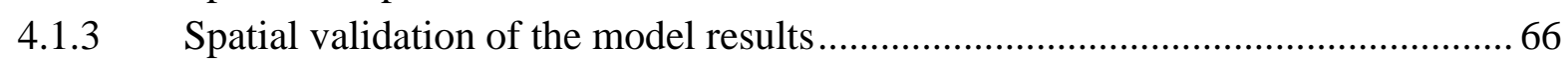

$4.2 \quad$ Downscaling of the MM5 wind fields............................................................... 72

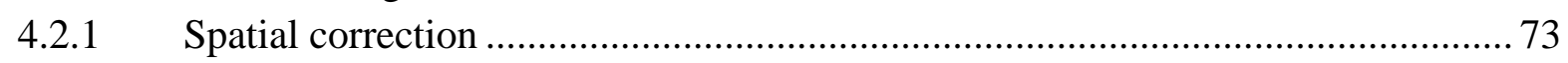

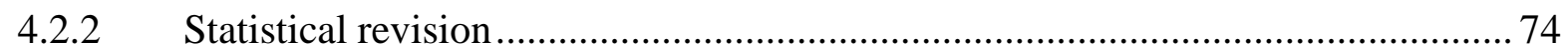

4.2.3 Inclusion of the elevation difference between MM5 and 30m DEM ..................... 75

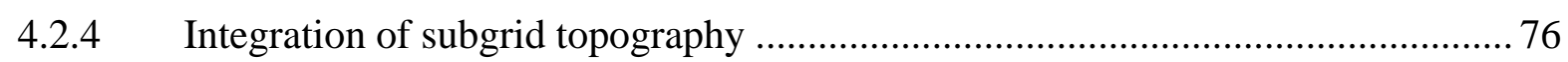




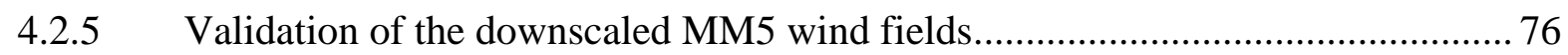

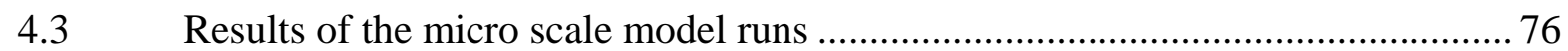

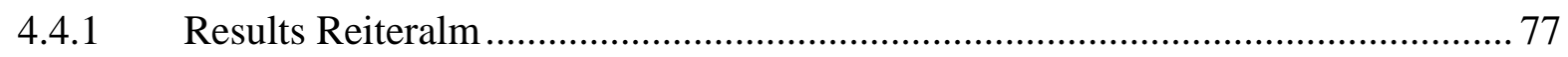

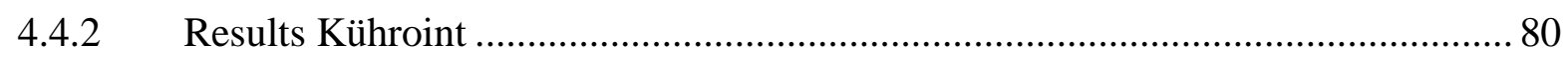

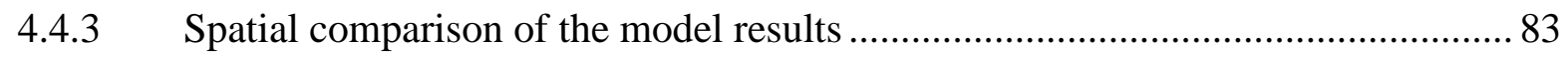

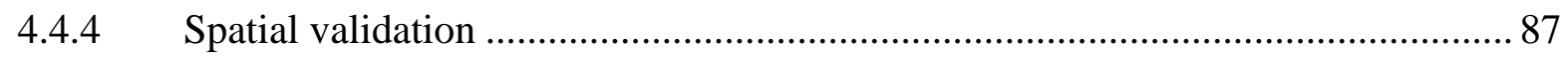

\section{Chapter 5 Discussion of the SnowModel results}

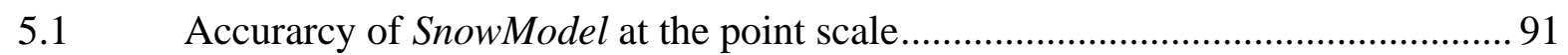

5.2 Accurarcy of SnowModel with respect to remotely sensed data............................. 94

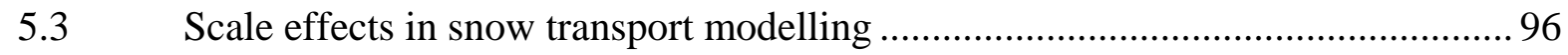

5.4 Discussion of enhanced accumulation and sublimation rates when using MM5

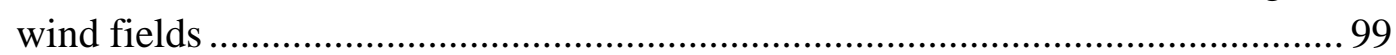

5.5 High interpolated precipitation rates as a possible reason for the underestimation

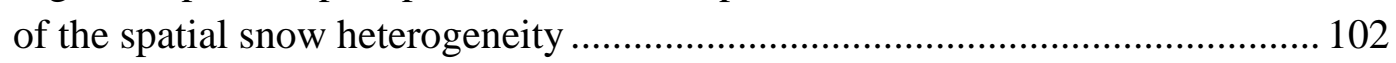

5.6 The effects of snow slides and preferential snow distribution............................ 103

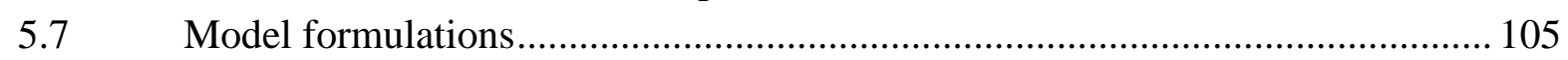

\section{Chapter 6 Outlook and Conclusion}

6.1 Presentation of a scheme which allows for a better description of the snow cover

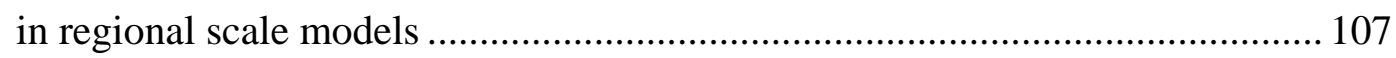

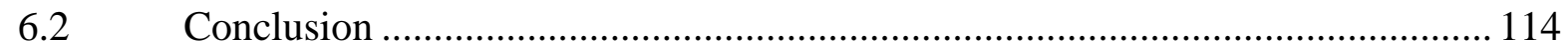

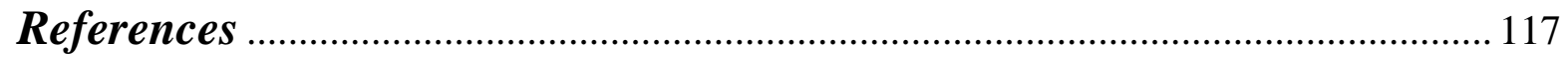

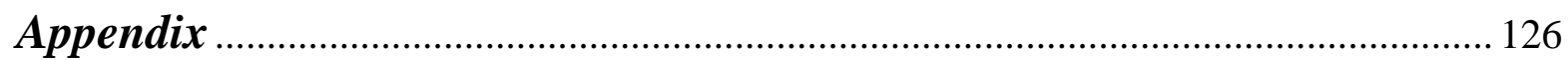




\section{List of figures}

Figure 1: Examples for snow heterogeneity in the Arctic region, in undulating terrain and within a mountainous area (Photos by: M. Sturm, D. Marks)................................. 1

Figure 2: a) Snow cover at Watzmann Mountain (turquoise) superimposed by a $1 \mathrm{~km}^{2}$ grid. b) Interrelation between snow covered area and energy fluxes $(\mathrm{Qli}=$ incoming longwave radiation, Qle = emitted longwave radiation, $\mathrm{Qh}=$ turbulent exchange of sensible heat, $\mathrm{Q}_{\mathrm{e}}=$ turbulent exchange of latent heat, $\mathrm{Q}_{\mathrm{ns}}=$ net solar radiative flux at the surface, $\mathrm{Q}_{\mathrm{m}}=$ energy flux available for melt) (cp. Liston 1995)............. 4

Figure 3: Schematic of the five nested domains used in MM5. The largest one is nesting domain_1, the smallest is domain_5. Domain_3 is marked as red rectangle. 10

Figure 4: Scales used in this thesis. The work starts at the meso scale for which the MM5 wind fields are representative for $(200 \mathrm{~m})$. After than the wind fields are downscaled to a $30 \mathrm{~m}$ resolution (micro scale). The SnowModel results at the micro scale are validated on the basis of field campaign and remotely sensed data. The information produced by the micro scale runs is used for a parameterisation scheme for the snow heterogeneity which can be used in regional scale Models. 12

Figure 5: Test site (Berchtesgaden National Park) (Bayerisches Landesvermessungsamt 1994, modified). The locations of Reiteralm 1, 2 and 3, Schönau, Kühroint and Jenner are marked with arrows. The test sites at Reiteralm and Kühroint are displayed as chequered areas.

Figure 6: Profile through the National Park area which displays the rapid changes in altitude in the test area.

Figure 7: Location of the meteorological stations.

Figure 8: GIS data used in this work. a) elevation (m a.s.l.), b) vegetation types, c) aspect $\left({ }^{\circ}\right)$ and d) slope $\left(^{\circ}\right)$

Figure 9: Sample points at Reiteralm. 15 sample points were installed in the winter season 2004/05 the points are named 1-15.

Figure 10: Sample points at Kühroint. 15 sample points were installed in the winter season 2004/05 the points are named A-O.

Figure 11: Schematic illustration of the transport model. Qt = mass transport rates of saltation, Qs = mass transport rates of turbulent suspended snow, Qv = sublimation of transported snow particles. $\mathrm{P}=$ water equivalent precipitation rate. $\mathrm{CV}=$ snow holding capacity. $\mathrm{h} *=$ top of the saltation layer.

Figure 12: Connection between wind-shear velocity and transport rate (ср. Liston and Strum 1998) 
Figure 13: Schematic illustration of the MM5 nesting domains (the largest domain is domain_1, the smallest domain_5) and of the needed input parameters.

Figure 14: a) Spatial distribution of the meteorological stations within the upper Danube catchment, b) Area of the different elevation bands and number of stations at the respective altitudes.

Figure 15: Temperature recordings of Reiteralm II meteorological station. Comparison of hourly modelled and observed data for the winter season 2003/2004.

Figure 16: Incoming solar radiation data from Reiteralm 3 meteorological station. Comparison of hourly modelled and observed data for the winter season 2003/2004.

Figure 17: Relative humidity from Reiteralm 3 meteorological station. Comparison of hourly modeled and observed data for the winter season 2003/2004. 40

Figure 18: Correlation between measured and calculated precipitation rates (winter season 2003/2004) (mm). a) Including hours with precipitation at other stations but no precipitation at the validation station (Reiteralm 1) and b) precipitation at all stations, including Reiteralm 1.

Figure 19: Accuracy of interpolated wind directions in comparison to measurements at Reiteralm I (winter season 2003/2004).

Figure 20: Comparison of measured and interpolated wind speeds at Reiteralm 1 (winter season 2003/2004).

Figure 21: Frozen anemometer. This picture shows a very common situation in Alpine regions. The sensor becomes snow covered and becomes therefore unusable.... 44

Figure 22: Vertical profile through a MM5 wind field. a, b and c are fictive meteorological stations. The transects I, II, III are used for declare the wind conditions at the faces of Watzmann mountain. The wind speed is slightly enhanced at the windward site (transect I) as the wind direction is constant to North. Transect II and II showing the complex wind conditions at the leeside. The wind speeds are about $6[\mathrm{~m} / \mathrm{sec}]$ at transect II, the wind direction is to north. The situation changes at transect III were the wind speed is between 0 and $2[\mathrm{~m} / \mathrm{sec}]$ and the wind direction is to south.

Figure 23: Generalized flow behaviour over a hill: a) flow separation and b) a rotor (Barry 1992, modified).

Figure 24: a) MM5 wind field (input parameters: wind direction $=140^{\circ}$ and $10[\mathrm{~m} / \mathrm{sec}]$ at $10 \mathrm{~m}$ and $25[\mathrm{~m} / \mathrm{sec}]$ at $100 \mathrm{hpa}$ ) b) MM5 wind field calculated with the same input wind speeds but an input wind direction of $270^{\circ}$. 
Figure 25: Interpolated wind fields. a) The average wind directions at the meteorological stations are $140^{\circ}$ and b) $270^{\circ}$.

Figure 26: Spatial characteristics of $M M 5$ wind direction fields in dependency of the synoptic inflow. The inflow direction is 265 degrees and 270 degrees respectively.

Figure 27: Spatial characteristics of an interpolated wind direction field. The wind directions used for the interpolation corresponding to the wind directions produced by MM5 (fig 26) for the three indicated meteorological stations.

Figure 28: Dependency of the calculated MM5 wind direction field on the input wind speed. The wind speeds used for the model setup were $05[\mathrm{~m} / \mathrm{sec}]$ for the $10 \mathrm{~m}$ model level and 20 [m/sec] for the uppermost model level (cp. fig. 13)

Figure 29: Schematic illustration of the synchronization of MM5 wind field library and SnowModel via hourly DWD Lokalmodell information.

Figure 30: $D W D$ historical data for the $700 \mathrm{hPa}$ level (gray dots) vs. averaged MM5 domain_3 vectors (black dots). The DWD observations were used for defining the initialisation wind speeds and directions needed for the MM5 runs (cp. fig. 13). 55

Figure 31: The red coloured areas in a) and b) stand for wind speeds $>3[\mathrm{~m} / \mathrm{sec}]$ which would be able to initialise snow transport processes. The MM5 wind fields were calculated with very moderate input wind speeds $\left(30^{\circ} / 5[\mathrm{~m} / \mathrm{sec}]\right.$ at $10 \mathrm{~m}$; $16[\mathrm{~m} / \mathrm{sec}]$ at $100 \mathrm{hpa}$ and $143^{\circ} / 5[\mathrm{~m} / \mathrm{sec}]$ at $10 \mathrm{~m} ; 20[\mathrm{~m} / \mathrm{sec}]$ at $\left.100 \mathrm{hpa}\right)$ 56

Figure 32: Comparison of measured and MM5 wind a) direction (01.09.03-30.08.04) and b) speed (01.09.03-31.12.03)at Reiteralm I. A comparrison to figures 19 a) and b) clearifies the advantages in contrast to the interpolation routine.

Figure 33: Wind speed provided by the interpolation procedure of Liston and Sturm (1998) (left) and MM5 (right). The images represent the situation on January 9, 2004, 7:00. Wind direction is 270 degrees.

Figure 34: Wind direction (detail of the Watzmann region), derived after Ryan (1977) (left) and MM5 (right), respectively. The images represent the situation on January 9, 2004, 7:00. Wind direction is 270 degrees. 58

Figure 35: a) Percentage of hours with wind speeds higher than 3 [m/sec] (MM5 fields). b) Percentage of hours with wind speeds higher than $3[\mathrm{~m} / \mathrm{sec}]$ (interpolated fields). Difference between the averaged interpolated and MM5 wind speed for the winter season 2003/2004 (The black line is the $1800 \mathrm{~m}$ a.s.l. contour). 59

Figure 36: Comparison of model results and measured values for the meteorological stations a) Reiteralm II, b) III and c) Jenner. 62 
Figure 37: Amount of accumulated and eroded SWE within the study area and for the winter season (2003/04) (Please note the different scales of the legends). The accumulation zone at Blaueis glacier is marked with a black ellipse. The black line is the $1800 \mathrm{~m}$ isohypsis. 63

Figure 38: a) SWE [m] - elevation dependency b) SWE - aspect dependency for the total elevation interval c) SWE - aspect dependency for elevations higher than 1800m a.s.l. d) SWE - aspect dependency for elevations higher than 2200m a.s.l. SWE is the average values for the modelled time period. The different volumes under the curves are due to higher sublimation losses within the MM5 runs. The illustrations belonging to the winter season 2003/04 64

Figure 39: Intensities of the different transport terms: saltation, suspension and sublimation in a) c) e) INTER and b) d) f) MM5 (winter season 2003/04). The black line is the $1800 \mathrm{~m}$ isohypsis. 66

Figure 40: a) Spectral bands of Landsat ETM+ and spectral characteristics of different snow types. b) spectral Characteristics of different land cover types 68

Figure 41: a) modelled snow cover of April 28, 2004, b) NDSI map of the same date, c) modelled snow cover of Mai 30, 2004 d) NDSI map of the same date. The black line is the $1800 \mathrm{~m}$ isohypsis. 70

Figure 42: a) c): Landsat ETM+ images (April, 282004 and May, 30 2004. resampled to a 200m resolution). e) f): Differences between model an classification results at April and May respectively (red indicates: only classified snow cover. Green: only modelled snow cover).

Figure 43: a) The smoothed Reiteralm area (marked with an arrow) within the MM5 DEM (200 m resolution) compared to b) the National Park DEM (30 m resolution). ... 72

Figure 44: Performed downscaling steps. The figure shows the a schematic illustration of the downscaling steps conducted in 4.2.1 to 4.2.3. 73

Figure 45: a) Correlation between MM5 results and station recordings before the downscaling procedure (Reiteralm $I$, daily resolution) b) Correlation between MM5 results and station recordings after the downscaling procedure. The regression line is forced through the origin. 76

Figure 46: Comparison of model and measurements. White dots indicating that the model is within $10 \%$ of the measurements. Green dots stand for a model overestimation of the snow depth from more than $10 \%$, red dots for a model underestimation from more than $10 \%$. 78

Figure 47: a) is representative for the upper part of Reiteralm. b) For the central region and c) For the lower part. 79 
Figure 48: Comparison of model and measurements. White dots indicating that the model is within $10 \%$ of the measurements. Green dots stand for a model overestimation of the snow depth from more than $10 \%$, red dots for a model underestimation from more than $10 \%$.

Figure 49: Three representative points at Kühroint. Point N) is located at the edge of the forest at the northern part of Kühroint; point F) is located at the clear cut area, and point $\mathrm{K}$ ) can be found on the meadows in the western part of the area.

Figure 50: Mean modeled SWE distribution (of INTER_30 and MM5_30) for a) the total area, b) areas above $1800 \mathrm{~m}$ a.s.l. and c) areas above $2200 \mathrm{~m}$ a.s.l. The different volumes under the curves are due to higher sublimation losses within the MM5 runs.

Figure 51: Snow transport rates of a) INTER_30 and b) MM5_30. The black line is the $1800 \mathrm{~m}$ isohypsis.

Figure 52: Intensities of the different transport terms: saltation, suspension and sublimation in a) c) e) INTER_30 and b) d) f) MM5_30. The black line is the $1800 \mathrm{~m}$ isohypsis.85

Figure 53: Simulated contributions to annual snow sublimation (additive representation) from the ground, canopy intercepted snow and wind-induced, turbulent suspended snow along a cross-section from Hochkalter (2607m a.s.l.) through the Wimbachtal to Watzmann (2713m a.s.l.). (Strasser et al. 2008). 86

Figure 54: a) modelled snow cover of April 28, 2004, b) NDSI map of the same date, c) modelled snow cover of Mai 30, 2004 b) NDSI map of Mai the same date, e/f) Differences between model an classification results at April and Mai respectively (red indicates: only classified snow cover. Green: only modelled snow cover. Pink: cloud mask). The black line is the $1800 \mathrm{~m}$ isohypsis. 88

Figure 55: validation areas of April 28, 2004; Blue: Snow covered regions (Bands: 5,4,3), Red: test areas.

Figure 56: validation areas of Mai 30, 2004; Blue: snow covered regions (Bands: 5,4,3), Red: test areas.

Figure 57: DEM of Kühroint test site. 93

Figure 58: a) Comparison of run_baseline and INTER_30 results on April 28, 2004, b) comparison between run_baseline and MM5_30 at the same date. c) Picture of a crest were the snow cover on the windward side (right) is reduced considerably by snow transport processes 94

Figure 59: a) wooded region at Watzmann mountain (the snow covered area appears in blue).

b) NDSI classification in gray, MM5_30 results in blue. 96 
Figure 60: Predicted loss and gain of SWE due to wind induced snow transport at Blaueis glacier a) 30m resolution results using MM5 wind fields, b) 200m resolution results using MM5 wind fields. (The results were fitted to the $30 \mathrm{~m}$ grid for the

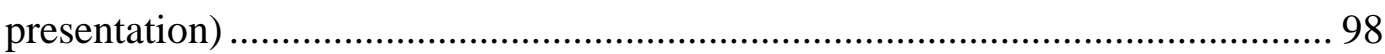

Figure 61: Picture of the Watzmann upper east face under full snow coverage..................... 99

Figure 62: Accumulated Snow masses transported by snow slides (winter season 03/04). Strasser at al. (2008) modified.

Figure 63: The figure shows a theoretical subscale SWE depth distribution and common model representatios. a) Shows a situation with full snow coverage, b) shows a situation where the model shows no snow coverage. 108

Figure 64: Landsat images of a) April 2002, b) March 2003 and c) April 2004. Channels 3,5,6 (R,G,B) are displayed. The snow cover is indicated by the red colour. It can be seen that the spatial characteristics of the snow distribution is very similar from year to year. 109

Figure 65: results of the CV classification. Predicted on the basis of the ratio between per pixel mean modelled SWE and standard deviation of the SWE (30m results of SnowModel with SnowTran-3D/MM5).

Figure 66: If the model simulates snow melt the curve shifts against the y-axis and if the curve intersects the axis the area under the curve which is equivalent to the total grid cell is reduced. Any curve stands for the SWE distribution of the respective grid cell.

Figure 67: Subpixel snow coverage in percent on May 30, 2004. a) Results based on a scaled NDSI map, b) Model results based on CV values predicted by the ratio approach with SnowTran-3D and MM5 wind fields, c) Model results based on CV values generated with the iterative approach.

Figure 68: Average available melt energy per $\mathrm{km}^{2}$ grid cell: a) aggregated $30 \mathrm{~m}$ results (equivalent to MM5_30), $\left(220 \mathrm{~W} / \mathrm{m}^{2}\right)$ b) $1 \mathrm{~km}^{2}$ model runs without the subgrid routine $\left(270 \mathrm{~W} / \mathrm{m}^{2}\right)$, c) corrected $1 \mathrm{~km}^{2}$ results using the subgrid routine (200 $\left.\mathrm{W} / \mathrm{m}^{2}\right)$.

Figure 69: Upper Danube catchment. Red: Areas for which the parameterization results are potentially applicable. 


\section{List of tables}

Table 1: Geographic position of the National Park 15

Table 2: Meteorological stations which were used, their abbreviations, geographical coordinates, elevation, and associated meteorological fields: global radiation (GR), humidity $(\mathrm{H})$, precipitation $(\mathrm{P})$, snow height $(\mathrm{SH})$, temperature $(\mathrm{T})$, temperature of the snowpack $0 \mathrm{~cm}$ above ground (TS0), $20 \mathrm{~cm}$ above ground(TS2), $4 \mathrm{~cm}$ above ground (TS4) and 60 $\mathrm{cm}$ above ground (TS6), wind speed (WS), wind direction (WD)

Table 3: Hours showing wind speed and direction recordings vs. hours with data lacks compared to recordings of other sensors.

Table 4: Column I: Mean value of all 220 wind fields between the average value of the original and the modified MM5 wind speeds. Column II: Maximal observed difference between original and modified MM5. Column III: Minimal observed difference.

Table 5: The table shows the standard deviations of the measurements and of the respective model results for the observation dates. 78

Table 6: The table shows the standard deviations of the measurements and of the respective model results for the observation dates. 81

Table 7: Comparison between SnowModel results generated with SnowTran-3D and with as well as without the usage of MM5. The values belonging to the areas highlighted in Figure 55. The areas are snow free in reality, the values within the table showing the improvement of the SnowModel results when the transport routine is used....

Table 8: Comparison between SnowModel results generated with SnowTran-3D and with as well as without the usage of MM5. The values belonging to the areas highlighted in Figure 56. The areas are snow free in reality, the values within the table showing the improvement of the SnowModel results when the transport routine is used. 90

Table 9: Contributions relative to total snowfall and scale-dependent significance of the winter water balance components for the Berchtesgaden National Park domain for 2003/2004. The additional amount of snowmelt is caused by rain-on-snow (cp. Stasser et al. 2008). 101 


\section{Chapter 1 Introduction}

\subsection{Aim of the thesis}

The presented thesis investigates the Alpine snow cover and its spatial heterogeneity in due consideration of wind induced snow transport processes. An appropriate knowledge of snow transport, its mode of action, and its effectiveness is essential for understanding and predicting the spatial distribution of the snow cover and thereby the correct water balance as well as moisture and energy fluxes in mountainous regions. The thesis presents results of high resolution physically based snow model runs (for the winter seasons 03/04 and 04/05), used for an estimation of the effectiveness of snow transport processes within an Alpine catchment. Furthermore, a parameterisation scheme is presented which allows for consideration of the snow heterogeneity in Alpine regions within regional scale models.

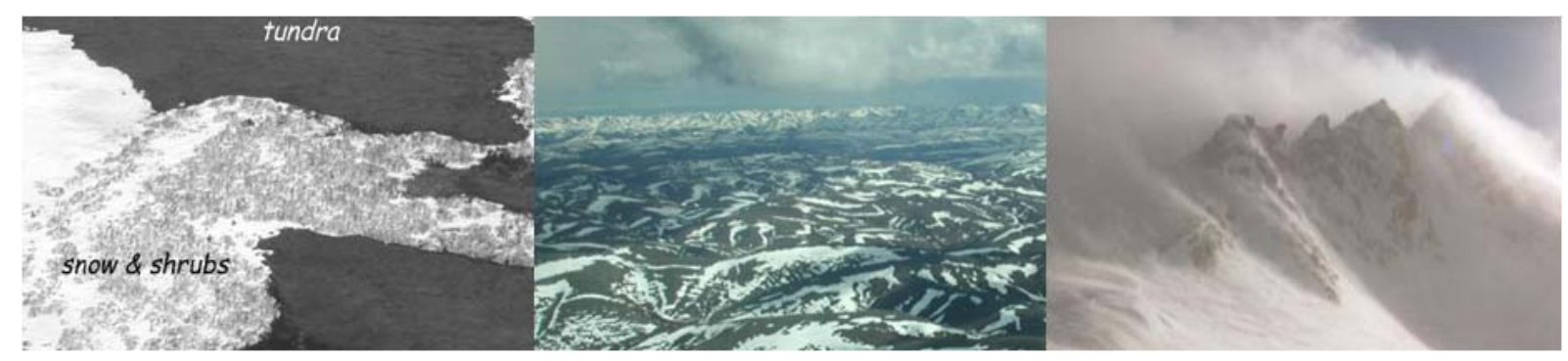

Figure 1: Examples for snow heterogeneity in the Arctic region, in undulating terrain and within a mountainous area (Photos by: M. Sturm, D. Marks)

At the end of the 1970's snow transport processes were not well understood, Gray et al. (1979) noted that: "it is evident that, at the present time, because of the lack of knowledge of the snow transport and deposition processes and the complex nature of the accumulation phenomenon, it is impossible for the hydrologist to define snow cover distribution patterns by a physically-based, mathematical model." Later on in the 1990's first numerical studies considering the connection between the most important transport terms, saltation and suspension, and wind speed as well as direction were presented by Pomeroy and Gray (1995) and Liston and Sturm (1998). Since this time numerous studies about snow transport and its influence on the water balance were carried out in flat terrain (Pomeroy et al. 1993; Déry and Yau 1999) or in slightly undulating terrain (Liston and Sturm 1998) (fig. 1). 
In most of these studies it is stated that the mountainous snow cover is especially influenced by snow transport (e.g. Pomeroy et al. 1997; Liston 2004) but only a few studies are known which have numerically simulated the efficiency of this process (e.g. Pomeroy et al. 1997; Lehning et al. 2006; Bernhardt et al. 2008). Hence, the real impact of blowing snow processes in hydrological modelling of Alpine regions is still unknown. This lack of information can be traced back to the limited knowledge about the wind conditions in Alpine regions (Balk and Elder 2000; Essery 2001; Liston et al. 2006; Bernhardt et al. 2007). Liston and Sturm (1998) as well as Winstral and Marks (2002) stated that a reasonable description of wind fields in complex terrain is needed for a satisfying description of the Alpine snow cover. Fulfilling this demand was one of the scopes of this work. Hence, wind fields predicted by the physically based PSU/NCAR MM5 model (Grell et al. 2005) were used as an input for the well established snow model SnowModel (Liston and Elder 2006) which uses SnowTran-3D (Liston and Sturm 1998, Liston et al. 2006) as a snow transport routine. The produced SnowModel results are discussed on the basis of results calculated under usage of conventionally interpolated wind fields. A validation of the obtained model results will be achieved with the help of station and field campaign measurements of snow depth and remotely sensed data of the snow distribution. Finally, an approach to parameterise the snow heterogeneity in alpine regions as subscale input for regional models is presented.

The thesis was funded by the GLOWA_Danube project of the German Ministry for Education and Research $(b m b+f)$.

\subsection{Introduction and methodology}

\subsubsection{The snow cover an important land surface feature}

Snow is defined as falling or deposited ice particles formed mainly by sublimation (UNESCO/IHAS/WMO 1970). Any snow cover is a product of accumulation and ablation processes. Their occurrence and duration is spatially and temporally variable and depends on the distribution of meteorological parameters, topography, and vegetation. Beside global trends like an increase in both snowfall and duration of the snow cover with altitude and latitude, there are a lot of local phenomena influencing the characteristics of the snow cover (Blöschl 1999; Essery and Pomeroy 2004, Liston and Elder 2006, Bernhardt et al. 2007). It has to be recognized that only about $5 \%$ of world's total precipitation falls as snow (Hoinkes 
1967). But the values can reach 50\% to $100 \%$ in Arctic or Alpine regions (Winther and Hall 1999; Strasser et al. 2007). In general one has to distinguish between permanent, seasonal, or temporal snow covers. A permanent snow cover is retrained for many years, seasonal and temporal snow covers disappear after a certain period. The difference between a seasonal and a temporal snow cover is that a seasonal snow cover exists for months and a temporal snow cover for days. The snow cover type that is the subject of this work is a seasonal one. This type can be observed north of $60^{\circ}$ and in mountainous regions (Rees 2006). The appearance of snow has remarkable effects on the energy balance of the surface and on the hydrological features of an area. The seasonal snow cover leads to the largest annual and inter-annual variations of the land surface albedo (Armstrong and Brodzik 2002; Rees 2006) with respective consequences on the energy fluxes to and from the surface (fig. 2 b) and therefore on the large and local scale climate. From a hydrological point of view, snow is important because it acts as temporal storage of precipitation during the winter season. The stored water is later released as snowmelt and represents an important component of water supply for the downstream population of large mountain-foreland river systems worldwide. Modelling the amount and heterogeneity of the snow water storage in the headwater catchments helps to quantify the available water resources and estimate the timing of their entrainment.

Snow itself is a complex body which is interacting with the atmosphere and the underlying surface. In response to these interactions the crystal structure of the snow pack transforms. Equilibrium and kinetic metamorphism can be observed. The snow pack additionally acts as a cushion between the underlying surface and the atmosphere. It insulates the soil and the underlying vegetation from low winter air temperatures and leaves them much warmer than they would be otherwise (Liston and Elder 2006). This means that increased snow coverage lowers positive fluxes of sensible heat to the atmosphere. Furthermore, melting snow reduces latent heat fluxes. If the snow coverage drops below of $100 \%$, the proportion of the snow covered area is important for the soil moisture, the runoff generation and the energy and moisture fluxes between surface and atmosphere (Ellis and Lethers 1999; Liston and Elder 2006). The snow free fraction shows a different behaviour in comparison to the snow covered one. First off all, the albedo of the surface decreases instantly if the snow cover is gone and a lot more radiative energy is absorbed in consequence. Furthermore, the surface temperature is able to exceed $0^{\circ} \mathrm{C}$ now. This and the surplus of absorbed energy lead to a rapid increase of 
the sensible heat fluxes. The available melt energy on the other hand decreases with the snow covered fraction. When considering fig $2 \mathrm{~b}$ ) it becomes obvious that all of the mentioned fluxes are linearly coupled. Patchy snow covers are common in high alpine regions where wind induced and gravitational snow transport, preferential deposition of precipitation, as well as hillside-inclinations of more than $50^{\circ}$, which prohibit the adherence of snow on the surface, lead to an extremely uneven snow distribution. The resulting snow coverage is mostly below 100\% even during the high winter season. Figure 2 a) shows a Landsat ETM+ image (bands 5, 3, 2; 28.04.04) of the Watzmann mountain which illustrates this effect. The turquoise colour represents the snow covered regions. The mesh size of the Gauss/Krüger coordinate system is one kilometre (green coloured cells) which matches the medium resolution of many Soil Vegetation Atmosphere Transfer (SVAT) models. As one can imagine, all of these cells are partly snow free and would fall in the range of $10 \%$ to $90 \%$ snow coverage. Understanding the reasons for this heterogeneity and making information about the spatial heterogeneity of the snow cover available for regional scale models (like presented in Mauser and Bach 2008) is the aim of this thesis.

a)

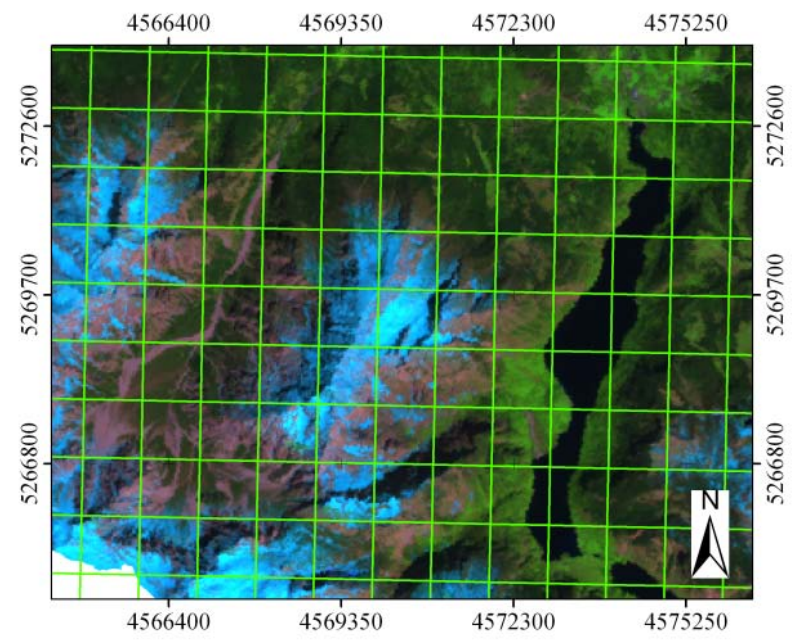

b)

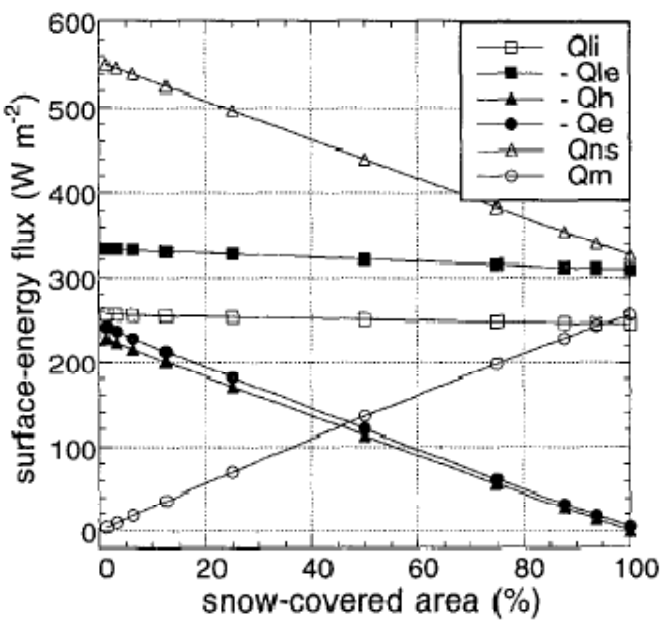

Figure 2: a) Snow cover at Watzmann Mountain (turquoise) superimposed by a $1 \mathrm{~km}^{2}$ grid. b) Interrelation between snow covered area and energy fluxes (Qli = incoming longwave radiation, Qle = emitted longwave radiation, $\mathrm{Qh}=$ turbulent exchange of sensible heat, $\mathrm{Q}_{\mathrm{e}}=$ turbulent exchange of latent heat, $\mathrm{Q}_{\mathrm{ns}}=$ net solar radiative flux at the surface, $\mathrm{Q}_{\mathrm{m}=}$ energy flux available for melt) (cp. Liston 1995) 


\subsubsection{Snow cover modelling}

Over the last decades, a lot of snow models calculating the vertical and the spatial development of the snow cover were presented (Pomeroy et al. 1993; Liston and Sturm 1998; Dery and Yau 1999; Essery et al. 1999; Winstral and Marks, 2002; Lehning et al., 2006). According to Marsh (1999) and Liston (2004) and Liston and Elder (2006) most of these models tend to a more physically based description of the relevant processes. When omitting empirical or temperature index models the remaining physically based models can be divided into three different groups. The following classification gives a broad but sufficient overview over the most important models and their range of operation. It has to be mentioned that the classification is not strict; the models which are listed under 1-dimensional models could also be used in a distributed mode. Nevertheless, this is unusual and often impossible because of a lack of input data and because of the computational resources that would be needed. The presented classification is based on the spatial dimensions on which the models are working on.

- 1-dimensional models are often used for the assessment of avalanche or flood risk. The aim is a precise calculation of the vertical stratification of the snow pack and of the metamorphism of snow and its connection to mechanical properties such as thermal conductivity and viscosity (Spreitzhofer et al. 1993). For an adequate description of the mentioned factors, complex and physically based formulations are needed. A numerical solution of these models is only possible if comprehensive input data is available. As this is commonly not the case, these models are limited to well instrumented sites. Very prominent representatives are: CROCUS (Brun et al. 1989; Brun et al. 1992), SNOWPACK (Bartelt and Lehning 2002; Lehning et al. 2002) and SNTHERM (Jordan 1991). The numerical model CROCUS has been developed by Météo-France to predict the evolution of the snow pack and its stability with respect to avalanches. SNOWPACK was developed by the Eidgenössisches Institut für Schneeund Lawinenforschung (SLF) for supporting avalanche warning in Switzerland and runs operationally at approximately 100 sites. SNTHERM has a different scope and was developed as a routine for runoff forecasting models and is widely used both in the United States and in other countries. 
- 2-dimensional models are usually used as subroutines in atmospheric models and Soil Vegetation Atmosphere Transfer schemes (SVAT). Stand alone models are seldom but known (e.g. AMUNDSEN of Strasser et al. 2007). 2-dimensional models conventionally dispose over one single layer and do not explicitly predict snow crystal metamorphism. Lateral transport processes by wind or gravity are ignored and the subscale snow distribution is commonly approached by a modification of the snow albedo (Liston 2004).

- 3-dimensional models consist of at least two components, one which calculates the vertical snow cover evolution while the other simulates the snow transport processes. The complexity of the individual components determines whether a model can be used for simulating a complete snow cover period or just some individual transport events. Hence, they have to be divide between I) event based and II) seasonal models:

o Event based models are usually very complex and used for basic research: Uematsu et al. (1991) and Sundsbø (1997) modelled snow transport rates around snow fences; Gauer (2001) modelled snow drift around a single crest. Lehning et al. (2002) coupled SNOWPACK with a snow drift routine (Doorschot 2002) and with the Advanced Regional Prediction System (ARPS) (Xue, et al. 2000) and applied it to Gaudergrat ridge (Switzerland).

o Seasonal transport models in contrast are generally of intermediate complexity. They commonly use a first order approximation of the transport physics and a single layer snow evolution model. The first known seasonal and physically based transport model is the Prairie Blowing Snow Model (PBSM) (Pomeroy et al. 1997) which has strongly influenced the latter development in this area. SnowTran-3D which is used in this work is one of the most prominent successors of PBSM. Other models like SYTRON3 (Durand et al. 2005) and ALPINE-3D (Lehning et al. 2006) can be found in literature but are currently not very well documented.

The Snow Models Intercomparison Project (SnowMIP) (Etchevers et al. 2002) has shown that present-day 1-dimensional snow models are able to reproduce the snow cover evolution very well in close vicinity of a meteorological station. Results become less confident for spatially 
distributed 2- or 3-dimensional models especially in areas with complex or mountainous terrain or in forested areas (e.g. Liston 2006). This is due to errors and uncertainties of the meteorological fields that drive the models and due to simplifications of the model formulations with respect to snow-canopy interactions, windblown snow, gravitational snow transport, and preferential snow deposition (e.g. Lehning et al. 2006). The extent of which an integration or omission of the indicated processes can improve or deteriorate the accuracy of a snow model depends on the observed scale and area:

- In flat and forested environments snow-canopy interactions like snow sublimation from canopy stands or snow released from branches are the controlling parameters with respect to snow heterogeneity. The involved processes are effective at scales of one to hundreds of meters (Liston 2004; Strasser et al. 2007). First results of SnowMIP2 have shown that a misinterpretation of snow-canopy interactions can lead to almost unusable model results (Rutter and Essery 2006) in these areas/scales.

- In tundra, prairies, Arctic and Alpine environments wind induced transport processes, which can be observed at scales of tens to hundreds of meters, are described as decisive (Sturm et al. 1995; Essery et al. 1999; Essery, 2001; Bernhardt et al. 2008a). The high frequency of blowing snow conditions (wind speeds higher than $3 \mathrm{~m} / \mathrm{sec}$ (Liston and Sturm 1998) and the lack of snow cover stabilizing vegetation (Pomeroy et al 1997; Pohl et al. 2007) is mentioned as the reason for the assumed large impact of blowing snow processes in these regions. But, to the knowledge of the author there is no study available which is describing the quantity of the transported snow masses and the areas which are mainly influenced for an Alpine region and on the catchment scale.

- Finally, on scales larger than 1 kilometre, snow cover heterogeneity is mainly influenced by the orographic precipitation gradient (Barros et al. 1994; Liston 2004). 


\subsubsection{Model approach of the presented work}

The presented work uses a seasonal 3-dimensional model and is focused on wind induced snow transport in Alpine regions. For an accurate modelling of snow transport events knowledge about the different transport terms, the snow conditions at a given time step, and the driving force, namely the current wind field, are prerequisites. While the first two requirements can be numerically solved in a satisfying way (Marsh 1999), the calculation of realistic wind fields especially in alpine regions is still an open research topic (Liston and Sturm1998; Winstral and Marks 2002; Raderschall et al. 2002; Walter and McCool 2004; Liston et al. 2007).

An literature review has shown that wind fields are commonly predicted in two different ways: I) simple interpolations between stations that may or may not include statistical approaches that incorporate information about elevation and relief (Essery 2001; Winstral and Marks 2002) and II) calculations using physically based models (Lehning et al. 2002; Bernhardt et al. 2008a). It is well known that I) is not feasible in areas with complex terrain (Liston and Sturm 1998; Winstral and Marks 2002; Bernhardt et al. 2008a). This is mainly due to the spatial characteristics of wind fields. They are extremely heterogeneous and unsteady because of a nonlinear relation between wind speed and height, as well as synoptic flow and topography dependent wind direction fields. The whole system is furthermore complicated by the turbulent movement of air masses. On the other hand, the hydraulic computation of wind fields with a meso scale or regional atmospheric model is timeconsuming and thus does not allow for the modelling of snow-transport processes over large areas at the spatial scales required to adequately represent the underlying physics (that operate at spatial scales of 200 meters or less). Furthermore, most of the available atmospheric models were not able to estimate high resolution wind fields for complex terrain until today due to unresolved numerical problems.

For the presented work a modified version of the PSU/NCAR MM5 model (Grell et al. 1995; Zängl 2002; Zängl 2003) was used. The model was set up with 5 interactively nested domains (fig. 3). The largest covers most of Europe the smallest an Alpine area with an extent of $400 \mathrm{~km}^{2}$. Due to a new formulation of the vertical diffusion term (Zängl 2003) a target resolution of 200 meters could be realized. Since an operational use of MM5 would reduce the 
performance of a coupled SnowModel/MM5 algorithm significantly (the calculation of one 200meter wind field needs three days on a high performance computer) a new approach was developed and applied. A static library of separately calculated MM5 wind fields was used instead of operational model results. The library is connected with the snow model by means of the German Weather Service Lokalmodell (LM) (Chapter 3). This becomes possible as LM produce hourly wind fields for an area comparable to one of the MM5 nesting domains (red rectangle in fig. 3) at the 700hpa level. Using the average wind vector of the $L M$ wind field of this area as selection criteria and comparing it to the equivalent information of the available fields in the MM5 wind field library makes a selection of the most identical field in the library possible. The respective field is used in the SnowModel for the current model time step. Hence, the static precompiled MM5 wind field library is synchronized with the snow transport model over hourly information delivered by $L M$. The presented approach has the advantage that it combines modelling efficiency with a physically based description of the processes affecting local winds and the associated snow redistribution processes. A further advantage is that all of the used models are validated and have been shown to perform well. 


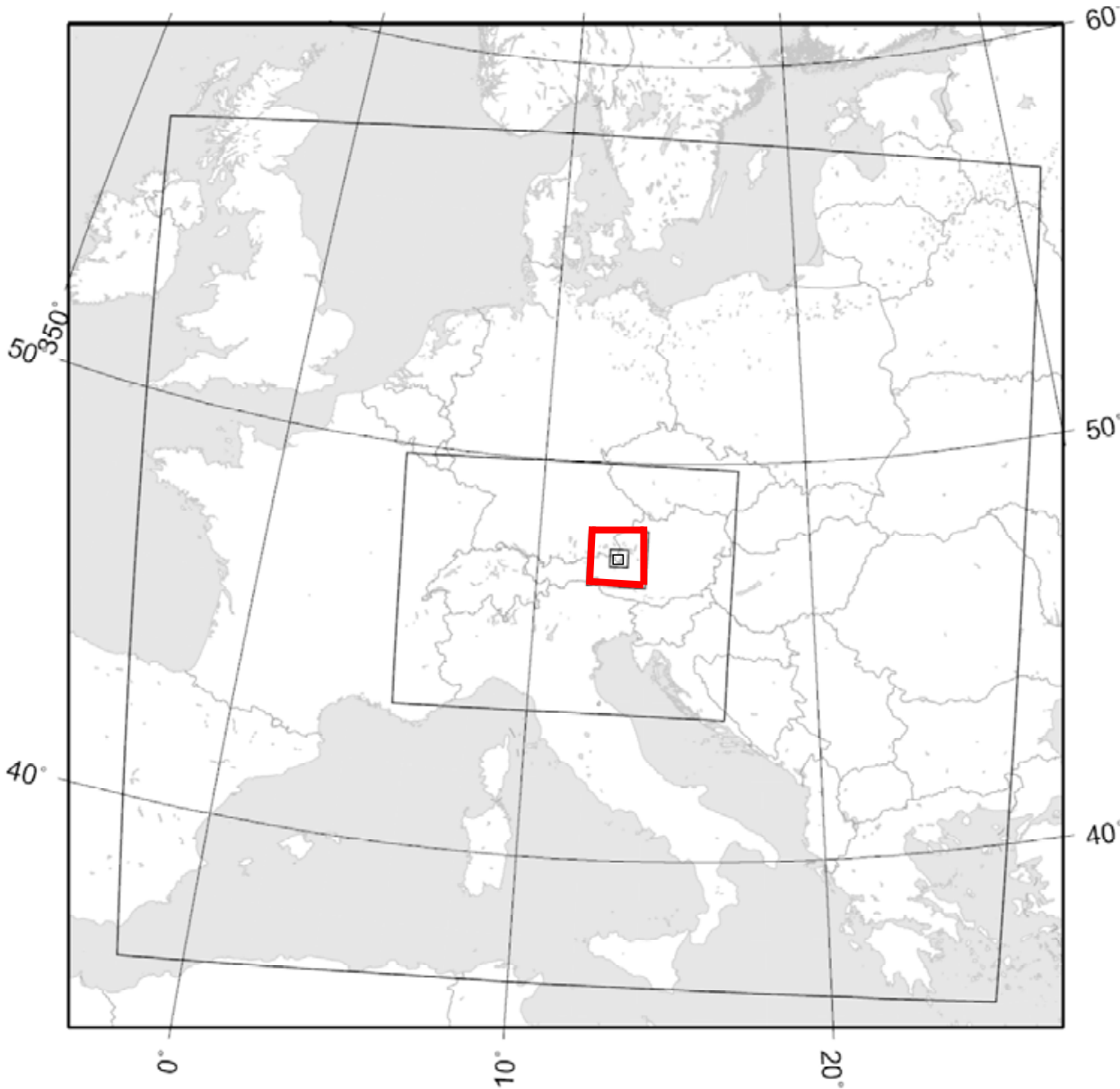

Figure 3: Schematic of the five nested domains used in MM5. The largest one is nesting domain_1, the smallest is domain_5. Domain_3 is marked as red rectangle.

It is well known to the author that there are atmospheric or aerodynamic models available which are working at finer scales than the mentioned MM5 model. Detailed studies of the Eidgenössisches Institut für Schnee- und Lawinenforschung (SLF) have shown the capabilities of ARPS (Xue et al. 2000; Xue et al. 2001) and CFX-4 (AEA, 2001) for event based modelling at a scale of 25 meters. The application of these models is very useful for a better theoretical understanding of wind induced snow transport processes including sublimation of turbulent suspended snow particles. Nevertheless, an operational coupling between these models and snow models is currently impossible because of model limitations and/or unrealistic computational demands. 
At the outlook (chapter 6), the results of the high resolution model runs serve as the basis for the parameterization of a subscale routine which is able to predict the snow covered fraction of grid cells of regional models.

The presented work deals with processes and models which are occurring and working at significantly different scales. Furthermore, it uses data from a coarse scale model (MM5) for predicting processes which are occurring at scales of 200m or less (Liston et al. 2006). So, a definition and explanation of the used scales is given in the following section.

\subsubsection{Scales used in this work}

Operations at three different scales were performed in connection with the presented work, so the used scales and their connection will be declared here. Blöschl (1999) defines three different scales for snow hydrology: 1) the process scale 2) the measurement scale and 3) the model scale. The process scale is characterized over the specific characteristic length of a natural process (like the correlation length of the spatial SWE variability), the measurement scale over the size of e.g. a snow density sample, and the model scale over the grid cell size of a distributed model (Blöschl 1999). The measurement and the model scale are further characterized with three additional terms: spacing, extent and support (Blöschl and Sivaplan 1995). The term spacing refers to the distance between samples, the extent defines the overall coverage of the data and support refers to the integration volume of a sample. Following these terms the measurement scale is defined by the distance between the snow poles (spacing), the extent of the measurements (extent), and the area for which the measurement is representative for (support). The model scale is defined by the model resolution (spacing), the total area which is respected (extent) and the scale for which the model formulations are representative for (support). 


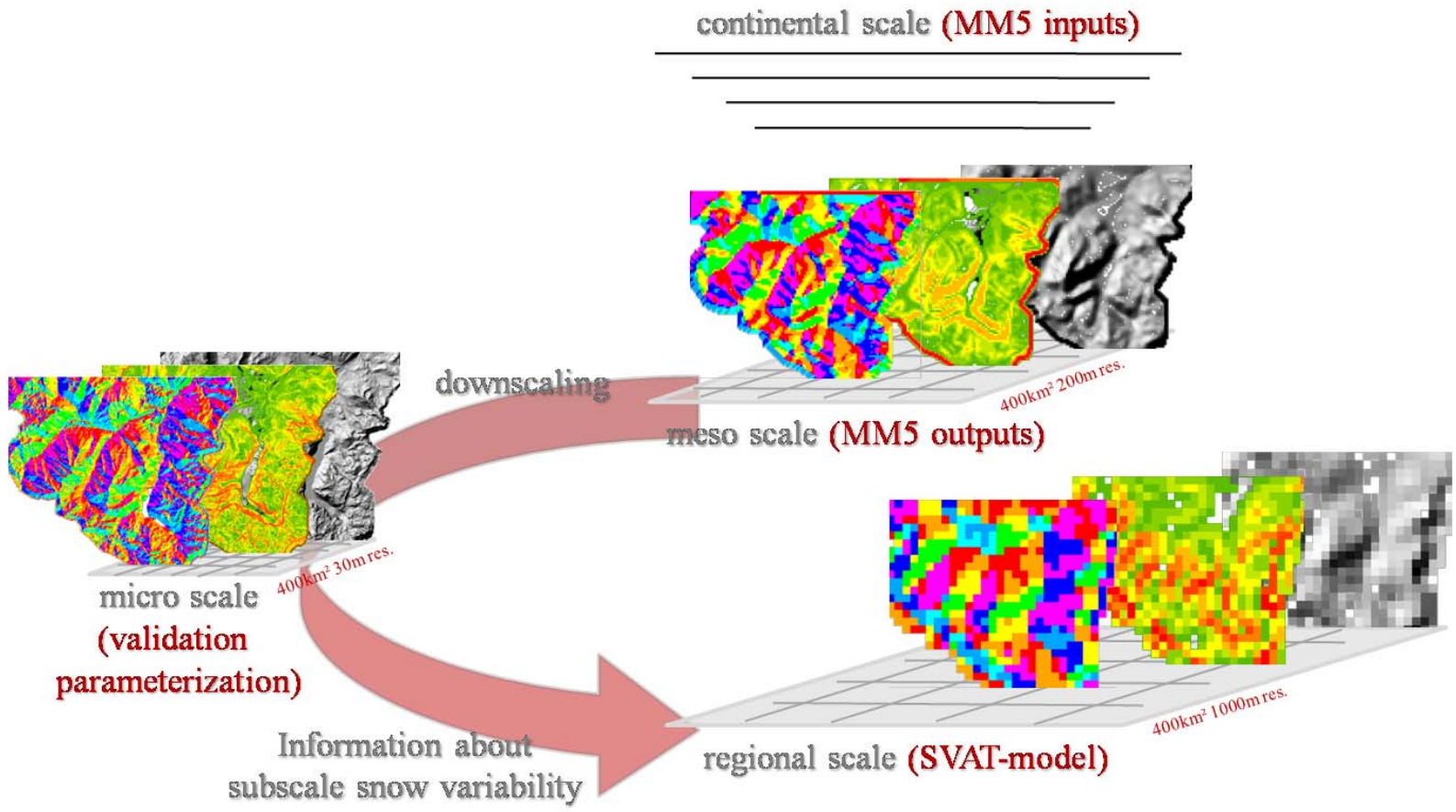

Figure 4: Scales used in this thesis. The work starts at the meso scale for which the MM5 wind fields are representative for $(200 \mathrm{~m})$. After than the wind fields are downscaled to a $30 \mathrm{~m}$ resolution (micro scale). The SnowModel results at the micro scale are validated on the basis of field campaign and remotely sensed data. The information produced by the micro scale runs is used for a parameterisation scheme for the snow heterogeneity which can be used in regional scale Models.

In accordance to Blöschl (1999) the measurement and the model scale should not differ too much from each other. Hence, the application and validation of the model was progressed at different scales. These scales are defined as the micro, meso and regional scale in the following (fig. 4).

At the micro scale the snow model was performed with a spatial resolution of 30 meters and within a total area of $400 \mathrm{~km}^{2}$. The total area remains the same at the meso and regional scale but the grid size increases to 200 meters and 1000 meters respectively. As illustrated in Figure 4 the study starts at the meso scale (200m resolution) which corresponds to the reachable extent and support of the meteorological model and to the upper limit of the physical descriptions within the snow transport model (and consequently to the upper limit of the support of this model). The overlap between extent and support of these models allows for a common usage. Hence, the general performance of the coupled wind field/snow model algorithm was tested at this scale and first plausibility checks were made (Chapter 4). Subsequently, the MM5 results were downscaled to a 30 meter resolution (micro scale) which 
exactly fits the support and extent of the Landsat ETM+ data and which is close to the extent of the snow courses (Chapter 4). In a last step, the information which was obtained at the micro scale was parameterised to make it available for regional scale $(1 \mathrm{~km})$ land surface models (Chapter 6)

\subsection{Test Sites and field measurements}

The Berchtesgaden National Park is located in southeast Germany in Bavaria, at the southern corner of the administrative district Berchtesgadener Land (fig. 5). The park was founded in 1978 and comprises an area of $210 \mathrm{~km}^{2}$. For the most part, the border of the National Park is represented by the national boundary to Austria. Only in the north, the National Park adjoins the settlement areas of the communities Berchtesgaden, Schönau at the Königssee as well as Ramsau, all of them at the border of the National Park. The valley areas are characterized by extensive forests with larch, spruce and mountain pine stands, subordinated to the National Park Authority since 1987. The high alpine area of the National Park includes the massifs Watzmann (2713m a.s.l.) and Hochkalter (2606m a.s.l.) as well as parts of the massifs Hoher Goell, Hagengebirge, Steinernes Meer and Reiteralm, separated from each other by the deep valleys stretching mostly from south to north. Lakes cover an area of approximately $6 \mathrm{~km}^{2}$. The hydrological drainage of the area is represented by the rivers Bischofswieser Ache, Ramsauer Ache and Königseer Ache. All of these creeks flow into the Salzach (Danube river system). 


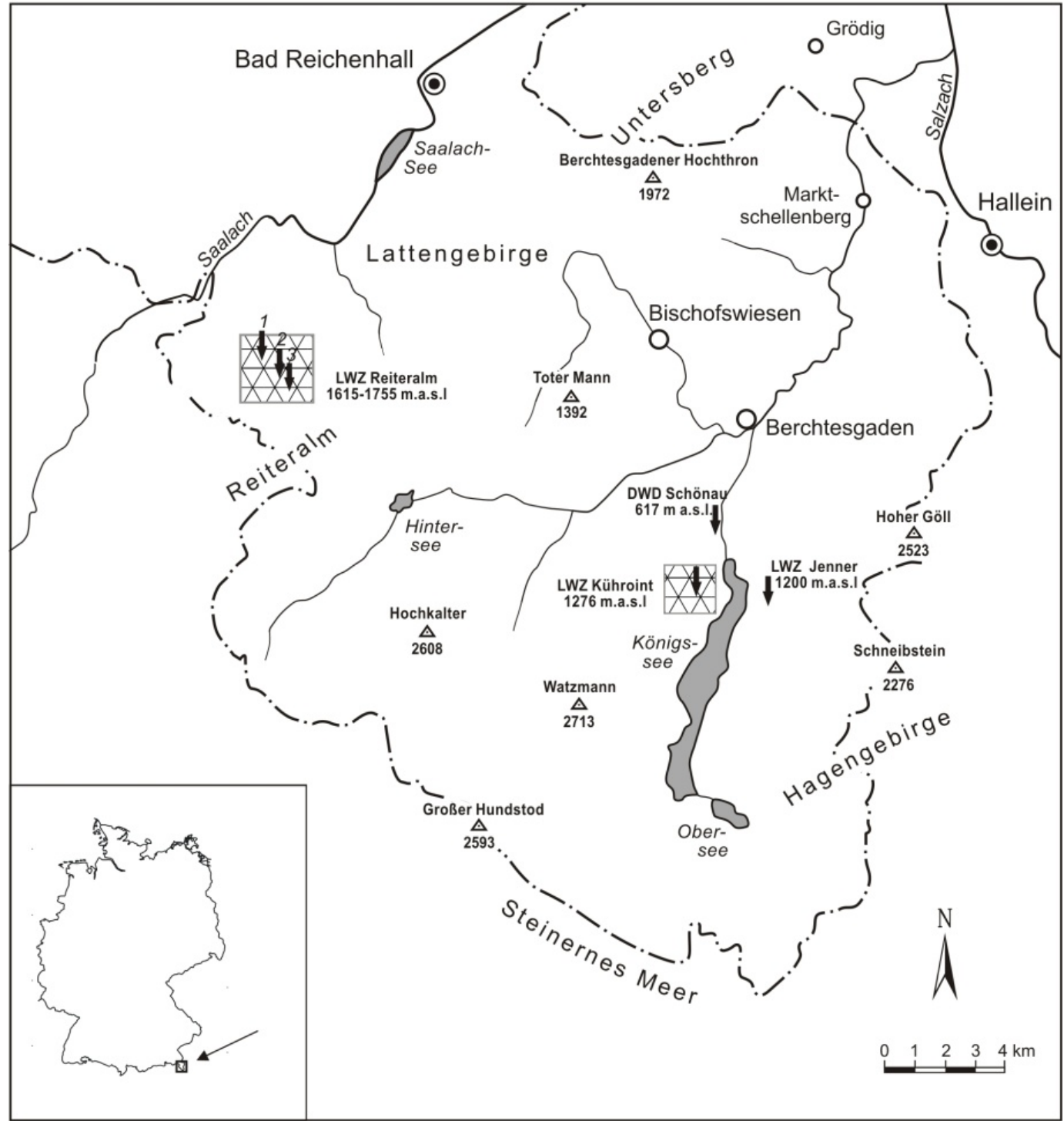

Figure 5: Test site (Berchtesgaden National Park) (Bayerisches Landesvermessungsamt 1994, modified). The locations of Reiteralm 1, 2 and 3, Schönau, Kühroint and Jenner are marked with arrows. The test sites at Reiteralm and Kühroint are displayed as chequered areas.

As an effect of local topography, some small glaciers still exist at altitudes where their specific mass balance would always be negative if only the climatologically processes were taken into account. The Blaueisgletscher, the most northern glacier of the Alps, is shaded by the surrounding steep rock walls and fed by wind induced snow transport and avalanches. The Watzmanngletscher also receives additional accumulation by wind-blown snow originating from the west slopes of Watzmann. Finally, the Eiskapelle at 920m a.s.l., a perennial snowfield at the base of the Watzmann east face, is fed by both wind-blown snow from the 
Watzmann crest and frequent avalanches from the east face which effectively is a snow funnel depositing masses of snow at a location far from where it has fallen, or been eroded. Nevertheless, the glaciers in the Berchtesgaden Alps have retreated dramatically during the past decades and it can be assumed that they will completely disappear in the near future (Winkler 2005). Only the Eiskapelle has shown little reaction on the changing climate.

Because of the extremely steep topography it is very challenging to model snow processes and snow transport processes here.

Table 1: Geographic position of the National Park

\begin{tabular}{l|ll|lc}
\hline \hline & Geographical & & \multicolumn{2}{l}{ Gauss Krüger (Zone 4) } \\
\hline Corner & Longitude $\left[^{\circ}\right]$ & Latitude $\left[^{\circ}\right]$ & Easting [m] & Northing [m] \\
\hline Upper Right & $13^{\circ} 06^{\prime} 22^{\prime \prime}$ & $47^{\circ} 43^{\prime} 05^{\prime}{ }^{\prime}$ & 4583001.00 & 5287682.00 \\
Lower Left & $12^{\circ} 45^{\prime} 17^{\prime}$, & $47^{\circ} 27^{\prime} 23^{\prime}$, & 4556920.69 & 5258267.75 \\
\hline
\end{tabular}

The test site was selected for the following reasons:

- The topographic characteristics which guarantee high wind speeds and therefore high snow transport intensities. The area can be seen as representative for high alpine regions.

- The instrumentation of the site. Meteorological Networks of the Avalanche Warning Service (LWD) and of the German Weather Service / Berchtesgaden National Park $(D W D / N P B)$ were available.

- The availability of a high resolution GIS database including sophisticated land use information which allows for high resolution distributed modelling.

- The chance to carry out field campaigns with the help of skilled National Park Rangers, which had long term experiences in conducting snow courses.

- The general assistance of the partners: the Avalanche Warning Service (LWD) and the administration of the Berchtesgaden National Park (NPB), who have provided any data free of charge. 


\subsubsection{Topography}

The Berchtesgaden Alps can be seen as a solitary part of the northern limestone Alps. They are located between the rivers Saalach and Salzach and are characterized by the plateau type of the different massifs and by the petrographical attributes of the rocks. The Dachstein limestone is determined within the sediment sequence of this area (Institut für Landeskunde, 1970). The area shows steep terrain which traces back to massive crust movements during the Eocene, 45 million years ago. The relief was additionally intensified by the glaciations of the last ice ages.

The minimum elevation of the area is $514 \mathrm{~m}$ a.s.l located at the outlet of the Berchtesgadener Ache in the north-eastern part of the area whereas the maximum elevation is the crest of Watzmann (2713m a.s.l.) Figures 6 give an idea about the relief energy of the area.
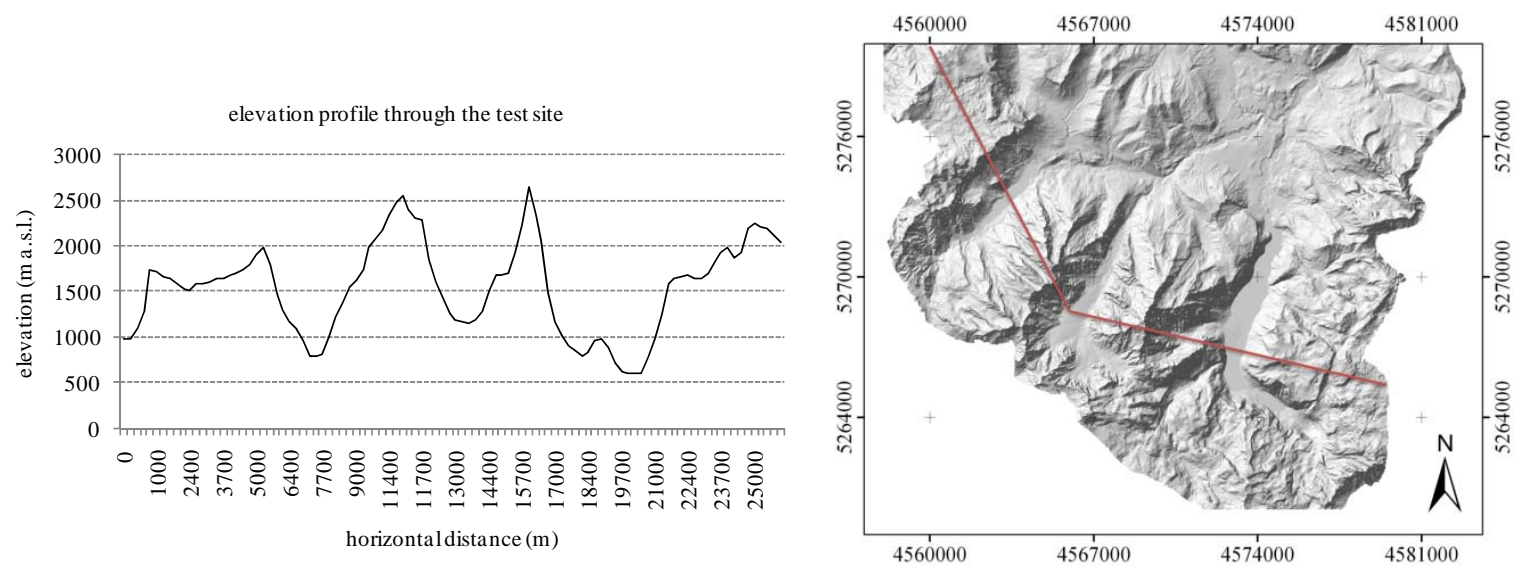

Figure 6: Profile through the National Park area which displays the rapid changes in altitude in the test area.

\subsubsection{Climate}

The climate of the National Park area is subject to significant spatial variability and strongly influenced by a relief gradient of more than 2000 m. Small scale local differences are caused by, for example, the general position in the mountainous landscape, the position in relation to the prevailing winds (windward or leeward), and the solar incidence angles.

The observed mean temperature is $8.1{ }^{\circ} \mathrm{C}$ at $470 \mathrm{~m}$ a.s.l. while for the maximum elevation of $2713 \mathrm{~m}$ a.s.l a mean of $-2.5{ }^{\circ} \mathrm{C}$ was calculated (Enders, 1979). The observed average gradient 
in temperature with elevation is $0.47^{\circ} \mathrm{C}$ per 100 meters (Enders 1979). According to a study of Frei and Schär (1998) the area is located within a wet anomaly extending along the northern side of the Alps. This region shows the highest frequency of days with precipitation (precipitation $\geq 1 \mathrm{~mm}$ ). The annual precipitation shows measured values of $1655 \mathrm{~mm}$ at $500 \mathrm{~m}$ a.s.l. and estimated values of $2711 \mathrm{~mm}$ for an elevation of $2500 \mathrm{~m}$ a.s.l. The calculated mean for the total area is $1992 \mathrm{~mm}$ (Enders 1979). The model runs presented in this work were progresses from August to Juli for covering the total snow cover period. The observed winter seasons are on average if one compares the precipitation and temperatures measured at Schönau with the long term average of 1960-1990 (precipitation $=1519 \mathrm{~mm}$ and temperature $=7.2{ }^{\circ} \mathrm{C}$ ). The precipitation sum of $2003 / 2004$ was $1532 \mathrm{~mm}$ and $1473 \mathrm{~mm}$ in 2004/2005 and the average temperature was $7.1^{\circ} \mathrm{C}$ for $2003 / 2004$ and $7.8{ }^{\circ} \mathrm{C}$ for $2004 / 2005$.

\subsubsection{Meteorological data}

Data of four different meteorological stations was available for the presented work. The network of meteorological stations is owned by two different institutions: the stations at Jenner, Kühroint and Reiteralm are operated by the Bavarian avalanche warning service ( $L W Z$ ) whereas the Schönau station belongs to the network of the $D W D$. Figure 7 shows the location of the different stations.

By connecting these automatic stations via wireless Global System for Mobile Communications (GSM) transmission with a central database a unique data pool is available which allows the continuous operation of distributed models with a high temporal resolution. Table 3 gives an overview of the parameters which are recorded at each station. All data are aggregated to hourly means (i.e., average for temperature, humidity, wind speed, radiation, and air pressure; sum for precipitation; maximum for maximum wind speed) and checked for plausibility. Missing values due to periods in which a sensor was out of operation are characterized as such. Continuous records of the meteorological parameters start in 1998. 
Table 2 Meteorological stations which were used, their abbreviations, geographical coordinates, elevation, and associated meteorological fields: global radiation (GR), humidity $(\mathrm{H})$, precipitation (P), snow height (SH), temperature (T), temperature of the snowpack 0cm above ground (TS0), 20cm above ground(TS2), 4cm above ground (TS4) and 60cm above ground (TS6), wind speed (WS), wind direction (WD)

\begin{tabular}{llllll}
\hline Station & Elev (a.s.l.) & Long & Lat & Resolution & Parameters \\
\hline \hline & & & & & \\
Kühroint & 1407 & 12,57 & 47,34 & $10 \mathrm{~min}$ & T,H,GR,WS, WD, P \\
Reiter Alm I & $1755 \mathrm{~m}$ & 12,80 & 47,65 & $10 \mathrm{~min}$ & WS, WD \\
Reiter Alm II & $1670 \mathrm{~m}$ & 12,80 & 47,64 & $10 \mathrm{~min}$ & H, SH, T, TS0, TS2, TS4,TS6 \\
Reiter Alm III & $1615 \mathrm{~m}$ & 12,81 & 47,64 & $10 \mathrm{~min}$ & GR, H, P, SH, T \\
Jenner & $1200 \mathrm{~m}$ & 13,01 & 47,58 & $10 \mathrm{~min}$ & H, SH, T, TS0, TS2, TS4 \\
Schönau & $617 \mathrm{~m}$ & 12,98 & 47,60 & $10 \mathrm{~min}$ & T, H, GR, WS, WD, P \\
\hline
\end{tabular}

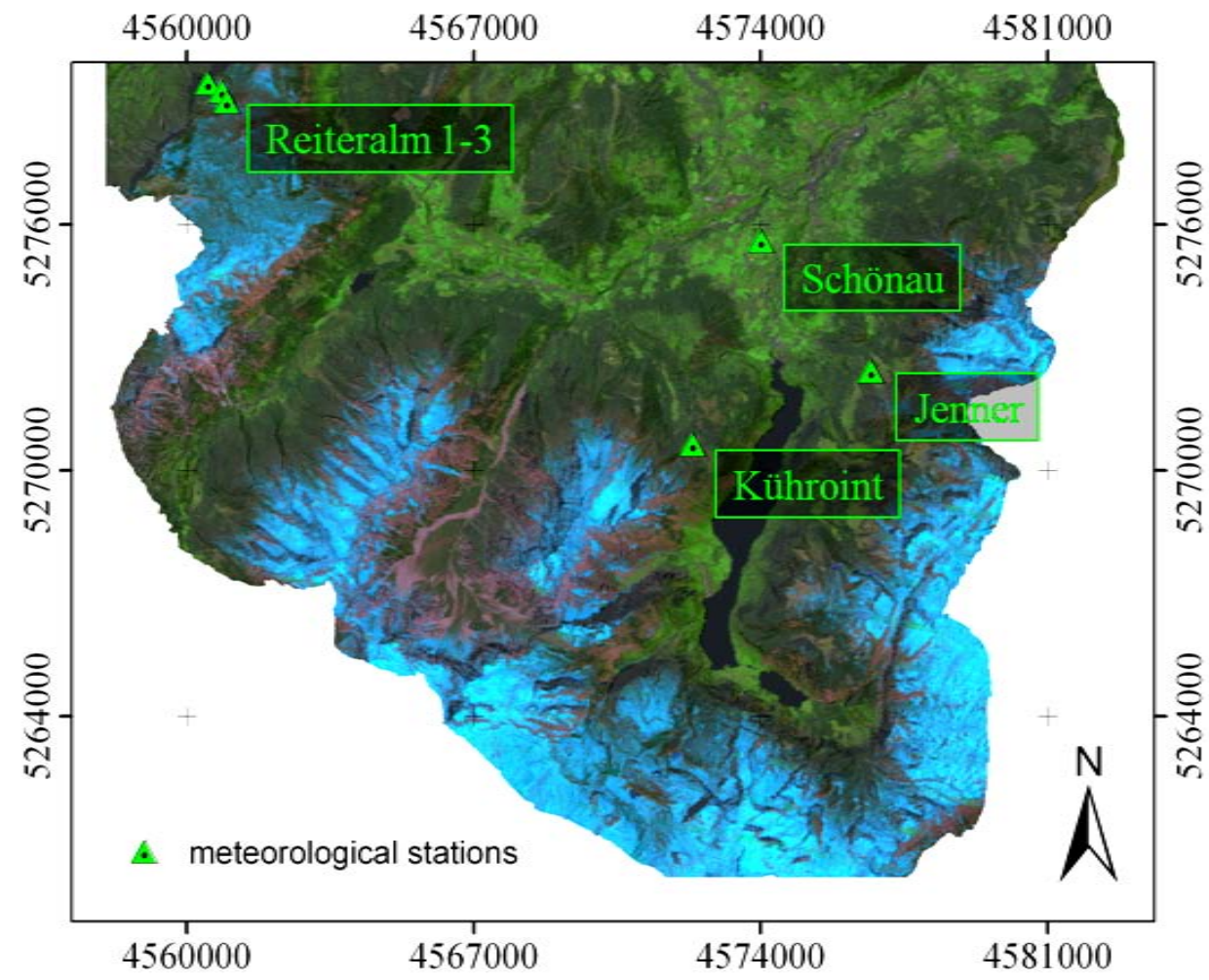

Figure 7: Location of the meteorological stations.

\subsubsection{Spatial data sets}

In addition to the meteorological data, a GIS providing information on vegetation and topography was used. The administration of the Berchtesgaden National Park has developed a wide set of GIS data over the past years. The cartographic reference system of all data is 
Gauss Krüger (Zone 4/WGS 84 ellipsoid). The original data has a resolution of 10m x 10m but was resampled to $30 \mathrm{~m} \times 30 \mathrm{~m}$ and $200 \mathrm{~m} \times 200 \mathrm{~m}$ respectively using the mean value for the elevation data and the majority in the case of vegetation data. These resolutions correspond to the available remotely sensed data (Landsat ETM+/30m) and to the topographic information and grid increment used by the MM5 model (200m) (fig. 8). The elevation data set originates from an analysis of 20m contour line maps (personal communication H. Franz 2007). The individual vegetation types were classified over a hierarchical scheme presented by the Bundesamt für Naturschutz (1995), using colour infrared aerial photos of 1997. As the resulting 101 classes are too detailed for this work they were aggregated to a final of 23 classes. This number of classes was chosen because it is slightly below the maximum number of classes the snow transport model (chapter 2.1.2) can process and allows for a meaningful aggregation of the original classes.

a)

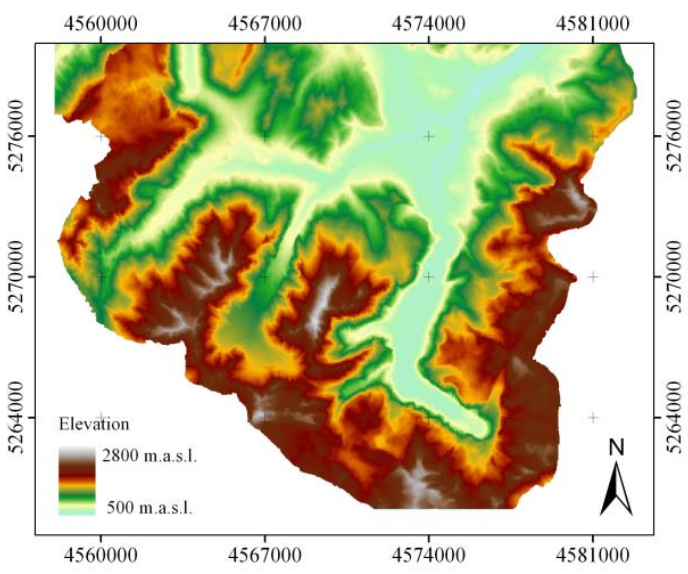

c)

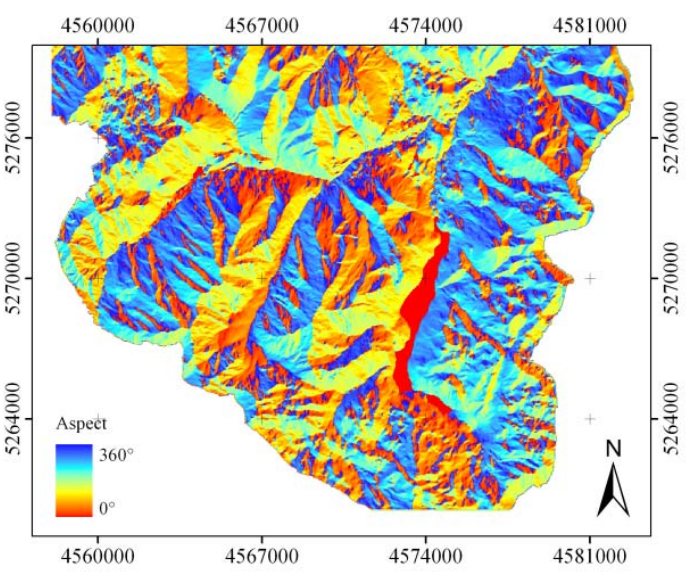

b)

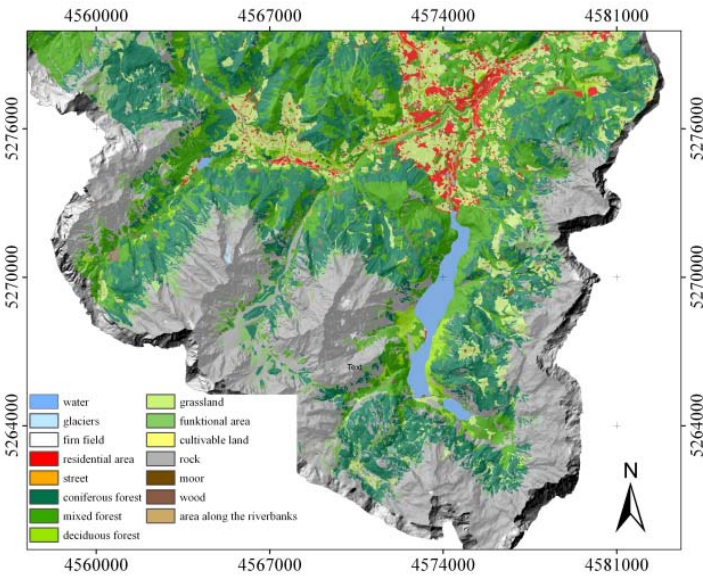

d)

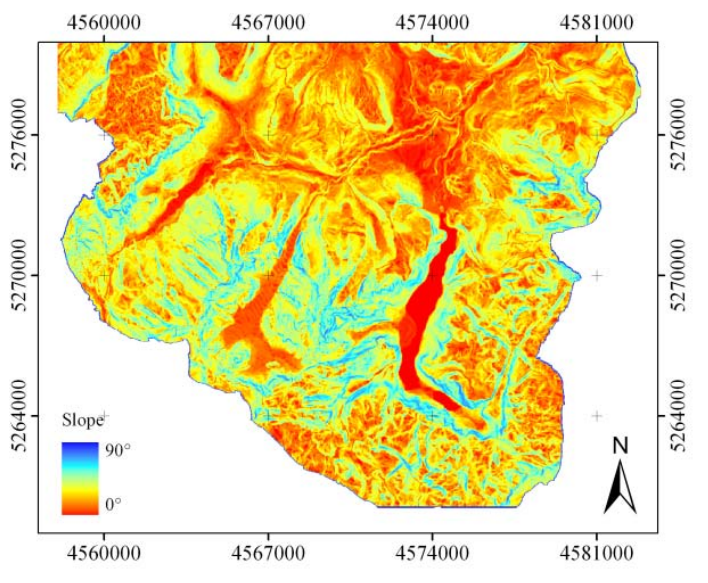

Figure 8: GIS data used in this work. a) elevation (m a.s.l.), b) vegetation types, c) aspect $\left(^{\circ}\right)$ and d) slope $\left(^{\circ}\right)$ 


\subsubsection{Field campaigns}

To evaluate the micro scale simulations, field measurements of snow depth were carried out. The choice of test sites was determined mainly by the accessibility of the region during the winter season. Hence, areas at Kühroint and Reiteralm were chosen (fig. 9 and fig. 10). Both can be reached easily, the first over a logging route and the second over a cable railway.

The Reiteralm (fig. 5, fig.9) plateau as a whole is made of Dachstein limestone and Ramsau dolomite and is characterized by an extensive flatland perched between 1500m a.s.l. and $2000 \mathrm{~m}$ a.s.l. and sharp drops around the edges. The average elevation of the part in which the test-site is located in is $1700 \mathrm{~m}$ a.s.l. the minimum and maximum elevations are $1610 \mathrm{~m}$ a.s.l. and $1753 \mathrm{~m}$ a.s.l. respectively. Mountain pine is the dominant vegetation type, followed by meadows and spruce.

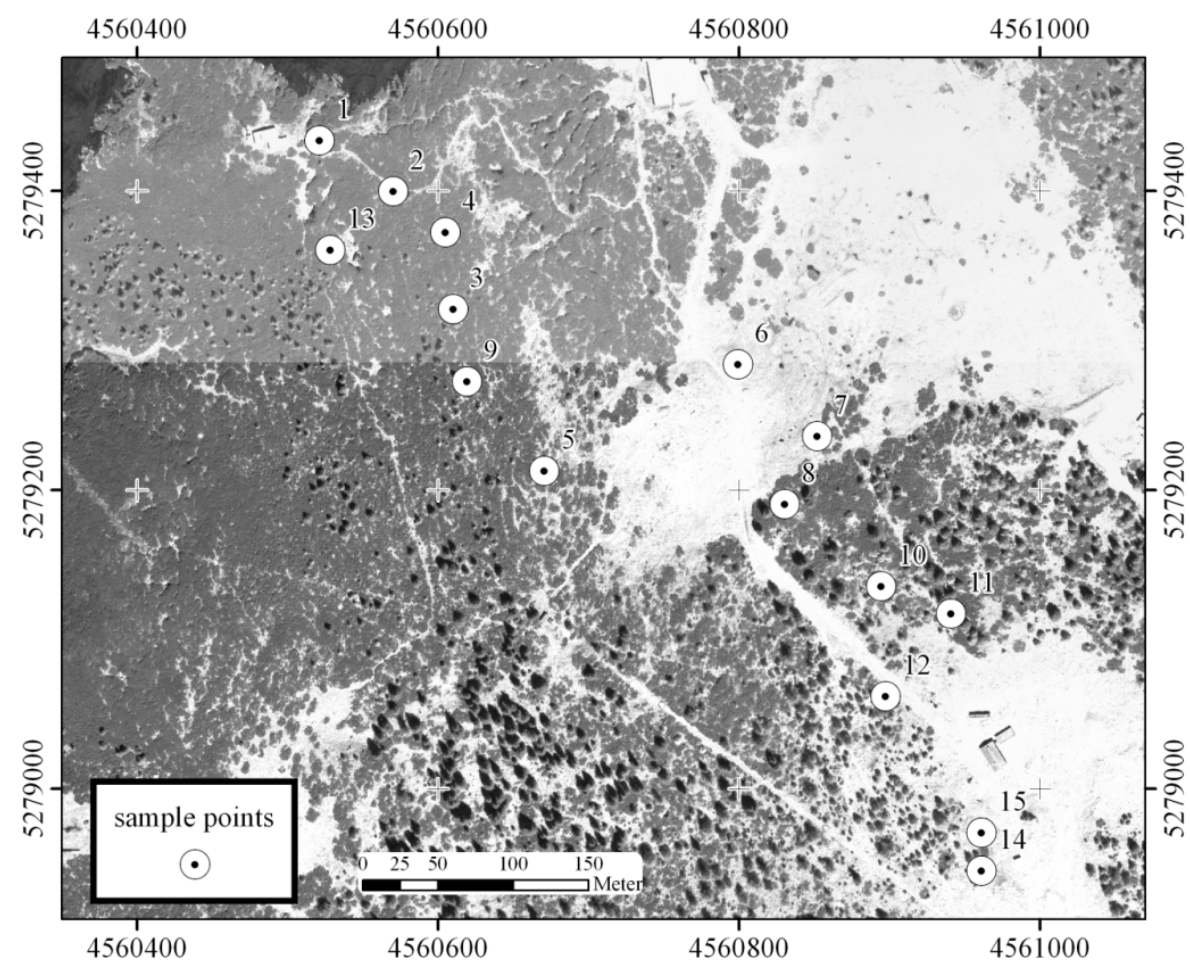

Figure 9: Sample points at Reiteralm. 15 sample points were installed in the winter season 2004/05 the points are named 1-15.

The mountain pasture Kühroint is located at approximately $1420 \mathrm{~m}$ a.s.l. in the north-eastern part of the Watzmann massif (fig. 5). Three different land use types can be found at this site: 
grassland, clear cut, and coniferous forest (fig. 10). The absolute difference in elevation is small (70 meters in total). The clear cut and the coniferous forest show undulating terrain with small hills of about five meters in height and an extent of 30 to 40 meters. The grassland in contrast is more planar and rises in a westerly direction. In 2004, the existing meteorological station at Kühroint was replaced with a new, fully automated, station of the Avalanche Warning Service of Bavaria (LWD) (the instrumentation can be found in tab. 2). Additionally, a snow pillow was installed but the data was not available for the winter season of 2004/05 due to a technical problem.

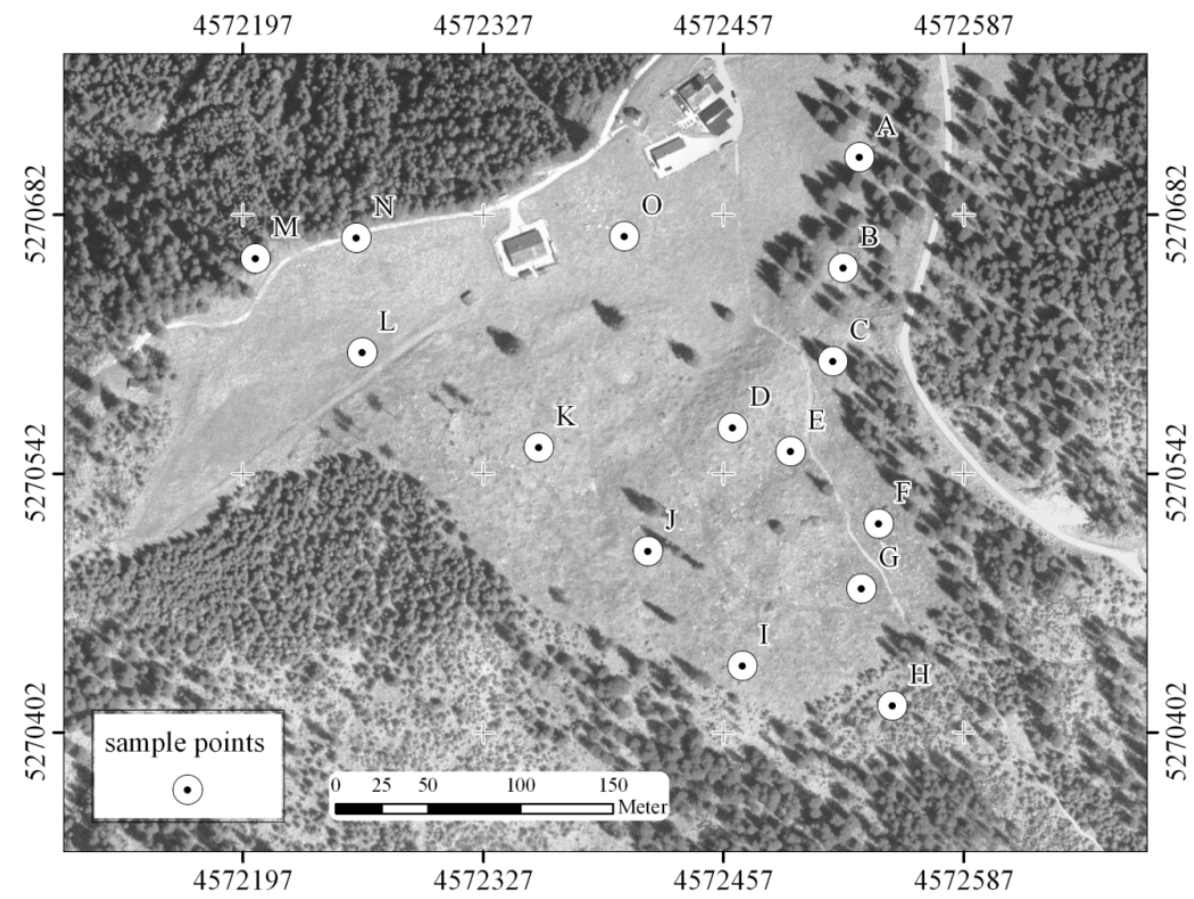

Figure 10: Sample points at Kühroint. 15 sample points were installed in the winter season 2004/05 the points are named A-O.

More remote sites at higher elevations would be desirably but were not feasible because of the expected risks.

A major problem of snow depth measurements is that every measurement influences the snow pack and its further development. To minimize this effect staff gauges were installed which can be read with the help of binoculars. The snow depth indicated by the staff gauges was 
routinely checked with snow pole measurements. These additional controls were needed because of the possible drift of the staff gauges due to e.g. snow pressure.

Measurements on 11 dates at 30 staff gauges were taken between February and April 2005 (the exact dates of the measurements are given in Tables 7 and 8). The choice of the location of the sample points bases on an analysis of the GIS and of the vegetation map. The objective of this process was to find representative points which allow for a characterization of the total study area. It was our plan to carry out a continuous series of weekly measurements but in some cases the intended interval could not be maintained due to difficult meteorological conditions and high avalanche risk 


\section{Chapter 2 Model descriptions}

The output from four different models was used for the presented work. For the estimation of the snow cover evolution, and of the meteorological fields, SnowModel (Liston et al. 2006) was utilized. Wind fields were predicted by a modified version of the PSU/NCAR MM5 model (Grell et al. 1995). To connect SnowModel and the MM5 wind fields during runtime, analysis results of DWD Lokalmodell (LM) (Adrian and Frühwald 2002) were used. As all of the named models are well documented in literature, only a short overview about the most important model formulations and modifications will be given in the next sections.

\subsection{SnowModel}

The SnowModel (Liston and Elder 2006) consists of six independent parts:

The quasi-physically-based meteorological distribution model MicroMet (Liston and Elder 2006) is used for the spatial interpolation of measurements of: air temperature, incoming longwave radiation, incoming solar radiation, precipitation, relative humidity, surface pressure, wind direction, and wind speed.

In a first step a Barnes objective scheme is applied (Eq. 1, Barnes 1964, 1973; Koch et al. 1983) to interpolate data from irregularly spaced stations to a regular grid (Liston and Elder 2006).

$$
w=\exp \left[\frac{r^{2}}{f(d n)}\right]
$$

Barnes interpolation scheme (Koch, et al. 1983): $\mathrm{w}=$ interpolation weights, $\mathrm{r}=$ distance between observation and observed grid point, $f(\mathrm{dn})=$ filter parameter which defines how smooth the interpolated field will be.

Afterwards different known relationships between meteorological parameters and terrain are used to modify the datasets (Liston and Elder 2006).

In the case of air temperature, lapse rates between the existing meteorological stations are used for the spatial distribution of the point measurements (Eq. 2 and 3). 


$$
\begin{gathered}
T_{0}=T_{s t n}-\Gamma\left(z_{0}-z_{s t n}\right) \\
T=T_{0}-\Gamma\left(z-z_{0}\right)
\end{gathered}
$$

Calculation of the gridded air temperature: $\mathrm{T}\left[{ }^{\circ} \mathrm{C}\right] . \mathrm{T}_{0}=$ air temperature at reference level, $\mathrm{T}_{\mathrm{stn}}=$ observed temperature at station elevation, $\mathrm{z}=$ topographic elevation of the topographic dataset, $\mathrm{z}_{0}=$ sea level, $\mathrm{z}_{\mathrm{stn}}=$ station elevation, $\Gamma=$ lapse rate $\left[\mathrm{C}^{\circ} \mathrm{m}^{-1}\right], \mathrm{T}\left[{ }^{\circ} \mathrm{C}\right]=$ gridded air temperature at the elevation of the topographic dataset.

As the relative humidity (Eq. 4) is a non-linear function of elevation the relative linear dew point temperature is used for elevation adjustments. In order to do that, the station measurements are first converted into dew point temperatures (Eq. 6), and subsequently adjusted to a common reference level using the dew point temperature lapse rate (Eq. 7) (Kunkel 1989) which can be predicted through station measurements. The reference level data are then distributed using the Barnes objective scheme and converted back into relative humidity in a final step (Liston and Elder 2006).

$$
R H=100 \frac{e}{e_{s}}
$$

Calculation of the relative humidity: $\mathrm{RH}=$ relative humidity, $\mathrm{e}=$ actual vapour pressure $[\mathrm{Pa}] \mathrm{e}_{\mathrm{s}}=$ saturation vapour pressure (Eq. 5)

$$
e_{s}=a \exp \left(\frac{b T}{c+T}\right)
$$

Calculation of the saturation vapour pressure: $\mathrm{e}_{\mathrm{s}}[\mathrm{Pa}]=$ saturation vapour pressure at temperature $\mathrm{T}\left[{ }^{\circ} \mathrm{C}\right]$, for water $\left(\mathrm{a}=611.21[\mathrm{~Pa}], \mathrm{b}=17.502, \mathrm{c}=240.97\left[{ }^{\circ} \mathrm{C}\right]\right)$, for ice $\left(=611.15[\mathrm{~Pa}], \mathrm{b}=22.452, \mathrm{c}=272.55\left[{ }^{\circ} \mathrm{C}\right]\right)($ Buck 1981)

$$
T_{d}=\frac{c \ln (e / a)}{b-\ln (e / a)}
$$

Calculation of the dew point Temperature: $T_{d}=$ dew point temperature.

$$
\Gamma_{d}=\lambda \frac{c}{b}
$$

Calculation of the dew point temperature lapse rate (Kunkel 1989)

Equation 8 was used to interpolate the measured precipitation rates to the model grid. The topographic reference level was calculated with the help of station elevations. This was done since the precipitation adjustment factor (Thornton et al. 1997) is a nonlinear function that uses elevation difference not total elevation. 


$$
P=P_{0}\left[\frac{1+\chi\left(z-z_{0}\right)}{1-\chi\left(z-z_{0}\right)}\right]
$$

$\mathrm{P}$ is precipitation [mm h-1], $\mathrm{P} 0=$ interpolated station precipitation, $\mathrm{z}=$ topographic elevation of the topographic dataset, $\mathrm{z}_{0}=$ station elevation surface, $\chi=$ monthly varying factor $\left[\mathrm{km}^{-1}\right]$ (Thornton et al. 1997)

The incoming solar radiation is predicted with a set of equations, considering the influence of the cloud cover, direct and diffuse solar radiation, as well as slope and aspect of the respective pixel. The cloud fraction is predicted over the relative humidity at the 700-mb level (Eq. 9, Walcek 1994).

$$
\sigma_{c}=0.832 \exp \left(\frac{R H_{700}-100}{41.6}\right)
$$

Calculation of the cloud fraction. $\sigma_{\mathrm{c}}=$ cloud fraction $\left[0 \leq \sigma_{\mathrm{c}} \geq 1\right], \mathrm{RH}_{700}$ relative humidity at 700hpa level which is predicted over the presented temperature lapse rates.

The solar radiation which is striking earth's surface is predicted via Equations 10. The direct and diffuse proportion of the net sky transmissivity is predicted over equations 11 and 12 (Burridge and Gadd 1974).

$$
\begin{gathered}
Q_{s i}=S *\left(\psi_{d i r} \cos i+\psi_{d i r} \cos Z\right) \\
\psi_{d i r}=(0.6-0.2 \cos Z)\left(1.0-\sigma_{c}\right) \\
\psi_{d i f}=(0.3-0.1 \cos Z) \sigma_{c}
\end{gathered}
$$

Calculation of the solar radiation in dependence of the sloping and zenith angle. $\mathrm{Q}_{\mathrm{si}}=$ solar radiation which is reaching earth's surface [ $\mathrm{W} \mathrm{m}^{-2}$ ], $\mathrm{i}=$ angle between a sloping surface and solar radiation, $\mathrm{S}^{*}=1370 \mathrm{~W} \mathrm{~m}^{-2}$ (Kyle et al., 1985), $\Psi_{\text {dir }}=$ direct net sky transmissivity, $\Psi_{\text {dif }}=$ diffuse net sky transmissivity.

Following Liston and Sturm (1998) wind speed and direction were spatially distributed using empirical wind topography relationships (Ryan 1977; Liston and Sturm 1998). To avoid the $0 / 360^{\circ}$ direction line problem when interpolating the station measurements, wind speed $W$ $(\mathrm{m} / \mathrm{s})$ and direction $\theta$ were converted into zonal and meridional components $u(\mathrm{~m} / \mathrm{s})$ and $v$ (m/s) (Liston and Sturm, 1998; Liston and Elder 2006).

$$
\begin{aligned}
& u=-W \sin (\theta) \\
& v=-W \cos (\theta)
\end{aligned}
$$

Calculation of the zonal and meridional components of wind speed and direction: $\mathrm{u}=$ zonal component, $\mathrm{v}=$ meridional component, $\mathrm{W}=$ wind speed, $\theta=$ wind direction.

After spatial interpolation the resulting values are converted back to speed and direction: 


$$
W=\sqrt{u^{2}+v^{2}}
$$

Conversion of meridional and zonal components to $\mathrm{W}=$ wind speed $[\mathrm{m} / \mathrm{sec}]$

$$
\theta=\frac{3 \pi}{2}-\tan ^{\wedge}-1\left(\frac{v}{u}\right)
$$

Conversion of meridional and zonal components to $\theta=$ wind direction $\left[{ }^{\circ}\right]$

Finally, wind speed and direction are modified with respect to topography using approaches by Liston and Sturm (1998) and Ryan (1977). For the modification of the wind speed a scaled slope $\left(\Omega_{\mathrm{s}}\right)$ and a scaled curvature $\left(\Omega_{\mathrm{c}}\right)$, in combination with two weighing factors $\left(\lambda_{\mathrm{s}}\right.$ and $\left.\lambda_{\mathrm{c}}\right)$ were used (Liston and Elder (2006) give a precise description of these parameters):

$$
W_{W}=1+\lambda_{s} \Omega_{s}+\lambda_{c} \Omega_{c}
$$

Modification of the wind speed with respect to the topography: $\mathrm{W}_{\mathrm{W}}=$ Modification value, $\lambda_{\mathrm{s}}$ and $\lambda_{\mathrm{c}}=$ empiric weight factors, $\Omega_{\mathrm{s}}=$ scaled slope, $\Omega_{\mathrm{c}}=$ scaled curvature.

Based on this the terrain modified wind speed $\left(W_{t}\right)$, is calculated from:

$$
W_{t}=W_{W} * W
$$

Calculation of the terrain modified wind speed $\mathrm{W}_{\mathrm{t}}[\mathrm{m} / \mathrm{sec}]$ (Liston and Sturm 1998). $\mathrm{W}=$ wind speed, $\mathrm{W}_{\mathrm{W}}=$ Modification value

The wind direction is modified by the diversion factor $\theta_{d}$ (Ryan, 1977) which is added to the wind direction ( $\zeta$ is the slope aspect):

$$
\theta_{d}=-0.5 \Omega_{s} \sin [2(\xi-\theta)]
$$

Calculation of the diversion factor $\theta_{\mathrm{d}}\left[^{\circ}\right]$ (Ryan 1977): $\theta=$ wind direction, $\Omega \mathrm{s}=$ scaled slope, $\zeta$ is the slope aspect.

The terrain modified wind direction $\left(\theta_{t}\right)$, is calculated from:

$$
\theta_{t}=\theta+\theta_{d}
$$

Calculation of the terrain modified wind direction $\theta_{\mathrm{t}}\left[^{\circ}\right]$ (Ryan 1977). $\theta=$ wind direction, diversion factor $\theta_{\mathrm{d}}$.

Finally, the wind fields are modified with a vegetation weighting factor considering the leaf area index (LAI) and the vegetation height $(\rho)$.

$$
W_{c a}=e^{((0.9 * L A I)(1.0-(0.6 * \rho) / \rho))}
$$

Calculation of the wind speed in canopy stands $\mathrm{W}_{\mathrm{ca}}[\mathrm{m} / \mathrm{sec}]$. LAI = leaf area index, $\rho=$ vegetation height. 
The snow model wind interpolation routine was identified as a limiting part of the model that should be improved or replaced (Liston and Sturm 1998). Hence, a MM5 wind field library was created in the course of this work and was used instead of the described interpolation routine (cp. eq. 13-20).

Enbal is described in detail in Liston (1995) and Liston et al. (1999). It predicts the surface temperature of the snow pack as well as the energy and moisture fluxes to and from the snow pack (eq. 22). The driving meteorological fields are provided by MicroMet.

$$
(1-\propto) Q_{s i}+Q_{l i}+Q_{l e}+Q_{h}+Q_{e}+Q_{c}=Q_{m}
$$

Basis equation of EnBal: $\mathrm{Q}_{\mathrm{si}}=$ solar radiation, $\mathrm{Q}_{\mathrm{li}}$ incoming longwave radiation, $\mathrm{Q}_{\mathrm{le}}$ emitted longwave radiation, $\mathrm{Q}_{\mathrm{h}}=$ turbulent exchange of sensible heat, $\mathrm{Q}_{\mathrm{e}}=$ turbulent exchange of latent heat, $\mathrm{Q}_{\mathrm{c}}=$ conductive energy transport, $\mathrm{Q}_{\mathrm{m}}=$ energy flux available for melt, $\alpha=$ surface albedo.

The formulations used within the model allow for an application in complex mountainous terrain (Liston 1995). In a first step the melt energy $Q_{m}$ is defined to be zero and Eq. 22 is solved in an iterative way. A resulting surface temperature greater than $0^{\circ}$ in the presence of snow indicates that energy for melt is available. In this case the surface temperature is fixed to $0^{\circ} \mathrm{C}$ and Eq. 22 is solved for $\mathrm{Qm}_{\mathrm{m}}$.

SnowPack (Liston and Hall 1995): is a simple, single layer snowpack evolution model. This model should not confused with SNOWPACK of Bartelt and Lehning (2002) which is the operational snow model of Switzerland's avalanche warning service.

Within SnowPack the precipitation is assumed to fall as snow if the wet-bulb temperature (eq. 23) is lower than $1^{\circ} \mathrm{C}$ (Liston and Hall 1995).

$$
T_{w b}=T_{a}+\left(e_{a}-e_{s}\left(T_{w b}\right)\right)\left(\frac{0.622}{P a} \frac{L_{s}}{C_{p}}\right)
$$

Approach for the calculation of the wet bulb temperature $T_{w b}$ (Rogers 1979): $e_{a}=$ vapour pressure of the air, $e_{s}=$ vapour pressure of the surface, $T_{a}=$ air temperature, $L_{s}=$ specific heat of air, $L_{s}=$ latent heat of sublimation, $\mathrm{Pa}$ $=$ atmospheric pressure.

The fallen precipitation is then added to the snow pack, and its new density is predicted with an equation of Anderson (1976):

$$
\rho_{n s}=50+1.7\left(T_{w b}-258.16\right)^{1.5}
$$

Calculation of the snow density $\rho_{\mathrm{ns}}$ (Anderson 1976): $\mathrm{T}_{\mathrm{wb}}=$ wet bulb temperature. 
As snow is, in general, a mixture of ice crystals, liquid water, and air, the snow density can also be modified by the liquid water content and the weight of the overlying snow. If melt occurs the liquid water will stay within the snow pack until a threshold density is reached. If this is the case any additional water will leave the snow pack (Liston and Hall 1995). All energy related calculations at the surface of the snow cover including ground sublimation are processed in EnBal.

SnowTran3D (Liston and Sturm 1998) is a three-dimensional model, able to simulate the transport terms: saltation, suspension, and sublimation (fig. 11). SnowTran3D has proven its applicability in a wide variety of landscapes (Green et al. 1999; Liston et al. 2000; Prasad et al. 2001; Hiemstra et al. 2002, Hasholt et al. 2003; Bruland et al. 2004) including the European Alps (Bernhardt et al. 2008a). The model algorithms which are important for a better understanding of subsequent steps are presented in the next section. A more detailed documentation of the model can be found in Liston and Sturm (1998) and Liston et al. (2006).

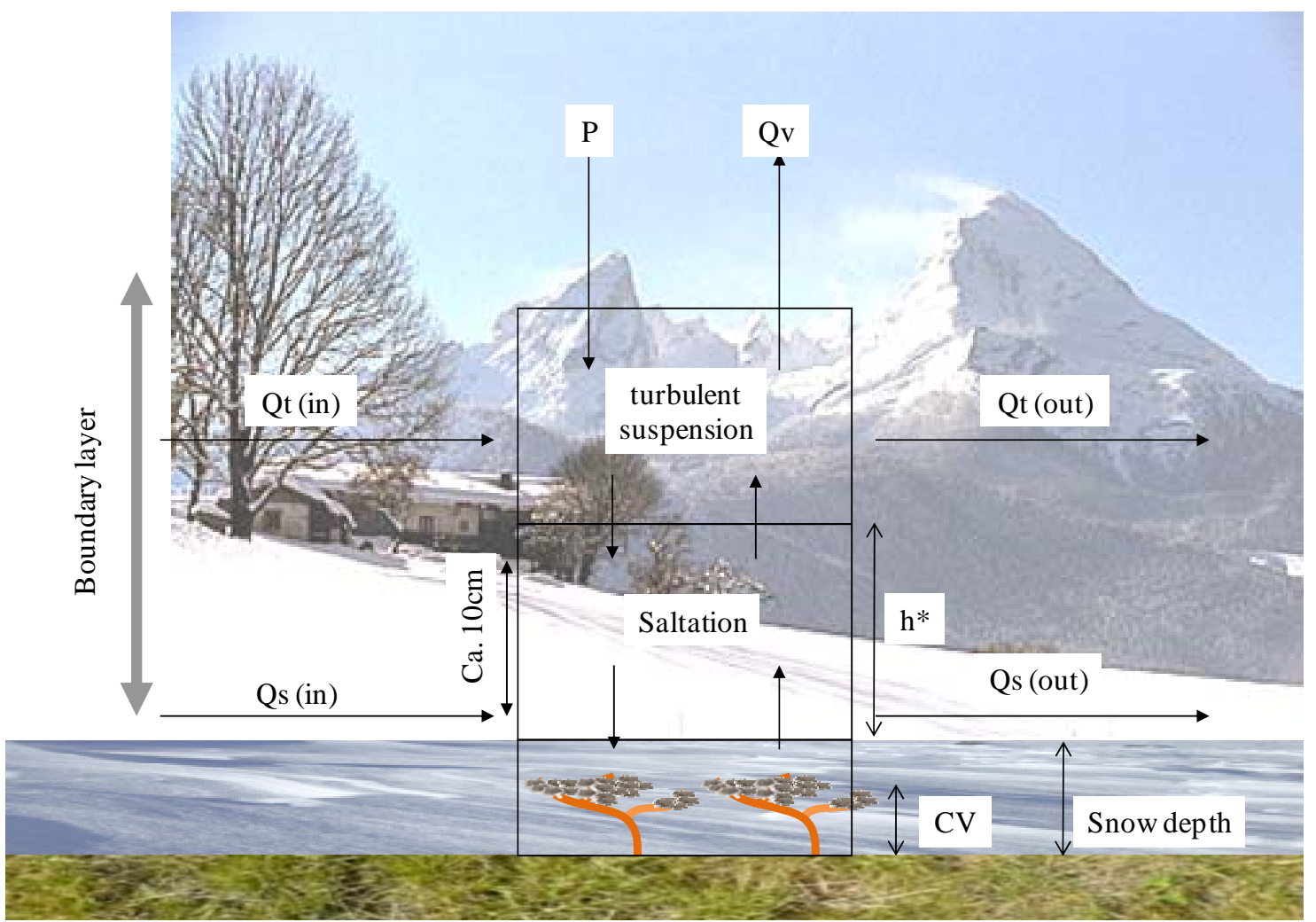

Figure 11: Schematic illustration of the transport model. Qt = mass transport rates of saltation, $\mathrm{Qv}=$ mass transport rates of turbulent suspended snow, Qs = sublimation of transported snow particles. $\mathrm{P}=$ water equivalent precipitation rate. $\mathrm{CV}=$ snow holding capacity. $\mathrm{h}_{*}=$ top of the saltation layer. 
Equation 25 shows the mass balance equation on which SnowTran-3D is based on.

$$
\frac{\mathrm{d} \zeta}{\mathrm{d} t}=\frac{1}{\rho_{s}}\left[\rho_{w} P-\left(\frac{\mathrm{d} Q_{s}}{\mathrm{~d} x}+\frac{\mathrm{d} Q_{t}}{\mathrm{~d} x}+\frac{\mathrm{d} Q_{s}}{\mathrm{~d} y}+\frac{\mathrm{d} Q_{t}}{\mathrm{~d} y}\right)+Q_{v}\right]
$$

Mass balance equation of SnowTran-3D. $\zeta=$ snow depth $(\mathrm{m}), \rho_{\mathrm{s}}=$ snow density $\left(\mathrm{kg} \mathrm{m}^{-3}\right), \rho_{\mathrm{w}}=$ water density $(\mathrm{kg}$ $\left.\mathrm{m}^{-3}\right), \mathrm{P}=$ precipitation rate $\left(\mathrm{m} \mathrm{s}^{-1}\right), \mathrm{Q}_{\mathrm{s}}=$ saltation rate $\left(\mathrm{kg} \mathrm{m}^{-1} \mathrm{~s}^{-1}\right), \mathrm{Q}_{\mathrm{t}}=$ amount of turbulent suspended snow ( $\mathrm{kg}$ $\left.\mathrm{m}^{-1} \mathrm{~s}^{-1}\right), \mathrm{Q}_{\mathrm{v}}=$ sublimation of transported snow particles $\left(\mathrm{kg} \mathrm{m}^{-1} \mathrm{~s}^{-1}\right), \mathrm{t}=$ time $(\mathrm{s}), \mathrm{x}=$ horizontal coordinates in west east direction $(\mathrm{m}), \mathrm{y}=$ horizontal coordinates in north south direction $(\mathrm{m})$.

SnowTran-3D is able to predict the most effective transport terms saltation and turbulent suspension while creeping is neglected. The description of the saltation process follows Pomeroy and Gray (1990).

$$
Q_{s_{-} \max }=\frac{0.68}{u_{*}}\left(\frac{\rho_{a}}{g}\right) u_{* t}\left(u_{*}^{2}-u_{* t}^{2}\right)
$$

Estimation of the equilibrium saltation rate: $\mathrm{Q}_{\mathrm{s} \text { max }}=$ saltation transport rate $\left(\mathrm{kg} \mathrm{m}^{-1} \mathrm{~s}^{-1}\right), \rho_{\mathrm{a}}=$ air density $\left(\mathrm{kg} \mathrm{m}^{-1}\right)$, $\mathrm{u}_{*}=$ friction velocity, $\mathrm{g}=$ gravity $\left(\mathrm{m}^{-1} \mathrm{~s}^{-2}\right), \mathrm{t}=$ time $(\mathrm{s}) u_{*_{t}}=0.25\left(\mathrm{~m} \mathrm{~s}^{-1}\right)$.

The amount of snow which is transported at a given time step largely depends on the shear stress which the wind exerts on the surface. Bagnold (1941) has defined two threshold values, the impact and the fluid threshold velocity, with the fluid threshold velocity exceeding the impact threshold velocity. Pomeroy (1988) found that the difference between the two threshold velocities is negligible. Based on his work, the threshold friction velocity $\mathrm{u}_{*}$ (Eq. 27) is commonly used instead of the terms defined by Bagnold.

$$
u_{*}=u_{r} \frac{\kappa}{\ln \left(z_{r} / z_{0}\right)}
$$

Threshold friction velocity $\mathrm{u}_{*}\left(\mathrm{~m} \mathrm{~s}^{-1}\right)$ (Pomeroy, 1988): $\mathrm{u}_{\mathrm{r}}=$ wind speed at reference height $\left(\mathrm{m} \mathrm{s}^{-1}\right), \mathrm{z}_{\mathrm{r}}=$ reference height $(\mathrm{m}), \mathrm{z}_{\mathrm{o}}=$ roughness length, $\kappa=$ Kármán's constant.

The threshold velocity which is needed for initializing the saltation can be modified by the roughness length of the surface $\left(\mathrm{z}_{0}\right)$ (eq. 29). The roughness length mainly depends on the snow depth fraction (eq. 28) and on the vegetation types of an area.

$$
F_{S}=\frac{\zeta}{C_{v}}
$$

Estimation of the depth fraction of vegetation covered by snow $F_{s}: \zeta=$ snow depth $(m), C_{v}=$ vegetation specific snow holding capacity (m). 
The snow holding capacities are between 0m (rock) and 15m (coniferous forest) (Liston and Sturm 1998).

$$
z_{0}=F_{S} z_{0 \_ \text {snow }}+\left(1-F_{S}\right) z_{0 \_ \text {veg }}
$$

Calculation surface roughness length $\mathrm{z}_{0} . \mathrm{F}_{\mathrm{s}}=$ depth fraction of vegetation covered by snow, $\mathrm{z}_{0_{\text {_snow }}}=$ roughness length of snow (0.001), $\mathrm{z}_{0_{\text {_vegetation_ }}}=$ roughness length of a vegetation covered surface (this value is approximated by: $0.25 *$ snow holding capacity)

If the wind speed is strong enough snow particles can be picked up by turbulent eddies and will enter into suspension. During snowdrift suspension the particle paths are fluctuating around a certain average height which is dependent on the immersed weight of the particles and on the balance between turbulent energy and gravity (Bintanja, 2000). The maximum thickness of the suspension layer is an object of discussion, the values in literature ranging from a few meters (Kobayashi, 1972; Takeuchi, 1980) to a several hundred meters (Budd et al., 1966).

Saltation has to be present to initialise turbulent suspension (eq. 30) (Liston and Sturm 1998). The saltation layer provides the lower boundary conditions and determines whether and to which degree turbulent suspension occurs. The equation which defines the concentration of snow within the turbulent-suspension layer follows Kind (1992).

$$
\phi_{t}\left(x^{*}, z\right)=\phi_{r}\left[\left(\frac{\phi^{*}}{\phi_{r}} \frac{u_{*}}{s}+1\right)\left(\frac{z}{z_{t r}}\right)^{-s / k u^{*}}-\frac{\phi^{*}}{\phi_{r}} \frac{u_{*}}{s}\right]
$$

Concentration of blowing snow within the suspension layer (Kind 1992): $\varnothing_{\mathrm{t}}=$ turbulent suspension layer $\left(\mathrm{kg} \mathrm{m}^{-1}\right.$ $\left.\mathrm{s}^{-1}\right), \emptyset_{\mathrm{r}}=$ mass concentration at reference level $\left(\mathrm{kg} \mathrm{m}^{-1} \mathrm{~s}^{-1}\right), z=$ height coordinate $(\mathrm{m}), x^{*}=$ horizontal coordinate $(\mathrm{m}), \varnothing^{*}=$ is a concentration scaling parameter, $\mathrm{u}_{*}=$ wind shear velocity $\left(\mathrm{m} \mathrm{s}^{-1}\right), \mathrm{s}=$ particle settling velocity $(\mathrm{m} \mathrm{s}$ $\left.{ }^{1}\right)$, $\mathrm{z}_{\mathrm{tr}}=$ height of the reference level, $k=$ Kármán’s constant.

The concentration reference level $\mathrm{z}_{\mathrm{tr}}(\mathrm{m})$ corresponds to the top of the saltation layer $\mathrm{h} *(\mathrm{~m})$ which ensures continuity between these two model layers. The horizontal particle velocity within the saltation layer ( $\mathrm{u} *$ ) that is needed to solve Eq. 31 is assumed to be constant with height and follows Pomeroy and Gray (1990) (fig. 12).

$$
h_{*}=1.6 \frac{u_{*}^{2}}{2 g}
$$

Particle velocity within the saltation layer (Pomeroy and Gray 1990): $\mathrm{h}_{*}=$ top of the saltation layer (m), $u_{*}=$ wind shear velocity $\left(\mathrm{m} \mathrm{s}^{-1}\right), \mathrm{g}=$ gravity $\left(\mathrm{m} \mathrm{s}^{-2}\right)$. 
The saltation layer mass flux is defined as independent of height, which is a known oversimplification (McKenna-Neuman and Nickling, 1994) but has to be used in this form until more valid formulations are available (Liston and Sturm 1998).

Lehning et al. (2002) criticised the presented algorithms of turbulent saltation/suspension for unsteady terrain because of Equation 26 which neglects advective and non-steady effects. This is a valid argument at the point scale but the effect at the catchment scale should be negligible (personal communication Liston and Pomeroy 2006) which makes the Equation applicable for this study.

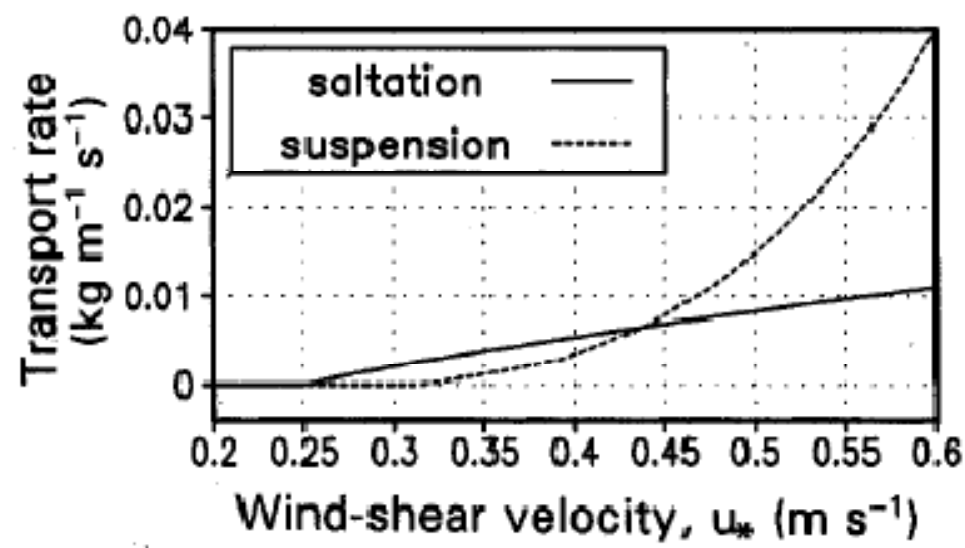

Figure 12: Connection between wind-shear velocity and transport rate (cp. Liston and Strum 1998)

The moisture fluxes due to sublimation between a snow pack and atmosphere are comparatively small, but considerable fluxes can be observed if snow particles are in transport (Hood et al. 1999, Strasser et al. 2007). The exact explanation of the equations used in SnowTran-3D can be found in Schmidt (1972), Pomeroy et al. (1993), Pomeroy and Gray (1995) and Liston and Sturm (1998). The principle formulation of the sublimation rates are given in Eq. 32 for one homogenous transport layer and Eq. 33 for saltation in combination with turbulent suspension.

$$
Q_{v}\left(x^{*}\right)=\int_{0}^{z_{t}} \Psi\left(x^{*}, z\right) \phi\left(x^{*}, z\right) \mathrm{d} z
$$

Sublimation rates if only one transport layer exists: $Q_{v}=$ sublimated amount of transported snow per unit area of snow cover $\left(\mathrm{kg} \mathrm{m}^{-1} \mathrm{~s}^{-1}\right), \Psi=$ sublimation loss rate coefficient $\left(\mathrm{s}^{-1}\right), \varnothing=$ vertical mass distribution $\left(\mathrm{kg} \mathrm{m}^{-3}\right)$. The integration limits are from the surface through the upper boundary of the transport layer, $x^{*}=$ horizontal coordinate $(\mathrm{m})$, vertical coordinate, $\mathrm{z}_{\mathrm{t}}=$ 


$$
Q_{v}\left(x^{*}\right)=\Psi_{\mathrm{s}} \phi_{\mathrm{s}} \mathrm{h}_{*}+\int_{h_{*}}^{z_{t}} \Psi_{\mathrm{t}}\left(x^{*}, z\right) \phi_{t}\left(x^{*}, z\right) \mathrm{d} z
$$

Sublimation rates of the saltation and sublimation layer: $Q_{v}=$ sublimated amount of transported snow per unit area of snow cover $\left(\mathrm{kg} \mathrm{m}^{-1} \mathrm{~s}^{-1}\right)$, the nomenclature is like in Eq. 32. The subscripts $\mathrm{s}$ and $\mathrm{t}$ refer to the saltation and turbulent suspension layer.

The calculation of the sublimation rates additionally depends on the humidity gradients between the snow particles and the atmosphere, conductive and advective moisture fluxes, snow particle size, and the intercepted solar radiation per snow particle (Liston and Sturm 1998).The respective Equations can be found in the Appendix I.

\subsection{MM5 model}

The numerical simulations used to compile the MM5 wind field library were conducted with an adapted version of the Penn State University-National Center for Atmospheric Research MM5 model, version 3.3 (Grell et al., 1995).

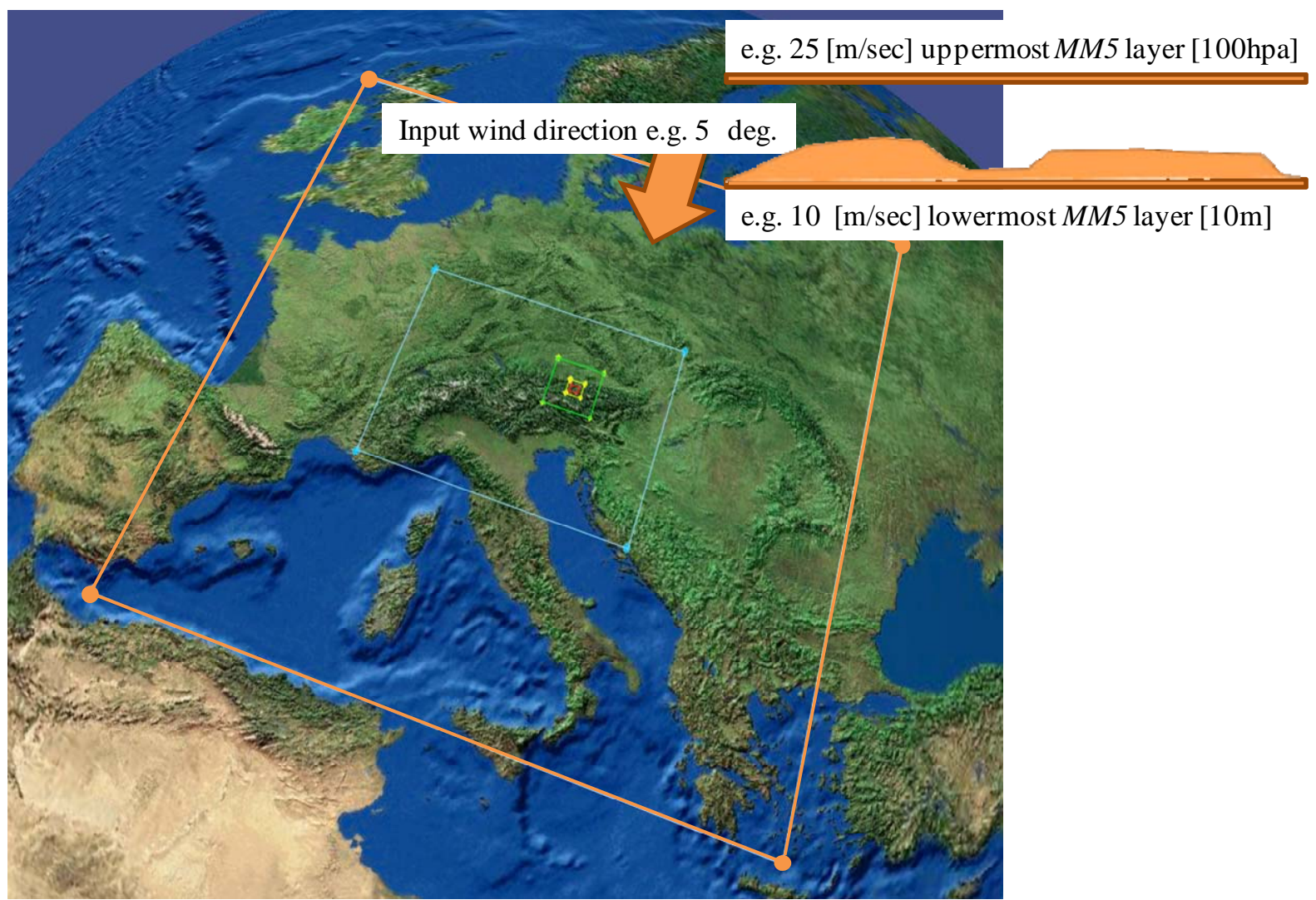

Figure 13: Schematic illustration of the MM5 nesting domains (the largest domain is domain_1, the smallest domain_5) and of the needed input parameters. 
The model solves the nonhydrostatic equations of motion in a terrain-following sigma coordinate system. Five interactively nested model domains were used, having a horizontal mesh size of $16.2 \mathrm{~km}, 5.4 \mathrm{~km}, 1.8 \mathrm{~km}, 600 \mathrm{~m}$, and $200 \mathrm{~m}$, respectively. The corresponding numbers of grid points were $148 \times 142,166 \times 127,88 \times 88,82 \times 82$, and $121 \times 97$, respectively. The area covered by the model domains is displayed in fig. 13. In the vertical, 39 full-sigma levels were used, corresponding to 38 half-sigma levels where all variables except the vertical wind are computed. The lowermost half-sigma level is located about $10 \mathrm{~m}$ above the ground, and the vertical distance between the model layers increases with height from about 20 m near the ground to about $700 \mathrm{~m}$ near the upper boundary which is located at $100 \mathrm{hPa}$. The needed model topography was created from US Geological Survey (USGS) terrain data with a horizontal resolution of 5' for domain_1 and 30” for model domains_2-_3. For the two inner model domains (4 and 5), high resolution topography data with a grid spacing of $600 \mathrm{~m}$ and $200 \mathrm{~m}$ was derived from $50 \mathrm{~m}$ DEM data (Ludwig et al., 2003). Information on surface roughness was based on land use classes derived from USGS data with a resolution of 30”.

For the initialisation of the model information about the wind direction and wind speed for the lowermost (10m) and the uppermost model layer (100hpa) was needed (fig. 13). Specifically, the boundary conditions are defined by a wind direction, the (theoretical) geostrophic wind speed at sea level, and by the wind speed set for the lowermost $(10 \mathrm{~m})$ and uppermost model level (100hpa) of domain_1. The ration between the wind speed used for the lowermost and the uppermost model layer was 1 (ground level) to 1.5 (100hpa level) which corresponds to the common difference in wind speed between these two layers (personal communication G. Zängl 2004). These three parameters constitute the backbone for setting up the computation of the wind field library. The target area corresponds to the MM5 nesting domain_5.

The diurnal cycle related to radiation is not taken into account, because solar radiation delivers only a comparatively small amount of energy during the winter season. Hence, thermally induced local wind systems usually don't induce significant snow transport processes. Consequently, the specified large scale fields are kept constant throughout the simulations, which are conducted for 24 hours so that the resulting fields represent steady state conditions. To keep the computational expense at a reasonable level, the first 15 hours of simulation are conducted with the three outer domains only. The fourth and fifth domain are 
started at $\mathrm{t}=15 \mathrm{~h}$ and at $\mathrm{t}=21 \mathrm{~h}$ respectively, so that the innermost domain is active for three hours only. Sensitivity tests with various wind directions revealed that this is sufficient to reach quasi steady state in the $200 \mathrm{~m}$ domain. This can be explained by the fact that the vertical group velocity of orographic gravity waves is inversely proportional to their horizontal scale, so that small scale waves rapidly reach a steady state.

The described large-scale wind field is assumed to be in geostrophic balance with the pressure field except for the frictional boundary layer. The Coriolis parameter is assumed to be constant at $10^{-4} 1 / \mathrm{s}$ throughout the model domain. The large scale wind field is allowed to have vertical shear, as is usually the case for real flows, but is forced to be unidirectional in order to limit the degrees of freedom.

The large scale temperature profile starts with a sea level temperature of $278.5 \mathrm{~K}$, followed by a vertical temperature gradient of $-6.5 \mathrm{~K} / \mathrm{km}$ up to the tropopause. Above that, an isothermal stratosphere is assumed. Though the low level static stability is frequently higher in winter, this temperature profile is reasonable for our purposes because strong wind conditions (which are critical to this study) force vertical mixing and thus tend to reduce the low level static stability. Unless mentioned otherwise, the large scale relative humidity starts with $75 \%$ at sea level, increases with height to reach a maximum of $90 \%$ between $750 \mathrm{hPa}$ and $650 \mathrm{hPa}$, and then decreases with height down to a value of $20 \%$ at tropopause level. The motivation for this setting is to allow for the formation of clouds and orographic precipitation under northerly flow conditions which may affect flow dynamics due to the reduction of the effective static stability. However, sensitivity experiments with lower humidity (no more than $60 \%$ throughout the troposphere) indicated that the local wind pattern in the target area is relatively insensitive to moisture conditions.

To properly account for the frictional processes relevant for setting up the local wind field in the target area, a sophisticated boundary layer parameterization with 1.5 order closure based on a prognostic equation for turbulent kinetic energy (TKE) was used (Shafran et al., 2000). Moreover, a cloud microphysics scheme of medium complexity was used to simulate cloud formation and precipitation processes (Reisner et al., 1998). To adapt MM5 to the extremely steep topography of our target area, several modifications of the model numerics were applied (Zängl 2002). Numerical diffusion of temperature and moisture is computed with the truly 
horizontal scheme implemented by Zängl (2002), which has proved to greatly reduce numerical errors over steep topography. To improve the numerical accuracy of horizontal advection over steep topography, the generalized vertical coordinate described by Zängl (2003) was used. Unlike standard terrain-following coordinates, this coordinate definition allows for a very rapid decay of the topographic structures with height in the coordinate surfaces. In addition, the numerical damping of sound waves has been increased in the implicit sound wave solver of MM5 in order to improve the numerical stability over very steep slopes (slope angle $>50^{\circ}$ ). Despite this, the $200 \mathrm{~m} \mathrm{DEM}$ used had to be smoothed at some locations to prevent numerical instability.

\subsection{Lokalmodell (LM)}

The second atmospheric model which was used is the Lokalmodell (LM) of the German Weather Service (DWD), serving as a link between the actual atmospheric situation and the MM5 wind fields.

Launched in December 1999, LM and Globales Modell Europa (GME) represent the operational model chain of the DWD. GME is the operational global forecast model that provides the lateral boundary conditions for $L M$. $L M$ itself is a nonhydrostatic model and can be used for forecasting as well as for analysis issues (Doms and Schättler 1999). LM is applicable for different areas and scales; the DWD uses it for an area of 2000x2000 km. The coordinate system uses rotated spherical coordinates in the horizontal and a height based terrain-following coordinate in the vertical (zeta) (Gal-Chen and Somerville 1975; Doms et al. 2002). The zeta coordinates divides the model atmosphere into 35 levels ranging from the earth's surface to $20 \mathrm{hPa}$. The used mesh width of $L M$ is $7 \mathrm{~km}$, the second edition of $L M$ has an improved resolution of $2.8 \mathrm{~km}$ becomes operational in 2007 but was not used here.

For this study operational $L M$ analysis data were used; the data were derived from modelling and continuous assimilation of observation data by a nudging system: Modelled data is shifted towards the observed data while maintaining dynamic and physical consistency. As a consequence, the analysis data reflects the actual atmospheric situation much better than the 
forecasting results (Wergen 2002). Operational analysis data are provided at an hourly resolution. 


\section{Chapter 3: Meteorological fields}

\subsection{Interpolation of meteorological parameters, capabilities and limitations.}

For a proper modelling of the snow cover, valid meteorological fields are needed as driving force. The following chapter will discuss I) the quality and number of the available measurements II) the possibility to generate adequate wind fields with the help of the interpolation scheme described in chapter 2 and III) the spatial characteristics of MM5 generated wind fields.

The horizontal and vertical distribution of the meteorological stations within the upper Danube catchment is used as baseline for the following discussion. The area was chosen because it reflects the general distribution of meteorological stations. A discussion on the basis of the test site Berchtesgaden National Park would be misleading because the site is exceptionally well equipped and is therefore not representative. Figure 14 a) shows that the horizontal distribution of the stations is nearly uniform but the vertical distribution shows a clear trend towards a lesser number of stations at higher altitudes. In the upper Danube catchment 313 of 360 available stations are located between $0 \mathrm{~m}$ a.s.l. and 1000m a.s.l., 37 between $1000 \mathrm{~m}$ a.s.l. and $2000 \mathrm{~m}$ a.s.l. and only 10 stations are located above $2000 \mathrm{~m}$ a.s.l. (fig. 14 b)). The thinning of the network from 1000 meters on is due to the steep alpine topography, extreme weather conditions, problematic data transfer from the stations to the receptor, limited power supply, and difficult maintenance of the stations.

a)

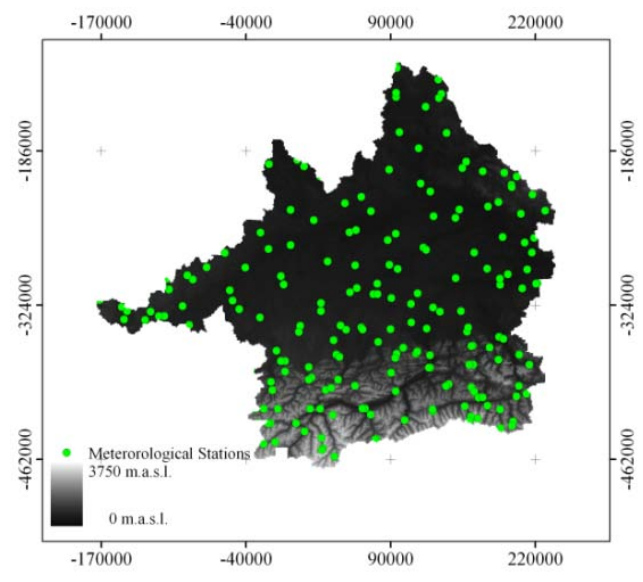

b)

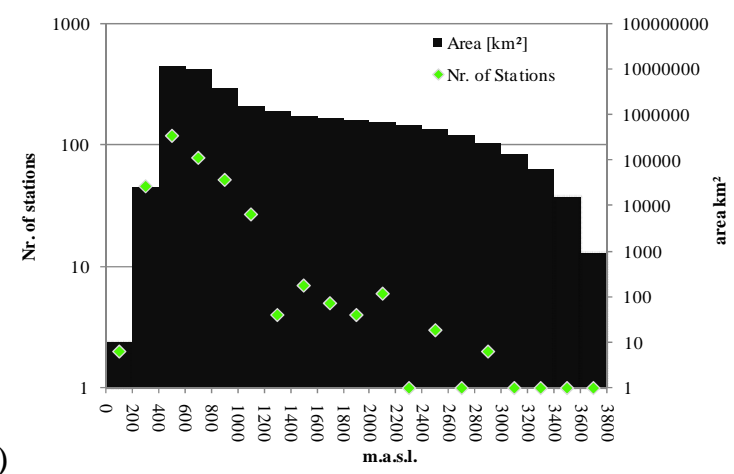

Figure 14: a) Spatial distribution of the meteorological stations within the upper Danube catchment, b) Area of the different elevation bands and number of stations at the respective altitudes. 
The thinning of the station network with altitude stands in direct contrast to the demands formulated by Barry (1992). He stated that the network of meteorological stations in mountainous regions should be 10 to 20 times denser than in flatlands to observe just the correct trend of the different meteorological parameters. The higher number is needed because the heterogeneous mountain terrain causes such a broad band of local weather conditions that the measurement at any particular station can only be seen as representative for a limited area (Barry 1992). That means that the spacing of the stations becomes especially wide if the support of the data becomes small. Furthermore, the measurements conducted in Alpine regions are less reliable than such in the flatlands which is due to frequent heavy weather conditions (Barry 1992). Apart from the measurements, the interpolation of meteorological parameters is a challenge in regions with remarkable elevation differences. The computation of continuous meteorological fields on the basis of point measurements is especially difficult if a meteorological variable is not directly coupled to a certain topographic parameter or if the topography is very complex. Furthermore, the limited number of meteorological stations from 1000 meter on (fig. 14 b)) leads to the need of an extrapolation of the meteorological measurements for regions which are located above the highest available station in the surrounding. This procedure has no physically based background and does not respect the real processes of the higher regions (e.g. inversion layers). The application of a gradient of e.g. precipitation which was predicted under usage of lower elevation stations can lead to an appreciable overestimation of the precipitation in high mountain regions. This is due to the fact that a decreasing or steady precipitation amount at higher elevations cannot be computed with common interpolation techniques. Nevertheless, the procedure of applying the respective gradient determined from lower elevation stations to regions above the elevation of the highest meteorological station was chosen for this study as there is no plausible reason that would legitimate the fixing of the gradients to a definite value or the modification of the gradient

The parameters required by the model used here are, temperature, relative humidity, precipitation, incoming solar radiation, wind speed and wind direction. The following discussion will consider just these parameters for the winter season 2003/04. For the validation of the interpolated values the stations at Reiteralm (fig. 5) were excluded from the interpolation scheme and used as the basis for comparison between model results and 
measured values as shown in Figures 15-20. The interpolation is based on data delivered by the meteorological stations, Schönau, Jenner and Kühroint. Interpolation results which show a good correspondence to the test station Reiteralm are only discussed shortly.

Air temperature is typically simple to interpolate because it shows a relatively stable correlation with height. Figure 15 shows that the temperature at Reiteralm station II can be reproduced in a satisfying way by the interpolation routine (eq. 2 and 3). However, the temperature calculations can be complicated for higher regions if inversion layers are present. Furthermore, the interpolation can become erroneous if the upper regions are snow covered while the areas with the meteorological stations are snow free.

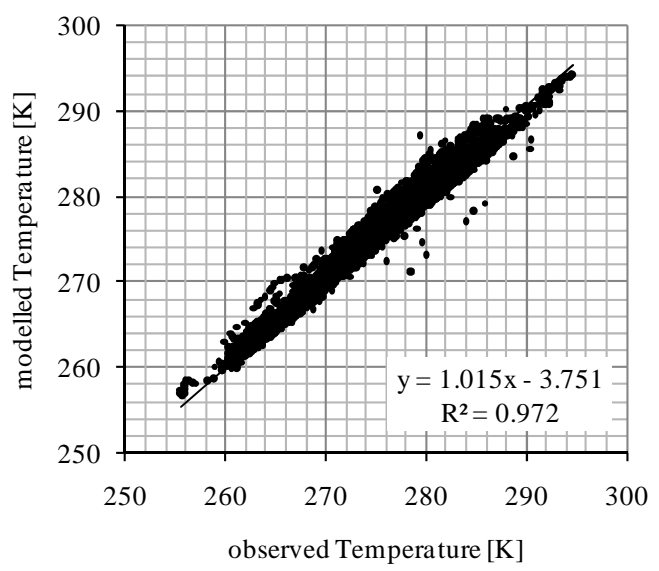

Figure 15: Temperature recordings of Reiteralm II meteorological station. Comparison of hourly modelled and observed data for the winter season 2003/2004.

Figure 16 shows that the calculation of the incoming solar radiation leads to a reasonably good correlation between measurements and model results $\left(\mathrm{R}^{2}=0.71\right)$. However, it becomes obvious that model results tend to be higher than observed values. This effect is due to an underestimation of the cloud cover (Eq. 9). More sophisticated radiation models like the one used in e.g. AMUNDSEN (Strasser et al. 2007) are able to describe the radiation balance at a given point more accurately because they respect shading effects and reflected longwave radiation from the surrounding terrain and applies. Nevertheless, it could be seen that the error of the interpolation scheme is especially high in summer and more accurate in winter which allows for an application of the presented formulations. 


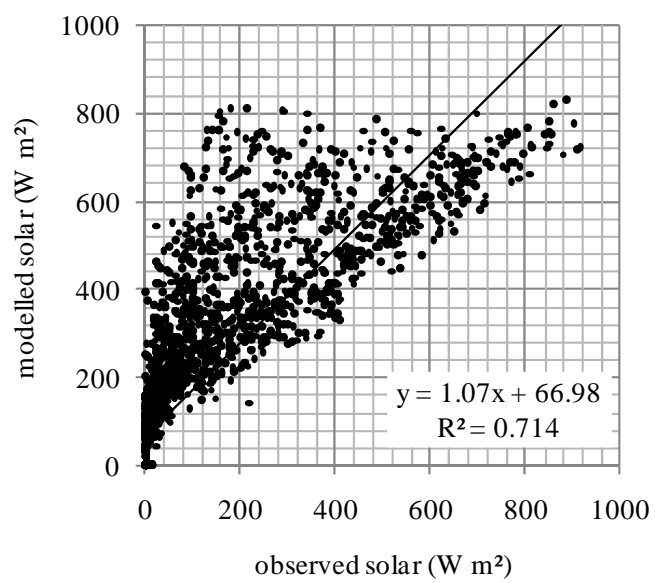

Figure 16: Incoming solar radiation data from Reiteralm 3 meteorological station. Comparison of hourly modelled and observed data for the winter season 2003/2004.

The interpolated humidity values show a strong correlation $\left(\mathrm{R}^{2}=0.97\right)$ between the modelled and measured values (fig. 17).

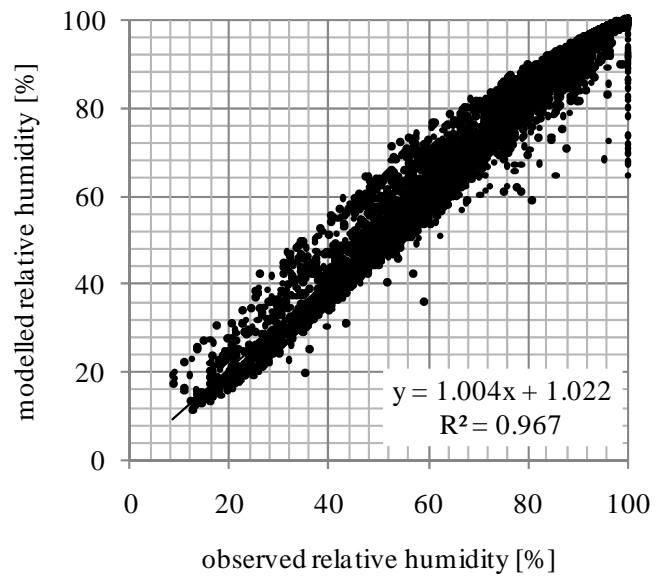

Figure 17: Relative humidity from Reiteralm 3 meteorological station. Comparison of hourly modeled and observed data for the winter season 2003/2004.

Other meteorological parameters like precipitation rates and phase as well as wind fields are more problematic to predict. This is due to the fact that these fields are not continuous in reality and that the local characteristics of these fields are caused by mechanisms which are not dependant on the location of their appearance.

The error of precipitation measurements can reach up to $100 \%$ if the precipitation gauge is snowed in or during high wind speeds which are affecting the catch of the gauges. 
Furthermore, the correct distinction between snow and rain is difficult because the phase of the precipitation is commonly not recorded and the air temperature as well as the wet bulb temperature can only be an indicator for the phase of the precipitation. Nevertheless, a comparison of modelled with measured snow depths at the meteorological stations indicates that these errors are small for the observed period. Figures 18 a) and b) show that the calculation of the precipitation rates works well if precipitation occurs at station Reiteralm and at the stations used for the interpolation (fig. 18b)). The precipitation calculation, however, is much less accurate if that is not the case (fig. 18a)) which causes a decrease in the overall correlation between station measurement and interpolation results (fig. $18 \mathrm{a}$ ) and b)).

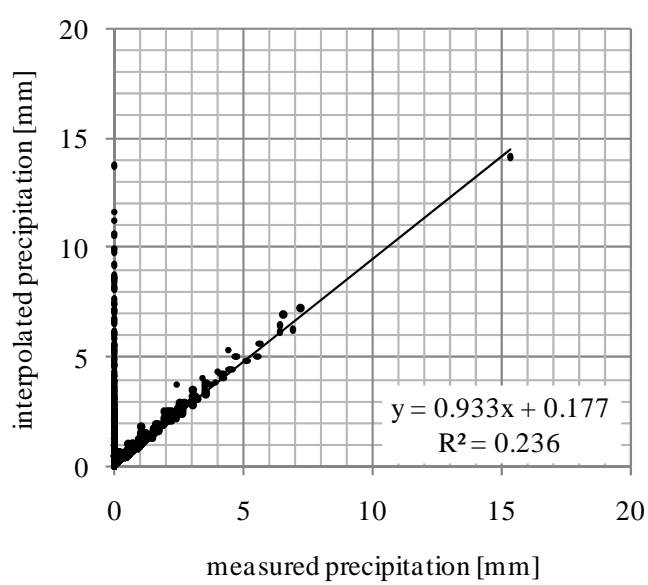

a)

Figure 18: Correlation between measured and calculated precipitation rates (winter season 2003/2004) (mm). a) Including hours with precipitation at other stations but no precipitation at the validation station (Reiteralm 1) and b) precipitation at all stations, including Reiteralm 1 .

The interpolation results of wind speed and direction are less substantive. It can be seen that the wind directions at Reiteralm 1 cannot be reproduced by the interpolation scheme (eq. 1321). The probability to compute a correct wind direction is approximately equal to the probability to predict any other wind direction (fig. 19). 


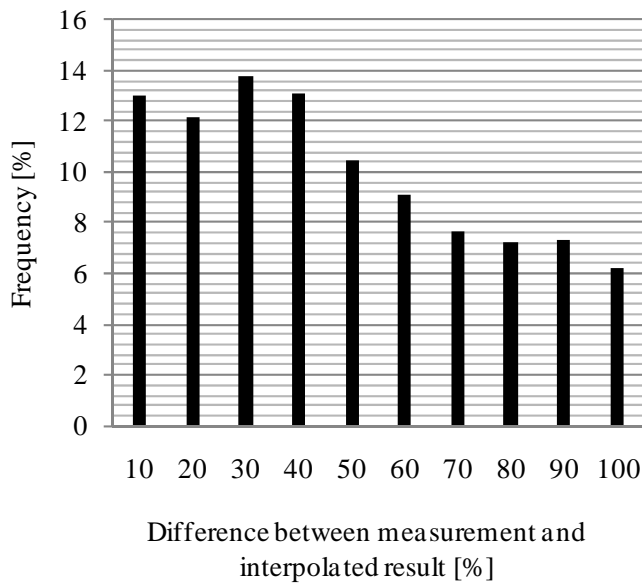

Figure 19: Accuracy of interpolated wind directions in comparison to measurements at Reiteralm I (winter season 2003/2004).

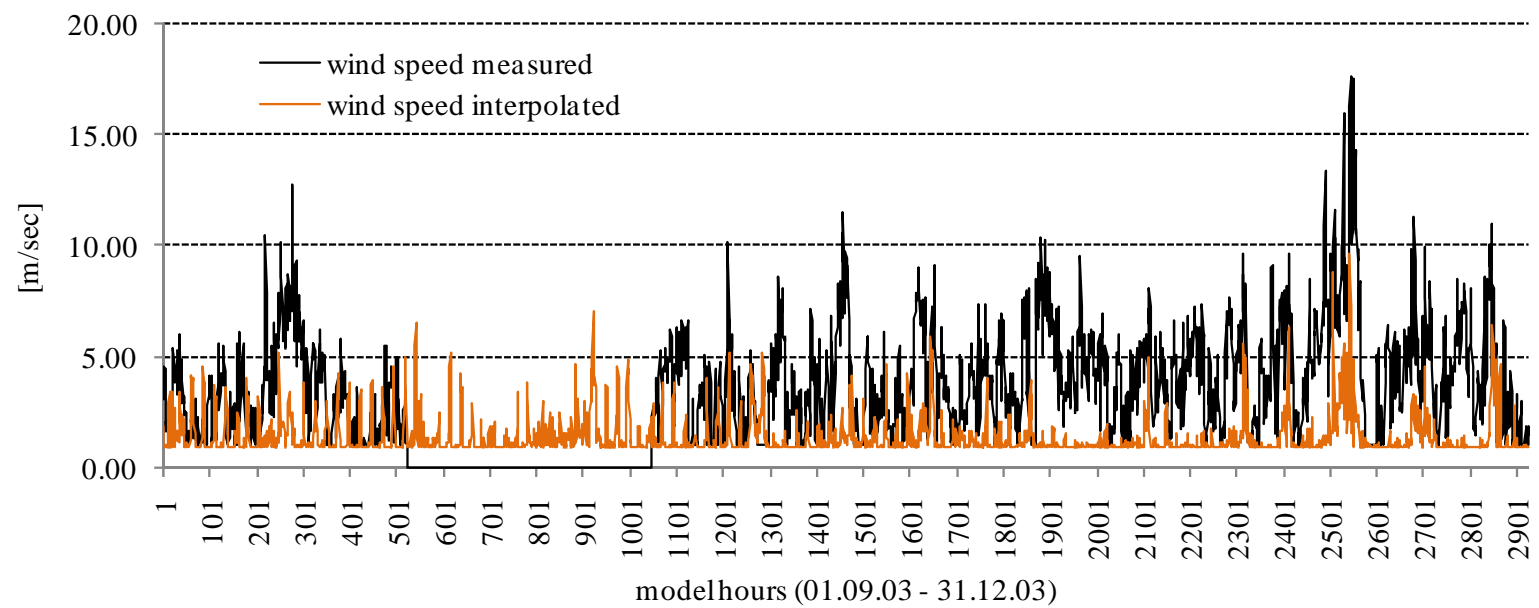

Figure 20: Comparison of measured and interpolated wind speeds at Reiteralm 1 (winter season 2003/2004).

The interpolated wind speeds (fig. 20) are commonly to low in comparison to the wind speeds measured at Reiteralm 1. Most of the situations with high wind speeds were not reproduced by the interpolation routine (fig. 20). This is because beside of the Reiteralm 1 station, there is no other meteorological station at a higher elevation which results in an even elevation wind speed gradient.

To recapitulate the former section, most of the needed meteorological input parameters can be computed with the help of the interpolation routines presented in Chapter 2 as most of these routines deliver results which are representative for the excluded station. Wind speed and direction have to be seen as an exception. The results does not show any connection to the test 
station in the case of wind direction and can only reflect the trend but not the level of the wind speed measurements. As the spatial characteristics of the used wind fields are from special importance for this work, possible reasons for the improvable results shown in figures 19 and 20 and general difficulties which can accrue when measuring and interpolating wind speed and direction are discussed in more detail in the next section.

\subsection{Calculation of wind fields in mountainous terrain}

The calculation of appropriate wind fields is a prerequisite for a more in-depth understanding of the patterns of erosion and accumulation areas in Alpine regions. This is due to the fact that any snow transport model directly "reacts" to the amount of energy supplied by the current wind field. The available energy determines if snow transport conditions exist or not. Furthermore, the wind direction given by the wind field is essential for the location of the modelled accumulation and erosion zones. In general, it could be stated that the difficulty of wind measurements and wind field calculations rise with the complexity of the terrain. The variables influencing the quality of the resulting wind fields are dependent on the method used:

I) Influencing variables (When using interpolation scheme):

a. The quality of wind speed and direction measurements.

b. The ability of the interpolation scheme to factor in the underlying topography.

II) Influencing variables (When using an atmospheric model):

a. A sufficient spatial resolution to adequately capture the local wind situations.

b. A numerical complexity which corresponds to the complexity of the terrain.

\subsubsection{Theoretical background}

Starting with I) a). With respect to the measurements it has to be considered that the local wind field is affected by the anemometer and the complete meteorological station itself as well as by barriers in the environment (e.g. Wieser et al. 2001). These local modifications of the wind field have a direct influence on the measurements and limiting their representativeness for the surrounding. This can be one reason for the limited accuracy of the 
results shown in fig. 19 and 20. Furthermore, anemometers are vulnerable to freezing (fig. 21; tab. 3 model hours 500-1000) since they consist of many mobile parts. Table 3 compares the operational hours of the wind sensor with hours without measurements at the meteorological station Reiteralm. A comparison to other measured values shows that the anemometer has much more missing data than the other sensors which can make a modelling of snow transport processes completely impossible.

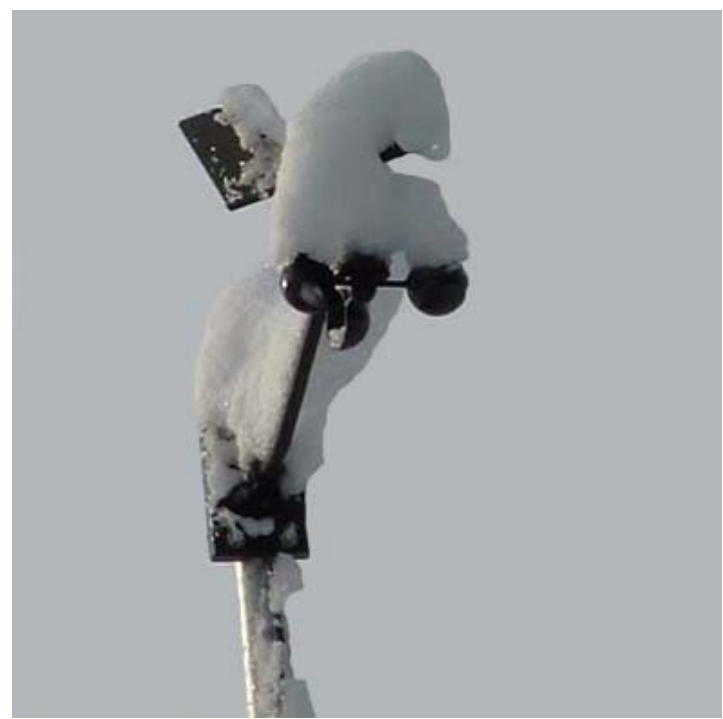

Figure 21: Frozen anemometer. This picture shows a very common situation in Alpine regions. The sensor becomes snow covered and becomes therefore unusable.

Table 3: Hours showing wind speed and direction recordings vs. hours with data lacks compared to recordings of other sensors.

\begin{tabular}{l|l|l|l|l}
\hline \hline Season & $\begin{array}{l}\text { Operating } \\
\text { hours }\end{array}$ & $\begin{array}{l}\text { Hours without } \\
\text { measurement } \\
\text { (anemometer) }\end{array}$ & $\begin{array}{l}\text { Hours without measurement } \\
\text { (temperature) }\end{array}$ & $\begin{array}{l}\text { Hours without measurement } \\
\text { (humidity) }\end{array}$ \\
\hline $01 / 02$ & 8760 & 1775 & 0 & 0 \\
$02 / 03$ & 8760 & 38 & 66 & 40 \\
$03 / 04$ & 7880 & 2920 & 0 & 0 \\
\hline \hline
\end{tabular}

The argument mentioned under I) b) belongs to the ability of the interpolation routine to factor in the underlying topography. Literature analyses has shown that the interpolation routine used by Liston and Sturm (1998) (eq. 14 to 21) works well for gently rolling terrain (Liston and Elder, 2006). The results presented in 3.1 on the other hand indicating that the scheme is unable to reproduce the wind conditions for a meteorological station located within an Alpine environment (fig. 19 and 20). This can be declared by some theoretical 
considerations. For the interpolation of the wind field measurements it is important to know that wind speed and direction are not directly correlated to a single topographic feature. If this were the case a few measurements would be enough to predict a wind speed/direction field. But, according to Barry (1992) wind speed is more closely coupled to the topography of a mountainous region than to their altitude. That means that all topographic parameters (aspect, slope, elevation) influence the wind field depending on the synoptic inflow. The assumption that wind speed increases with altitude might be correct if one is considering long term averages but not for a single event. Figure 22 shows a profile through a MM5 simulated wind field which displays the facts mentioned before. The upwind velocity is pretty much the same (approx. $4 \mathrm{~m} / \mathrm{s}$ ) over the whole south face of Watzmann (transect I), with only a small peak that can be observed at the crest. The situation changes at the north face were lower velocities (approx. $2 \mathrm{~m} / \mathrm{s}$ ) and a change from downwind (transect II) to upwind (transect III) conditions can be observed. This small example gives an idea about the complexity of air flows at one mountain and for one specific situation.

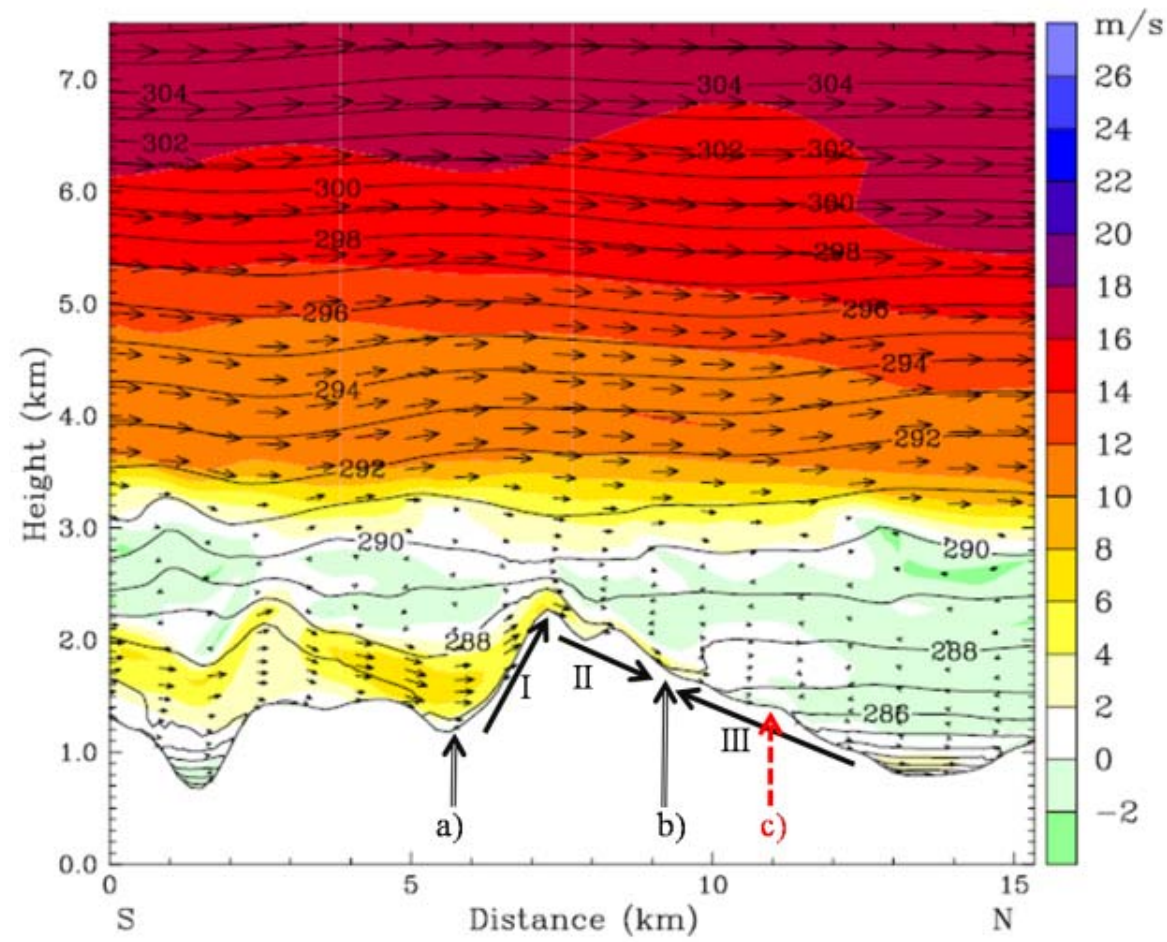

Figure 22: Vertical profile through a MM5 wind field. a, b and c are fictive meteorological stations. The transects I, II, III are used for declare the wind conditions at the faces of Watzmann mountain. The wind speed is slightly enhanced at the windward site (transect I) as the wind direction is constant to North. Transect II and II showing the complex wind conditions at the leeside. The wind speeds are about $6[\mathrm{~m} / \mathrm{sec}]$ at transect II, the wind direction is to north. The situation changes at transect III were the wind speed is between 0 and 2 [m/sec] and the wind direction is to south. 
Furthermore, if one would assume that two meteorological stations would be available at this mountain (fig. 22) point a) and b)), which is commonly not the case; one can imagine that it would be impossible to predict the wind speed and direction on point c) with the data from these two stations. This is because the wind speed and direction measured by these stations cannot include any information about a change from downwind to upwind conditions at the lower depths. A statistical inclusion of topographic parameters into any interpolation routine would not solve the problem because the phenomenon can be due to flow separation or a rotor (fig. 23 a) and b)) and would be caused by a large scale interaction of topography and airflow in this case. Such phenomena have nothing to do with the local topography and can be therefore not displayed with a 2D interpolation scheme which bases on point measurements at the $10 \mathrm{~m}$ level and which only figures in the local topography wind speed/direction interactions.

a)

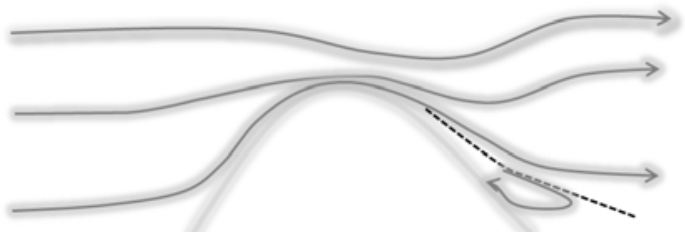

b)

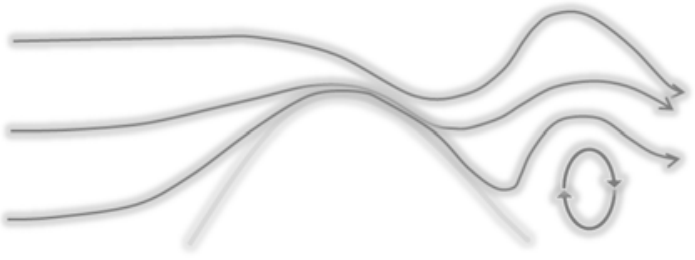

Figure 23: Generalized flow behaviour over a hill: a) flow separation and b) a rotor (Barry 1992, modified).

Another problem which complicates the interpolation of wind direction measurements can also be explained on the basis of Figure 22. If one would shift meteorological station b) to point c), the wind direction would be the exact opposite of station a). The interpolation of these values would lead to questionable results because the average between e.g. $180^{\circ}$ and $360^{\circ}$ is not defined. Although, the described situation would never occur in flat or slightly undulated terrain, it is common in mountainous terrain.

The next questions formulated at the begin of this section were if MM5 has a sufficient resolution for describing the prevailing wind systems in the test region and if the numerical complexity of MM5 is adequate with respect to the topography of the test site. These answers can be answered shortly. MM5 has a target resolution of $200 \mathrm{~m}$ in the current setup. This resolution is the absolute maximum with respect to the model formulations of MM5 in combination with the very rough topography of the test-site. The ability of MM5 to deliver 
acceptable results for a site like the National Park and the explanation that the model formulations of MM5 are sufficient for areas with steep topography is widely described in Zängl (2002) and (2003), as well as in Bernhardt et al. (2008a).

\subsubsection{Comparison of interpolated and modelled wind fields}

The MM5 wind fields shown in figures 24 a) and b) were produced using input wind directions of 140 and 270 degrees respectively (cp. fig. 13). The used input wind speed corresponds to the average in the test region (Bernhardt et al. 2008a) and was set to 10 [m/sec] at the lowest model level $(10 \mathrm{~m})$ and to $25[\mathrm{~m} / \mathrm{sec}]$ at the uppermost model level (100hpa) (cp. fig. 13). An analysis of the resulting fields reveals that the two situations have significantly different spatial characteristics. Most of the differences can be traced back to windward and leeward effects, which are particularly evident at the massifs of Watzmann and Hochkalter as well as at the Reiteralm plateau (fig. 24 a) and b), cp. fig. 5). In the case of an overflow of air masses over the crests, the relief-induced convergence of the air stream leads to a local increase in wind speed at the windward side (Barry, 1992) (fig. 24b). The interpolation routine by Liston and Sturm (1998) is not able to reproduce this effect because of the implemented linear increase of wind speed with height (fig. 25 a) and b)). Furthermore, the local variations in wind speed are much more distinctive in the MM5 field which makes it possible to easily identify of crest regions, windward and leeward sides and troughs at the north-western parts of the massifs. The interpolation routine, in contrast, produces a more homogenous field which is mainly dependent on the vegetation pattern (fig. $25 \mathrm{a}$ ) and b)). The interpolation routine generates a slight increase of wind speed with height which does not reflect the conditions observed in reality (Reiter, 1962; Barry, 1992). This is due to two factors: First, a lack of meteorological observations at higher elevations which would be necessary to generate a steeper wind speed gradient and secondly, the interpolation scheme is based on a Gaussian function (Barnes, 1964) and, therefore, predicts a continuous wind field which does not allow for an abrupt change of the magnitude of an parameter (eq. 17). With the help of the weight factor (eq. 17), wind speeds can be modified between 0.5 to 1.5 times the original value, which is by far not enough to reproduce the MM5 results. 


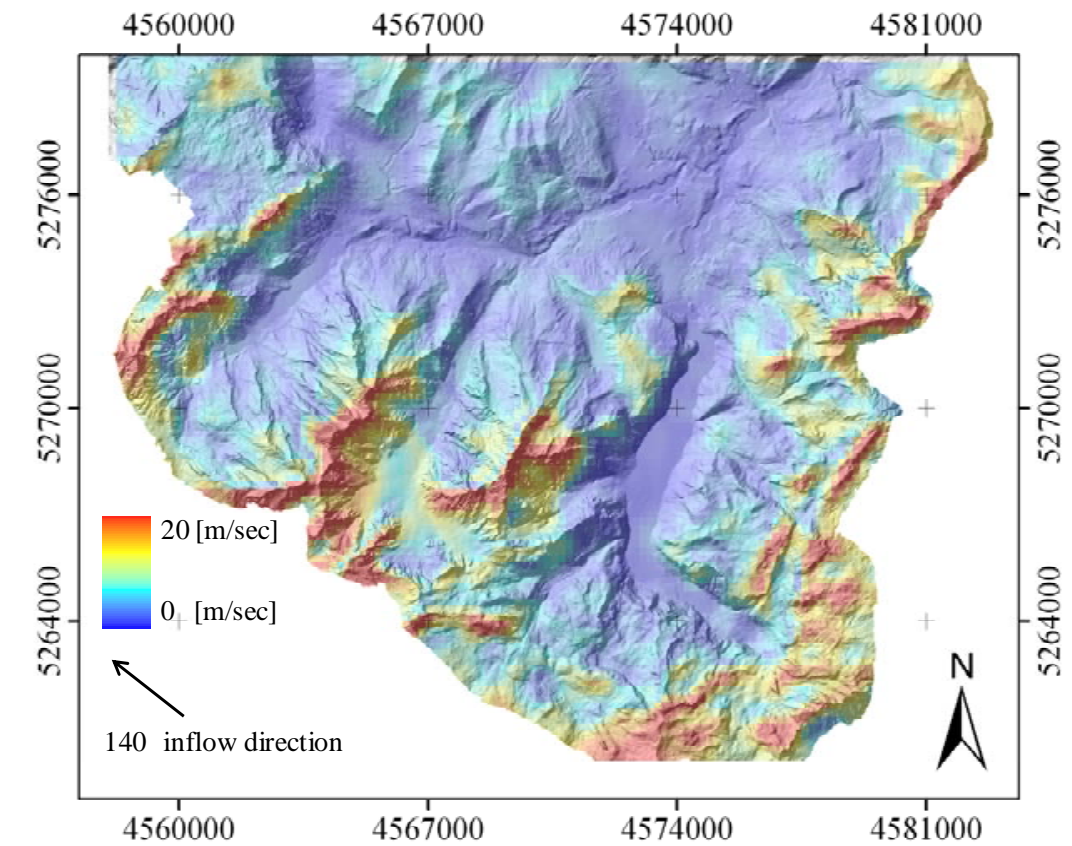

a)

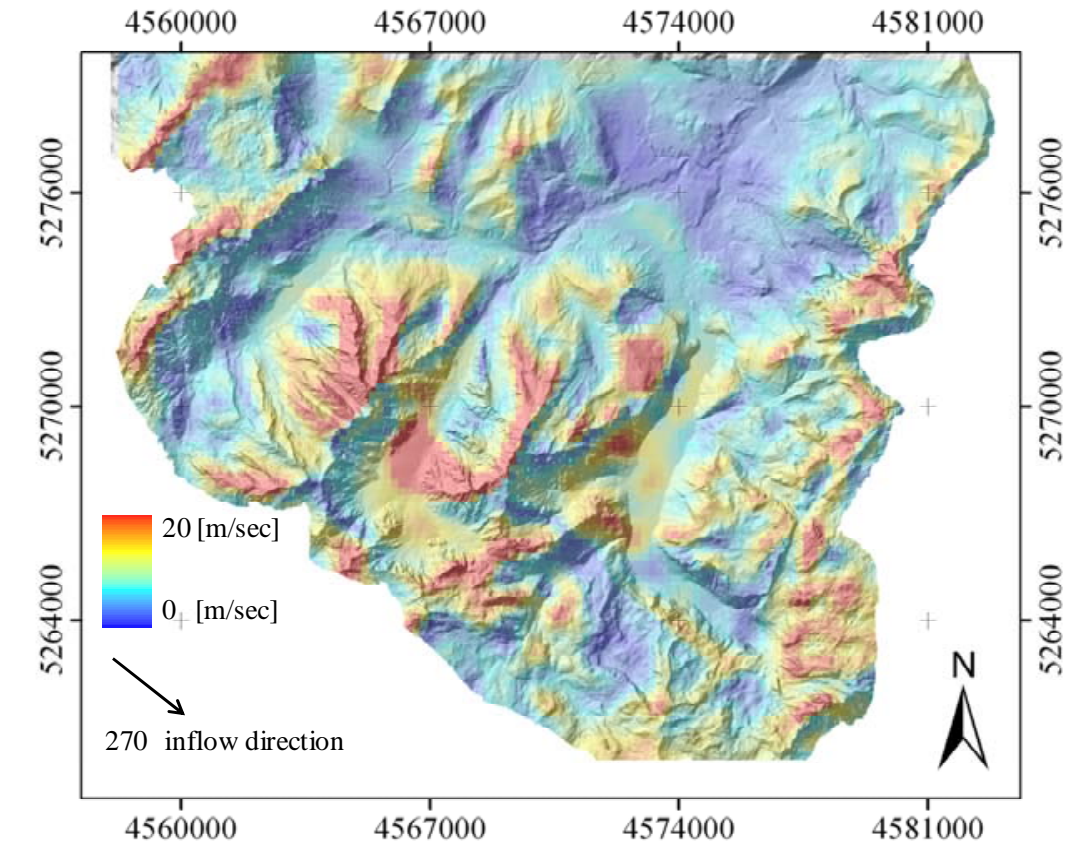

b)

Figure 24: a) $M M 5$ wind field (input parameters: wind direction $=140^{\circ}$ and $10[\mathrm{~m} / \mathrm{sec}]$ at $10 \mathrm{~m}$ and $25[\mathrm{~m} / \mathrm{sec}]$ at 100hpa) b) MM5 wind field calculated with the same input wind speeds but an input wind direction of $270^{\circ}$. 

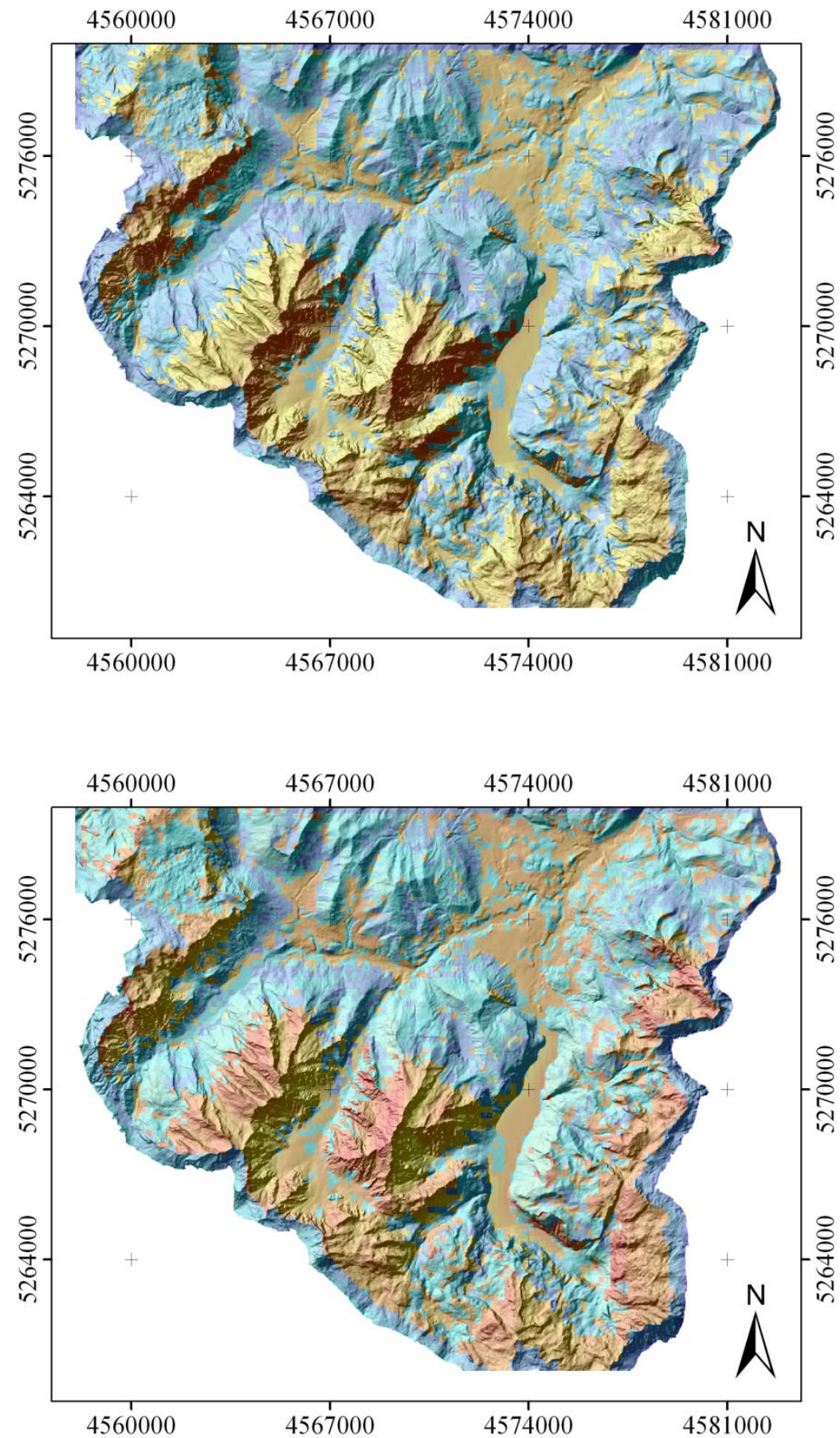

Figure 25: Interpolated wind fields. a) The average wind directions at the meteorological stations are $140^{\circ}$ and b) $270^{\circ}$.

An analysis of MM5 and interpolated wind direction fields reveals similar findings. Bendix (2004) stated, that wind direction is a highly variable factor in space and heavily dependent on the surrounding topography which modifies the synoptic flow direction. Based on this 
assumption the MM5 input wind direction was changed to analyze the effects on the local wind direction field. Subsequently, the wind directions predicted by MM5 for the meteorological stations Schönau, Jenner, and Kühroint were interpolated via Micromet and compared to the MM5 results.

Figure 26 shows MM5 wind direction fields, representative for input wind directions of $265^{\circ}$ and $270^{\circ}$ (the input wind speed was $10[\mathrm{~m} / \mathrm{sec}]$ (at $10 \mathrm{~m}$ ) and $25[\mathrm{~m} / \mathrm{sec}]$ at the uppermost model level (100hpa) for both model runs). Notwithstanding that the input wind direction differs by only 5 degrees, the resulting per pixel difference can reach up to $180^{\circ}$ (fig. 26). It is obvious that both MM5 wind direction fields show approximately the same value for pixels which are representative for a meteorological station (marked as coloured dots in figures 26 and 27) but the wind direction characteristics between the stations differ significantly (fig. 26). The range of occurring wind directions lies between 1 and 360 degrees which is not the case when using the interpolation scheme (286 to 317 degrees) (eq. 14-21; fig. 27). An interpolation of the MM5 predicted wind directions for the positions of Schönau, Jenner and Kühroint (results displayed in fig. 26) delivers uniform results (fig. 27), which are somewhere between the three MM5 calculated station values. Furthermore, the field does not show a noticeable sensibility to the underlying topography. The uniformity of the interpolation results can again be attributed to the applied Barnes scheme (Barnes, 1964) and the underlying Gaussian function which forbids abrupt changes within the calculated wind direction field. 


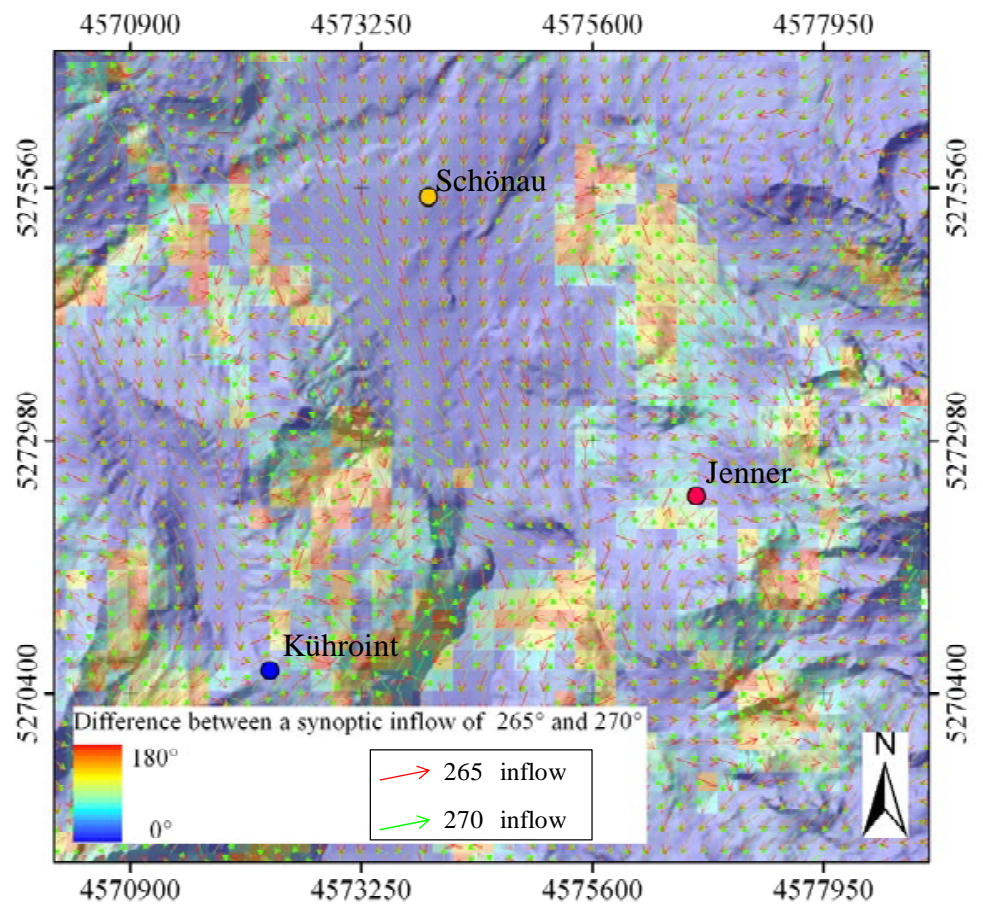

Figure 26: Spatial characteristics of MM5 wind direction fields in dependency of the synoptic inflow. The inflow direction is 265 degrees and 270 degrees respectively.

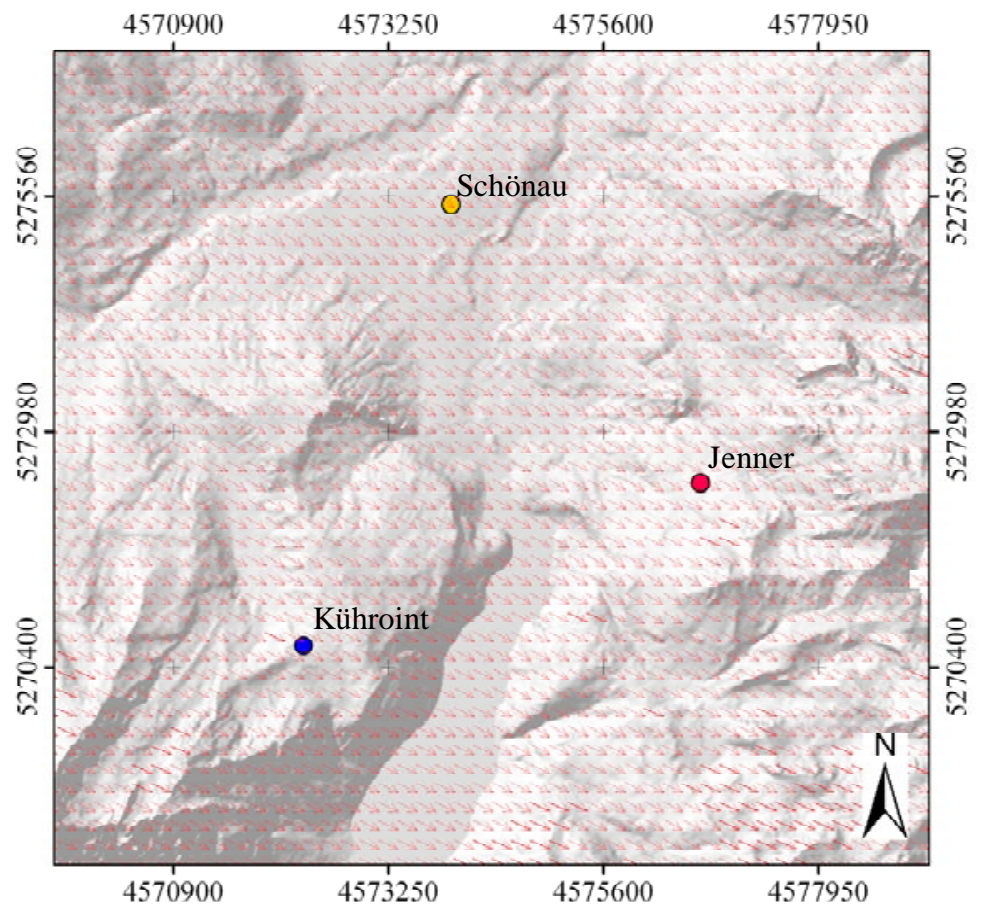

Figure 27: Spatial characteristics of an interpolated wind direction field. The wind directions used for the interpolation corresponding to the wind directions produced by MM5 (fig 26) for the three indicated meteorological stations. 
A similar finding can be made when analysing the change in local wind directions dependent on MM5 input wind speeds (fig. 28). The input wind speeds were changed from very moderate wind conditions $(5[\mathrm{~m} / \mathrm{sec}]$ at $10 \mathrm{~m}$ to $13[\mathrm{~m} / \mathrm{sec}]$ at $100 \mathrm{hpa})$ to high wind conditions (20 [m/sec] at $10 \mathrm{~m}$ a.s.l to $50[\mathrm{~m} / \mathrm{sec}]$ at $100 \mathrm{hpa})$, while keeping the input wind direction constant $\left(180^{\circ}\right)$. The effect is a per pixel change in wind direction reaching up to 180 degrees mainly caused by a shift of local eddies. The presented interpolation routine would not reflect changes of wind speed in the wind direction results because both parameters are treated separately. This seems to be inadequate when respecting the MM5 results.

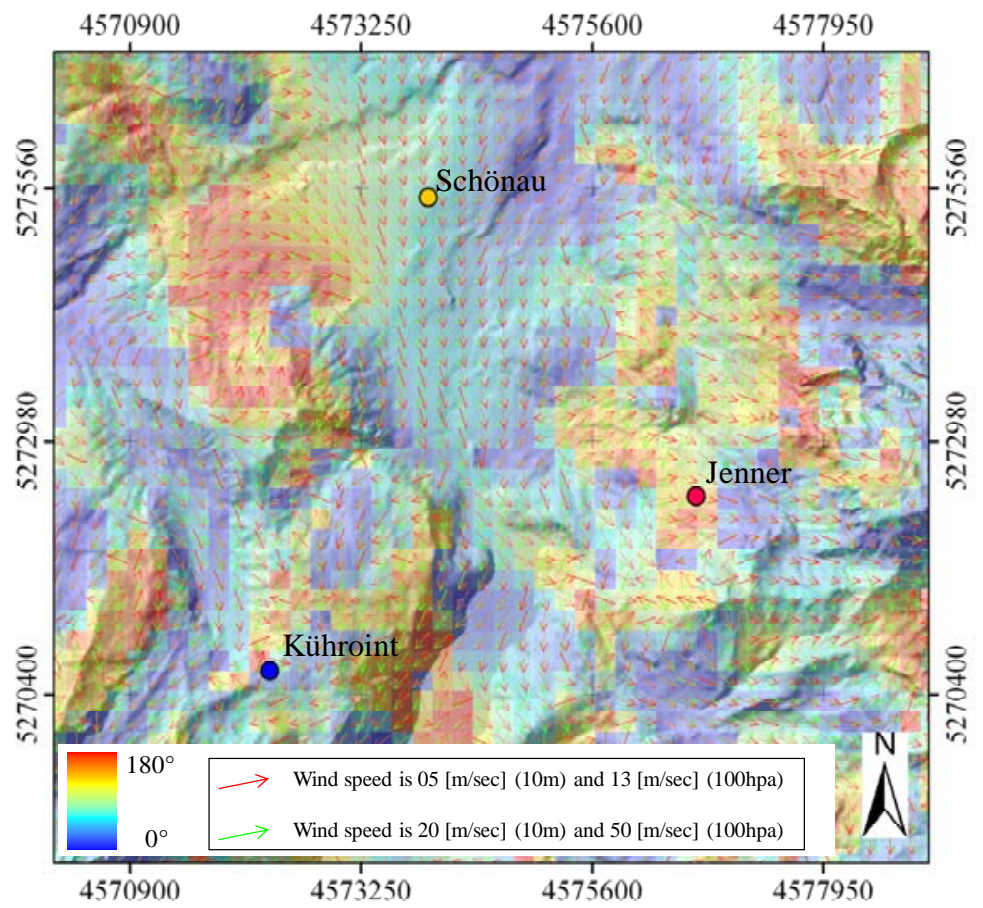

Figure 28: Dependency of the calculated MM5 wind direction field on the input wind speed. The wind speeds used for the model setup were $05[\mathrm{~m} / \mathrm{sec}]$ for the $10 \mathrm{~m}$ model level and $20[\mathrm{~m} / \mathrm{sec}]$ for the uppermost model level (cp. fig. 13)

The examples show that the interpolation routine delivers almost uniform and therefore questionable results in Alpine terrain. It has to be assumed that the estimation of a detailed and meaningful wind field is only possible if wind speed and wind direction are treated in combination for the simulation of distributed wind fields. This is done within MM5 where the complete aerodynamic flow around mountain massifs is calculated and wind speed as well as wind directions are results of the local flow conditions. The analysis shows that MM5 delivers 
highly variable and plausible wind fields, which, however, are useless if they are not taken within a temporal context. The next section will show how the MM5 library was compiled, synchronized with SnowModel, and how the MM5 wind fields performed compare to the measurements at the meteorological station Reiteralm.

\subsection{Creation and synchronisation of a MM5 predicted wind field library}

The concept of a pre-produced wind field library instead of conducting operational MM5 simulations at every model time step, allows the combination of a snow model with an atmospheric model at a high level of computational performance. The data used and the corresponding scales can be seen in fig. 29. The wind field library is based on two assumptions: First, a specific wind field is considered representative for a defined synoptic situation, and second, all situations leading to significant snow transport can be described by a finite set of wind fields. The creation of the library comprises two steps: 1) the modelling of the wind fields itself, and 2) the provision of an access key which defines the most appropriate MM5 wind field of domain_5 (fig. 13 and fig. 29) for the current SnowModel time step. For the creation of the wind field library and the access key two of five MM5 nesting domains were used (domains_3 and _5 in fig. 13). These domains are mutually dependent and give information about meteorological parameters at different scales and pressure levels. While domain_5 provides the high resolution wind fields, domain_3 can be used to provide the link to the $L M$ analysis data (fig. 13 and fig. 29). 


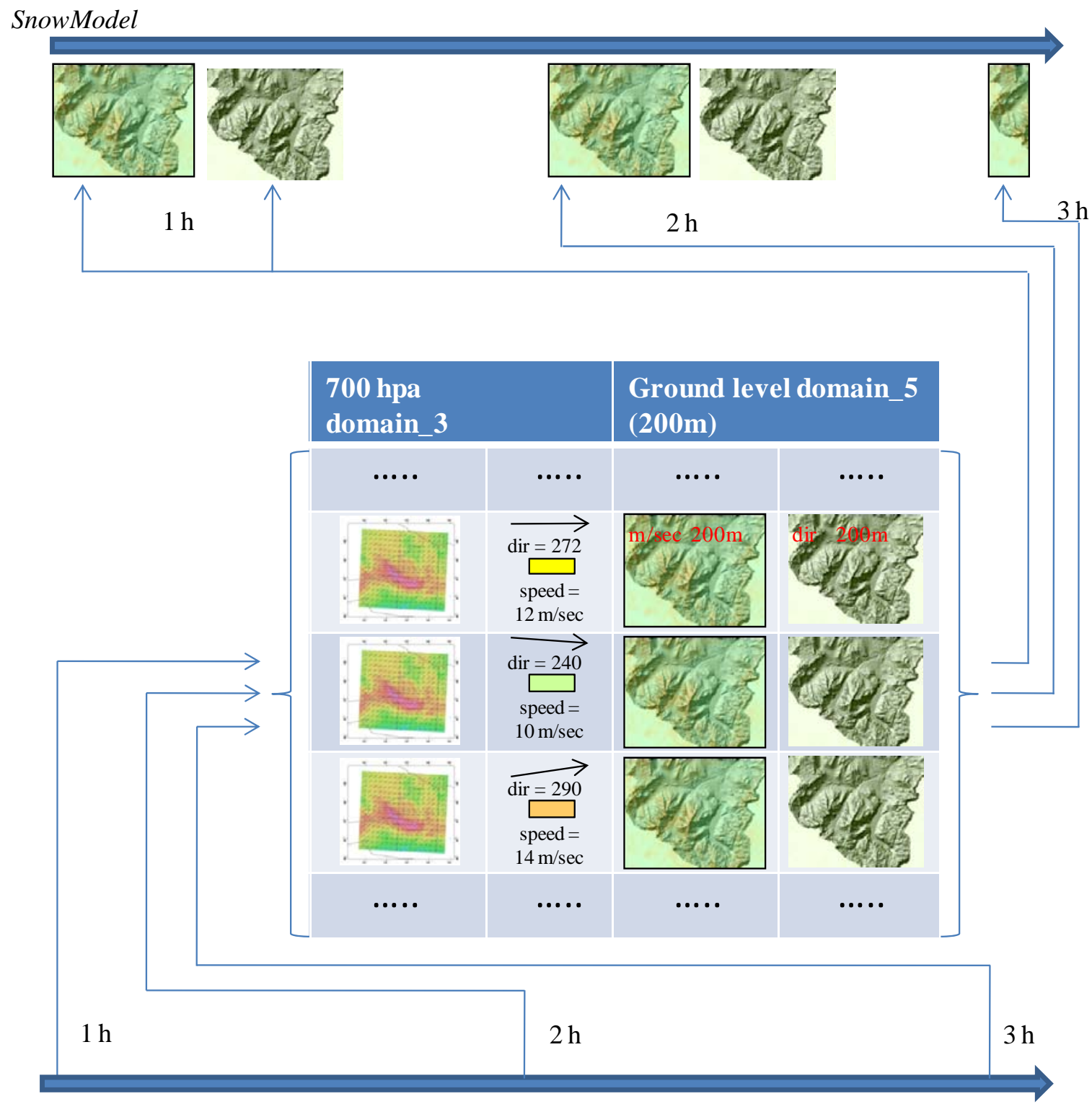

LM 700hpa hourly data (same scale as MM5 domain 3 results)
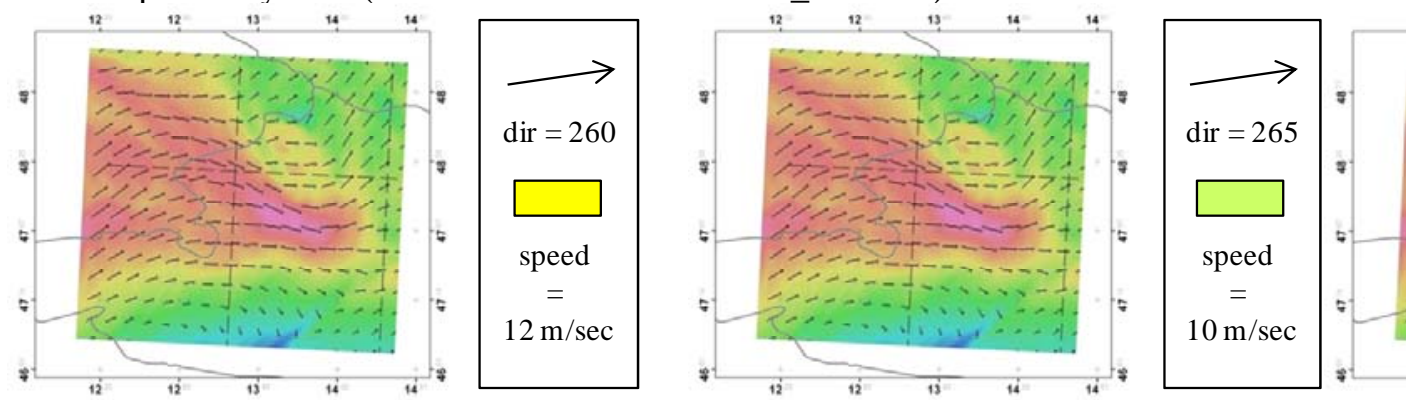

Figure 29: Schematic illustration of the synchronization of MM5 wind field library and SnowModel via hourly DWD Lokalmodell information. 
To determine the set of MM5 wind fields needed to cover the climatologically range of the test region; achieved DWD analysis data for the time period of 1991 to 2001 for an area approximately equivalent to MM5 nesting domain_3 were used (fig. 3 and fig. 30). However, an iterative approach with respect to the settings of the MM5 boundary conditions was needed because the resulting domain_3 fields had an average wind vector that differs from the largescale boundary conditions set for domain_1. This means that the input wind speed and direction used for the set up is not identical to the average domain_3 vector. The difference between setup and domain_3 values is due to the nonlinear interaction of the atmospheric flow with the Alpine massif. Hence, a first series of wind fields (from 0 to 360 degrees, with a step width of five degrees) was modelled under the assumption of a constant wind speed at the model boundary $(10 \mathrm{~m} / \mathrm{s}$ at sea level and $25 \mathrm{~m} / \mathrm{s}$ at tropopause level). Based on the deviations of the averaged domain three vectors from the set up values, it becomes obvious how the boundary conditions have to be modified in order to get the required domain_3 results. As the computation of one wind field needs about three days on a high performance computer the absolute number of fields had to be limited. It was determined that an adequate coverage of the total DWD data could be achieved with 220 computed wind fields.

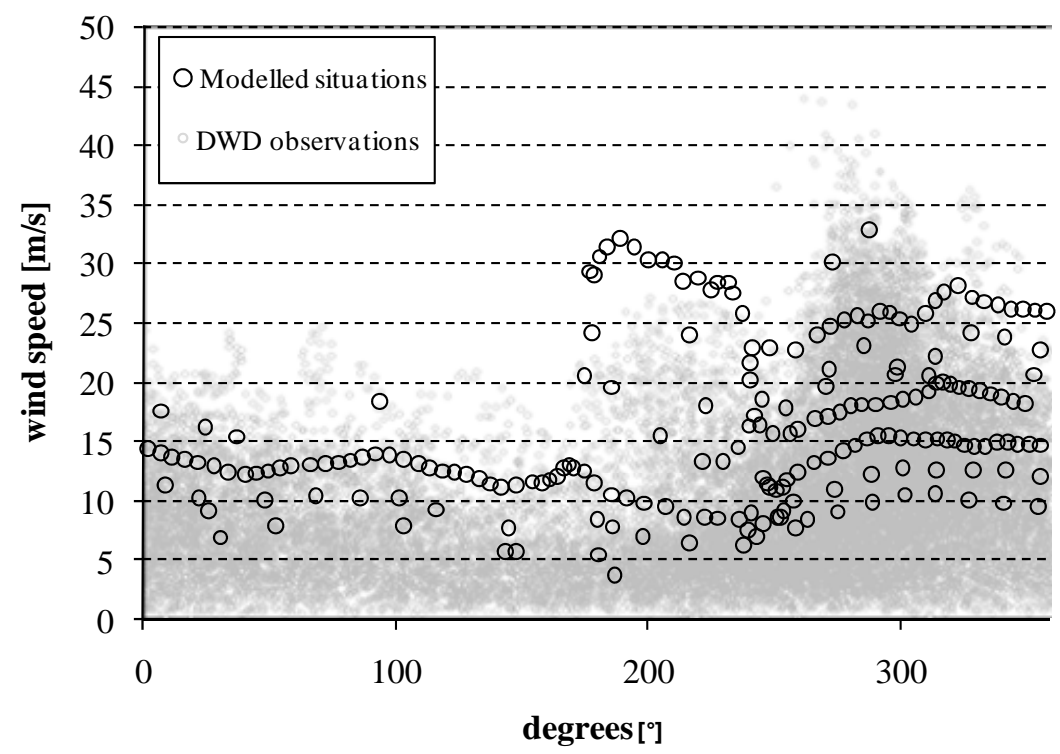

Figure 30: DWD historical data for the $700 \mathrm{hPa}$ level (gray dots) vs. averaged MM5 domain_3 vectors (black dots). The DWD observations were used for defining the initialisation wind speeds and directions needed for the MM5 runs (cp. fig. 13). 
It has to be taken into account that due to friction the shown 700hpa wind speeds are significantly smaller at the earth surface. Since snow transport events which are of relevance only starts when the surface wind speed exceeds a threshold value of about 3-5m/s (Barry 1992; Liston and Sturm, 1998), wind conditions below of 3 [m/sec] were disregarded. Consequently, there was only few wind fields modelled for situations with wind speeds less than $10[\mathrm{~m} / \mathrm{s}]$ at $700 \mathrm{hPa}$ at domain_3 (fig. 30) because they generally produce velocities less than the threshold at the surface of the National Park area (fig. 31).

a)

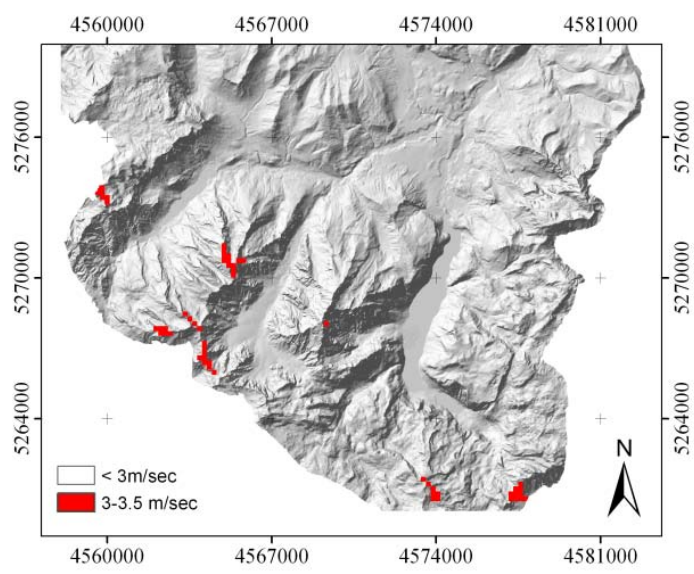

b)

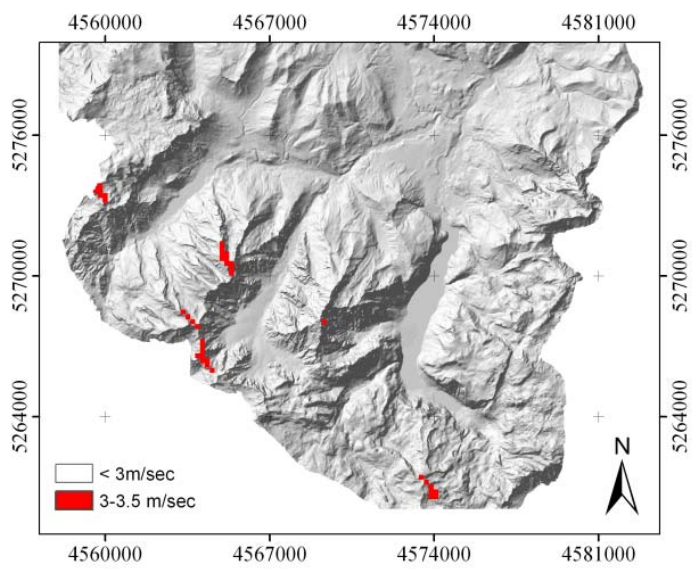

Figure 31: The red coloured areas in a) and b) stand for wind speeds $>3[\mathrm{~m} / \mathrm{sec}]$ which would be able to initialise snow transport processes. The MM5 wind fields were calculated with very moderate input wind speeds $\left(30^{\circ} /\right.$ $5[\mathrm{~m} / \mathrm{sec}]$ at $10 \mathrm{~m} ; 16[\mathrm{~m} / \mathrm{sec}]$ at $100 \mathrm{hpa}$ and $143^{\circ} / 5[\mathrm{~m} / \mathrm{sec}]$ at $10 \mathrm{~m} ; 20[\mathrm{~m} / \mathrm{sec}]$ at $\left.100 \mathrm{hpa}\right)$.

To extract the corresponding wind field from the library, $L M$ and MM5 domain_3 $700 \mathrm{hPa}$ results were used as selection criterion. The $700 \mathrm{hPa}$ level was chosen because it is the lowest standard pressure level of MM5 at which the large scale flow deflection of the Alps becomes negligible. Furthermore, $L M$ results of the 700hpa layer are easily accessible. MM5 nesting domain_3 contains 87x87 mesh points while the corresponding $L M$ dataset has 22x22 points. For each of the mesh points the two-dimensional vector $\vec{u}$ represents wind speed and direction. The average of these vectors was used as the measure for the library access key. Hence, the $L M$ results were averaged for every model hour and compared to averaged MM5 domain_3 results which were attached to the corresponding MM5 domain_5 files. This allows for an extraction of the one MM5 wind field that has the minimum difference between the averaged $L M$ vector and the attached MM5 domain_3 vector from the library (fig. 29). 


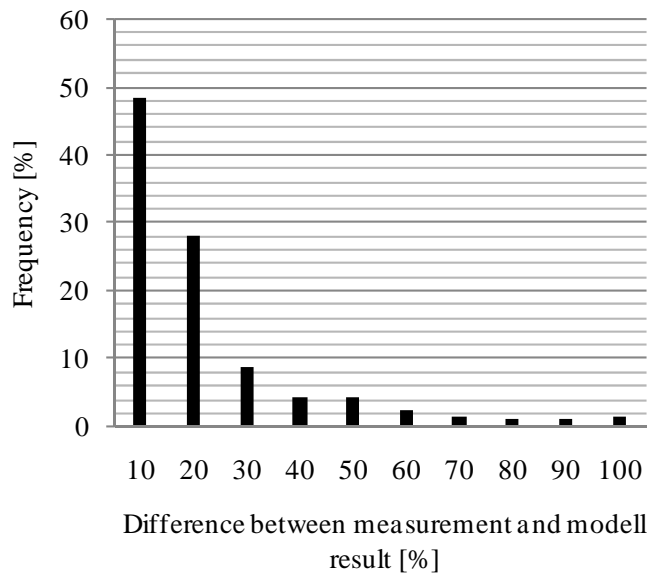

a)

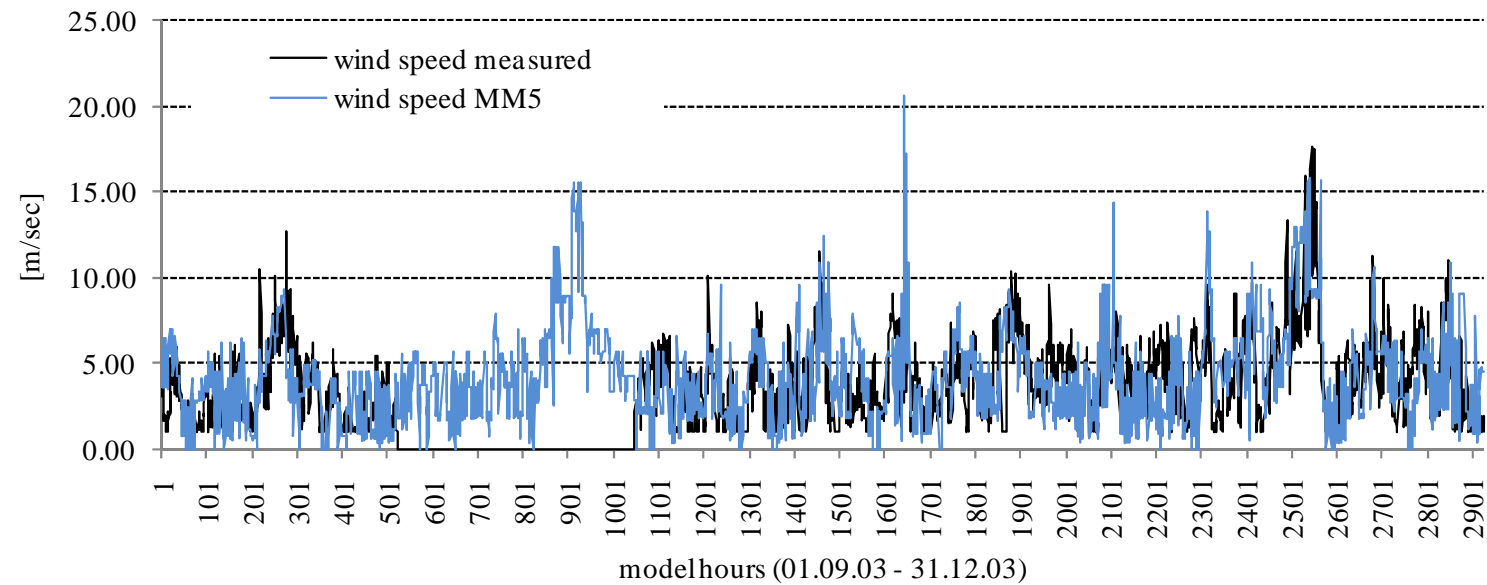

b) model hours (01.09.03 - 31.12.03)

Figure 32: Comparison of measured and MM5 wind a) direction (01.09.03-30.08.04) and b) speed (01.09.0331.12.03)at Reiteralm I. A comparrison to figures 19 a) and b) clearifies the advantages in contrast to the interpolation routine.

The upcoming results are extremely encouraging. The convergence of modelled MM5 wind direction with the measurements of Reiteralm is much better than that of the interpolation results. The accuracy of the model is within $10 \%$ in about $50 \%$ of all cases (the observed period is September 2003 to August 2004) and within 20\% in about 75\% of the cases (fig. 32a). As there was nearly no connection between interpolation results and measurements (fig.19 and 20) this has to be seen as fundamental improvement. When analysing MM5 and measured wind speed (fig. $32 \mathrm{~b}$ )) it becomes obvious that MM5 delivers reasonable results here. MM5 wind speeds are on the same level as the measurements and the course of the measurements is reproduced very well. 
a)

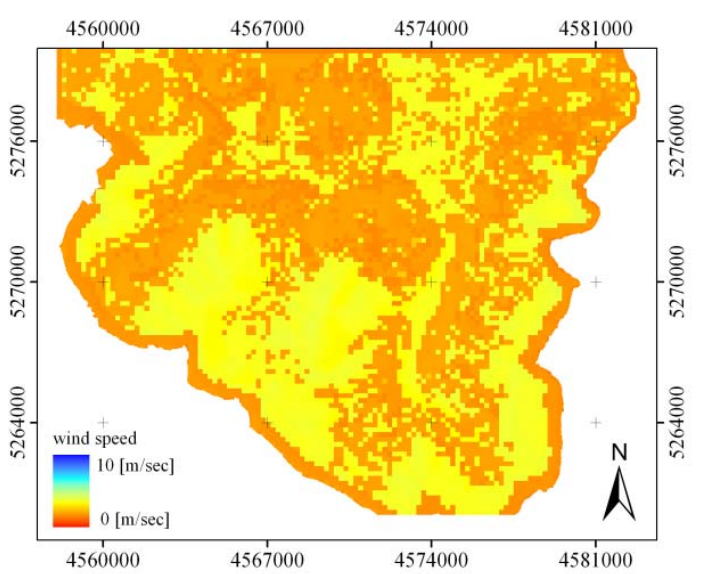

b)

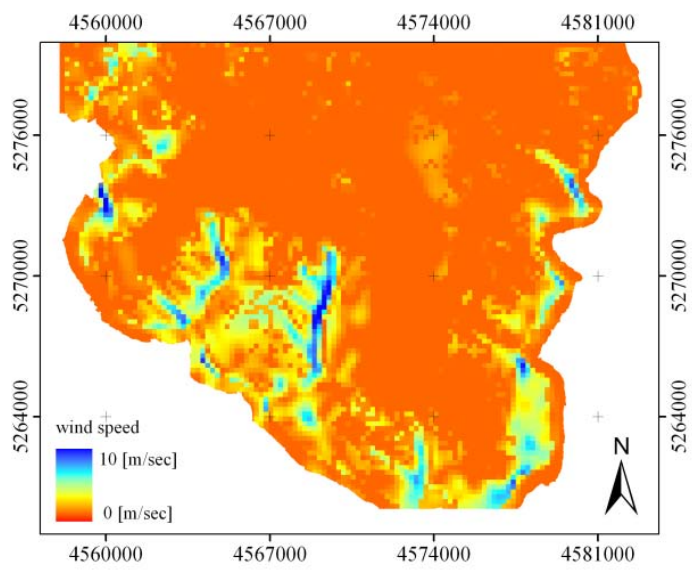

Figure 33: Wind speed provided by the interpolation procedure of Liston and Sturm (1998) (left) and MM5 (right). The images represent the situation on January 9, 2004, 7:00. Wind direction is 270 degrees.

a)

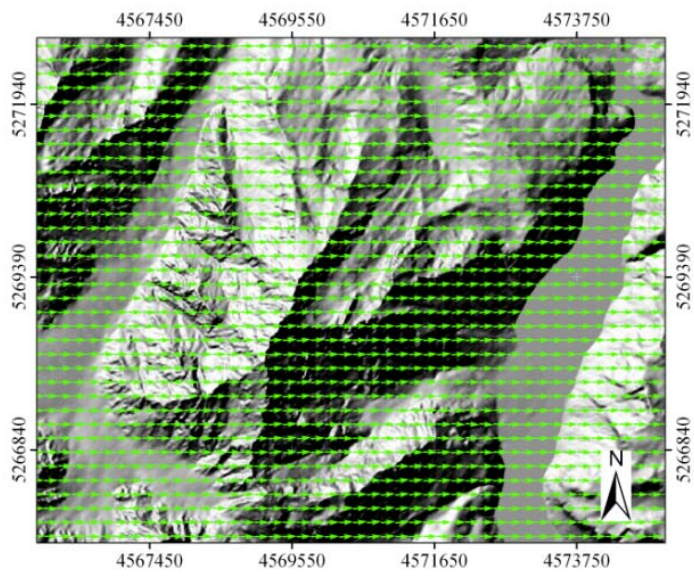

b)

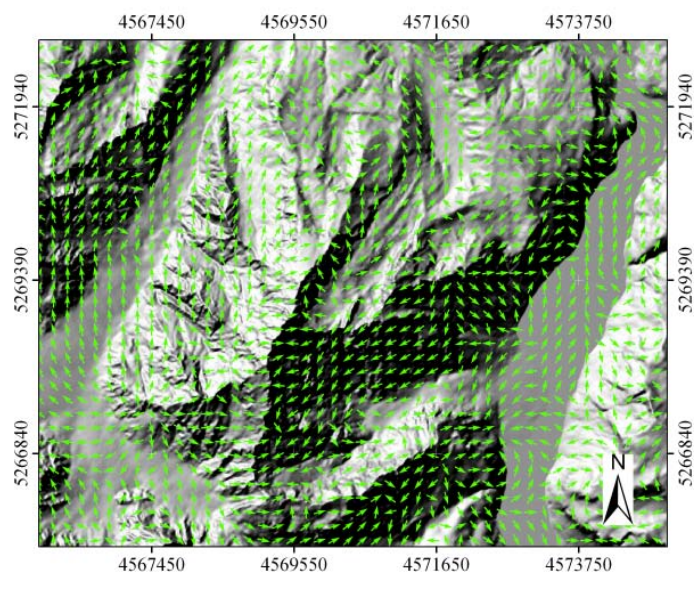

Figure 34: Wind direction (detail of the Watzmann region), derived after Ryan (1977) (left) and MM5 (right), respectively. The images represent the situation on January 9, 2004, 7:00. Wind direction is 270 degrees.

Figures 33 and 34 show a comparison between interpolated and MM5 wind fields for a specific model step (January 9, 2004, 7:00, a cut-out of the Watzmann region cp. fig. 5 is shown). The reasons for the differences of the spatial characteristics of interpolated (fig. 33a) and 34a)) and of MM5 wind fields (fig. 33b) and 34b)) was mentioned before. An additional example underlines the validity of the MM5 wind fields in Alpine terrain. During the period of Mai 1994 through December 1999 an anemometer was installed at the Watzmannhaus at 1918m a.s.l (fig. 35a the location of the anemometer is marked with an arrow). The available measurements indicate that about 600 hours per year (or 6.8\% of all hours) are showing wind speeds of more the $10[\mathrm{~m} / \mathrm{sec}]$. When analysing the MM5 data 634 hours (or $7.2 \%$ of all hours) with wind speeds of more than 10 [m/sec] were predicted for this location (fig. $35 \mathrm{a}$ )), 
whereas 0 hours with wind speeds above $10[\mathrm{~m} / \mathrm{sec}]$ could be found in the interpolated data (fig. 35 b)).

a)
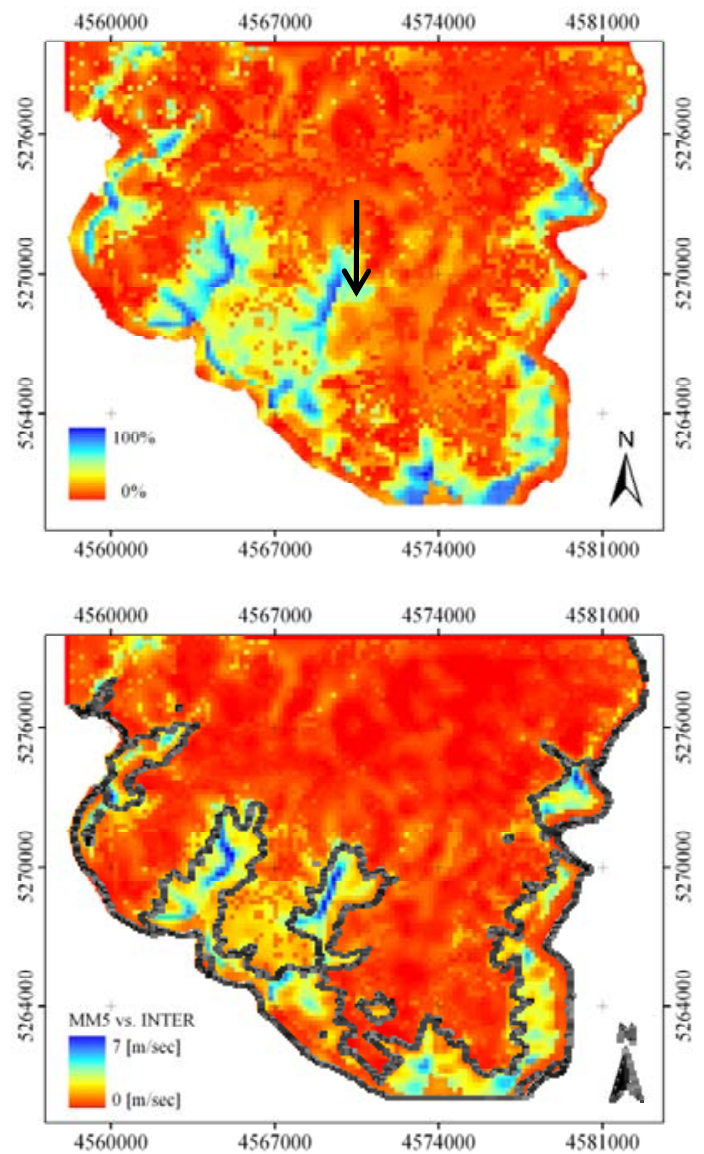

b)

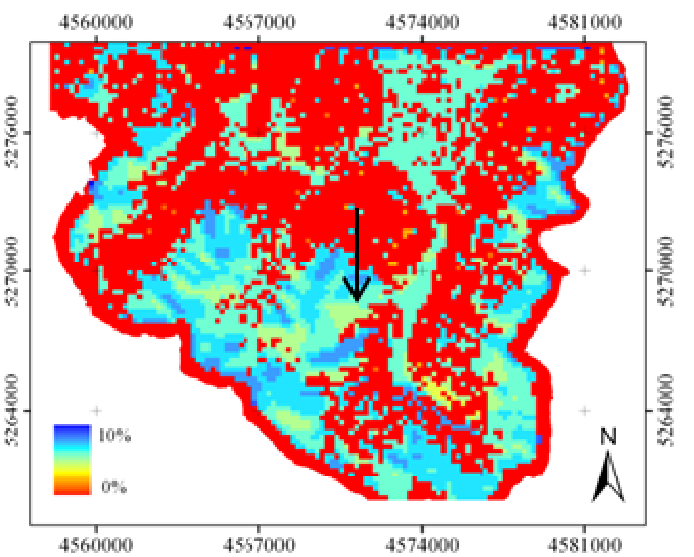

c)

Figure 35: a) Percentage of hours with wind speeds higher than 3 [m/sec] (MM5 fields). b) Percentage of hours with wind speeds higher than $3[\mathrm{~m} / \mathrm{sec}]$ (interpolated fields). Difference between the averaged interpolated and MM5 wind speed for the winter season 2003/2004 (The black line is the $1800 \mathrm{~m}$ a.s.l. contour).

Finally, it can be assumed that MM5 delivers more applicable data (fig. 32 to 35) for the test site. As the accuracy of MM5 should be almost similar for all modelled cells, figure 32 a) and b) can be seen as representative for the whole area. 


\section{Chapter 4 Snow transport modelling}

For the simulation of snow transport, accumulation, and ablation processes the SnowModel (Liston and Elder, 2006) including SnowTran-3D (Liston and Sturm, 1998) was used. SnowTran-3D as described in section 2.1 is a three dimensional, physically based model which simulates the wind forcing field (which was replaced by the MM5 simulations lateron), the wind shear stress at the surface, the transport of snow by saltation and turbulent suspension, the sublimation of saltation and suspended snow, and the accumulation and erosion of snow. Therefore, the initial entrainment and the intensity of snow transport processes are dependent on the current wind conditions and on the modelled surface conditions.

First, SnowTran-3D runs were performed using interpolated station data (of Snowmodel/Micromet), and afterwards the interpolation scheme was substituted by the application of the MM5 wind field library. This procedure was applied at the meso $(200 \mathrm{~m})$ and micro (30m) scale. The topographic information for the meso scale runs was provided by the same $D E M$ as used for the MM5 wind field generation: This implies that the smoothing of the $D E M$ which was conducted to ensure numeric stability of MM5 is also reflected in the results of the snow model. For the succeeding micro scale runs downscaled MM5 wind fields and topographic information provided by the DEM of the National park authority were used.

\subsection{Results of the meso scale model runs}

The results of the SnowModel runs were studied in three different steps. First, model grid elements which coincide with meteorological stations were analysed and the snow cover development of these grid cells was compared with the measurements. Secondly, the spatial characteristics of the modelled snow cover were analysed for SnowModel runs with (these runs will be indicated by MM5 from now on) and without the MM5 wind field library (these runs will be indicated by INTER from now on) and thirdly the results were compared with remotely sensed data. 


\subsubsection{Model results at the point scale}

For checking the general model performance, modelled snow depth results were compared with ultrasonic snow depth measurements from meteorological stations Reiteralm II, III, and Jenner. Obviously a direct comparison of modelled and measured data is problematic due to different scales of the compared quantities: The ultrasonic measurements are representative for the observed point only, whereas a simulated grid cell represents the average of an area of $40,000 \mathrm{~m}^{2}$ (200x200 m). Snow water equivalent measurements or data from field campaigns were not available for the observed winter season.

In general, the model reproduces the snow depth of the observed season quite well for both the MM5 and the INTER inputs (fig. 36a) b) c)). The overall accuracy seems to depend only little on the method used, which can be explained by the fact that the average wind speed derived from interpolated station data and the MM5 wind field library are relatively similar for altitudes below $1800 \mathrm{~m}$ a.s.l. (fig. 35c). Unfortunately, there are no meteorological stations available above $1800 \mathrm{~m}$ a.s.l. where such differences are much greater (fig. 35c)). However, the results computed for Reiteralm II and Jenner are slightly more accurate when using the MM5 library instead of the INTER input data, although Reiteralm II is located in the vicinity of a wind sensor. Further analysis also revealed, that the timing of observed transport events correlates very closely with those predicted by INTER and MM5 at Reiteralm II. This indicates that the MM5 library reflects the situation at the stations very well. 
a) MM5 method vs. measured: $\mathrm{r}^{2}=0.85$ INTER method vs. measured: $\mathrm{r}^{2}=0.73$

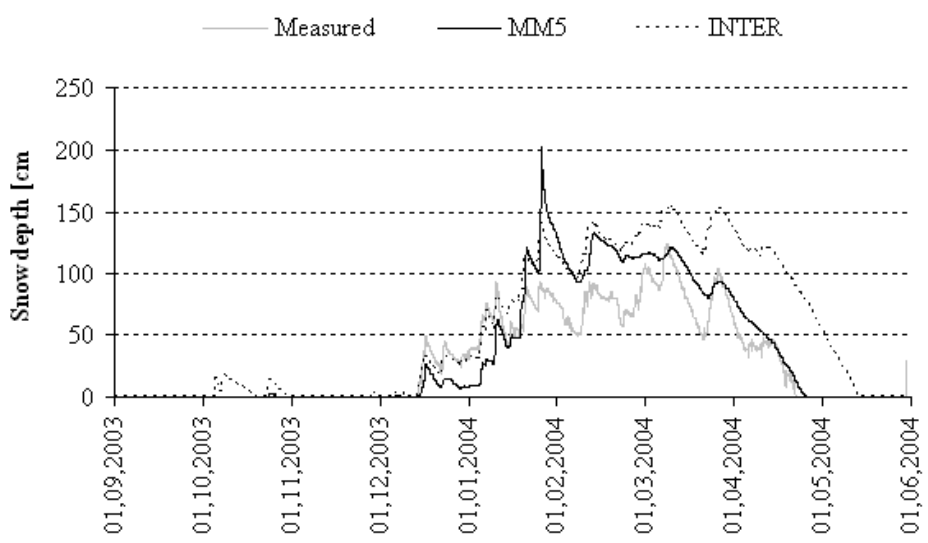

b) MM5 method vs. measured: $\mathrm{r}^{2}=0.88$ INTER method vs. measured: $\mathrm{r}^{2}=0.88$

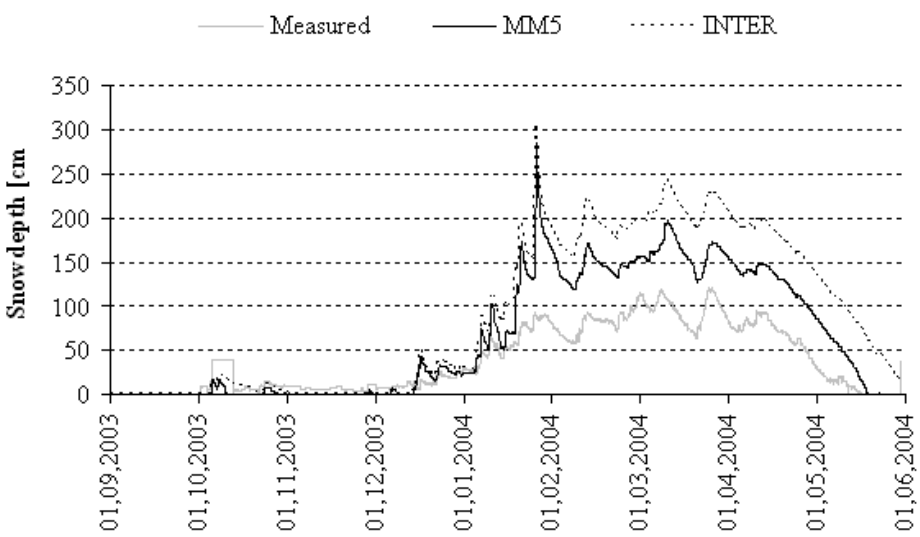

c) MM5 method vs. measured: $\mathrm{r}^{2}=0.73 \quad$ INTER method vs. measured: $\mathrm{r}^{2}=0.64$

$$
\text { Measured MM5 …. INTER }
$$

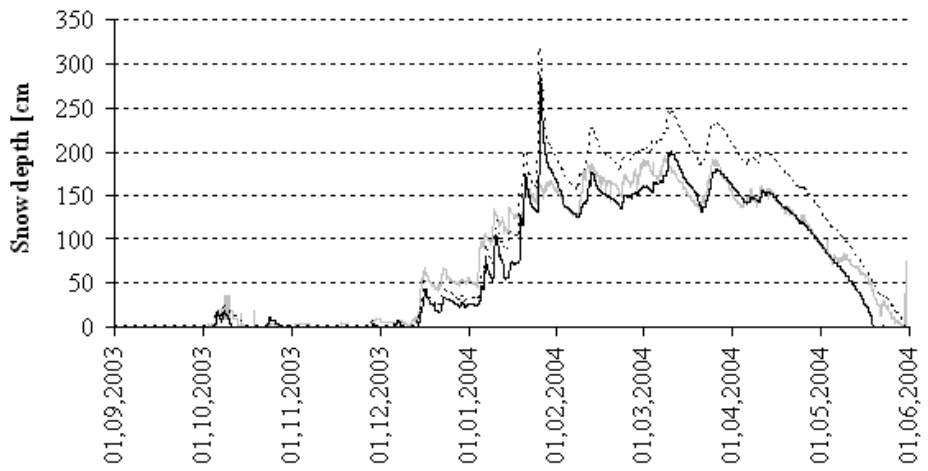

Figure 36: Comparison of model results and measured values for the meteorological stations a) Reiteralm II, b) III and c) Jenner.

Nevertheless, the model runs produce transport rates at the observed points which are too small compared to observations of the Bavarian Avalanche Warning Service (LWZ) for the 
Reiteralm stations. This is likely caused by the smoothed topography in the used DEM and its relatively coarse resolution of $200 \mathrm{~m}$. A similar result was reported by Liston et al. (2006) who found that snow transport events are underestimated when using a grid spacing larger than $100 \mathrm{~m}$. Additionally, snow depth is overestimated in most cases, which can be explained by a precipitation event on January 24-25 registered at Reiteralm III: This event produced a significant increase of snow depth within all model results though a corresponding increase in measured data cannot be detected. Whether this results from an error in the station data or an inaccuracy in the conversion of snow-water-equivalent (SWE) to snow depth cannot be decided here because of the lack of additional meteorological data.

\subsubsection{Spatial comparison of the model results}

As mentioned in section 3.1.3, the increase in wind speed with elevation and the differentiation between windward and leeward areas is more distinctive when using MM5 wind fields. This leads to regional differences within the SWE and snow transport rates when comparing INTER and MM5 results (fig. $37 \mathrm{a}$ ) and b)). In a first step the SWE distribution in relation to altitude and aspect was analysed. The INTER scheme which induces less snow transport events with less intensity (fig. 37 a) and b)), produces a SWE distribution that is almost exclusively driven by the altitudinal increase of precipitation (fig. 38a)).

a)

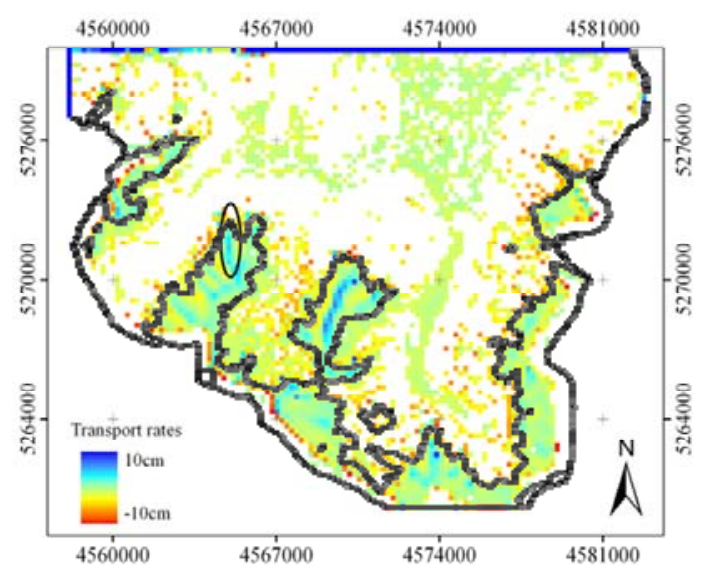

b)

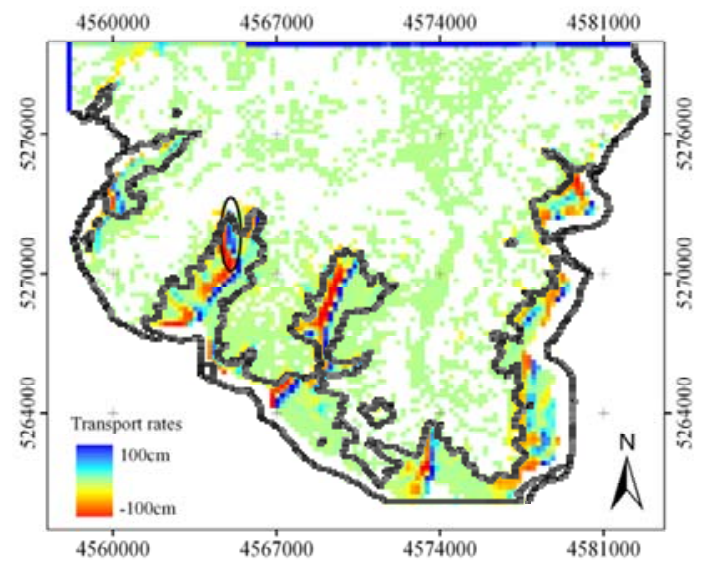

Figure 37: Amount of accumulated and eroded SWE within the study area and for the winter season (2003/04) (Please note the different scales of the legends). The accumulation zone at Blaueis glacier is marked with a black ellipse. The black line is the $1800 \mathrm{~m}$ isohypsis. 
Almost $96 \%$ of the variance within the SWE distribution can be explained by elevation (fig. 38a)). The scattering around the mean SWE at a given elevation zone is small (fig. 38 a)). A noticeable dependency of SWE on aspect could not be found when using INTER. This can be explained by the fact that the homogeneous wind fields predicted by the interpolation routine lead to almost similar transport rates for all aspects. The transport terms saltation, suspension, and sublimation show a slight increase with altitude, but no significant dependency on the aspect (fig. 38 a), c), e)).

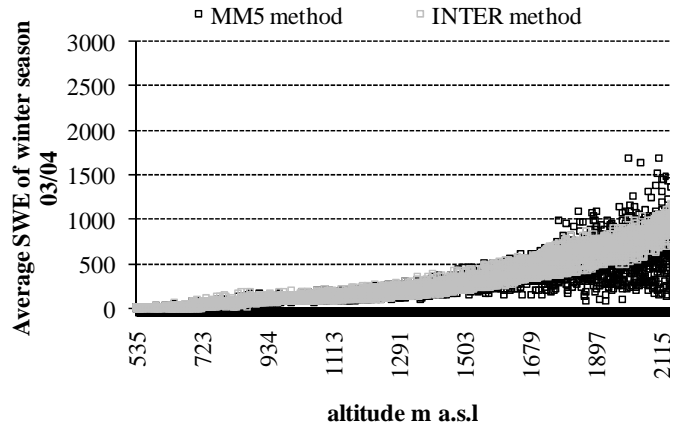

a)

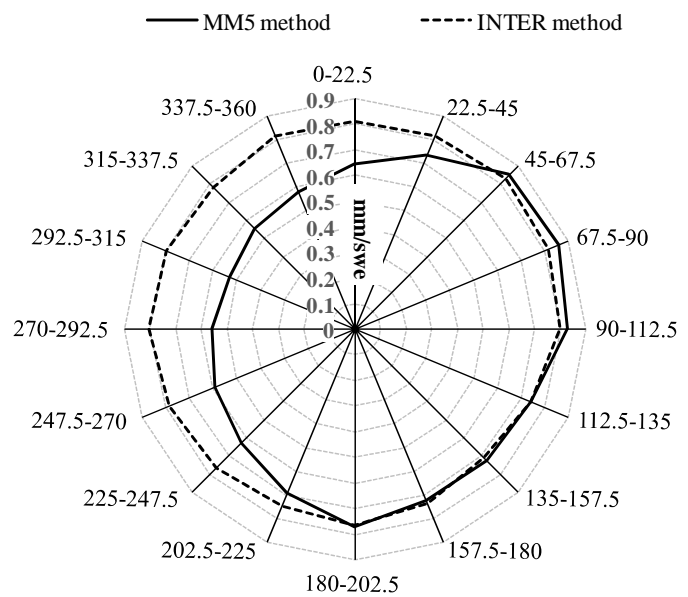

e)

Figure 38: a) SWE [m] - elevation dependency b) SWE - aspect dependency for the total elevation interval c) SWE - aspect dependency for elevations higher than 1800m a.s.l. d) SWE - aspect dependency for elevations higher than $2200 \mathrm{~m}$ a.s.l. SWE is the average values for the modelled time period. The different volumes under the curves are due to higher sublimation losses within the MM5 runs. The illustrations belonging to the winter season 2003/04 
Using the MM5 method, only $84 \%$ of the modelled variance within the SWE distribution can be related to altitudinal effects. The remaining variance is due to aspect (fig. 38 b), c), d)): Below 1800m a.s.l. the correlation of SWE and aspect explains only $2 \%$ of the variances, whereas aspect accounts for $17 \%$ of the variance above $1800 \mathrm{~m}$ a.s.l., and $21 \%$ above $2200 \mathrm{~m}$ a.s.l (fig. 38 b), c), d)). This dependency is caused by anisotropic transport effects which are represented in the Snowtran-3D model when using the MM5 wind fields of the library. The application of this method leads to a considerable differentiation of the windward sides with predominantly erosion areas and of the leeward sides where snow preferentially accumulates (fig 39 b), d), e)). These accumulations are especially intense at the eastern slopes of Watzmann and Hochkalter (cp. fig. 5). Again, it was seen that the transport and sublimation rates are negligible for elevations below 1800m a.s.l. (fig. 39 a)-e)) which explains the minor differences between the model results for the lower altitudes and in particular for the areas around the meteorological stations. Above $1800 \mathrm{~m}$ a.s.l. the rates of the different transport terms increase greatly when using MM5 whereas the increase was minor under usage of INTER (fig. 39). Furthermore, measurements of De Quervain and Meister (1987) have shown that transport fluxes are enhanced at mountain crests and slopes perpendicular to the main wind direction (230 degrees for the observed winter season). This result was reproduced when using the MM5 model wind fields (fig. 37b). An additional effect related to the higher transport rates generated by the MM5 method are increased sublimation rates at elevations above 1800m a.s.l. (39 e) and f)). The modelled sublimation loss rate is considerable larger when using the MM5 method and for elevations above 1800m a.s.l. (fig. 39 f)). Sublimation losses can be neglected for elevations below 1800m a.s.l., but can reach $860 \mathrm{~mm}$ SWE or 27 $\%$ of the total precipitation for altitudes between $2400 \mathrm{~m}$ a.s.l. to $2500 \mathrm{~m}$ a.s.l. (fig. $39 f$ )). The results when using the INTER method are one magnitude smaller and show maximum values of $50 \mathrm{~mm}$ (fig. 39 e)). 
a)

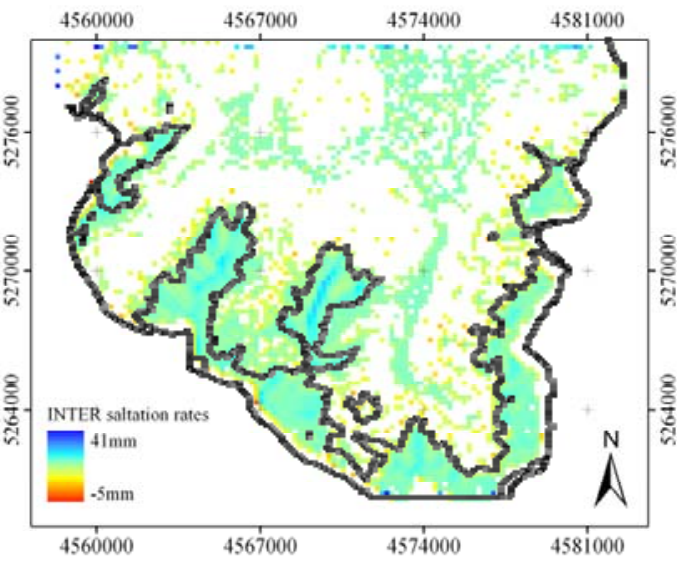

c)

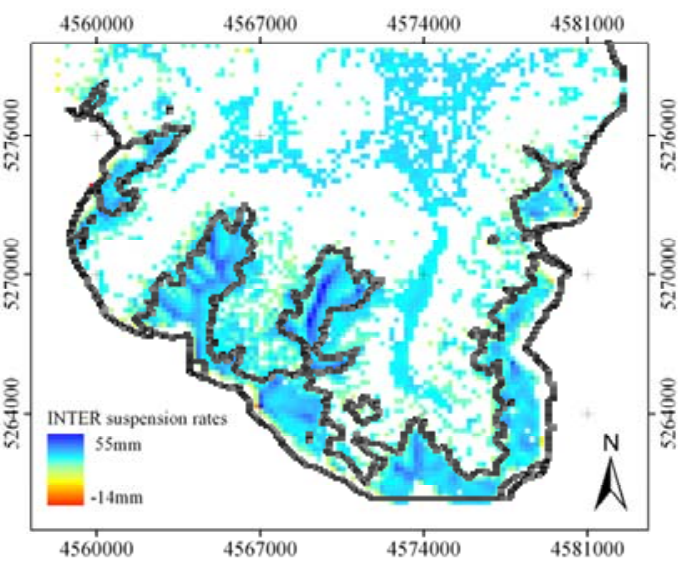

e)

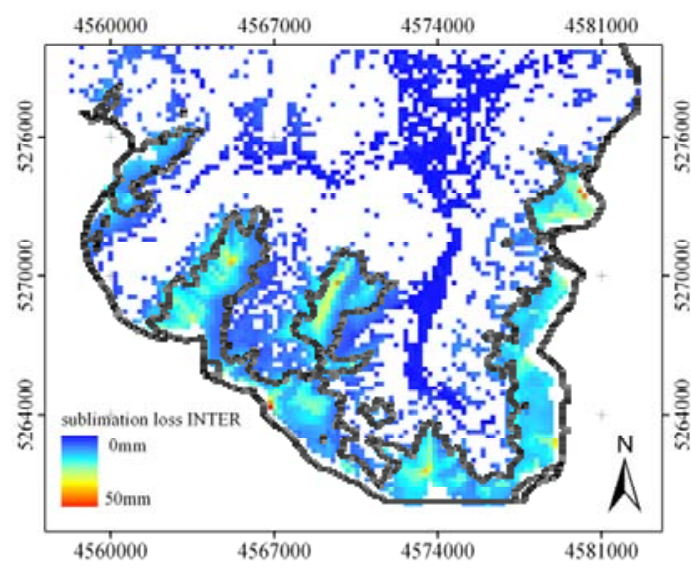

b)

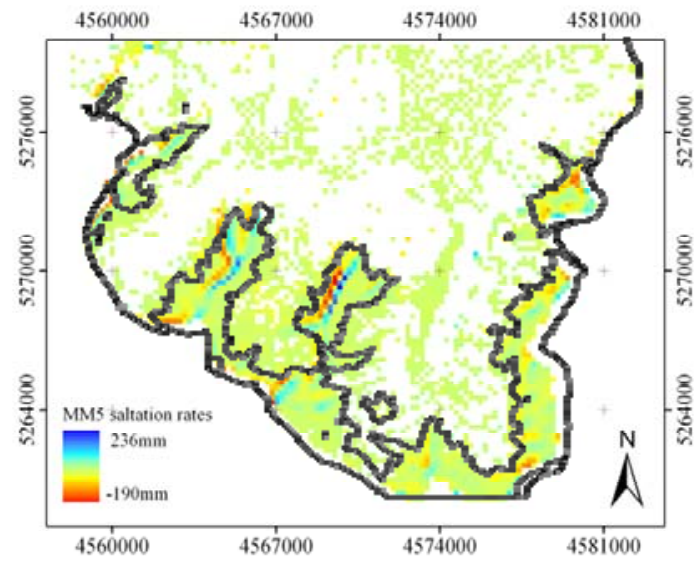

d)

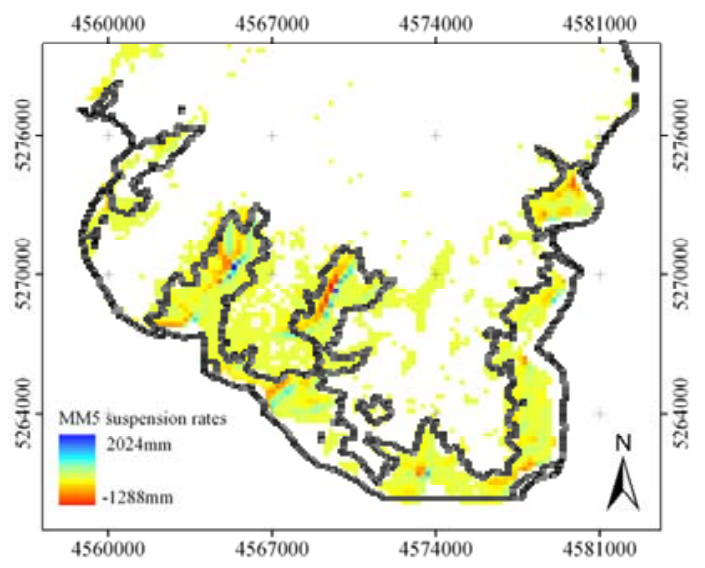

f)

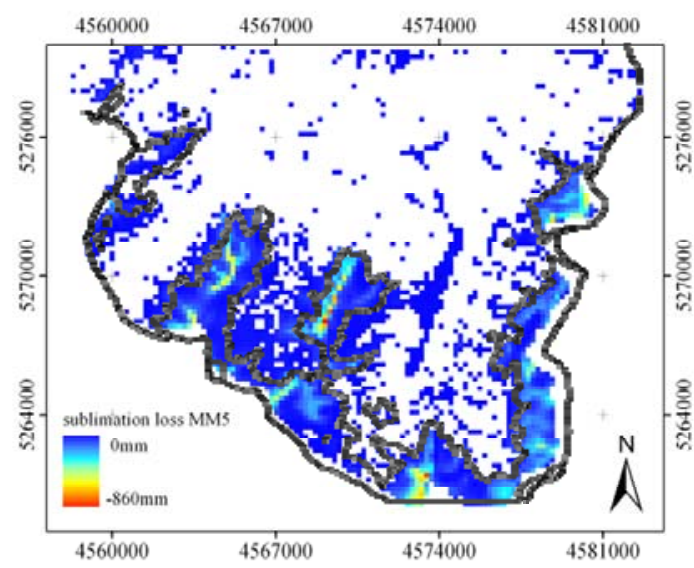

Figure 39: Intensities of the different transport terms: saltation, suspension and sublimation in a) c) e) INTER and b) d) f) MM5 (winter season 2003/04). The black line is the $1800 \mathrm{~m}$ isohypsis.

\subsubsection{Spatial validation of the local scale results}

For the spatial validation of the model results, remotely sensed data was used. Hence, a short overview about remote sensing of snow and the techniques used in this work will be given. 
Optical and microwave remote sensing techniques are powerful tools for acquiring information about the spatial distribution and the physical properties of the snow cover. As insitu data collection in the National Park area is both sparse and non-uniform, depends heavily on human observers and the accessibility of the region and data verification is almost impossible, remotely sensed data is needed to get a comprehensive picture of the snow distribution. The mapping of snow by optical systems can still be seen as the most common application in snow remote sensing. But there are also other applications. Knap et al. (1999) used Landsat TM data for the estimation of the albedo of the Arolla glacier (Switzerland) whereas the Multiangle Imaging SpectroRadiometer (MISR) is used for the same variable by Stroeve and Nolin (2002). In another work, Klein and Stroeve (2002) predicted the surface grain diameter of a snowpack with albedo information. Painter et al. (2003) utilized hyperspectral data for an improved subpixel description of the snow heterogeneity. A comprehensive overview about the work with microwave sensors for the estimation of the SWE can be found in Durand and Margulis (2005).

For the presented work optical data was used exclusively, due to the problems of microwave sensors in regions with steep topography and due to the limited spatial resolution of the respective sensors. Landsat TM and ETM+ have shown their applicability for high resolution snow mapping in a lot of studies (e.g. Hall et al. 1995). The resolution of $30 \mathrm{~m}$ and the arrangement of the spectral bands (fig.40 a)) make Landsat images applicable for this task. Two Landsat ETM+ images, April 28, 2004 and May 30, 2004, were available and analysed to estimate the snow cover extent for the National Park area. The data was geometrically, terrain and radiometrically corrected for this behaviour. Comparison of the available GIS data and the spatially corrected Landsat images has revealed that the displacement of the 30m pixels is below of one pixel. 

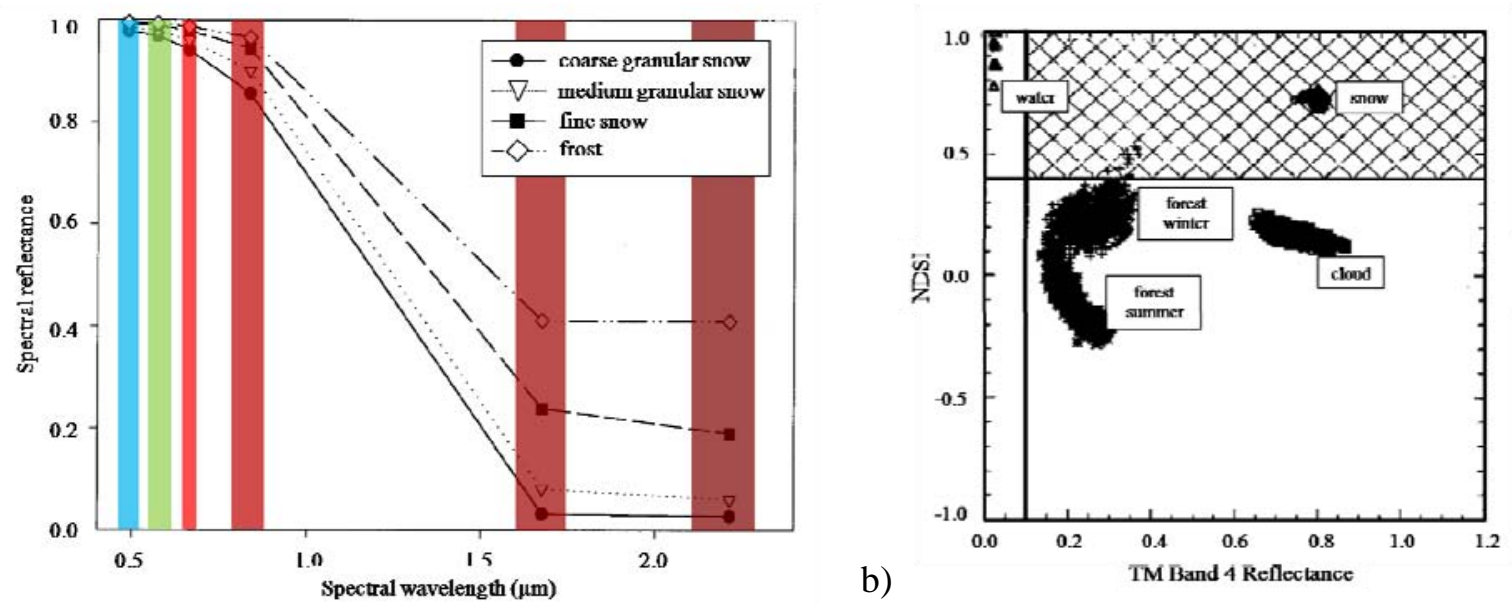

a)

Figure 40: a) Spectral bands of Landsat ETM+ and spectral characteristics of different snow types. b) spectral Characteristics of different land cover types

For the estimation of the snow covered area the normalized difference snow index (NDSI) was used (Eq. 34). The NDSI trace back to band rationing techniques (Kyle et al. 1978; Dozier 1984) and is related to the NDVI (Tucker 1976).

$$
N D S I=(E T M+2-E T M+5) /(E T M+2+E T M+5)
$$

The NDSI profits from the fact that snow reflects visible radiation much more intensively than it reflects radiation in middle infrared. According to Hall et al. (2001) the index achieves an accuracy of about $99 \%$ in non-forested areas and about $85 \%$ in forested areas under full snow coverage. If water bodies are present within the investigation area the inclusion of an additional threshold becomes necessary. Open water shows a more or less identical NDSI value as snow does, which can lead to a misinterpretation of the respective areas. When considering figure $40 \mathrm{~b}$ ) it becomes obvious that water and snow can be differentiated by means of the reflectance between $0.76 \mu \mathrm{m}$ and $0.90 \mu \mathrm{m}$. Hence, an additional inquiry was introduced if the NDSI exceeds 0.35 . It is also checked, if the reflectance in TM channel 4 exceeds 0.4 , if both are warranted the pixel is classified as snow. The threshold of 0.35 was chosen on the basis of literature (Hall et al. 1995) and because of visual comparisons. At lower thresholds many non-snow-pixels were identified as snow, greater values lead to an underestimation of the snow cover especially in wooded areas. Hall et al. (1995) found that an additional classification error of about $3 \%$ has to be expected if the NDSI is applied to images without a radiometric correction. They predicted a greater snow cover when reflectance was 
used instead of Digital Number (DNs). Thus, the used Landsat images were processed with the help of PULREF-H (Bach 1995).

According to Hall et al. (1995) the detection of snow with the help of the NDSI is straightforward and accurate in open and fully snow covered areas. The situation changes if the snow coverage drops below of $100 \%$, or if the snow is covered by e.g. trees. Snow in mixed pixels is widely detected by the NDSI at the 30m scale of the Landsat images and is therefore not a significant source of errors. The existence of dense woods on the other hand can make the detection of snow nearly impossible, which has to be regarded as a bigger limitation of optical systems than an error during analysis. It is a common approach to classify wooded areas as snow covered if they are completely surrounded by snow (e.g. for the NOAA snow product Hall et al. (1995)). Nevertheless, this procedure is only useful if one can assume identical melt rates for the woods and for the surrounding areas. This is often not the case due to the fact, that a forest canopy can lead to both less $S W E$ and shorter duration, or more SWE and longer duration of the snow cover beneath the trees, depending on many factors such as canopy density, gap size and distribution, geographic location, and meteorological conditions (Pomeroy et al. 2002). This makes any conclusion drawn from the surrounding conditions to snow conditions within canopy stands difficult.

Data processing has shown that the NDSI is nearly independent of the resampling sequence. This fact causes that the NDSI value to stay approximately the same, weather the Landsat image is resampled first to a $200 \mathrm{~m}$ resolution and the NDSI is predicted afterwards or if the procedure is reversed. For the estimation of a cloud mask for the April scene the NDSI was used again. Clouds and snow are both highly reflective in Landsat ETM+ Band 2, but the reflectance differs at band 5 were the cloud reflectance is higher than the snow reflectance. An iterative adaption of the threshold value has lead to a satisfying cloud mask (pink areas in fig. 41a/b). As the MM5 and INTER results does not differ with respect to the snow line they are not separately discussed. The MM5 results can be seen as representative for both which is due to the fact that the snow line is located below of $1800 \mathrm{~m}$ a.s.l. (black line in fig. 41) and therewith below of the region were wind induced snow transport processes significantly influence the snow distribution (cp. fig. 39). 
Model and classification results are shown in fig. 41 a) to d). The analysis shows that the model is overestimating the snow coverage on both dates and for all of the four massifs in the region. The modelled snow line lies approximately 200-400 meters (1-2 pixels) in distance lower than the observed one. It has to be stated that an exact analysis of the model error is difficult due to the fact that the snow line is located in wooded regions on both observation dates. Furthermore a quantitative validation is impossible on the basis of optical remote sensing data.

a)

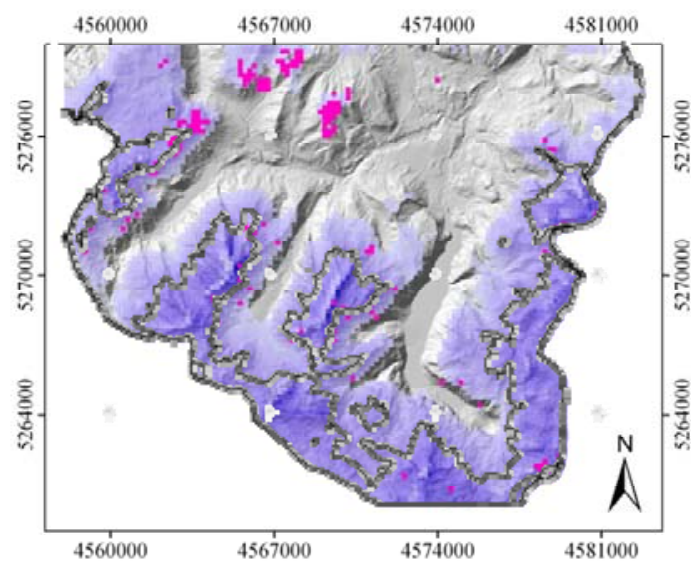

c)

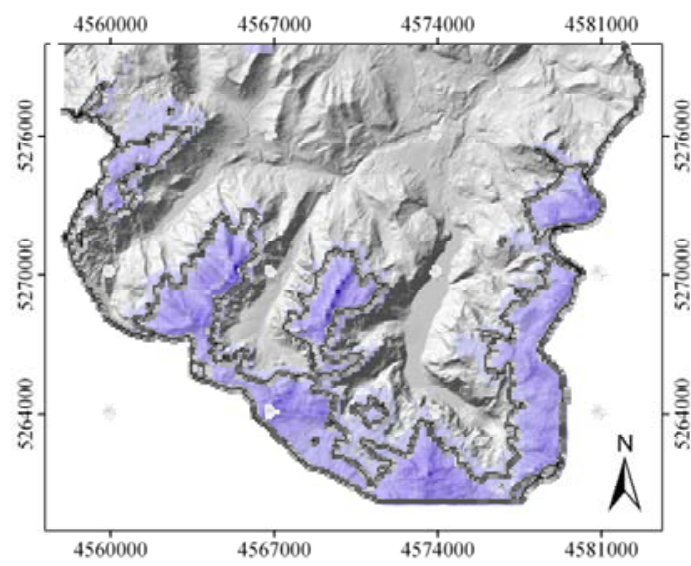

b)

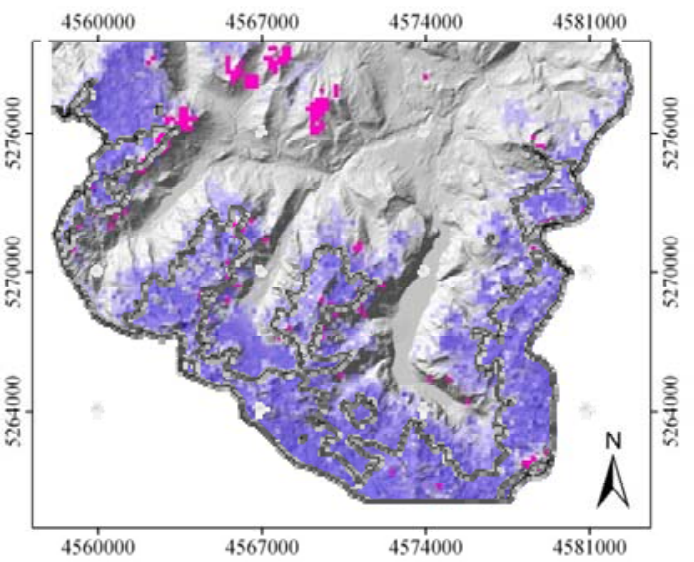

d)

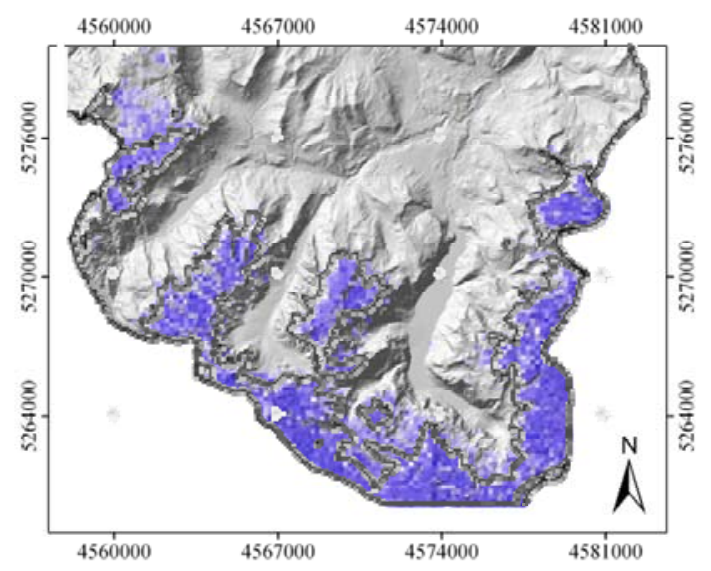

Figure 41: a) modelled snow cover of April 28, 2004, b) NDSI map of the same date, c) modelled snow cover of Mai 30, 2004 d) NDSI map of the same date. The black line is the $1800 \mathrm{~m}$ isohypsis.

86\% of the pixels show an agreement between modelled and classification results on April 28. $3 \%$ of the pixels are classified as snow free but are snow covered in the model results whereas $11 \%$ of the pixels are defined as snow covered by the model but are snow free in the classification. The results of May 30 are very similar; the agreement is $88 \%, 2 \%$ of the pixels 
show a classified snow cover but no modelled one, and $10 \%$ show a modelled snow cover but no classified one. The Landsat images are shown in fig. 42 a) and c), the differences between classification and model results in fig. 42 b) and d).

a)

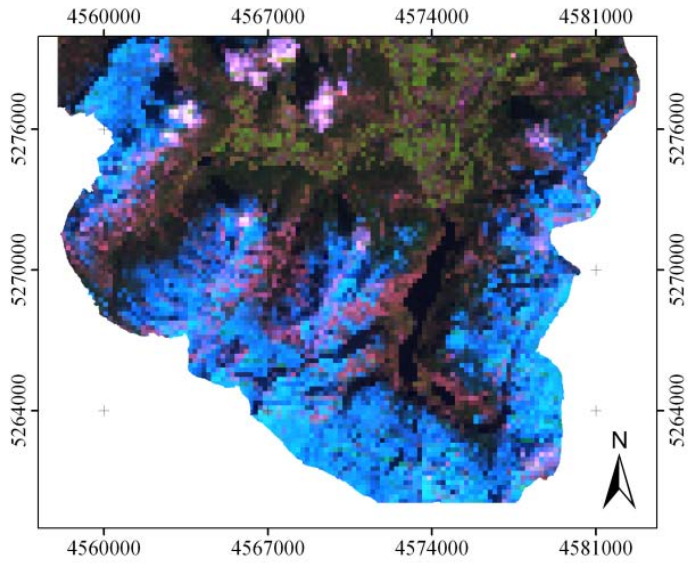

b)
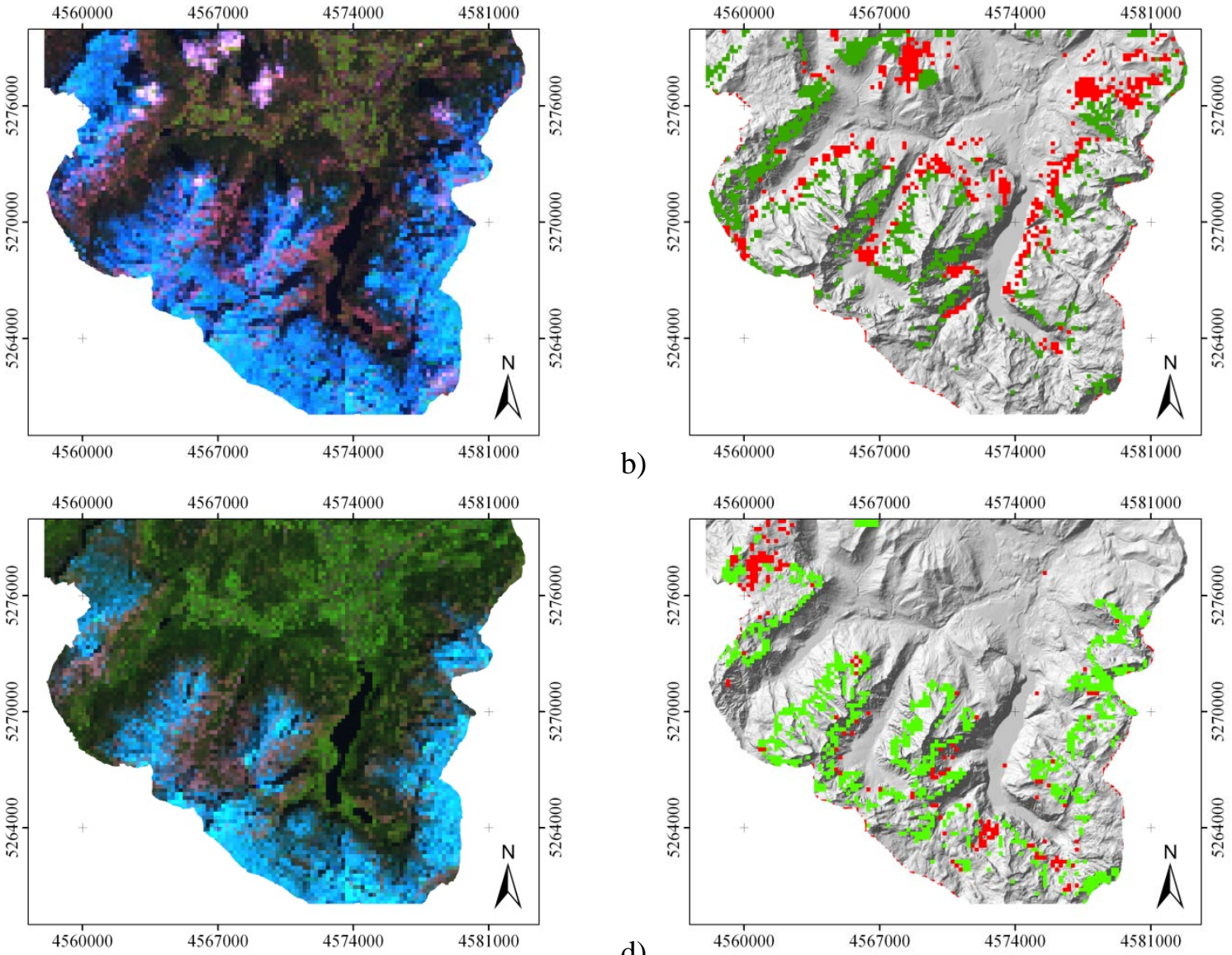

c)

d)

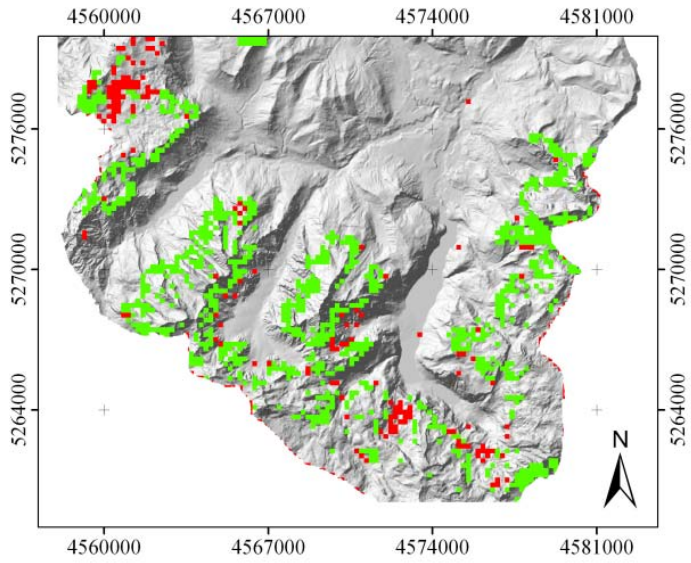

Figure 42: a) c): Landsat ETM+ images (April, 282004 and May, 30 2004. resampled to a 200m resolution). e) f): Differences between model an classification results at April and May respectively (red indicates: only classified snow cover. Green: only modelled snow cover). 


\subsection{Downscaling of the MM5 wind fields}

It can be seen that the model delivers plausible results at the $200 \mathrm{~m}$ scale. Nevertheless, a definition of the precise locations of accumulation and erosion is impossible at the meso scale (Liston et al. 2006).

a)
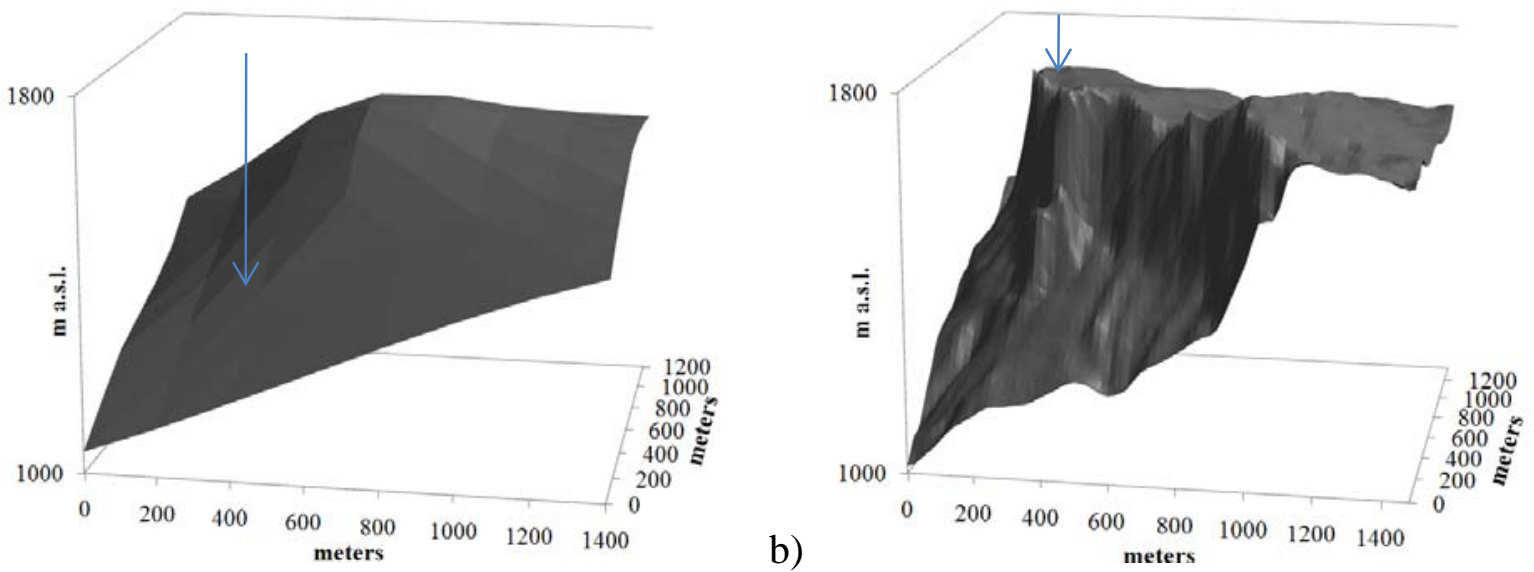

Figure 43: a) The smoothed Reiteralm area (marked with an arrow) within the MM5 DEM (200 m resolution) compared to b) the National Park DEM (30 m resolution).

To determine these locations, model runs with a higher spatial resolution are needed. Furthermore, a finer resolution than $200 \mathrm{~m}$ is needed to analyze the model performance by comparing the model results to the close meshed field campaign data and to remotely sensed data. The selected target resolution of 30m meets the requirement that the support, spacing, and extent of model results, remotely sensed data and field measurements are unitary. The adaption of SnowModel to a 30m resolution was unproblematic because all components are scale independent and permit model runs up to a resolution of 5 meters (Liston et al. 2006). However, to realise the $30 \mathrm{~m}$ model runs, the MM5 wind fields had to be downscaled to this resolution. A downscaling and correction of the MM5 wind fields is required because of the smoothing of the DEM which processed in prior of the MM5 model runs. Figures 43 show the area around Reiteralm (marked with an arrow) within the $200 \mathrm{~m}$ and the $30 \mathrm{~m}$ DEM. The effect is apparent; Reiteralm is located at the mountains slope in the $200 \mathrm{~m}$ DEM and not at the crest like in reality. Hence, the original MM5 data is not representative for the "real" location of Reiteralm and has to be overworked therefore. The different downscaling steps are displayed in figure 44. 


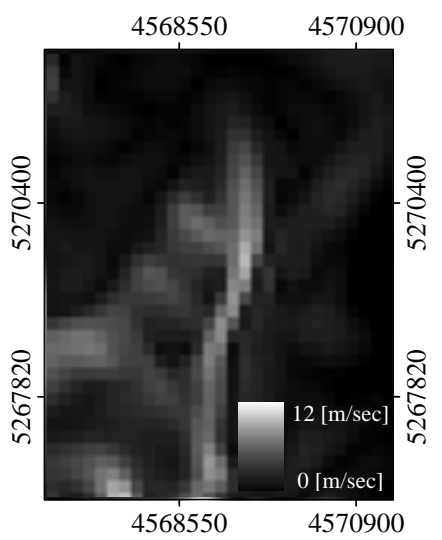

Original MM5 output:200m resolution

- $\quad$ Spatial resolution $=200 \mathrm{~m}$

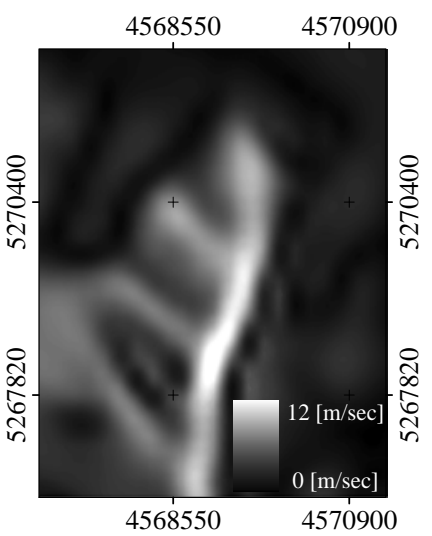

Step I: Spatial correction and statistical revision

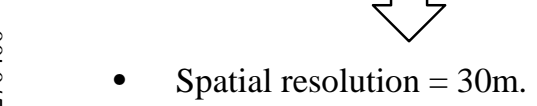

- A spatial correction was applied using Eq. 35 and 36.

- $\quad$ The field is smoothed via Eq. 37

- The total Energy of the field is conserved (Tab. 4).

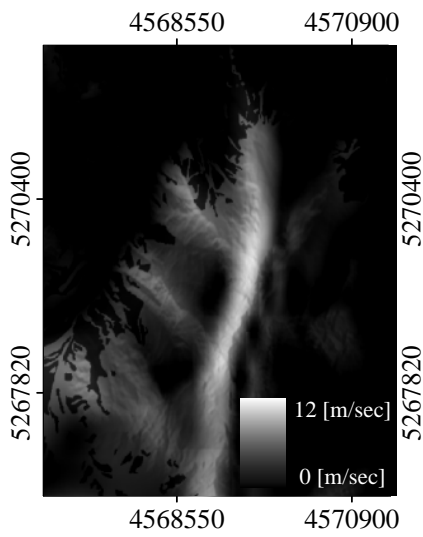

Step II: Integration of subgrid topography

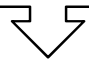

- $\quad$ Spatial resolution $=30 \mathrm{~m}$.

- The fields were overworked with respect to the elevation difference between $30 \mathrm{~m}$ and 200 DEM.

- The subgrid topography was respected over Eq. 18-20

- The underlying vegetation type was respected over Eq. 21.

Figure 44: Performed downscaling steps. The figure shows the a schematic illustration of the downscaling steps conducted in 4.2.1 to 4.2.3.

\subsubsection{Spatial correction}

A prerequisite for the model runs at the $30 \mathrm{~m}$ scale was a geometric correction of the MM5 wind fields. This is necessary for two reasons I) the modifications at the $200 \mathrm{~m} \mathrm{DEM}$ to guarantee numerical stability of the MM5 model (Bernhardt et al. 2008a and b) and II) 
resolution dependent shifts of the apexes and minima between $30 \mathrm{~m}$ and $200 \mathrm{~m}$ DEM. The deviations resulting from the higher resolution are especially obvious at very exposed areas like Reiteralm (fig. 43) Watzmann, or Hochkalter (ср. fig. 5) and can be observed when comparing the 30m DEM with the $200 \mathrm{~m} \mathrm{DEM}$ as well as the predicted wind fields. In the case of Reiteralm the crest of Wartsteinkopf (fig. 43 a)) still appears, but not in the position that it is in in reality (fig. 43 a)). Therefore, a validation of predicted data with the help of station measurements is complicated without a correction. Compared to the $30 \mathrm{~m} D E M$ the crests of Watzmann and Hochkalter (cp. fig. 5) are shifted eastwards within the 200m DEM. This offset can be also detected when analyzing the wind fields itself. The topographically caused convergence of the airstream and the resulting acceleration of the air masses at the mountains crests are shifted into the eastward faces of the respective massifs under usage of the $30 \mathrm{~m}$ DEM.

For the correction a well known approach used by a number of remote sensing applications was used. The correction was achieved with two 2 dimensional second order polynomials:

$$
\begin{aligned}
& Z^{\prime}=a 1 * Z^{2}+a 2 * S^{2}+a 3 * Z+a 4 * S+a 5 * Z * S+a 6 \\
& S^{\prime}=b 1 * Z^{2}+b 2 * S^{2}+b 3 * Z+b 4 * S+b 5 * Z * S+b 6
\end{aligned}
$$

Equation 35 stands for the new row coordinate and equation 36 for the new column coordinate. Pass points were used for the determination of the coefficients a1-a6 and b1-b6. Under usage of more than six control points the system of equations becomes overdetermined and could be solved with the smallest quadratic deviance between the coefficients a1-a6 and b1-b6. As all of the MM5 wind fields are based on the same DEM the whole library could be adapted to the $30 \mathrm{~m}$ DEM using the same set of control points.

\subsubsection{Statistical revision}

The statistical revision was done in order to prevent of artefacts of the original $200 \mathrm{~m}$ pixels in the downscaled $30 \mathrm{~m}$ data and in the snow model results, respectively. A Radial Basis Function $(R B F)$ (eq. 37) was used to smooth the wind fields and to eliminate the coarse grid structure while conserving the total amount of energy of each wind field (tab 4, fig. 44)). 
$R B F$ is a local statistical technique, calculating predicted values from measured points within a defined neighbourhood that is smaller than the total area. As this approach maintains the total energy, the modeled 200 m pixel values are conserved. For verification, comparisons of mean wind speeds were made before and after applying this statistical approach between the original $200 \mathrm{~m}$ pixels and the $30 \mathrm{~m}$ pixels corresponding to the area of the original $200 \mathrm{~m}$ grid cell. The differences were close to zero (tab. 4).

Table 4: Column I: Mean value of all 220 wind fields between the average value of the original and the modified MM5 wind speeds. Column II: Maximal observed difference between original and modified MM5. Column III: Minimal observed difference.

\begin{tabular}{ccc}
\hline Mean deviation & Maximal deviation & Minimal deviation \\
\hline $0.003[\mathrm{~m} / \mathrm{s}]$ & $0.02[\mathrm{~m} / \mathrm{s}]$ & $0.00[\mathrm{~m} / \mathrm{s}]$ \\
\hline
\end{tabular}

The completely regularized spline function that was used is:

$$
\phi(r)=-\sum_{n=1}^{\infty} \frac{(-1)^{n}\left(\sigma^{*} r\right)^{2 n}}{n ! n}=\ln \left(\sigma^{*} r / 2\right)^{2}+E_{1}\left(\sigma^{*} r / 2\right)^{2}+C_{E}
$$

$\phi(r)=$ Radial basis function, $r=$ the Euclidean distance $\left(r=\left\|s_{i}-s_{0}\right\|\right.$ is the distance between the estimation location $s_{0}$ and each data location $\left.s_{i}\right), \sigma=$ the smoothing parameter, $l n=$ natural logarithm, $E_{l}=$ exponential integral function, $C_{E}=$ Euler constant.

\subsubsection{Inclusion of the height difference between MM5 and $30 \mathrm{~m}$ DEM}

The coarser resolution of the modified MM5 DEM leads to smoothed elevation minima and maxima. This has a direct effect on the generated wind fields, which also show over- or underestimated wind speeds. To address this effect, the difference between the two DEM was calculated for the thirty meter resolution. Subsequently, the elevation gradient of wind speed was calculated for each modelled wind field. It became obvious that there are two distinguishable elevation gradients within the datasets. There is one gradient for the interval from 500 to $1800 \mathrm{~m}$ a.s.l. and another for 1800 to $2700 \mathrm{~m}$ a.s.l.. This separation was necessary because the gradient above $1800 \mathrm{~m}$ a.s.l. was considerably steeper than the gradient for the lower elevation interval. As a result, this analysis provides a value for the increase of wind 
speed per meter elevation for the two intervals. In a subsequent step, these gradients were combined with the elevation difference of the two DEMs. As a result, higher wind speeds were generated at locations with positive divergences, and reduced values were computed at locations where MM5 DEM elevation values are higher than the ones of the $30 \mathrm{~m} D E M$. Therefore, the resulting correction file contains a positive or negative correction value for all 30 m pixels. These values were added to the statistically corrected MM5 wind field.

\subsubsection{Integration of subgrid topography}

Due to the relatively coarse resolution of 200 meters most of the small scale sinks and hills of the $30 \mathrm{~m} D E M$ were not considered during the MM5 modelling procedure which means that they had no influence on the generated wind fields. That makes a subsequent consideration of this subscale information necessary. The algorithms of Ryan (1977) and Liston and Sturm (1998) described in 2.1.2 were used for this purpose.

Figure 44 shows a detailed view of the Watzmann region, fig. 44 (Original MM5 output) shows an unprocessed wind field as fig. 44 (step 1) show a wind field after application of the statistical revision and fig. 44 (step II) shows the final result of the downscaling process. It is obvious that the downscaled version shows much more details. Furthermore, it can be seen that the influence of the vegetation leads to very small wind speeds in forested regions (identifiable as black edges).

\subsubsection{Validation of the downscaled MM5 wind fields.}

The correlation between measured and modelled daily wind speeds was greatly improved by the downscaling procedure. The original modelled data correlated with an $\mathrm{r}^{2}$ of 0.23 to the measurements while the downscaled set produced an $r^{2}$ of 0.62 for the season 2003/2004 (fig. 45 a) and b)). The regression line is forced through the origin in both cases. It can be argued that the measured wind speeds could only be reproduced adequately by using the downscaling routine. The hourly data show a lower convergence between measurements and model results the $\mathrm{r}^{2}$ is 0.21 here. The limited accuracy of the hourly data is mainly due to the fact that the measurements have a higher variability than the modelled data (fig. 32)) which is due to local 
phenomena (like cooling or heating of some areas etc.). These temporary effects cannot and should not reproduced by the MM5 model when using the presented scheme, since the MM5 model was run with the intention that the wind fields reach steady state conditions under a certain synoptic inflow. This was done because of the assumption that high wind speeds which are generating remarkable snow transport events are due to the synoptic inflow and not to local and micrometeorological influences. These were ignored due to their abundance and because of the fact that they are not the driving force for snow transport processes. To sum it up, the determination of the current wind field depends on the synoptic situation which changes less frequently than the local conditions and the results are therefore in line with expectations. Overall, the application of the downscaling routine leads to a considerable improvement of the model results which are now reflecting the local conditions much better than before.
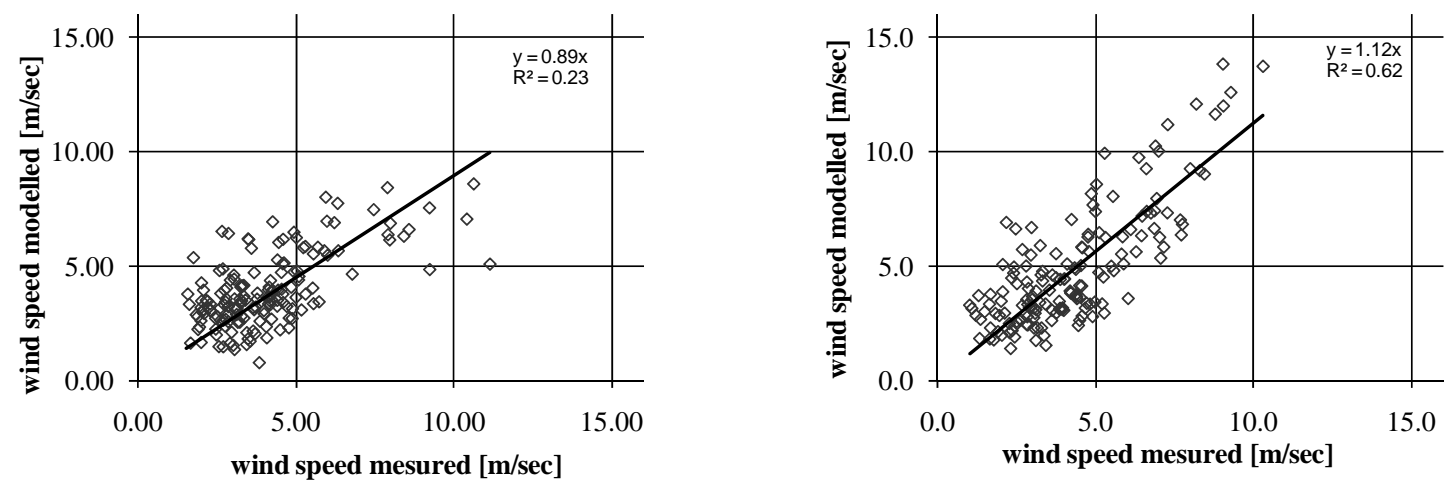

Figure 45: a) Correlation between MM5 results and station recordings before the downscaling procedure (Reiteralm I, daily resolution) b) Correlation between MM5 results and station recordings after the downscaling procedure. The regression line is forced through the origin.

\subsection{Results of the micro scale model runs}

The model runs presented within the next section cover the winter seasons of 2003/04 and 2004/2005. Unfortunately, there was no winter season where field campaign data, remotely sensed data, and Lokalmodell data for the library key, were available simultaneously. Hence, the 30m model runs of 2003/04 were validated on the basis of remotely sensed data, while the runs of 2004/05 were compared to the field measurements. The required input parameters 
were provided by the same meteorological stations as described before (tab. 2). In accordance to section 4.1 where model runs with MM5 wind fields were named MM5 and INTER if the interpolation routine was used, the different $30 \mathrm{~m}$ runs will be also indicated by two different abbreviations. The runs will be called: INTER_30 (SnowModel/SnowTran-3D/interpolated wind fields) and MM5_30 (SnowModel/SnowTran-3D/MM5wind fields) in the following sections.

The well instrumented sites Reiteralm and Kühroint were selected for this behaviour (cp. fig. 5, fig. 46 and fig. 47). Reiteralm has an area of about $2 \mathrm{~km}^{2}$. Two of the three available automatic stations were installed for observe snow transport processes from the higher situated area (meteorological station II), to the lower area around station III (fig. 5). ). This site was used to test the ability of the coupled MM5_30 model algorithm to reproduce the recorded transport events. At Kühroint, which is more sheltered from the wind, the correct reproduction of minimal or no transport conditions by MM5_30 was tested.

\subsubsection{Results at Reiteralm}

The results at Reiteralm showed a satisfying convergence between modelled and measured snow depth. However, the modelled snow depth was generally overestimated at the upper part of Reiteralm and underestimated at the lower parts (fig. 46). Figure 46 shows the location of the measuring points. The green colour indicates that the modelled snow depth was in average $10 \%$ higher than the measured one, whereas the red colour indicates that the modelled snow depth was in average $10 \%$ below of the measurements. The white colour denotes measuring points were the model results were within these thresholds. 


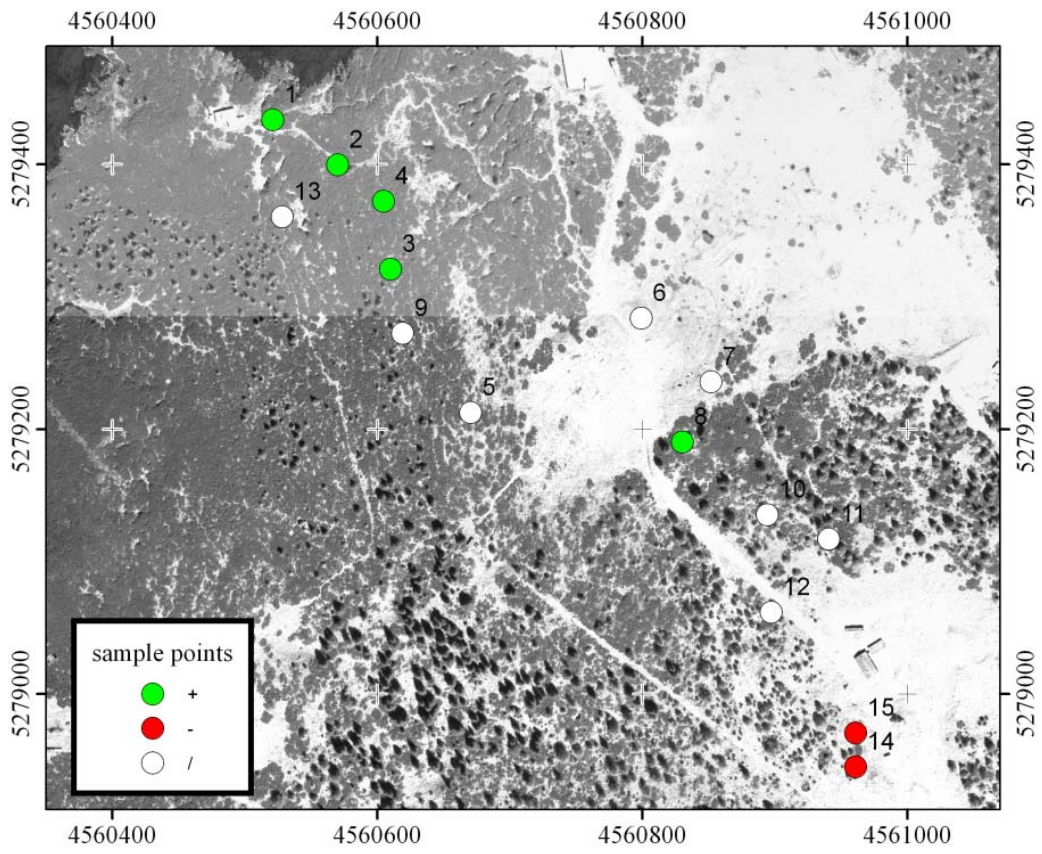

Figure 46: Comparison of model and measurements. White dots indicating that the model is within $10 \%$ of the measurements. Green dots stand for a model overestimation of the snow depth from more than $10 \%$, red dots for a model underestimation from more than $10 \%$.

A comparison of model and field campaign results also reveals that differences between the measurements at the sample points could be reproduced by the model to some degree, but the modelled variability is generally too small (tab. 5).

Table 5: The table shows the standard deviations of the measurements and of the respective model results for the observation dates.

\begin{tabular}{l|l|l|l|l|l|l|l|l|l|} 
& 08.02 .04 & 15.02 .04 & 23.02 .04 & 02.03 .04 & 10.03 .04 & 14.03 .04 & 23.03 .04 & 30.03 .04 & 05.04 .04 \\
\hline Measured & $43 \mathrm{~mm}$ & $41 \mathrm{~mm}$ & $35 \mathrm{~mm}$ & $39 \mathrm{~mm}$ & $54 \mathrm{~mm}$ & $53 \mathrm{~mm}$ & $38 \mathrm{~mm}$ & $37 \mathrm{~mm}$ & $39 \mathrm{~mm}$ \\
\hline Modelled & $19 \mathrm{~mm}$ & $19 \mathrm{~mm}$ & $21 \mathrm{~mm}$ & $20 \mathrm{~mm}$ & $24 \mathrm{~mm}$ & $23 \mathrm{~mm}$ & $17 \mathrm{~mm}$ & $14 \mathrm{~mm}$ & $12 \mathrm{~mm}$ \\
\hline
\end{tabular}

Table 5 show the standard deviations of all measurements per date and the same information for the respective model results. It can be seen that the standard deviations between the measurements are a magnitude higher than that of the SnowModel results. Furthermore, the variation of the measured snow depth between the dates is higher, than that of the modelled values. The differences within the model results are approximately similar for the first seven dates and only slightly smaller for the last two dates. 


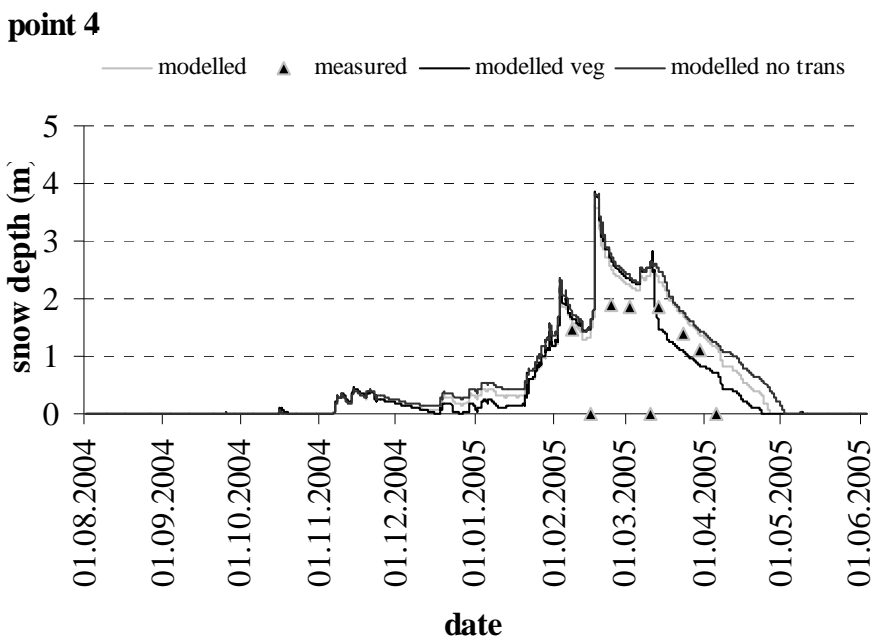

point 7

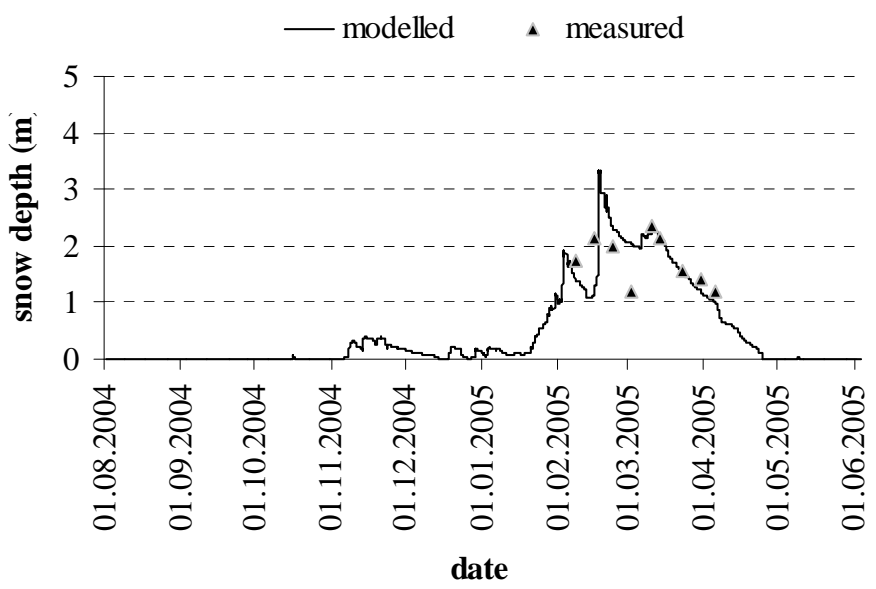

point 14

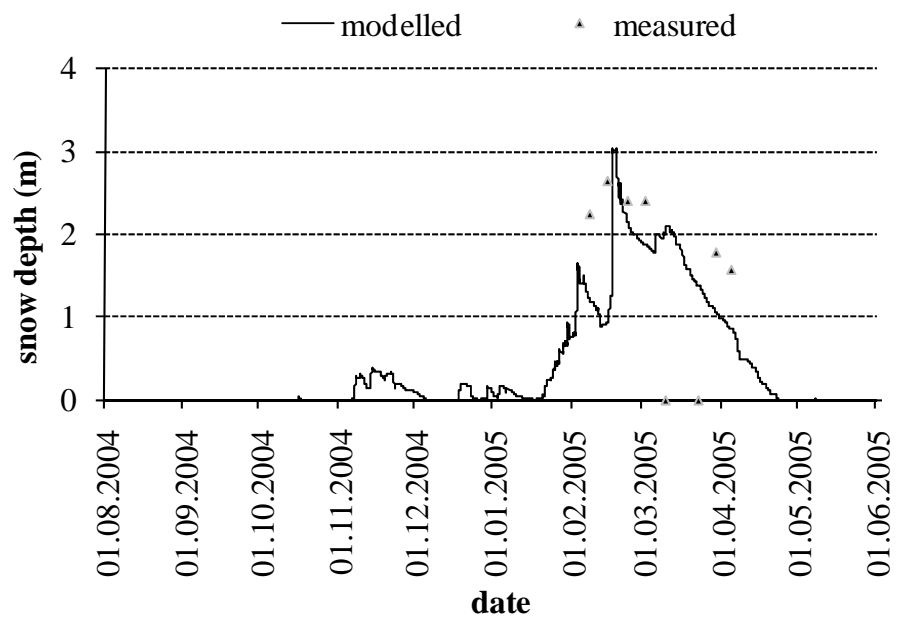

Figure 47: a) is representative for the upper part of Reiteralm. b) For the central region and c) For the lower part. 
Experiences of the Avalanche Warning Service of Bavaria which has observed this site for over 10 years indicate that considerable amounts of snow are blown from the upper (characterised by sample points 1-8, fig. 46) to the lower part of the site (sample points 14 and 15, fig. 46). This experience is confirmed by the snow depth measurements of the automatic meteorological stations Reiteralm II and III but could not be reproduced to some degree by the snow transport model. Hence, the transport processes were underestimated during the first model run and using the existing vegetation snow holding capacities. For the first model run at Reiteralm the parameterisation of the vegetation classes was adopted from Liston and Sturm (1998). After that, the vegetation type mountain pine was introduced and adapted with respect to field measurements and to model results. Additionally, a vegetation type sporadic trees was created for areas with sparse canopy stands. For doing so the snow holding capacities of the vegetation type, deciduous forest were reduced.

By adding the new vegetation types and MM5 wind fields the model results could be improved at the upper part of the Reiteralm (fig. 47 a)), but there are only minor changes at the lower part. A difference in the model results caused by the use of modelled MM5 versus the interpolated wind fields could only be found at the upper stations. The other stations are close to the forest or within the forest which causes the differences to be negligible.

\subsubsection{Results Kühroint}

The overall accuracy of the SnowModel results is very well for Kühroint. The convergence of modelled and measured results is good. The model is within $10 \%$ error at seven of 15 sample points. It underestimates the snow depth by more than $10 \%$ in average for six points and overestimates the snow depth by more than $10 \%$ in average for two points. The distribution of the sample points is visualized in fig. 48. It can be seen that the snow depth is especially underestimated by the model for the sample points in the north eastern part, whereas the results at the centre and at the western parts fitting very well to the measurements. 


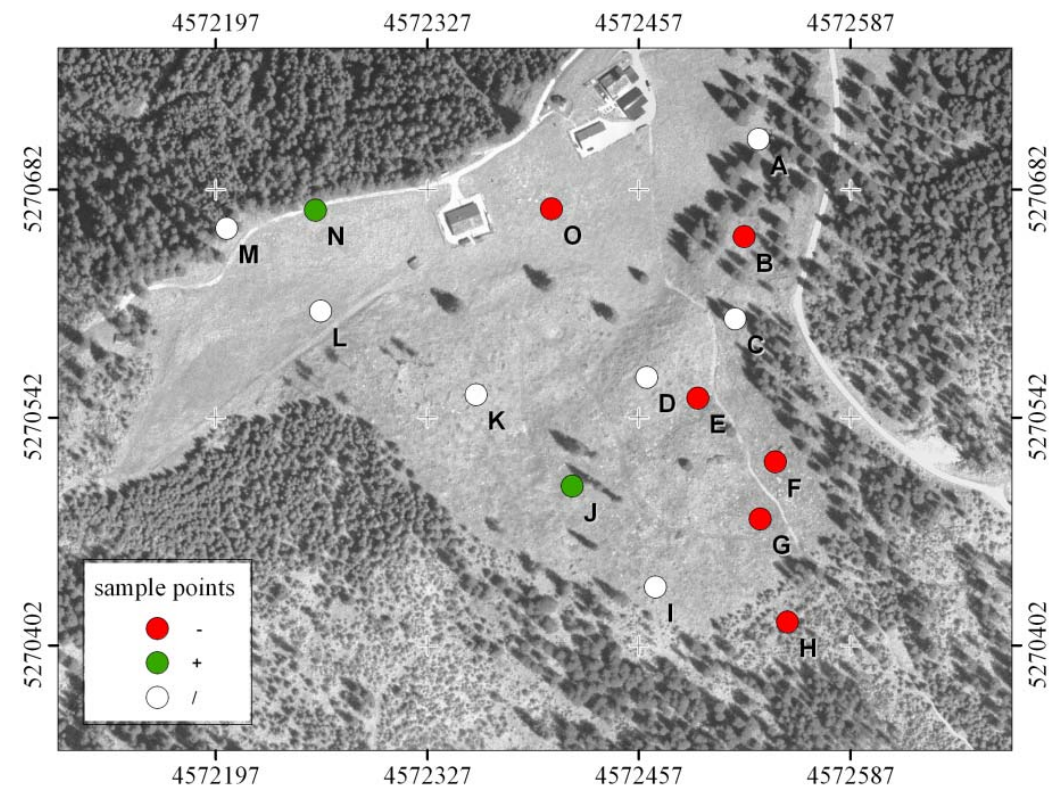

Figure 48: Comparison of model and measurements. White dots indicating that the model is within $10 \%$ of the measurements. Green dots stand for a model overestimation of the snow depth from more than $10 \%$, red dots for a model underestimation from more than $10 \%$.

The results shown in table 6 corresponding to them found at the test site Reiteralm. The standard deviations of the measurements are again higher than these of the model results. The predicted values lie between $31 \mathrm{~mm}$ and $43 \mathrm{~mm}$ (tab. 6). The range of the values is smaller than that detected for the measurements at Reiteralm $(12 \mathrm{~mm})$. The predicted standard deviations for the SnowModel results are especially small at the first five dates (around $4 \mathrm{~mm}$ ) and reach up to $17 \mathrm{~mm}$ for the succeeding dates.

Table 6: The table shows the standard deviations of the measurements and of the respective model results for the observation dates.

\begin{tabular}{l|l|l|l|l|l|} 
& 08.02 .04 & 15.02 .04 & 22.02 .04 & 02.03 .04 & 08.03 .04 \\
\hline Measured & $37 \mathrm{~mm}$ & $36 \mathrm{~mm}$ & $31 \mathrm{~mm}$ & $32 \mathrm{~mm}$ & $40 \mathrm{~mm}$ \\
\hline Modelled & $4 \mathrm{~mm}$ & $5 \mathrm{~mm}$ & $4 \mathrm{~mm}$ & $4 \mathrm{~mm}$ & $4 \mathrm{~mm}$ \\
\hline
\end{tabular}

\begin{tabular}{l|l|l|l|l|l|} 
& 15.03 .04 & 22.03 .04 & 29.03 .04 & 12.04 .04 & 19.04 .04 \\
\hline Measured & $37 \mathrm{~mm}$ & $33 \mathrm{~mm}$ & $36 \mathrm{~mm}$ & $43 \mathrm{~mm}$ & $36 \mathrm{~mm}$ \\
\hline Modelled & $17 \mathrm{~mm}$ & $15 \mathrm{~mm}$ & $13 \mathrm{~mm}$ & $16 \mathrm{~mm}$ & $14 \mathrm{~mm}$ \\
\hline
\end{tabular}




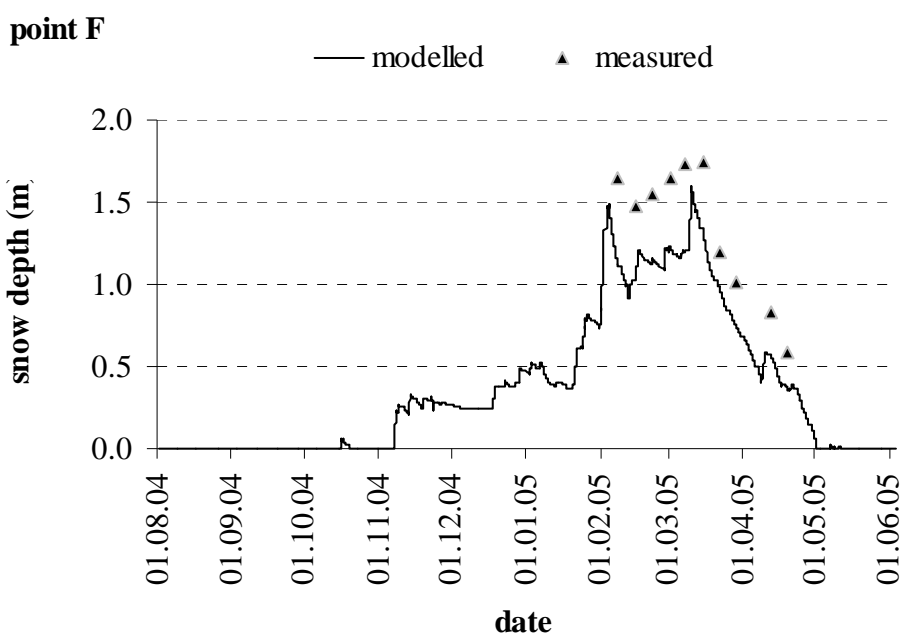

point $\mathbf{N}$

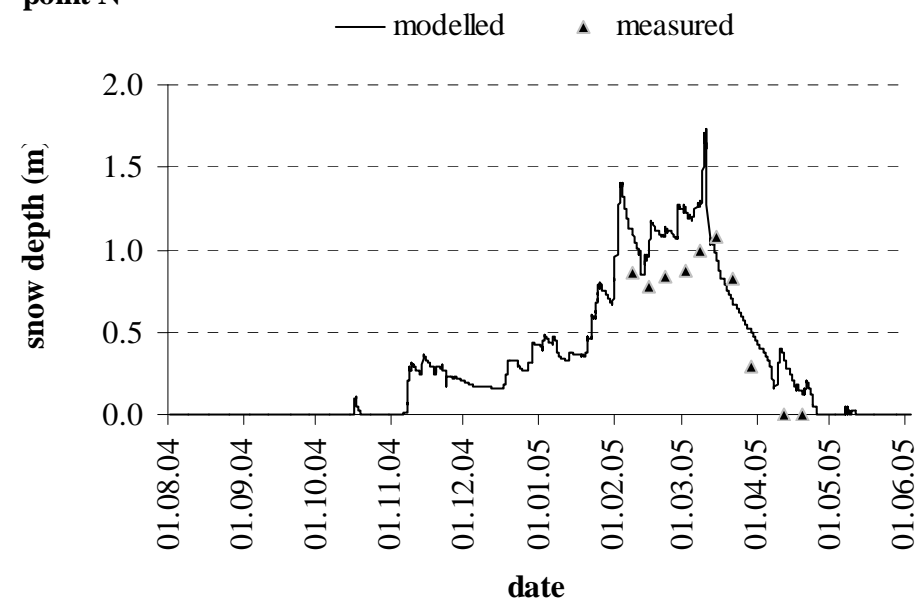

point K _ modelled _ $\quad$ _ measured

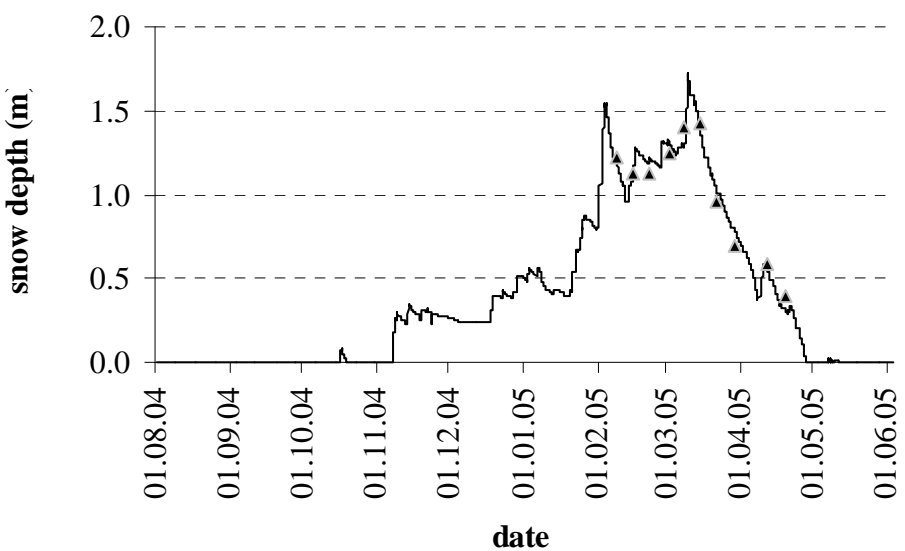

Figure 49: Three representative points at Kühroint. Point N) is located at the edge of the forest at the northern part of Kühroint; point F) is located at the clear cut area, and point K) can be found on the meadows in the western part of the area. 
Figure 49 shows three sample points at Kühroint. Point N) is located at the edge of the forest at the northern part of Kühroint; point F) is located at the clear cut area, and point K) can be found on the meadows in the western part of the area. The three points represent the range of model results of snow depth versus observational data: maximum overestimation $\mathrm{N}$ ), best fit K) and maximum underestimation F). It is important to note that there are almost no differences in amount and timing of snow transport between the MM5 wind fields and interpolated wind fields, for the observed winter season. This proves the applicability of the MM5 wind fields, because the wind speed and direction measured by the meteorological station Kühroint can be seen as representative for the whole clearance. As a result, the MM5 wind fields can be regarded as representative for Kühroint.

\subsubsection{Spatial comparison of the model results}

The spatial comparison of the 30m results will be performed on the basis of section 4.1.2. The analysis will show to which extent the model raster resolution influences the general pattern of the snow distribution. Figure 50 a) (model results at $30 \mathrm{~m}$ resolution) seems to be very similar to figure 38 a) (model results at 200m resolution) at first sight. However, other than in the $200 \mathrm{~m}$ model resolution runs, the statistical correlation of elevation and SWE is approximately the same for INTER_30 $\left(\mathrm{r}^{2}=0.94\right)$ and MM5_30 results $\left(\mathrm{r}^{2}=0.93\right)$. This effect can also be seen in Figures 50 b) to d). Both Figures show that there is no significant interrelation between SWE distribution and aspect.

The transport intensities in opposite show a similar distribution to the $200 \mathrm{~m}$ runs with the application of the MM5 wind fields leading to a considerable increase of the transport rates (fig. 51 and fig. 52 a)-f)). But the spatial extent of the areas affected by intensive transport processes is smaller in the micro scale results and does therefore not significantly influence the absolute SWE distribution of the area. A comparison of fig. 38 and 50 illustrates this fact. Furthermore, in comparison to the 200m MM5 results the MM5_30 transport pattern is more heterogeneous and does not show the clear transport tendency from west to east (fig. 51 b) fig. $52 \mathrm{~b}$ ) and d)). For example, transport processes with a south to north component can now be observed at the small crests at the west side of Hochkalter or Watzmann which are stretching from west to east. 


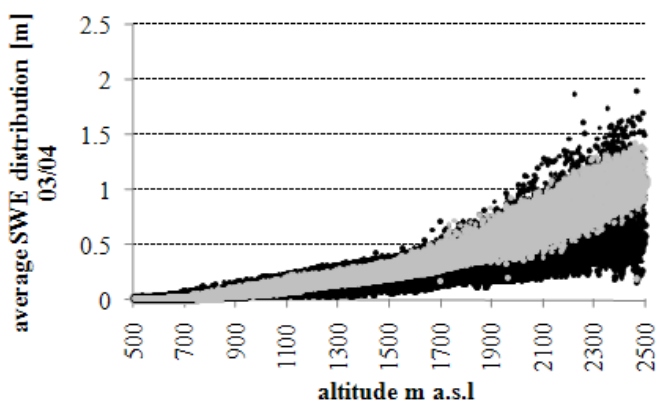

a)

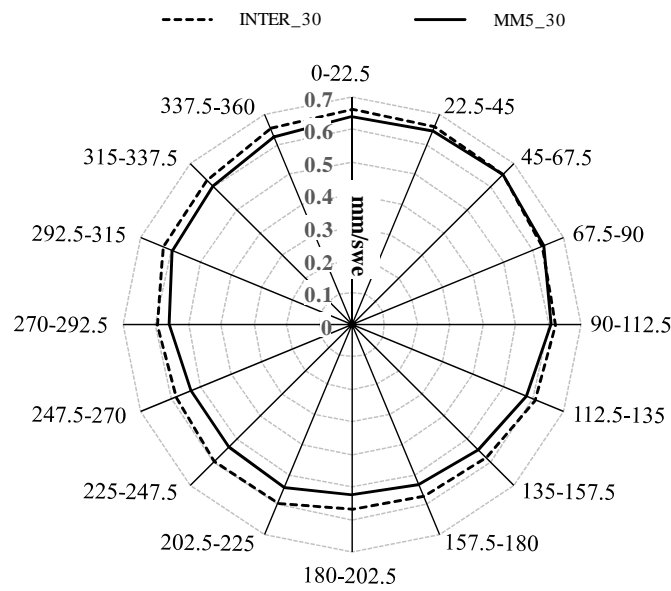

c)

Figure 50: Mean modeled SWE distribution (of INTER_30 and MM5_30) for a) the total area, b) areas above $1800 \mathrm{~m}$ a.s.l. and c) areas above $2200 \mathrm{~m}$ a.s.l. The different volumes under the curves are due to higher sublimation losses within the MM5 runs.

a)

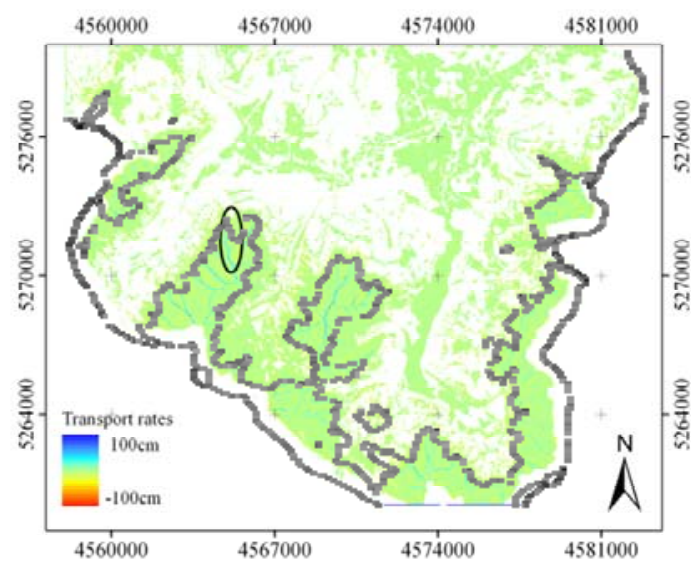

Figure 51: Snow transport rates of a) INTER_30 and b) MM5_30. The black line is the 1800m isohypsis.

b)

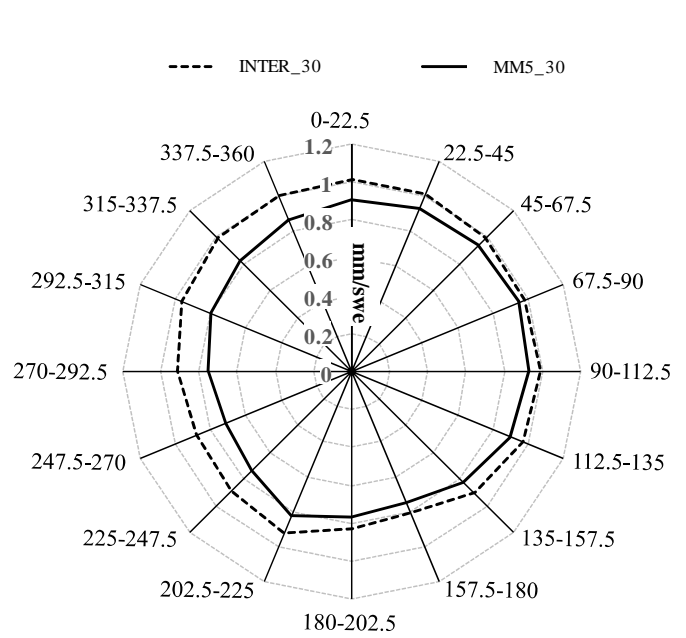

d)

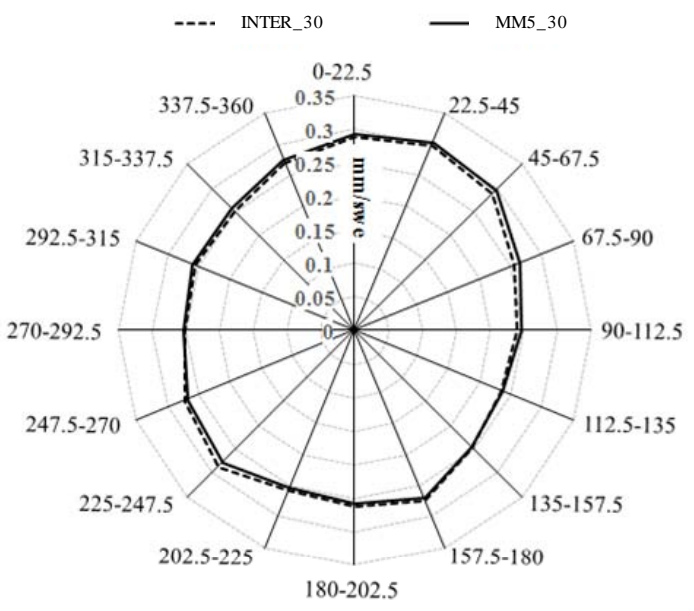


The inclusion of these transport rates in MM5_30 improves the model accuracy (cp. section 4.4.5) in a considerable way.

a)

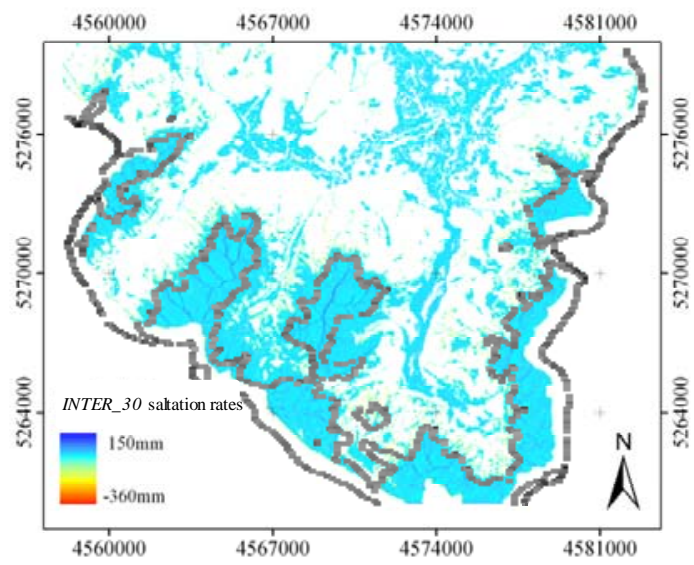

c)

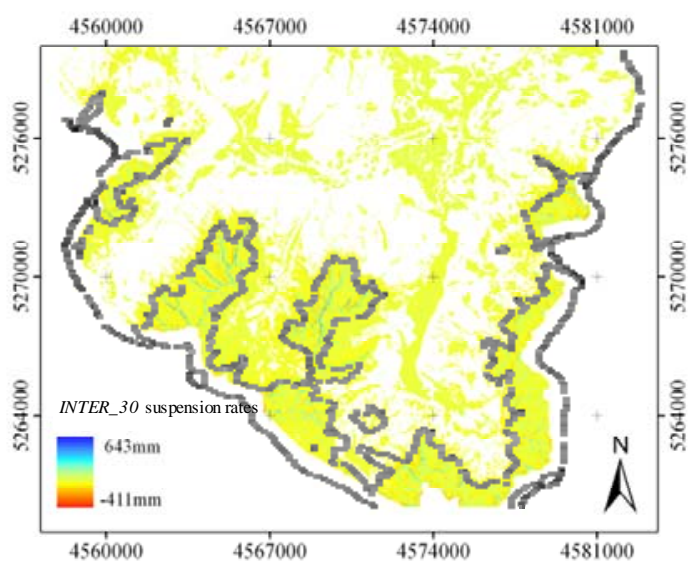

e)

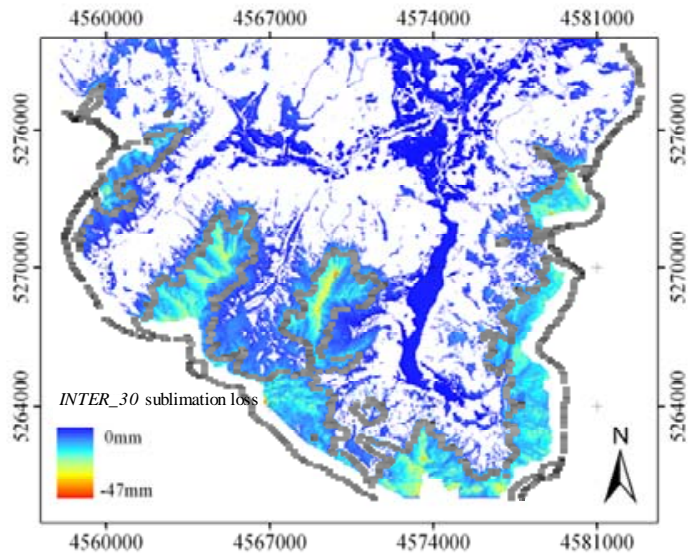

b)

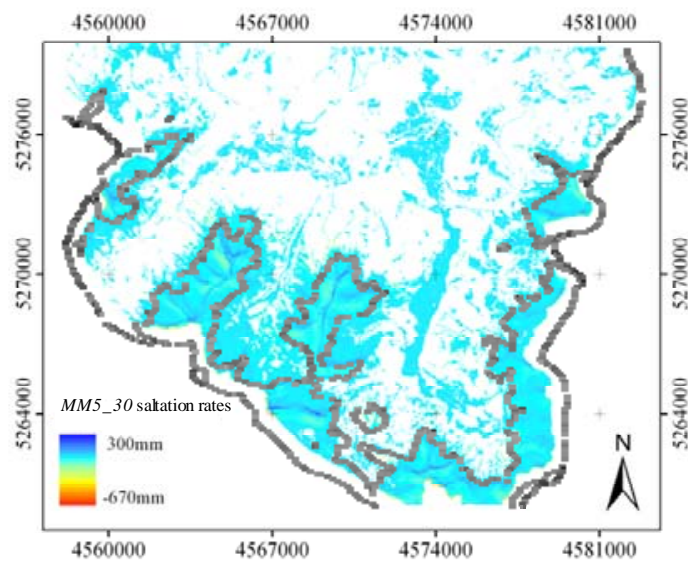

d)

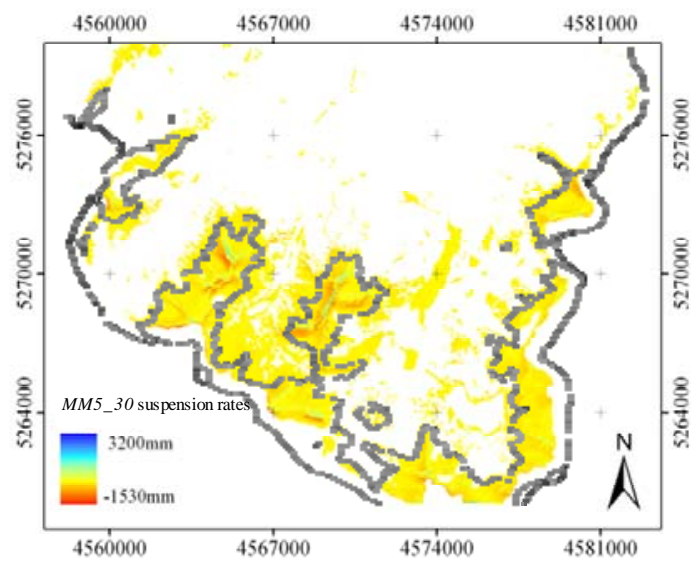

f)

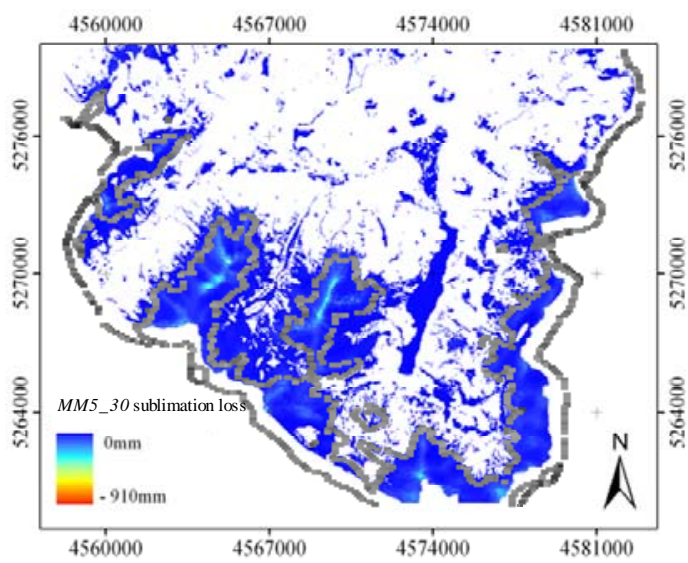

Figure 52: Intensities of the different transport terms: saltation, suspension and sublimation in a) c) e) INTER_30 and b) d) f) MM5_30. The black line is the $1800 \mathrm{~m}$ isohypsis. 
The effect of sublimation processes within the MM5_30 results can be observed in fig. $50 \mathrm{~b}$ ) to d) where the total amount of SWE declines with height compared to INTER_30 which produces transport and sublimation rates that are considerably lower (fig. 52 e) and f)). The maximum modelled sublimation rates are overall slightly higher than those of the 200m MM5 runs $(920 \mathrm{~mm}$ to $860 \mathrm{~mm})$ but the total amount of sublimation for the whole area is significantly smaller $(0.5 \mathrm{~mm}$ to $12 \mathrm{~mm}$ per $30 \mathrm{~m}$ grid cell in average). This is due to the fact that areas with high sublimation rates are limited to the crest regions which have a smaller spatial extent in the high resolution DEM. Figure 53 by Strasser et al. (2008) shows a profile between Hochkalter and Watzmann (cp. fig. 5) with the respective sublimation losses. The yellow curve corresponds to MM5_30 results. It becomes obvious that the influence of sublimation from turbulent suspended snow is comparably small in the valley regions but reaches considerable amounts in the crest regions. This can be explained by the pronounced turbulence resulting from the wind simulations at such exposed locations (fig. 35c).

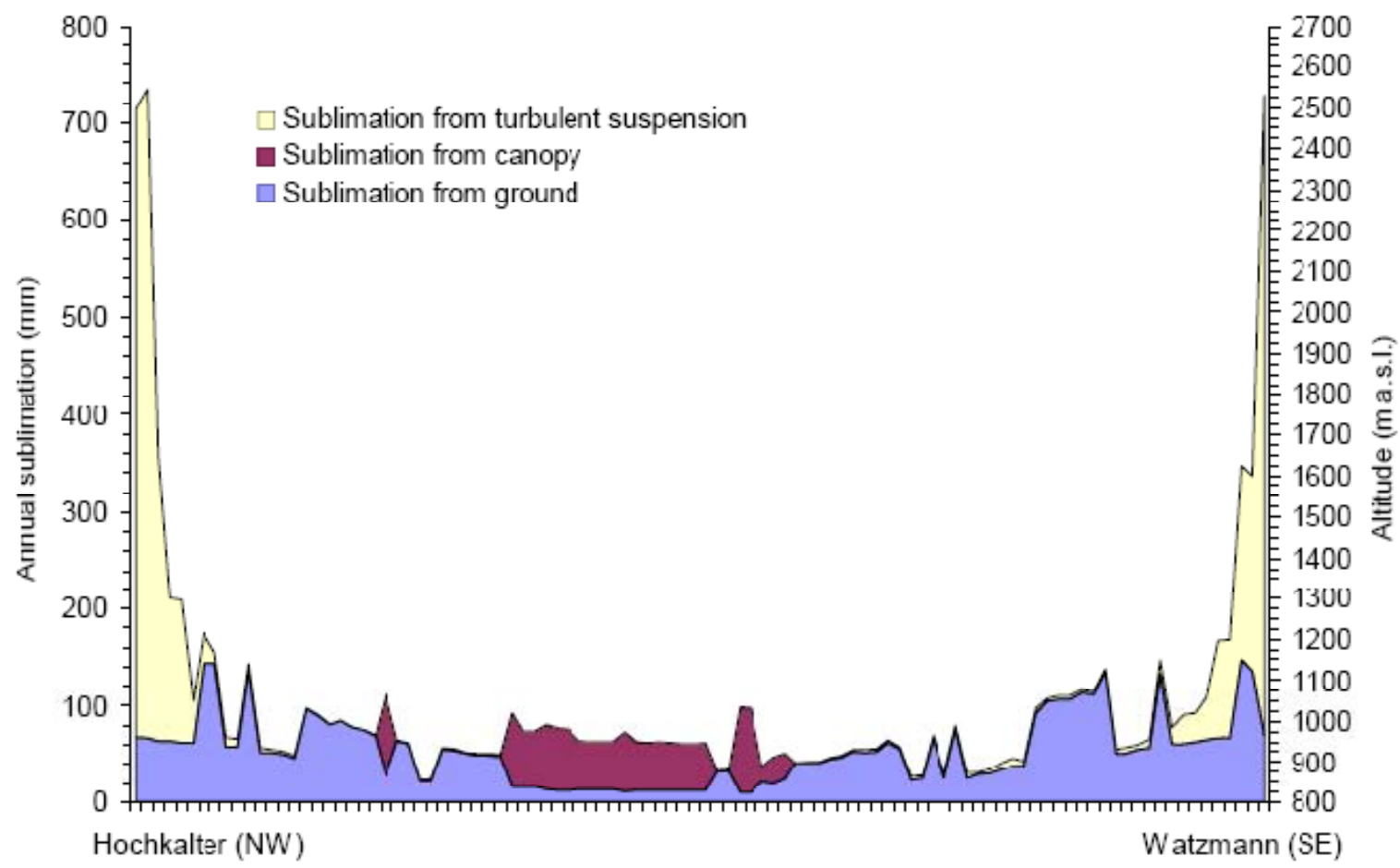

Figure 53: Simulated contributions to annual snow sublimation (additive representation) from the ground, canopy intercepted snow and wind-induced, turbulent suspended snow along a cross-section from Hochkalter (2607m a.s.l.) through the Wimbachtal to Watzmann (2713m a.s.l.). (Strasser et al. 2008). 


\subsubsection{Spatial validation}

The 30m results correspond to the extent and support of the Landsat ETM+ data. Hence, a direct comparison of the data becomes possible. In a first step, the spatial extent of the mapped and modelled snow cover was compared for both available dates. As it is impossible to quantify the SWE distribution via the available optical remotely sensed data a different way to validate the model results was chosen. Areas which are snow free within the Landsat images but are predicted to be snow covered by the model were detected in a first step. After than INTER_30 and MM5_30 SWE depths were compared with a SnowModel stand alone model run (without transport routine) which is called run_baseline from now on. When using the run_baseline results as basis one can determine to which extent the results could be improved by including the blowing snow model algorithm in INTER_30 and MM5_30.

The results of INTER_30 and MM5_30 are virtually identical with respect to the snow line and can be discussed on the basis of the MM5_30 results. A comparison of classified versus modelled snow cover from MM5_30 has shown that the model once again produced a snow cover that was too homogenous (fig. 54 a) to d)). This can be attributed to an inability of the model to reproduce the extent of the real transport rates or to the fact that the model is not able to predict all processes leading to the real distribution. Which of these two reasons is more likely to be responsible for the underestimation of the snow cover distribution will be discussed later on. As a first step, the extent of the predicted snow cover from MM5_30 was compared to the remotely sensed data. 86 percent of the model grids are in agreement with the produced snow map for April 28, 2004 and 88 percent for May 30, 2004. 5 percent of the pixels are classified as snow but do not show a snow cover within the modelled data on April 28, 2004 (4 percent at Mai 30) while 9 percent (for both dates) of the modelled grid cells are predicted to be snow covered but are snow free within the classification (fig. 54 e)-f)). 
a)

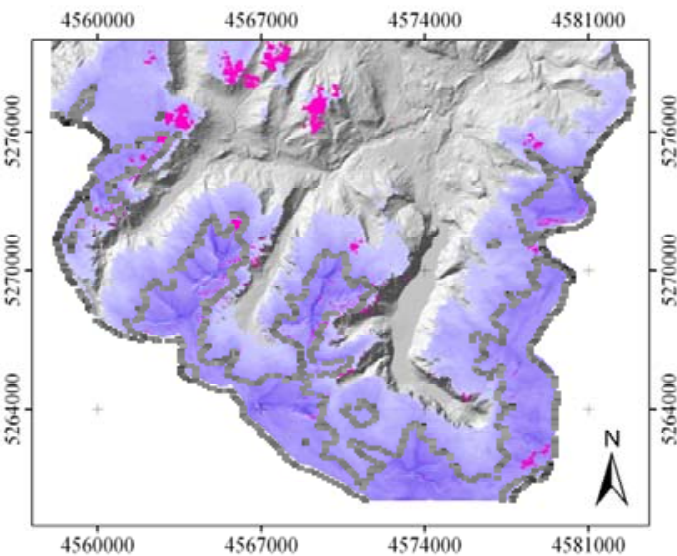

C)

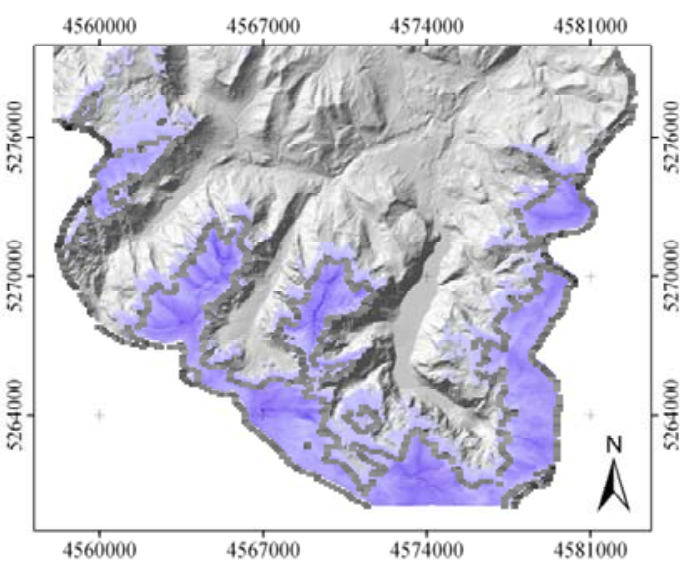

e)

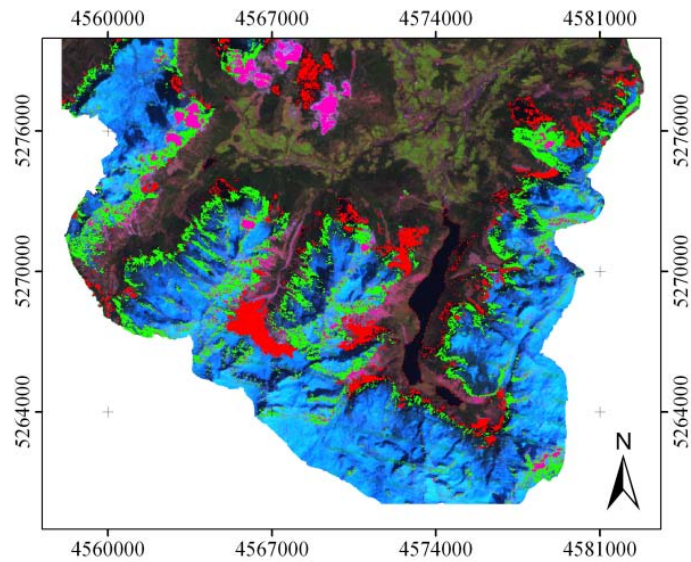

b)

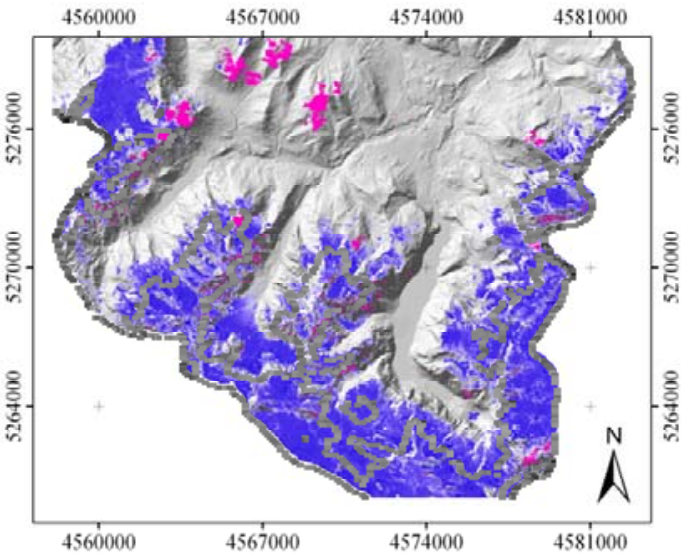

d)
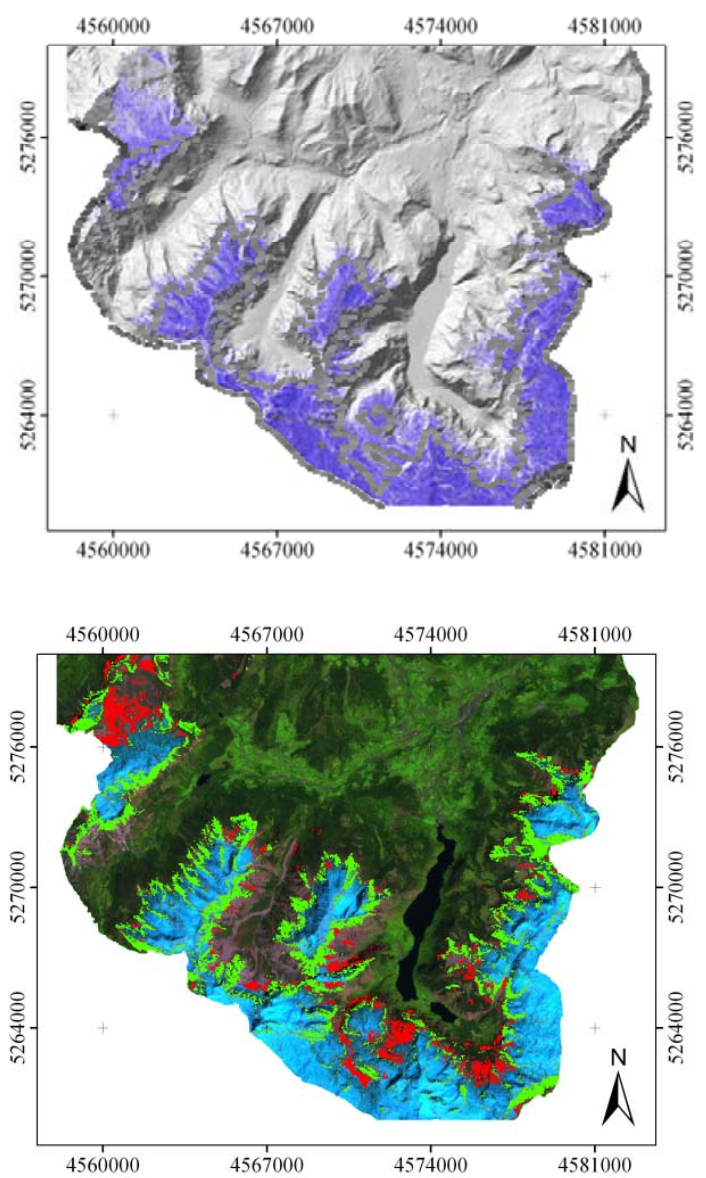

Figure 54: a) modelled snow cover of April 28, 2004, b) NDSI map of the same date, c) modelled snow cover of Mai 30, 2004 b) NDSI map of Mai the same date, e/f) Differences between model an classification results at April and Mai respectively (red indicates: only classified snow cover. Green: only modelled snow cover. Pink: cloud mask). The black line is the $1800 \mathrm{~m}$ isohypsis.

In a subsequent step, nine validation areas were selected within the Landsat April image and six for the May image (fig. 55 and fig. 56, Table 7 and 8). The criteria for the selection was that the respective areas are snow free in the satellite images while they are snow covered in 
the model results. The values shown in Table 7 and 8 are averages for the whole test areas Results show that run_baseline is overestimating the SWE depth significantly on April 28, 2004 and slightly on May 30, 2004 (tab. 7 and 8). It is also obvious that INTER_30 does not lead to a significant improvement of the results. Moreover, it could be seen that the accuracy of the results can even decline in INTER_30 (tab. 7: area 7 and 9; tab. 8: area 2). MM5_30 on the other hand shows improvements for all results and at all dates. On April 28 the results were improved by approximately $23 \%$ while results on May 30 were improved $60 \%$ in average when using the MM5 wind fields (MM5_30).

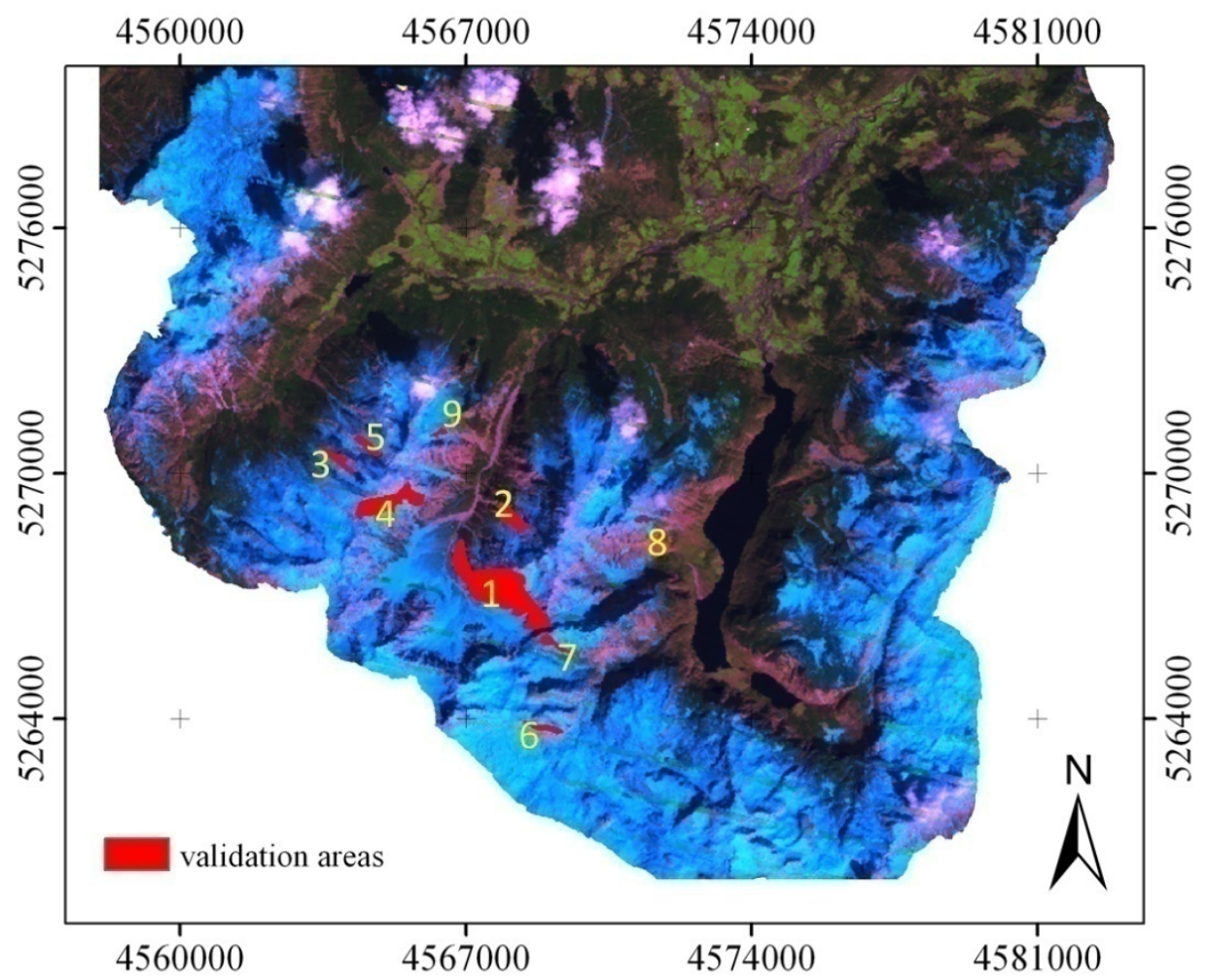

Figure 55: validation areas of April 28, 2004; Blue: Snow covered regions (Bands: 5,4,3), Red: test areas.

Table 7: Comparison between SnowModel results generated with SnowTran-3D and with as well as without the usage of MM5. The values belonging to the areas highlighted in Figure 55. The areas are snow free in reality, the values within the table showing the improvement of the SnowModel results when the transport routine is used.

\begin{tabular}{c|ccccccccc}
\hline $\begin{array}{c}\text { Improvement } \\
\text { when using: }\end{array}$ & Area 1 & Area 2 & Area 3 & Area 4 & Area 5 & Area 6 & Area 7 & Area 8 & Area 9 \\
\hline \hline INTER_30 \% & $5 \%$ & $3 \%$ & $3 \%$ & $0 \%$ & $2 \%$ & $2 \%$ & $-100 \%$ & $0 \%$ & $-2 \%$ \\
MM5_30 \% & $28 \%$ & $26 \%$ & $9 \%$ & $16 \%$ & $30 \%$ & $26 \%$ & $12 \%$ & $22 \%$ & $26 \%$ \\
\hline INTER_30 SWE & $-3 \mathrm{~mm}$ & $-2 \mathrm{~mm}$ & $-1 \mathrm{~mm}$ & 0 & $-2 \mathrm{~mm}$ & $-2 \mathrm{~mm}$ & $+132 \mathrm{~mm}$ & $0 \mathrm{~mm}$ & $+2 \mathrm{~mm}$ \\
MM5_30 SWE & $-18 \mathrm{~mm}$ & $-20 \mathrm{~mm}$ & $-3 \mathrm{~mm}$ & $-18 \mathrm{~mm}$ & $-26 \mathrm{~mm}$ & $-23 \mathrm{~mm}$ & $-16 \mathrm{~mm}$ & $-22 \mathrm{~mm}$ & $-21 \mathrm{~mm}$ \\
\hline
\end{tabular}




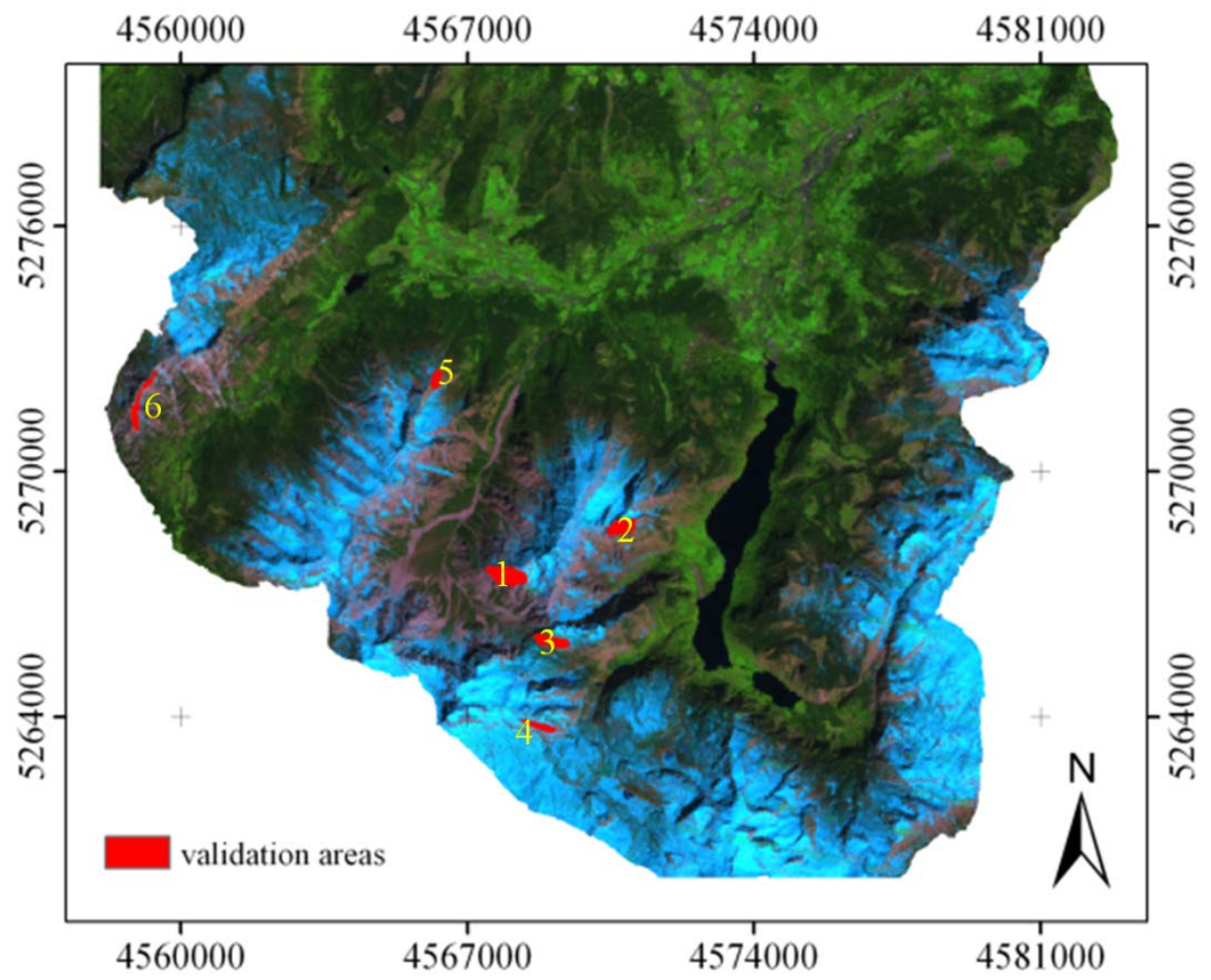

Figure 56: validation areas of Mai 30, 2004; Blue: snow covered regions (Bands: 5,4,3), Red: test areas.

Table 8: Comparison between SnowModel results generated with SnowTran-3D and with as well as without the usage of MM5. The values belonging to the areas highlighted in Figure 56. The areas are snow free in reality, the values within the table showing the improvement of the SnowModel results when the transport routine is used.

\begin{tabular}{c|cccccc}
\hline $\begin{array}{c}\text { Improvement when } \\
\text { using: }\end{array}$ & Area 1 & Area 2 & Area 3 & Area 4 & Area 5 & Area 6 \\
\hline \hline INTER_30 \% & $0 \%$ & -2 & $1 \%$ & $0 \%$ & $1 \%$ & $12 \%$ \\
MM5_30 \% & $80 \%$ & $46 \%$ & $63 \%$ & $55 \%$ & $35 \%$ & $86 \%$ \\
\hline INTER_30 SWE & $0 \mathrm{~mm}$ & $+2 \mathrm{~mm}$ & $-1 \mathrm{~mm}$ & $0 \mathrm{~mm}$ & $-1 \mathrm{~mm}$ & $-2 \mathrm{~mm}$ \\
MM5_30 SWE & $-78 \mathrm{~mm}$ & $-43 \mathrm{~mm}$ & $-39 \mathrm{~mm}$ & $-84 \mathrm{~mm}$ & $-30 \mathrm{~mm}$ & $-31 \mathrm{~mm}$ \\
\hline
\end{tabular}




\section{Chapter 5: Discussion of the SnowModel results}

Validating wind fields and snow transport processes in mountainous areas is a highly difficult and mostly impossible task (Klemes 1988). The limited accessibility of high alpine and crest regions, which are most interesting for model validation, leads to a remarkable lack of validation data which can only be overcome if one has "a team of Olympic skiing heroes available for the field campaign” (Klemes 1988). Remotely sensed information can balance this deficit to some degree but generally also shows deficiencies in areas with steep topography or forested regions (Klemes 1988, Hall et al. 1995). Because of these difficulties, a detailed validation of the spatial SWE distribution is virtually impossible. Hence, the performance of the model was checked where validation data was available and only the qualitative plausibility of the results is discussed for locations where no validation data was available.

\subsection{Accuracy of SnowModel at the point scale}

To evaluate the advantages of using physically based MM5 wind fields in snow transport modelling, SnowModel results generated with and without transport routine using interpolated wind fields were used as baseline. Subsequently these baseline results were compared to coupled SnowModel/MM5 results and to observed snow data. Furthermore, the scaling effect when using resolutions of $30 \mathrm{~m}$ and $200 \mathrm{~m}$ resolution is discussed. In a first step, the results of the sections 4.1.1 and 4.3.1 are summed up.

A first validation was performed by using comparisons between measured and modelled snow depths. Results at the micro and meso scale have shown a good correlation to field measurements and remotely sensed data. The correlations between measurements and model results are at a satisfying level (fig. 47 a)-c)) for all available snow measuring points (MM5/INTER $\mathrm{r}^{2}=0.85 / 0.73$ [Reiteralm II], $\mathrm{r}^{2}=0.88 / 0.88$ [Reiteralm III] and $\mathrm{r}^{2}$ 0.73/0.64 [Jenner]]). The overall accuracy of the results corresponds to the results presented in other studies (cp. Liston et al. 2007). When considering the operational snow depth measurements of the meteorological stations and the field campaign data, the performance of the coupled 
MM5 and MM5_30 model was identical or better than INTER or INTER_30 results using interpolated fields (fig. 47 a) to c)). The validation has shown that MM5_30 is able to reproduce the measured snow depth at Reiteralm and Kühroint in a satisfying way but the modelled variability between the different measuring points was still too small (ср. section 4.3.1 and 4.3.2, tab. 5 and 6). Transport processes from the higher to the lower part of Reiteralm could not be displayed. Further analysis revealed that this is due to the forest which subdivides Reiteralm into two parts. The model treats this forest as a physical barrier which blocks snow transport. The introduction of the vegetation class sporadic trees resulted in no improvement. This can be attributed to the general model setup. So, a simple reduction of the snow holding capacity (fig. 11) makes more snow available for transport but cannot solve the existing lack within the model formulations. The model predicts a boundary layer wind speed which is modified by eq. 21. The wind speed is reduced in accordance to the LAI of the vegetation type of the respective model grid. The used LAI has been derived from a combination of forest inventory data, a colour infrared photo interpretation, as well as by application of these relations by Hammel and Kennel (2001) and is therefore a fixed value. A usage of the given $L A I$ values at Reiteralm leads to calculated wind speeds which are by far too low for initialising snow transport events from the higher to the lower area of this site. For accounting for the real process, namely snow transport over the forest land cover, two different wind velocity layers would be required within SnowModel but only one is available. The needed input wind fields would be available as the second model layer of MM5 can deliver the needed information.

The results at Kühroint have demonstrated that SnowTran-3D/MM5 can reproduce notransport conditions at a wind sheltered site, but the variability observed between the different measuring points was again underestimated by the model (cp. section 4.3.2, fig. tab. 5 and 6). In correspondence to the results at Reiteralm, the overall variance of the modelled data is too small with respect to the snow depth differences between the sample points. This might be due to the DEM used in this study which describes Kühroint, which is undulated in reality, as an almost completely flat area.

The DEM at Kühroint was checked because of model runs which produced an unexpectedly homogenous snow distribution. The analysis revealed some inaccuracies within the data, 
which were unfortunately only detected after the progression of the field campaign. It became evident that the small knolls in the area are not displayed in the DEM even in its original $10 \mathrm{~m}$ resolution. The inner area of Kühroint is portrayed as absolutely flat within the DEM which does not correspond to the reality.

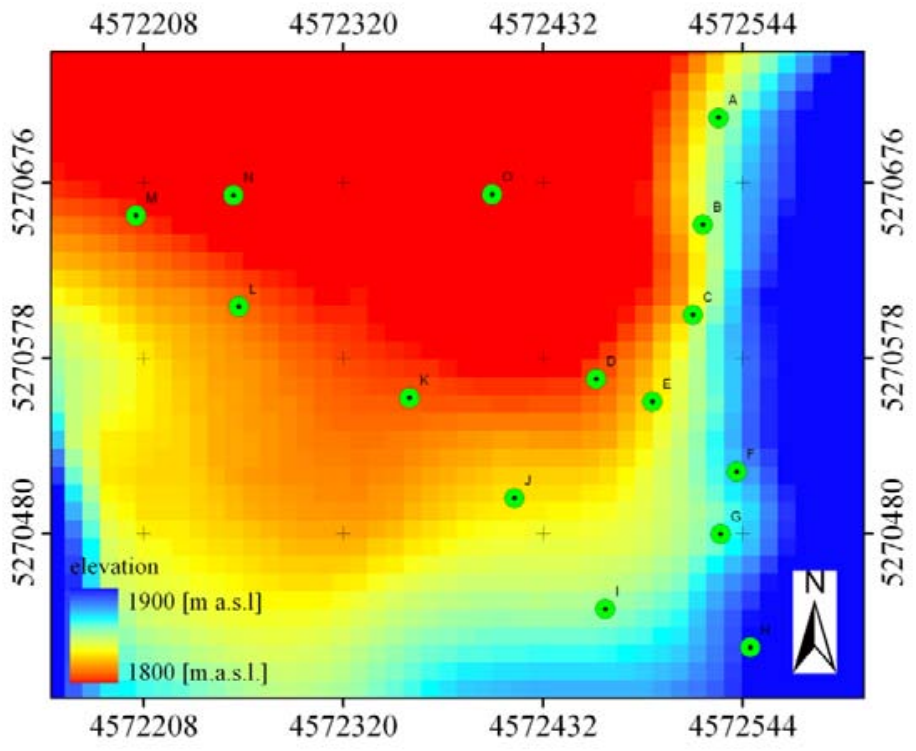

Figure 57: DEM of Kühroint test site. The area which is undulated in reality but flat in the DEM involves points D), K), L), M), N), O).

Considering this, the model results are meaningful because as the $D E M$ is used for distributing meteorological variables the model estimates an even distribution of the different meteorological variables for Kühroint. As this is the case the calculated snow cover is also homogenous and does not show significant differences in snow depth or SWE. However, the example shows that the generation of topographical input parameters can be problematic in Alpine regions and can therefore represent a source for deviations between model and measurements. A faithful investigation, if these errors are widespread within the data or if they are only observable at a few locations was impossible because of a lack of reference data. These will be available in the coming years since a $1 \mathrm{~m}$ resolution DEM is in preparation for the National Park and will be available for future investigations (personal communication $\mathrm{H}$. Franz 2007). 


\subsection{Accuracy of SnowModel with respect to remotely sensed data}

In regard to the spatial distribution of the snow cover, the inclusion of the MM5 wind fields leads to an overall more heterogeneous SWE distribution. The SWE becomes less dependent on elevation (fig. 38 a) and 50a)) and an efficient transport of snow from the windward to the leeward sides of mountains was predicted (fig. 39 and 52). This is in agreement with expectations and with the work of other authors (e.g. Barry 1992). The overall transport efficiency was considerably higher for all transport terms when using MM5 wind fields (fig. 38 and 50) especially for elevations higher than 1800m a.s.l. where the MM5 wind speeds were significantly higher (fig. 35c).

a)

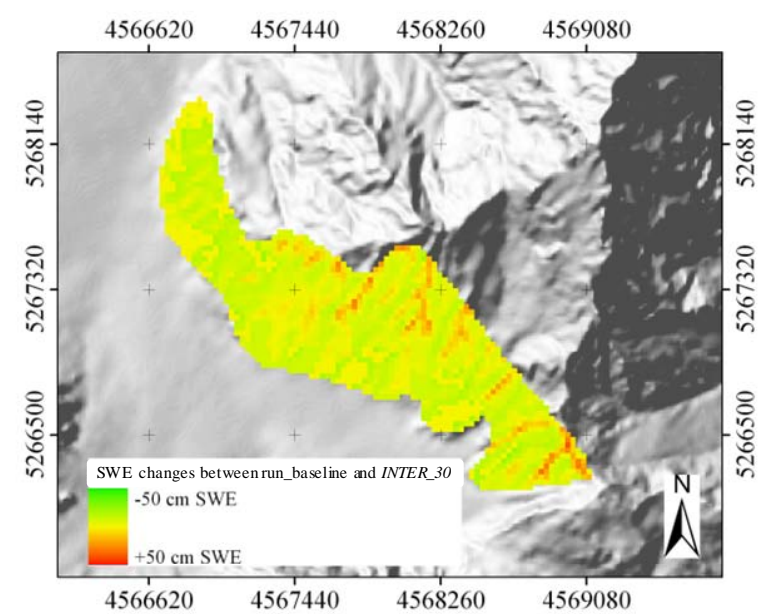

c)

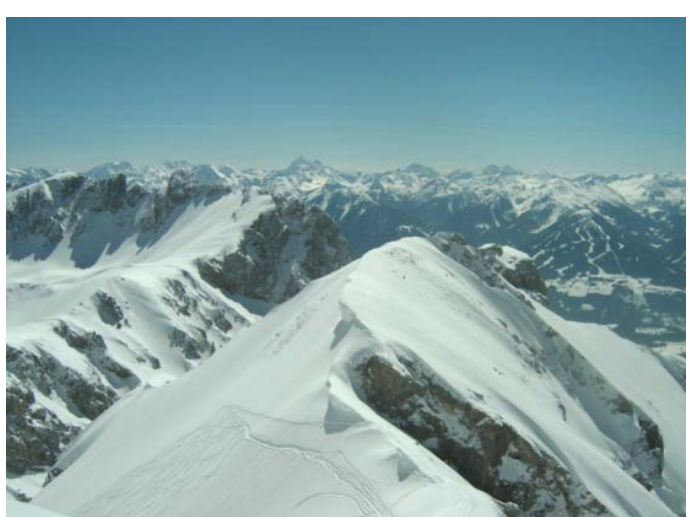

b)

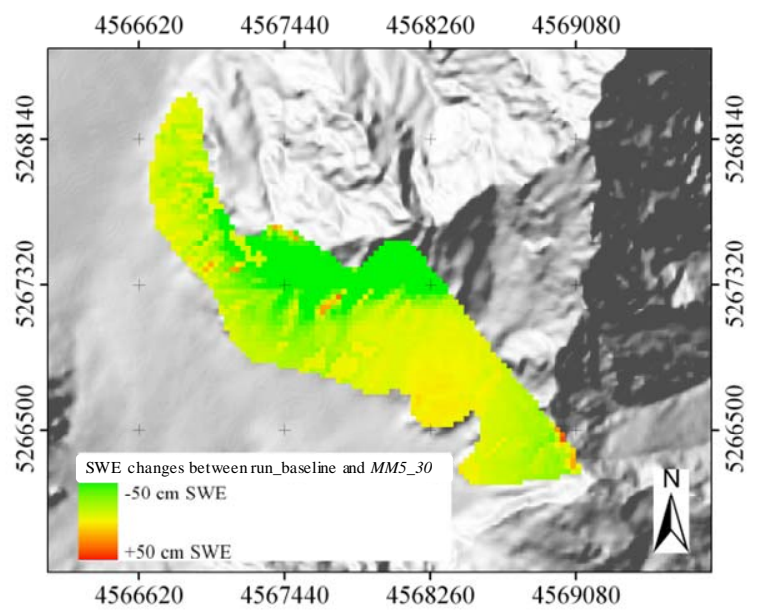

Figure 58: a) Comparison of run_baseline and INTER_30 results on April 28, 2004, b) comparison between run_baseline and MM5_30 at the same date. c) Picture of a crest were the snow cover on the windward side (right) is reduced considerably by snow transport processes 
The generated, more heterogenic snow cover also shows a better agreement with the remotely sensed data, with respect to the spatial heterogeneity of the snow cover (tab. 7 and 8). This was proven for areas which are snow free in the satellite pictures but snow covered in the model results. Analysis of these test areas shows that the reduction of the SWE depth of INTER_30 in comparison to run_baseline shows no clear trend or pattern over the areas (ср. fig 58 a); tab. 7) and 8). Moreover, it could be seen that the snow is mainly redistributed within the areas but not transported out of the areas when using INTER_30. This is caused by the comparatively low interpolated wind speeds and unrealistic wind direction fields used in INTER_30. Hence, the snow is sometimes transported back and forth and not into a specific direction. In contrast, the results of MM5_30 show a trend within the spatial pattern; the SWE depth is particularly reduced at higher elevations and in the direction of the next crest (fig. 58b). This conforms to observations one can make in nature (fig, 58 c)) where it can be seen that the SWE depth are especially reduced on the windward side of the crest regions (fig. 55 c)).

The integration of the MM5 wind fields can improve the results at the point scale and in comparison to the satellite images, as SnowTran-3D in combination with interpolated wind fields can also reduce the accuracy of the results (tab. 7 and 8). This indicates that the MM5 wind fields are more trustable at least in Alpine settings than the interpolated MicroMet fields which are generally used in the application of SnowModel. The more accurate wind direction fields provided by MM5 furthermore prevent the calculation of accumulation zones that do not correspond to zones that can be observed in nature (tab. 7 and 8).

According to Hall et al. (1995) it can be stated that wooded areas are limiting the usability of remotely sensed data as validation tool in snow sciences. Trees obscure the underlying snow cover and make a reliable detection of the snow cover/line impossible. This effect is especially pronounced in the study area because the snow line is located in wooded areas on all satellite image acquisition dates. 

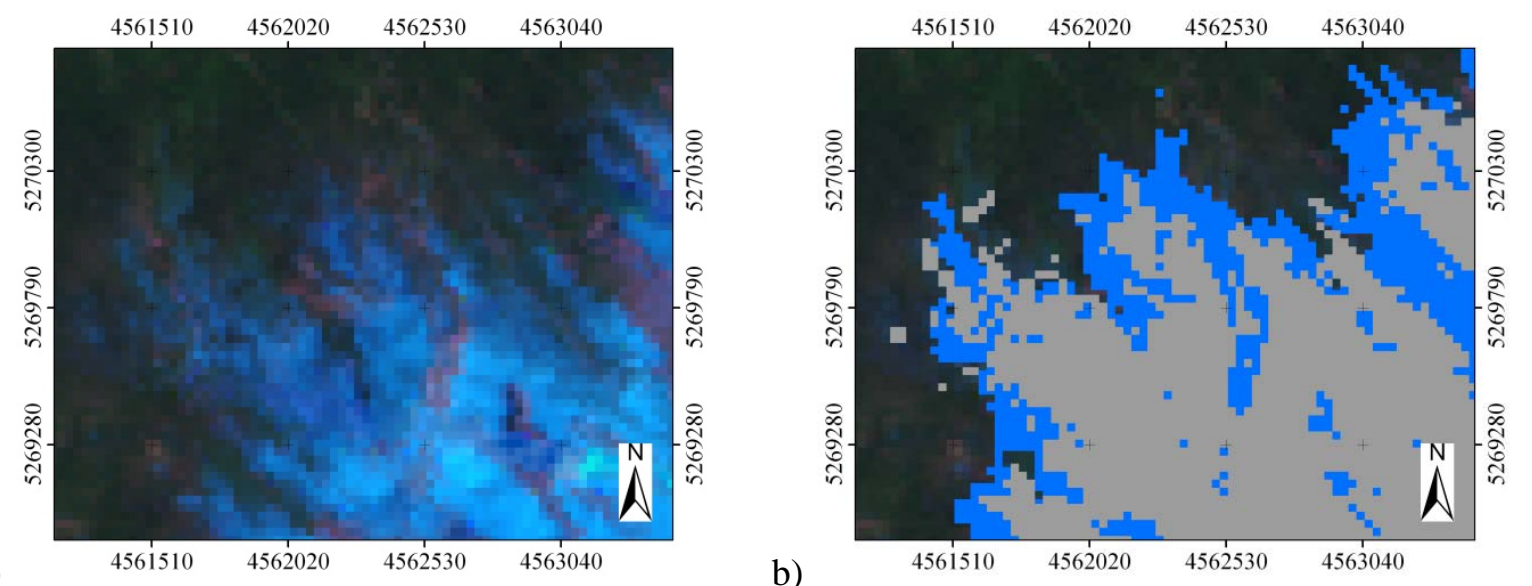

a)

b)

Figure 59: a) wooded region at Watzmann mountain (the snow covered area appears in blue). b) NDSI classification in gray, MM5_30 results in blue.

A visual comparison of model and classification results indicates that an assessment if the model or the classification results are more accurate is difficult or simply impossible in the respective regions. Figure 59 can serve as an example for this dilemma. The model has predicted a snow cover which is of a larger expanse than the classified one (this reflects the situation for the whole area). A visual analysis of the satellite scene has shown that the snow line seems to be somewhere between the model and classification results (fig. 59 a) and b)). An adaption of the NDSI threshold for including these local phenomena only leads to a partial improvement of the results but decreases the accuracy of the total classification. It is therefore difficult to assess the accuracy of the model results with respect to the snow line with the help of the available satellite data. Nevertheless, the modelled snow line is always close to the classification in case which indicates that the extent of the modelled snow cover has the correct dimension.

\subsection{Scale effects in snow transport modelling}

The influence of wind induced snow transport on the spatial distribution of the SWE is more significant with respect to the total area at the meso scale. Figures $38 \mathrm{~b}$ ) to d) indicate that the SWE distribution within the test site becomes heavily dependent on wind induced snow transport processes from $2200 \mathrm{~m}$ a.s.l. on. This effect was not reproduced in the micro scale results. Rather, they suggest that wind induced snow transport can have a remarkable effect on the snow distribution in limited areas but do not modify the general SWE distribution in the 
test site. This finding is in line with other studies that have stated that general transport intensities can be simulated adequately at coarser scales but the location of individual accumulation and erosion zones can be misinterpreted in a significant way (e.g. Liston et al. 2006). The Blaueis glacier serves as an example. It was found that the amount of transported SWE considerably depends on the selected model scale and wind simulation method. Wind induced transport of SWE form surrounding areas to Alpine glaciers is mentioned as important for their existence (Kuhn 1993, 1995). Especially small kar glaciers like the Blaueis glacier (fig. 5 and fig. 60)) and many other glaciers e.g. in the Karwendel region are dependent on additional SWE delivered by avalanches or wind induced snow transport (Kuhn 1995). Plattner et al. (2006) have applied a statistical analysis of the SWE distribution at Vernagtferner (Tirol/Austria) and have found that the SWE distribution is very likely dependent on the wind conditions and on wind induced snow transport. However, a quantitative estimation of the transported amounts was not possible. The work presented here shows that a numerical calculation of the transported SWE amounts is possible via the presented scheme. Principally, it can be stated that the use of SnowTran-3D does not lead to any transport rates from and to the glacier if interpolated wind fields are used. This finding is independent of the used scale. When MM5 wind fields are used on the other hand, significant transport processes can be observed. The MM5_30 30m runs produce a maximum SWE gain per pixel of $2140 \mathrm{~mm}$ SWE. The average contribution of windblown snow over the total glacier area is $220 \mathrm{~mm}$ SWE. The additional amount of SWE corresponds to $12 \%$ of the total precipitation $(1850 \mathrm{~mm})$ and to $23 \%$ of the snow fall $(950 \mathrm{~mm})$ within the observed period (03/04) (fig. 60a). The 200m runs in contrast produce considerably different results. The maximum per pixel gain is greatly reduced $(740 \mathrm{~mm} S W E)$ and the total average contribution is only $4 \mathrm{~mm} S W E$ (fig. 60b). This can be explained by the fact that because of a scale dependent shift like presented at Reiteralm before (fig. 43 a) and b)) the accumulation zone of the glacier is located in the crest region of Hochkalter within in the 200m DEM. Hence, erosion prevails and the $S W E$ is reduced and not enhanced like it is in the 30m runs. Figure 60 a) and b) show the wind induced gain and loss of SWE for the Blaueis glacier (30m and 200m again). The figures further illustrate that the accurate estimation of the location of the accumulation and erosion zones becomes problematic at coarser scales. 
The results show that the quantitative calculation of wind induced transport of snow from neighbouring areas to adjacent glacier areas becomes possible via the presented scheme at the micro scale. A validation of the transported snow amounts at Blaueis glacier or at other well instrumented glaciers like the Vernagtferner is the subject of future work. The obtained knowledge about gain rates is crucial for a better understanding for accurate mass balance calculations of the respective glaciers.

a)
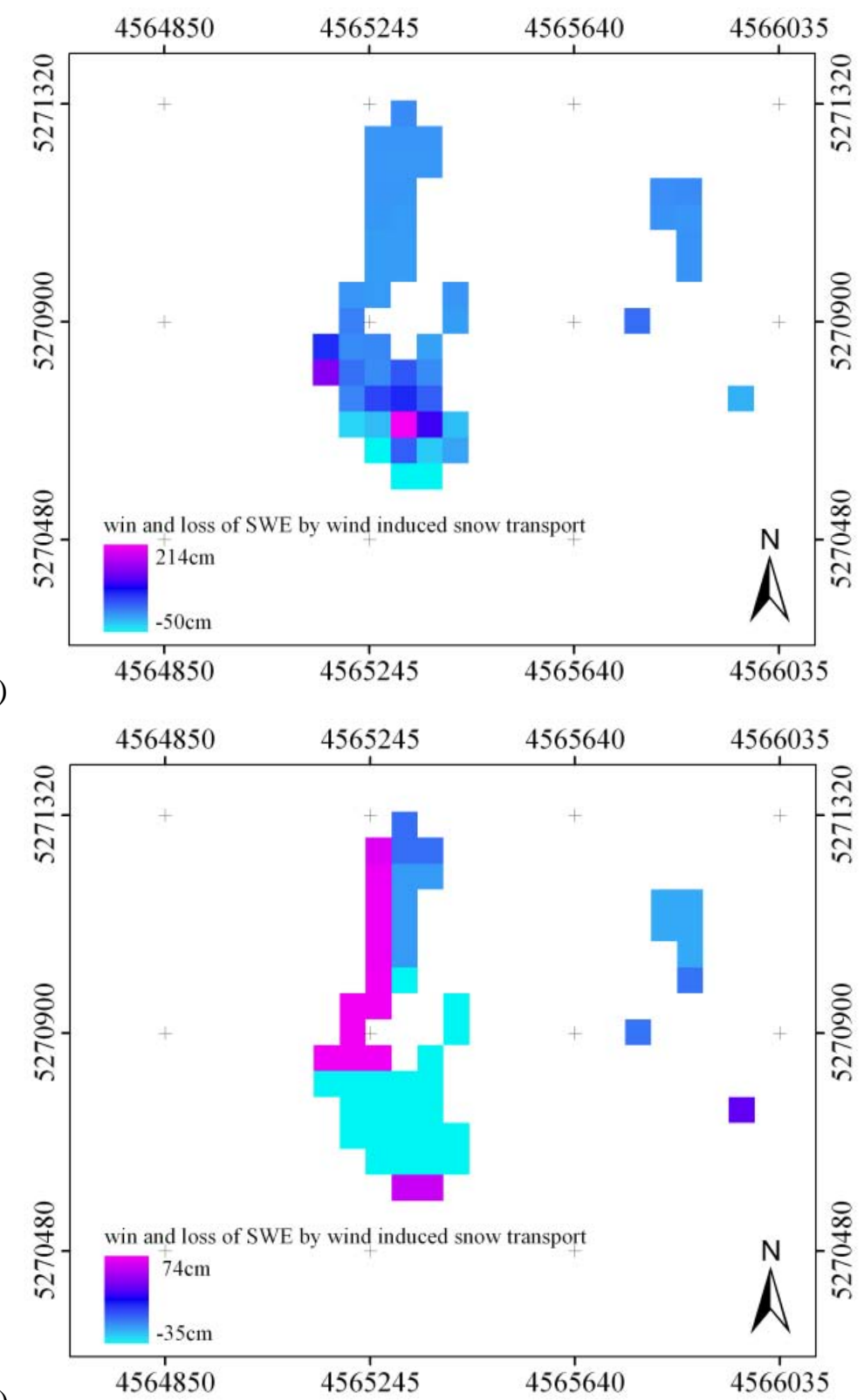

Figure 60: Predicted loss and gain of SWE due to wind induced snow transport at Blaueis glacier a) 30m resolution results using MM5 wind fields, b) 200m resolution results using MM5 wind fields. (The results were fitted to the $30 \mathrm{~m}$ grid for the presentation) 
Very high modelled accumulation rates on the leeward sides of the mountains and remarkable sublimation rates on the mountain crests which could not be directly validated should be and are discussed in the next paragraphs.

\subsection{Discussion of enhanced accumulation and sublimation rates when using MM5 wind fields}

The inclusion of MM5 wind fields leads to remarkable simulated snow depths, on the leeward side of the crests. At Watzmann crest region (predicted precipitation: 3100mm) a maximum SWE depth of about 6000mm (MM5_30 30m results) and 4500mm (MM5 method 200m results) were calculated for the leeward side. These values were not obtained with INTER_30 or with INTER method (the maximum was about $3000 \mathrm{~mm}$ here for both runs $(30 \mathrm{~m}$ and 200m)). A direct validation of the modelled SWE depths is impossible but fig. 61 gives an idea about the conditions at this site and shows that $6000 \mathrm{~mm}$ SWE could probably exist.

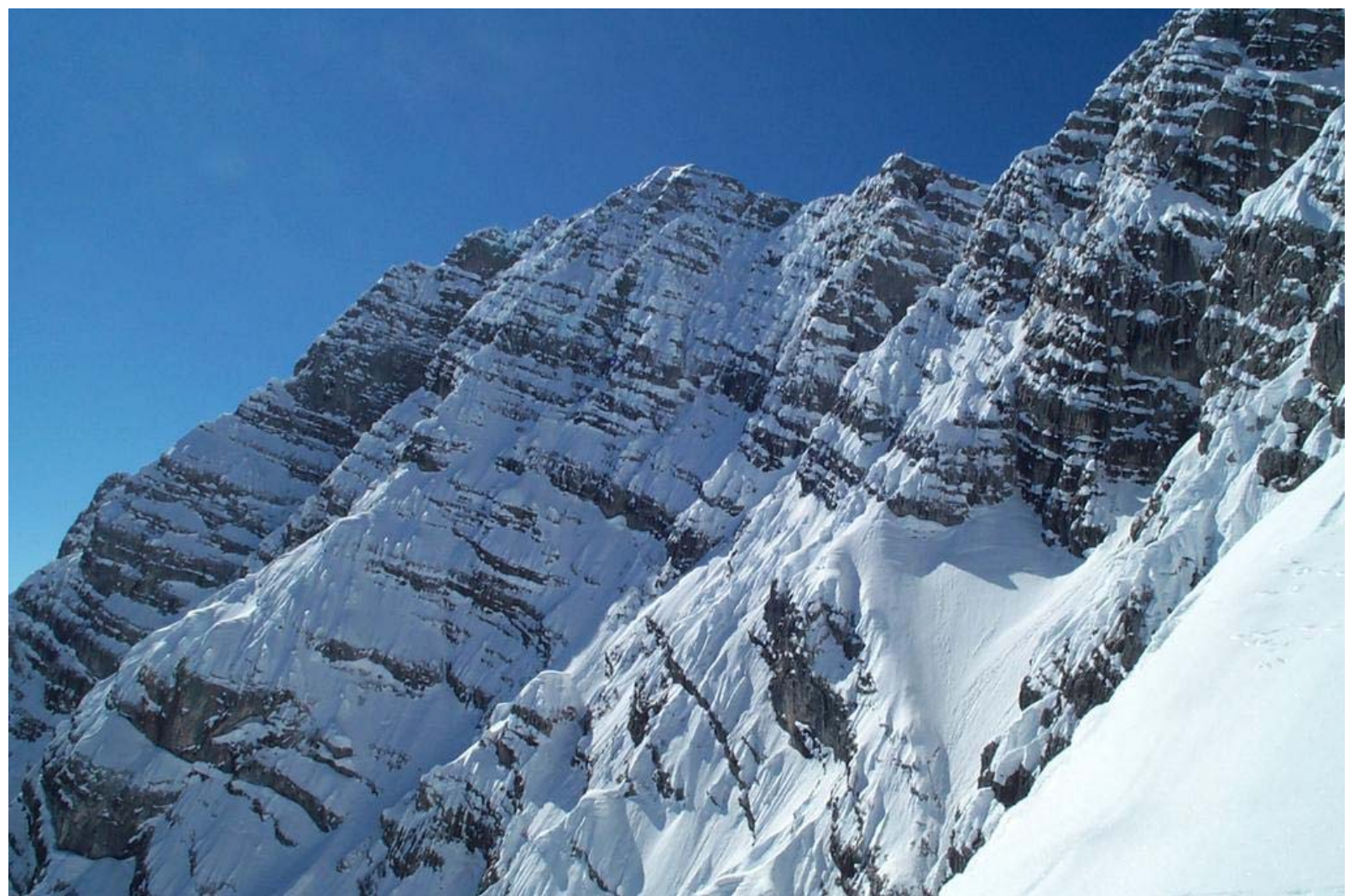

Figure 61: Picture of the Watzmann upper east face under full snow coverage. 
The predicted sublimation rates of up to 910mm (MM5_30) or 860mm (MM5, 200m) (fig. 39 e) and f) and 52 e) and f)) when using the MM5 wind fields are very high and, therefore, need to be discussed.

Total sublimation can be differentiated in three major sources: Sublimation from the ground snow cover (Weber, 2005), loss from previously intercepted snow from within the canopy (Essery et al., 2003), and sublimation of airborne snow particles during blowing snow conditions (Schmidt, 1972; Liston and Sturm, 1998; Pomeroy and Essery, 1999). Strasser et al. (2007) have quantified the effect of all three sublimation processes on the water balance in the Berchtesgaden National Park region (fig. 53 and tab. 9). While the first two of them are mostly driven by the amount of available radiation, the sublimation of airborne snow particles is mainly steered by the transport efficiency at a given place. The formulation of the sublimation process within SnowTran-3D follows that of Schmidt (1972), Pomeroy et al. (1993) and Pomeroy and Gray (1995) were the sublimation rate depends on the amount of snow within the saltation and suspension layer (eq. 32 and 33). The sublimation loss rate coefficient, describing the rate of particle mass loss as a function of height within the drifting snow profile, is a function of temperature-dependent humidity gradients between the snow particle and the atmosphere, conductive as well as advective energy and moisture transfer mechanisms, particle size and solar radiation intercepted by the particle. It is assumed that I) the mean particle size decays exponentially with height, II) the relative humidity follows a logarithmic vertical profile, III) the air temperature in the snow-transport layer is well mixed and constant with height, IV) the variables defined within the saltation layer are constant with height and those in the turbulent suspension layer vary with height, and V) the solar radiation absorbed by snow particles is a function of the solar elevation angle and fractional cloud cover (eq. 9). In SnowTran-3D, high sublimation rates (fig. 39 f) and 52 f)) are projected during blowing-snow events due to the high snow particle surface-area to mass ratios and the high ventilation rates achieved when the particles are in the wind stream (Schmidt 1972), and assuming the existence of a pool of dry air overlying the surface layer with efficient mixing between the two (the model belongs to the "Schmidt-type" family of sublimation models, Liston and Sturm 2004). Using Schmidt-type sublimation models, 15 - 50 \% of the snow cover were found to be returned to the atmosphere by sublimation in the Arctic (e.g., Liston and Sturm 1998, Essery and Pomeroy 1999, Pomeroy and Essery 1999), and 15 - 41 \% in the 
Canadian prairies (Pomeroy and Gray 1995). In contrast, other studies suggest that during blowing-snow events, the air above the surface rapidly saturates with moisture, limiting the amount of snow that can sublimate (e.g. Déry and Yau 2001, King et al. 2001). As thoroughly discussed in Liston and Sturm (2004), there is not necessarily a contradiction between the two types of sublimation: both regimes may exist depending on the interaction of the surface layer with the overlying air mass. Above inclined snow surfaces, efficient mixing is particularly forced by the frequent catabatic flows and related entrainment of air masses into the shallow surface layer (Smeets et al. 1998). Hence, for the application here, a mixing of the surface layer with an overlying mass of dry air was assumed which leads to an efficient removal of moisture from the turbulent suspension layer during blowing-snow events. This leads to enhanced sublimation rates from up to $95 \%$ of the annual snowy precipitation for several crest regions. The overall losses which are due to sublimation of turbulent suspended snow are small in contrast and are only about $4.1 \%$ of the total snowfall for the whole test site (tab. 9).

Table 9: Contributions relative to total snowfall and scale-dependent significance of the winter water balance components for the Berchtesgaden National Park domain for 2003/2004. The additional amount of snowmelt is caused by rain-on-snow (cp. Stasser et al. 2008).

\begin{tabular}{c|cccc}
\hline $\begin{array}{c}\text { Water balance } \\
\text { component: }\end{array}$ & $\begin{array}{c}\text { Seasonal amount } \\
{[\mathrm{mm}]}\end{array}$ & $\begin{array}{c}\text { Relative } \\
\text { contribution [\%] }\end{array}$ & $\begin{array}{c}\text { Local } \\
\text { significance }\end{array}$ & $\begin{array}{c}\text { Regional } \\
\text { significance }\end{array}$ \\
\hline \hline $\begin{array}{c}\text { Snowfall } \\
\text { Ground }\end{array}$ & +651.1 & $100 \%$ & high & high \\
$\begin{array}{c}\text { resublimation } \\
\text { Ground sublimation }\end{array}$ & +15.8 & $+2.4 \%$ & moderate & small \\
$\begin{array}{c}\text { Canopy sublimation } \\
\text { Sublimation from }\end{array}$ & -44.9 & $-6.9 \%$ & moderate & small \\
turbulent suspension & -84.9 & $-13.0 \%$ & moderate & high \\
Snowmelt & -26.5 & $-4.1 \%$ & high & small \\
\hline
\end{tabular}

The scheme presented here has produced results which are pretty close to data measured by Hood et al. (1999, Nivot ridge Colorado). Their measurements are the only known and published sublimation measurements in Alpine regions. When comparing the meteorological information and SWE accumulation rates given by Hood et al. (1999) with the Berchtesgaden site, it becomes obvious that their measurements correspond closely to predicted values for the elevation zone around $2100 \mathrm{~m}$ a.s.l. Here a mean sublimation rate of 250mm (MM5_30 and MM5) was predicted for the National Park area, as Hood et al. (1999) measured 195mm for their site at Nivot ridge (Colorado). The results obtained with interpolated wind fields 
(maximum $=47 \mathrm{~mm}$ INTER_30 and 50mm INTER; fig. 39e) and $52 \mathrm{e}$ )) were outside the range of this data. In which way the measurements of Hood et al. (1999) are representative for the Watzmann region cannot be concluded but the comparison shows that the results obtained in this study are within the range of data published by other authors. It is also an open question whether the very high sublimation rates in the crest regions are valid (e.g. fig. 53). This will be an open research topic until sublimation measurements from the respective regions become available. Nevertheless, the questionable areas are limited to the apexes of the mountains and should not have a significant importance for/or influence to the water balance of the overall catchment (tab. 9; Strasser et al. 2008).

\subsection{High interpolated precipitation rates as a possible reason for the underestimation of the spatial snow heterogeneity}

The spatial homogeneity of the modelled snow cover in comparison to the classification results was mentioned in connection with the remotely sensed data. The difference to the real more heterogenic snow cover can be due to an underestimation of the amounts of snow transported by wind or because of the negation of snow slides etc. Another possible explanation are to high amounts of interpolated snow fall. The interpolation results have demonstrated that the spatial interpolation of the precipitation measurements works well for the available stations (fig. 18) but produces questionably high amounts of precipitation for higher elevation levels within the test-site. An exact evaluation of the model error is impossible because of a lack of meteorological stations at the respective elevation belts. Nevertheless, a comparison to the values presented by Enders (1979) for the National Park area, who predicted an amount of $2711 \mathrm{~mm}$ precipitation for an elevation of $2500 \mathrm{~m}$ a.s.l. (the value is based on a comparison to the station Plattachferner at $2660 \mathrm{~m}$ a.s.l., which could be seen as representative for this elevation belt of the National Park (Enders 1979)), indicates that the 3100mm (September 2003 to August 2004) predicted by MicroMet are comparatively high. The high values can also not be explained by extreme weather conditions since a comparison to the time period of 1960 to 1990 (average precipitation at Berchtesgaden = $1519 \mathrm{~mm}$ ) reveals that the precipitation amounts of September 2003 to August 2004 (1532mm) were close to the long term average for this region. Nevertheless, the overestimated precipitation rates do not justify a substitution of the respective routine as the 
available station values are well reproduced and a conclusive calculation of the severity of the error in higher altitudes is impossible.

However, based on Enders (1979) an overestimation of about 15\% for the elevation belts above 2000 meters can be assumed. Because of low temperatures in these regions most of the additional precipitation falls as snow and is therefore added to the snow pack. As a result, the analysis, in section 4.3.4 has shown too much modelled SWE for all test areas. An effect of the overestimated SWE depth is that areas which are snow free in the satellite images, while showing lower snow depth when using the snow transport routine with MM5 compared to the other model schemes, are still predicted to be snow covered within the model results. Hence, the surplus of about 15\% precipitation masks the improvements which were achieved through the use of the MM5 wind fields with respect to the spatial distribution of the snow cover.

\subsection{The effects of snow slides and preferential snow distribution}

It became obvious, that wind induced snow transport is not the only factor which produces the remarkable spatial heterogeneity of the Alpine snow cover. There are other processes which are occurring before, during, and after the snow accumulation process that potentially can have a major impact on the snow distribution. Particularly important seem to be: preferential snow distribution and snow slides. The influence of preferential snow distribution is so far not well understood but it is assumed that it can have considerable effects especially at regions with steep topography (Lehning et al. 2002). Reduced snow accumulations on steep slopes are commonly mentioned as the main effect of preferential snow distribution but where the snow is accumulated instead is still a subject of speculations. On the other hand, recently there has been remarkable progress in the calculation of snow slides and there are inspiring publications which are illustrating the importance of this process (Gruber 2007; Strasser et al. 2007). Strasser et al. (2007) predicted SWE depositions due to snow slides of up to $10000 \mathrm{~mm}$ per winter season for some areas in the National Park (fig. 62). This value seems to be very high but members of the Commission of Glaciology of the Bavarian academy of science and humanities have found that snow depositions by snow slides at the Icechapel (Watzmann east face) reach these amounts (personal communication M. Weber 2008). Furthermore, Kuhn 
(1995) stated that an additional amount of $8000 \mathrm{~mm}$ SWE is needed for reaching equilibrium conditions of the mass balance for some small avalanche fed glaciers.

With respect to wind induced snow transport, gravitational snow transport has the effect that remarkable amounts of snow are shifted into regions where the wind induced processes are of subordinate importance because of low wind speeds (fig.35 c)). This and the fact that areas with slope angels of more than $50^{\circ}$ are commonly snow free (because of gravitational processes), should lower the amount of wind induced snow transport in a natural setting because of a lack of transportable snow. As these effects are neglected in the current model formulations it can be argued that the real wind induced transport rates should be lower than the modelled ones. This would also have an effect on the very high sublimation rates (fig. 39 f) and $52 \mathrm{f}$ )) predicted in the crest areas.

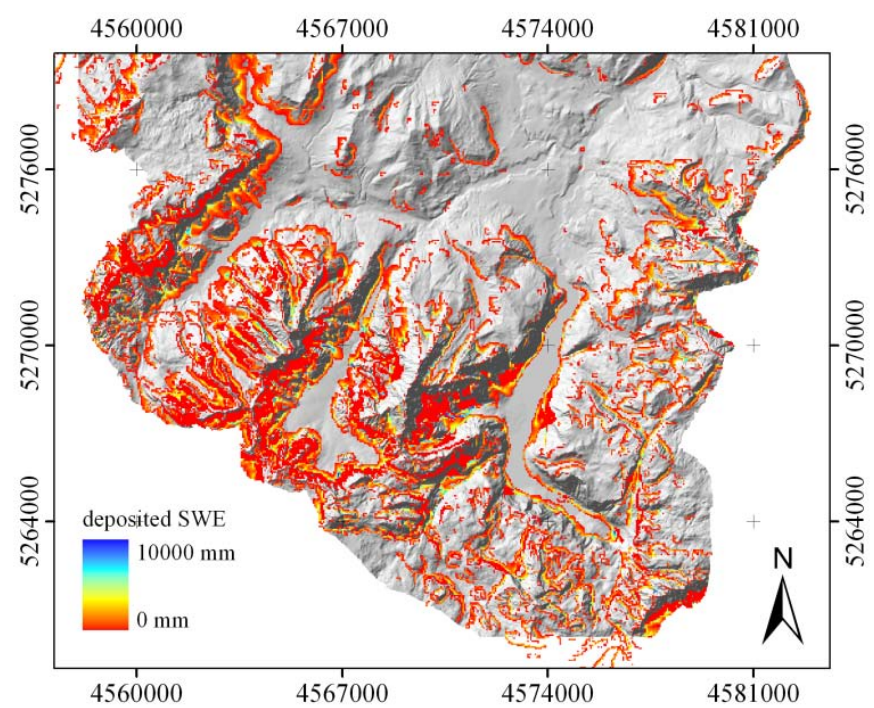

Figure 62: Accumulated Snow masses transported by snow slides (winter season 03/04). Strasser at al. (2008) modified.

A quantification of the efficiency of gravitational snow transport processes in combination with wind induced transport rates is complicated by the fact that there are no coupled model algorithms available which account for wind induced snow transport and snow slides. This would be a prerequisite for predicting correct transport rates for both modes of snow transport because wind induced transport could make snow of adjacent catchments available for snow slides, while snow slides, on the other hand, can prevent snow from being included in wind transport processes by shifting the snow masses to lower elevation bands where wind induced 
transport processes are far less effective. Furthermore, the estimation of the effect of snow slides is difficult because some available model routines, used by e.g. Strasser et al. (2007), are triggered at a given hour once per day and not as a result of snow pack conditions at a given time step. Therefore, it could only be assumed that the enhanced snow coverage in the valley areas (cp. Chapter 5.3) below snow free areas on steep slopes of more than 50 degrees are caused by this process.

\subsection{Model formulations}

This section will discuss in which way the used model schemes can deteriorate the model results and what improvements could be made in the model with respect to the accuracy of the available input data. It was mentioned before that the presented formulation of the saltation layer flux (eq. 26), was a subject of discussion in recent years (e.g. Lehning et al. 2006). The work presented here adds important points to this ongoing discussion. While very sophisticated model algorithms are useful and generally lead to more accurate results if suitable input data is available, they are useless if the input data is of less accuracy. The presented study shows that interpolated wind fields, routinely used in SnowModel applications, can decline the accuracy of the results by $100 \%$. This error is significantly higher than the errors which could potentially be produced because of the oversimplification of the saltation process (personal communication Liston (2006) and Pomeroy (2006)). The results of the presented study suggest another possible model improvement which could greatly enhance the performance of the model. It could be observed that the inclusion of a second suspension layer would be very favourable to allow the transport of suspended snow over trees and to make the explicit calculation of snow transport rates in areas of flow separation possible. In the current model setup, the model accumulates the transported snow particles instantly if the wind speed drops below a certain threshold. Hence, significant snow accumulations can be observed at the wood sites or immediately beyond mountain crests. The inclusion of a second suspension layer driven by e.g. the second model layer of MM5 which is still available would lead to a better description of the transport processes at the respective locations and could probably lead to a better description of the accumulation and erosion 
zones. The need for this model extension could be clearly seen at Reiteralm test site (ср. section 4.3.1).

Hence, it can be stated that the snow distribution that is obtainable with the current SnowModel version shows some deficits which were discussed in the former sections but was significantly improved over the inclusion of MM5 wind fields. The inclusion of additional processes could definitely improve the model results in the future but currently the presented results have to be seen as state of the art as they are from comparable accuracy as results published by other authors but for less complex terrain (cp. Liston et al. 2007) and are therefore applicable for future studies. 


\section{Chapter 6 Outlook and conclusion}

\subsection{Presentation of a scheme which allows for a better description of the snow cover in regional scale models}

The following section will present a method which allows the wider usage of the presented results in hydrologic modelling. As discussed in the previous chapters, the Alpine snow cover has a remarkable heterogeneity which is dependent on numerous factors. It was shown that in snow cover modelling, the explicit calculation of the transport processes and the required meteorological fields is time consuming and only functional at certain scales. It was also shown that the amounts of transported snow are dependent on the selected scale. Furthermore, the physically based description of snow transport processes is only valid up to a grid cell size of 200m (Liston 2006). As this is much lower than the resolution of regional SVAT or most hydrological models, an alternative method of describing the sub-grid snow distribution and with this accurate energy and moisture fluxes on the basis of this work is presented. Figure 63 illustrates the representation of the snow cover in a common snow model module where the snow or SWE depth is considered to be constant over the entire grid cell. This simple assumption results in:

- An instant snow covered or snow free effect for any grid cell during accumulation or ablation.

- Energy and moisture fluxes which are representative for the snow covered or the snow free part of the grid cell only.

- A general misinterpretation of the melt period (Liston 2004). 


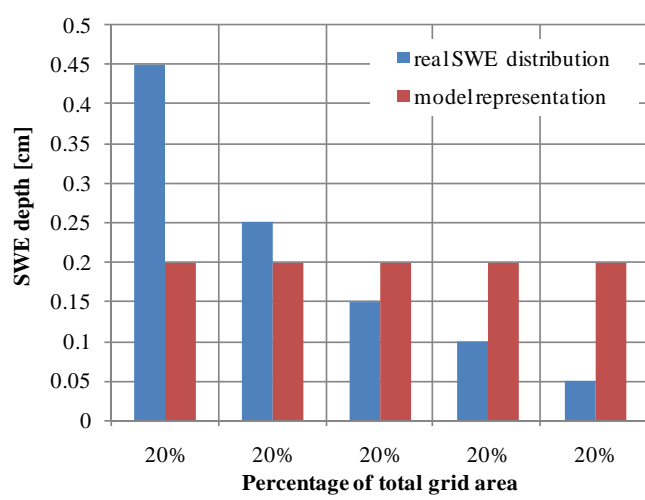

a)

Figure 63: The figure shows a theoretical subscale SWE depth distribution and common model representatios. a) Shows a situation with full snow coverage, b) shows a situation where the model shows no snow coverage.

A possible solution for the mentioned problems is presented here. A scheme of Liston (SSNOWD, 2004) is used to describe the subscale snow heterogeneity in regional scale models (the equations used here can be found in the Appendix II). The model is based on two basic assumptions that are supported by many studies over the last decades (Donald et al. 1995; Marks et al. 1999; Faria et al. 2000; Liston 2004). First, the spatial distribution of the snow cover is persistent and can be seen as approximately similar over the years (fig. 64). Secondly, the snow water equivalent within a given area is lognormal distributed (fig. 65 a)).

The accuracy of Subgrid Snow Distribution (SSNOWD) (2004) depends on the available information about the spatial heterogeneity of the snow cover. A good description of the spatial distribution of the $S W E$ is crucial to parameterize the model. The parameterisation of SSNWOD requires the definition of a log-normal distribution (fig. 65 a)) which is characteristic for the snow distribution in a regional model grid cell. The general form of the curve is characterised by a coefficient of variation (CV) within SSNOWD (fig. 65a)). 
a)

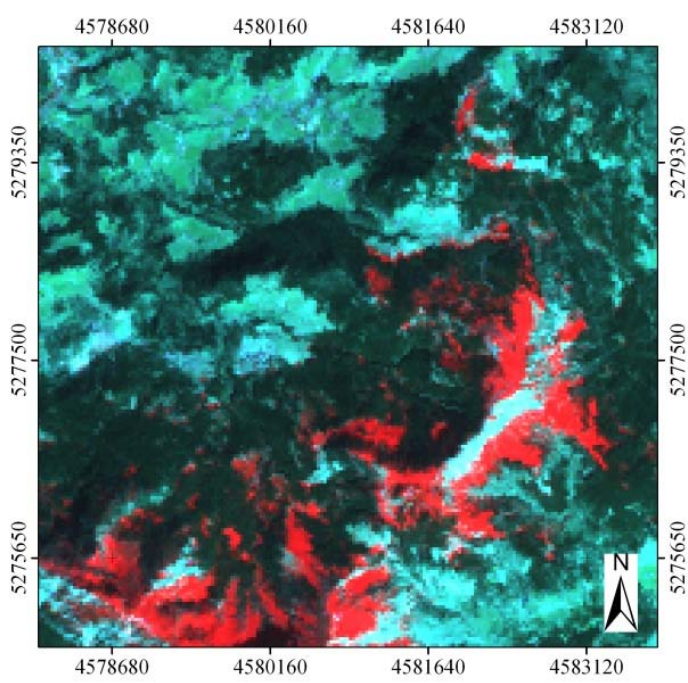

4578680 4580160 4581640 4583120

c)

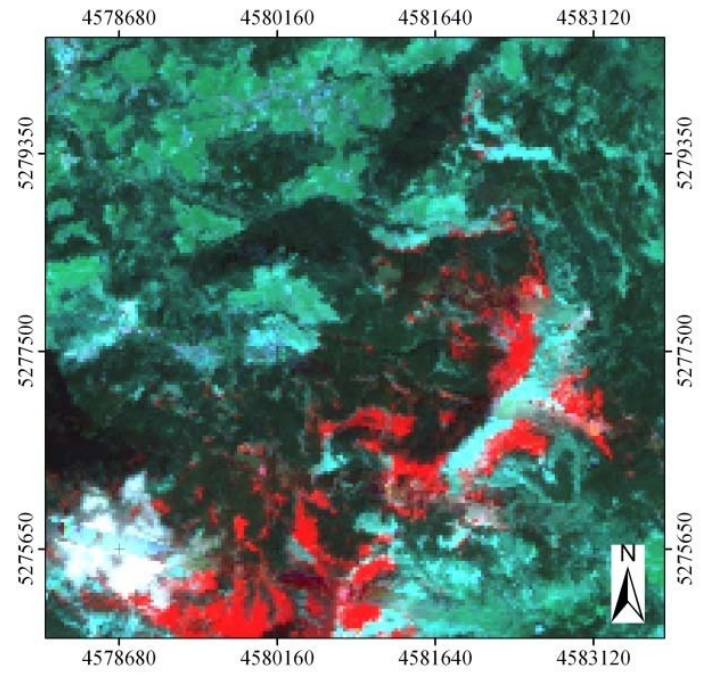

b)

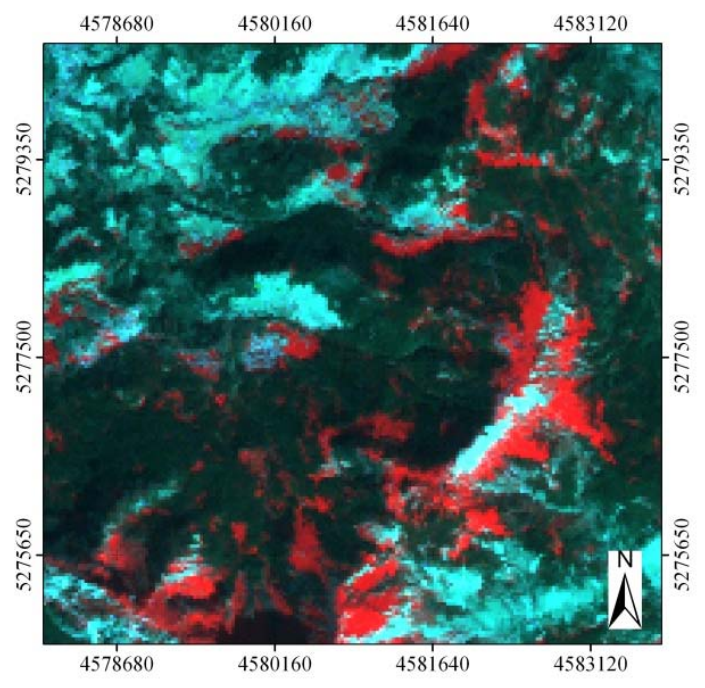

Figure 64: Landsat images of a) April 2002, b) March 2003 and c) April 2004. Channels 3,5,6 (R,G,B) are displayed. The snow cover is indicated by the red colour. It can be seen that the spatial characteristics of the snow distribution is very similar from year to year.

The coefficient can have values between 0 and 1. $C V$ values can be determined directly through extensive snow surveys as was done by Pomeroy et al. (1998) and subsequently used to validate blowing snow model results (Essery et al. 1999) or to create an initial snow cover at the start of snowmelt simulations (Pohl and Marsh 2006). The necessary detailed snow surveys, however, are extremely time consuming and virtually impossible to carry out in the difficult topography of Alpine regions. Alternative methods of obtaining $C V$ values are needed therefore. Liston (2004) used a decision tree to derive $C V$ values for the Regional Atmospheric modelling system (ClimRAMS, grid size $80 \mathrm{~km}$ ) which bases on the analysis of 
temperature, topography, and wind conditions. Since this classification scheme was designed for worldwide use, the predefined classes are relatively broad. An application of this scheme to the test site Berchtesgaden would lead to rather undifferentiated results with only a few different $C V$ values. The presented work presents an alternative approach which bases on the SnowModel MM5_30 results presented before. As Liston (2004) defines the CV value as the ratio between the mean SWE depth and the standard deviation of the SWE depth of a given area, it is easy to predict one value for a regional scale model box (which is assumed to be $1 \mathrm{~km}^{2}$ here) on the basis of the micro scale results (fig. $63 \mathrm{~d}$ ). Hence, 1111 micro scale (30m*30m) SWE depths had to be analysed for the calculation of one $C V$ value per $\mathrm{km}^{2}$ box. The results are illustrated in fig. $65 \mathrm{~b}$ ).

a)

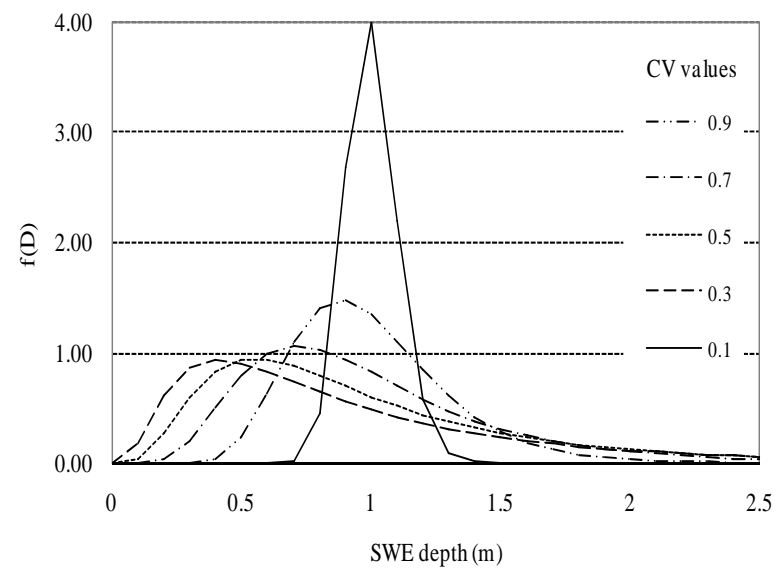

b)

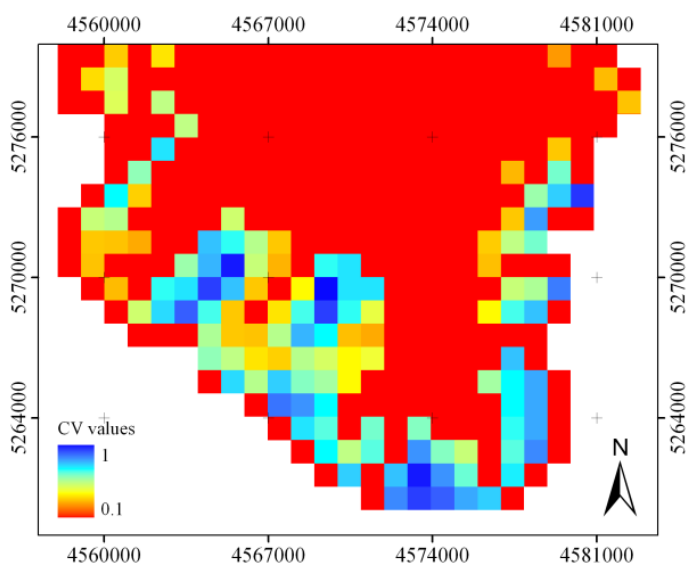

Figure 65: a) dependency of the log-normal distribution which is representative for the subscale per Pixel SWE distribution in dependency of the $C V$ value b) results of the $\mathrm{CV}$ classification. Predicted on the basis of the ratio between per pixel mean modelled SWE and standard deviation of the SWE (30m MM5_30 results).

The scheme of Liston (2004) bases on the assumption that if the snow depth drops below a given threshold one has to assume that some parts within a defined area (whether this is a model grid cell or a natural area like a field, a slope or a basin), become snow free while others stay snow covered. If the model simulates snow melt the curve shifts against the y-axis (fig. 66) and if the curve intersects the axis the area under the curve which is equivalent to the total grid cell is reduced. The remaining area, determines which fraction of the snow model grid cell remains covered. 


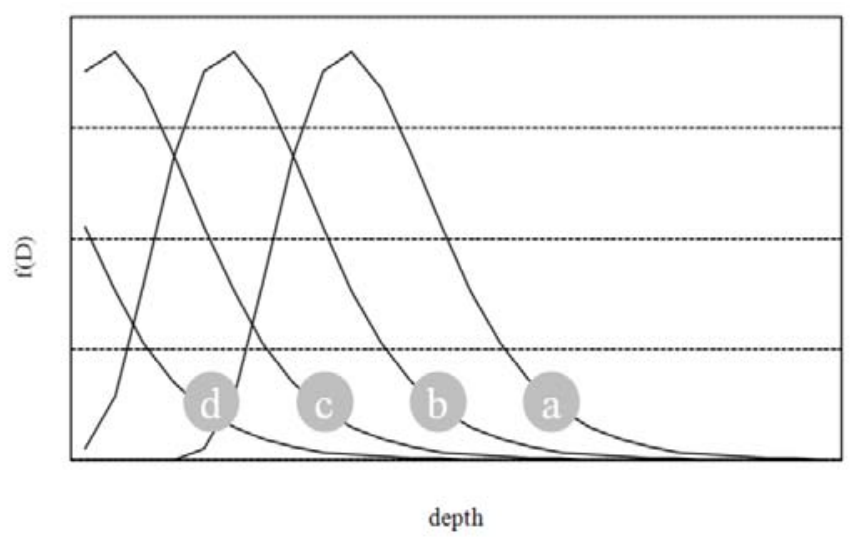

Figure 66: If the model simulates snow melt the curve shifts against the y-axis and if the curve intersects the axis the area under the curve which is equivalent to the total grid cell is reduced. Any curve stands for the SWE distribution of the respective grid cell.

As a first estimation whether the integration of information's about the subscale snow heterogeneity can improve the calculations of a regional scale model, SSNOWD (the equations are presented in the Appendix II) was integrated into SnowModel. The model was set up with a one kilometre resolution and driven with the input parameters used for the INTER_30 model runs. For the validation of the results the NDSI snow cover map of May 30, 2004 was used to determine the real snow covered fraction of the target $1 \mathrm{~km}^{2}$ grid cells (fig. 67 a)). The resulting dataset was subsequently used for a comparison with the model simulation using subscale information (fig. 67 a) and b)).

a)

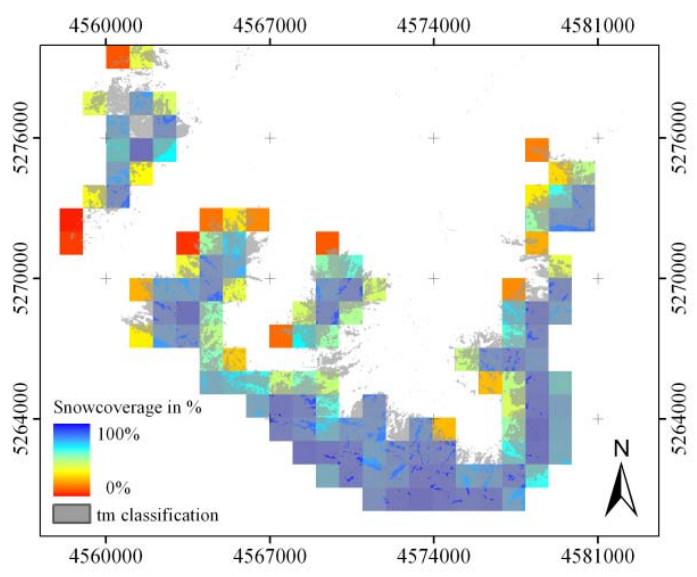

b)

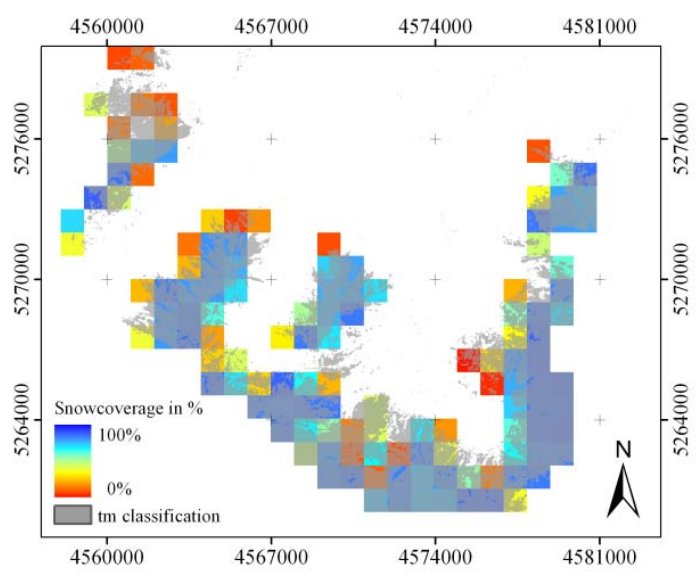

Figure 67: Subpixel snow coverage in percent on May 30, 2004. a) Results based on a scaled NDSI map, b) Model results based on CV values predicted by the ratio approach with SnowTran-3D and MM5 wind fields, c) Model results based on CV values generated with the iterative approach. 
Overall, the Figures show that the modelled spatial pattern of the subscale heterogeneity is acceptable as it is fairly similar to the pattern of the NDSI classification. However, the absolute values can differ greatly. In a next step, the melt energy on May 30, 2004 13:00 was predicted. To do so, MM5_30 results were aggregated to $1 \mathrm{~km}^{2}$ grid cells and compared to SnowModel/SSNOWD results using a $1 \mathrm{~km}^{2}$ resolution. It could be seen that the average melt energy for the snow covered area is higher in the SnowModel/SSNOWD $1 \mathrm{~km}^{2}$ results (without the subgrid snow cover parameterization) $\left(270 \mathrm{~W} / \mathrm{m}^{2}\right)$ than within the aggregated MM5_30 results $\left(220 \mathrm{~W} / \mathrm{m}^{2}\right)$. As the melt energy is linearly coupled with the snow covered fraction (fig. 2b)), the inclusion of a subgrid scale snow cover representation as shown in Figure 68 should lead to a reduction of the predicted melt energy. As expected, the modelled melt energy using the subgrid snow cover routine is much lower and lies slightly below the aggregated results $\left(200 \mathrm{~W} / \mathrm{m}^{2}\right)$.

a)

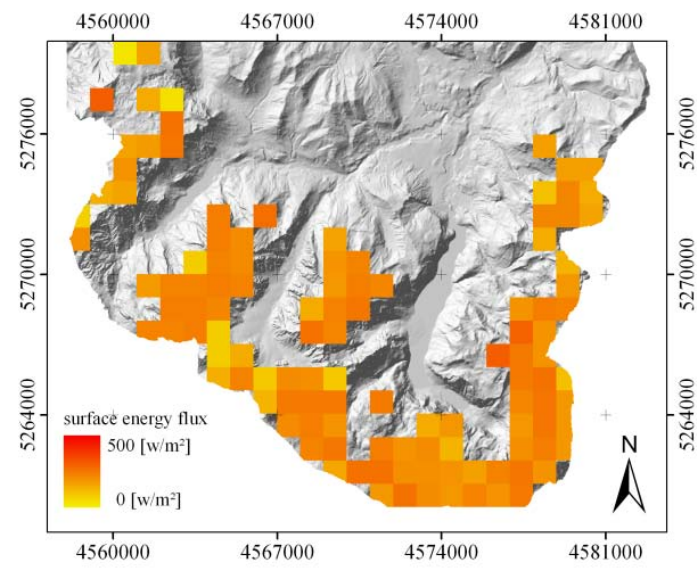

b)

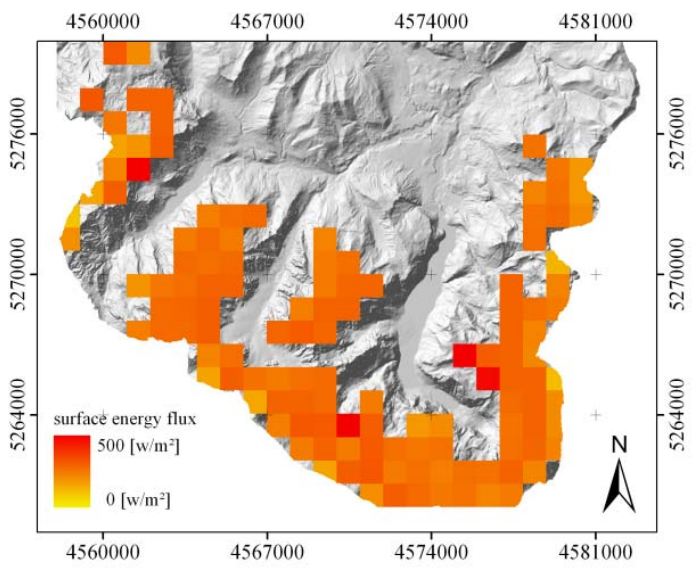

c)

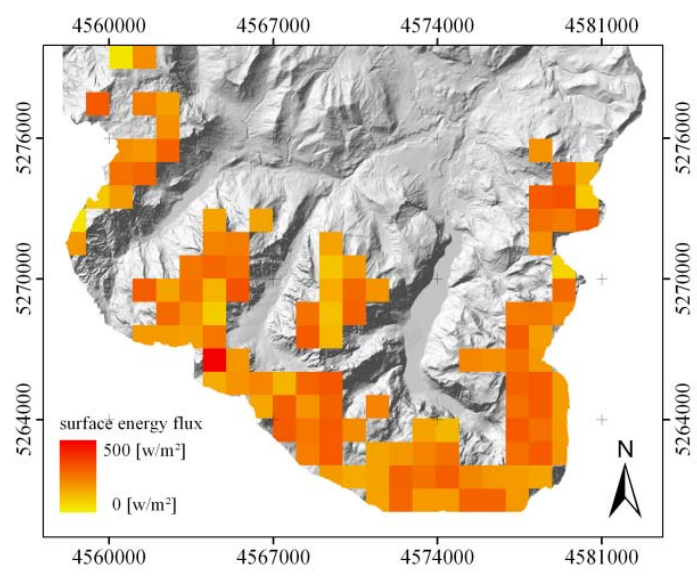

Figure 68: Average available melt energy per $\mathrm{km}^{2}$ grid cell: a) aggregated $30 \mathrm{~m}$ results (equivalent to $M M 5$ _30), $\left(220 \mathrm{~W} / \mathrm{m}^{2}\right)$ b) $1 \mathrm{~km}^{2}$ model runs without the subgrid routine $\left(270 \mathrm{~W} / \mathrm{m}^{2}\right)$, c) corrected $1 \mathrm{~km}^{2}$ results using the subgrid routine $\left(200 \mathrm{~W} / \mathrm{m}^{2}\right)$. 
Commonly there are no area wide micro scale model runs with a complexity comparable to the presented one available for the parameterisation of $C V$ values. So, an alternative scheme for the extrapolation of the presented $C V$ values to other, similar regions was developed. For this purpose, the $C V$ dataset was coupled with a set of topographic and meteorological information. The $C V$ values were inserted into a database in combination with the respective values of mean aspect $\left[{ }^{\circ}\right]$, elevation $[\mathrm{m}]$, slope $\left[^{\circ}\right]$, wind speed $[\mathrm{m} / \mathrm{sec}]$ and wind direction $\left[^{\circ}\right]$ for the respective $1 \mathrm{~km}^{2}$ box. All values are based on averaged $30 \mathrm{~m}$ data. The generated database enables the extrapolation of the data to areas with characteristics similar to the test site (fig. 69).

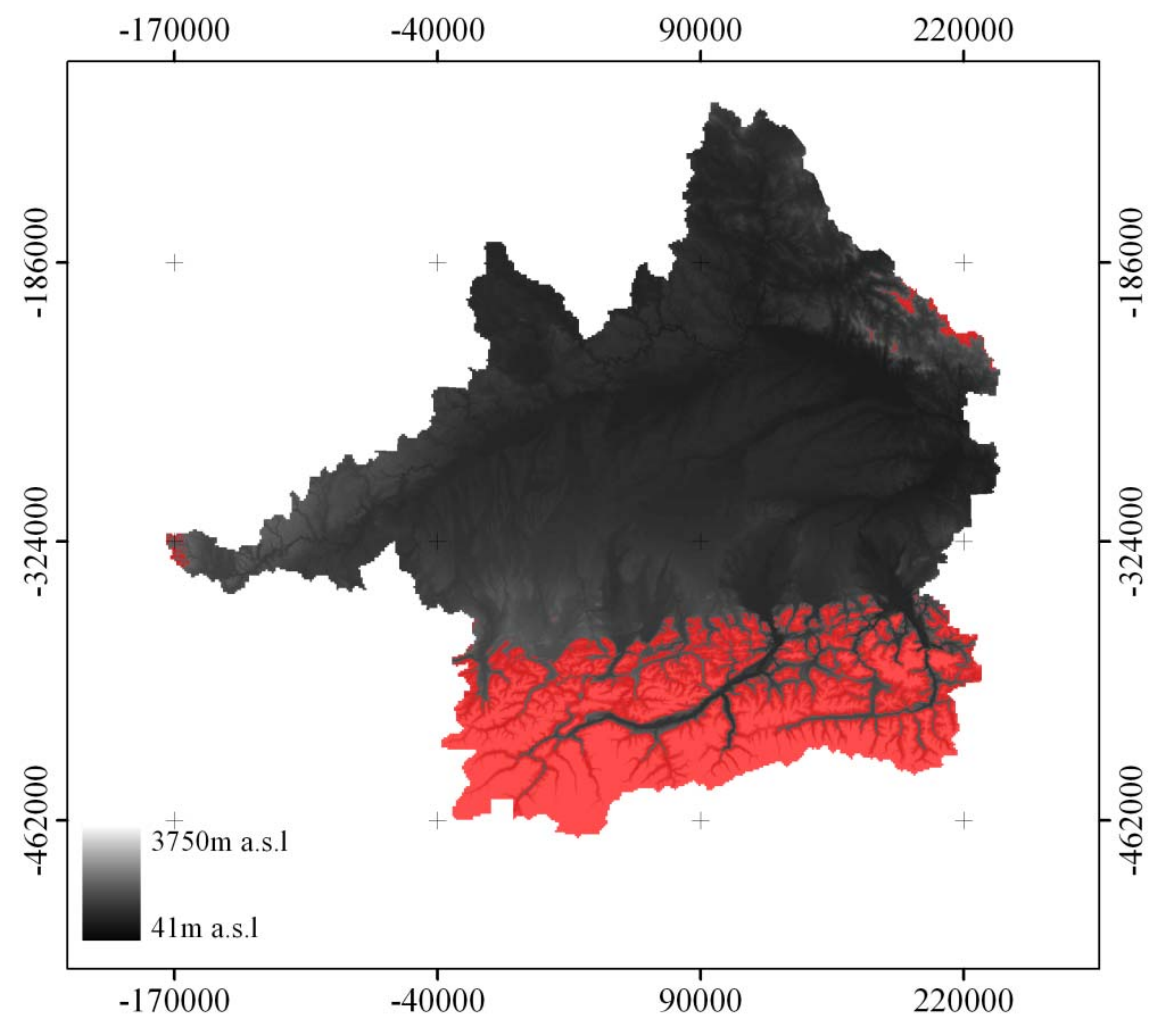

Figure 69: Upper Danube catchment. Red: Areas for which the parameterization results are potentially applicable.

The application and validation of the method proposed here is subject of future work. Nevertheless, first results presented in fig. 68 a) and b) are encouraging and clearly show the potential of the presented scheme. 


\subsection{Conclusion}

Finally, it could be argued that only a few things have changed since Klemes (1988) has written his paper: “The modelling of mountain hydrology: the ultimate challenge”. As he has stated therein, the hydrological modelling in mountain regions has benefited from atmospheric models and remotely sensed data but problems like limited input and validation data and limited accessibility of the respective regions are still relevant. Hydrologic modelling of high mountain regions will be a challenge for the next generations of scientists. This, however, is no reason for a dash of sadness; because it guarantees that there will be a lot of challenging and interesting research in the next decades. The presented work has tried to answer just one of all the open questions. Its results presented in the previous chapters, provide some valuable answers with respect to the impact of snow transport processes on the snow cover in Alpine regions.

One of the goals of the presented thesis was to evaluate the efficiency of snow transport processes and to investigate the relative importance of these processes for the Alpine snow distribution. Model runs have shown that the effect of snow transport processes on the modelled SWE distribution results is extremely dependent on the selected model scale. Runs using a 200m grid cell size have indicated that the total SWE distribution in the test site heavily depends on snow transport processes. However, the $30 \mathrm{~m}$ model runs revealed that snow transport processes can have a significant impact on the snow distribution in limited areas, but not on the overall SWE distribution of catchment. The same conclusion became evident with respect to sublimation. Modelled SWE losses due to sublimation of turbulent suspended snow can reach up to $920 \mathrm{~mm} \mathrm{SWE}$ at the mountains crests but are less than $50 \mathrm{~mm}$ in the valley regions and in the flatlands. The effect on the total SWE budget and therefore on the water balance is small in consequence.

It was also determined that the observed spatial heterogeneity of the snow cover can only partially be explained by the modelled processes. Hence, there have to be other mechanisms which are influencing the snow distribution in Alpine catchments. Strasser (2008) has shown that the simple inclusion of snow slides into his model environment leads to an improved reproduction of observed snow distribution as far as this distribution can be validated with optical data. Nevertheless, the quantification of the different snow transport processes (wind 
induced and gravitational) is impossible at the moment because there are no coupled models that simulate both processes simultaneously. Additionally, the effect of preferential snow distribution is completely unknown at the moment which complicates the resulting model calculations because of an unknown initial snow distribution.

The model validation at the micro and meso scale has shown that the model delivers acceptable data which is close to measurements at all sites (e.g. fig. 22). The used Landsat ETM+ data have clearly shown the limitations of optical systems for the determination of a snow cover in forested regions but have also revealed that the results of SnowModel could be improved by an inclusion of MM5 wind fields.

The subscale snow coverage routine which was presented in Chapter 6 has produced encouraging initial results which will be validated in future work.

Finally, it can be concluded that:

- The estimation of the spatial distribution of SWE in alpine terrain using SnowModel was considerably improved by the use of the MM5 derived wind fields.

- The physically based SnowModel/SnowTran-3D/MM5 couple delivers plausible results for distributed snow covers even in Alpine regions at the micro scale.

- The decreased accuracy of the results at the meso scale indicates that the simulation of snow transport processes should preferentially use small scales, especially if information about the snow distribution within a smaller area is needed. Despite their decreased accuracy, the meso scale results still show the principle functionality of the SnowModel/MM5 bundle for larger areas.

- The presented thesis illustrates that present day regional atmospheric models should be used instead of interpolated meteorological data as input for land surface models when studying snow transport in hilly terrain.

- While the model scheme used here can simulate some of the observed snow cover heterogeneity within the study area, it becomes obvious that the real extent of the snow cover distribution cannot be reproduced fully by the model. Rather, the coupled model still underestimates the heterogeneity of the real snow cover. 
It could be stated that the mountains do not give up their secrets easily (which is not only true for the Yeti) but the author hopes that he wrenched a little secret away from the mountains, which is now available in form of this thesis. 


\section{References}

Adrian, G and Frühwald, D. 2002. Design der Modellkette GME/LM. PROMET, 27. 2002, pp. 106-110.

AEA, Technology. 2001. CFX 4.4 Solver Manual. AEA Technology. 2001.

Anderson, E A. 1976. A point energy and mass balance model of a snow cover. NOAA Tech. Rep. NWS-19

Armstrong, R L and Brodzik, M J. 2002. Hemispheric-scale comparison and evaluation of passive-microwave snow algorithms. Annals of Glaciology, 34, pp. 38-44

Bach, H. 1995. Die Bestimmung hydrologischer und landwirtschaftlicher Oberflächenparameter aus hyperspektralen Fernerkundungsdaten. Münchener Geographische Abhandlungen, Band B 21

Bagnold, R A. 1941. The Physics of Blown Sand and Desert Dunes. London, Chapman and Hall.

Balk, B and Elder, K. 2000. Combining binary decision tree and geostatistical methods to estimate snow distribution in a mountain watershed. Water Resources Research, 36. 2000, pp. 13-26.

Barnes, S L. 1964. A technique for maximizing details in numerical weather map analysis. Journal of applied Meteorology, 3. 1964, pp. 396-409.

Barnes, S L. 1973. Mesoscale objective analysis using weighted time series observations. NOAA Tech. Memo. ERL NSSL-62, National Severe Storms Laboratory, Norman.

Barros, A P and Lettenmaier, D P. 1994. Dynamic modeling of orographically induced precipitation. Reviews of Geophysiks, 32, pp. 265-284.

Barry, R G. 1992. Mountain weather and climate. Routledge, London

Bartelt, $\mathbf{P}$ and M. Lehning 2002. A physical SNOWPACK model for Avalanche Warning Services. Part I: numerical model, Cold Reg. Sci. Technol., 35, 123-145.

Bernhardt, G., Liston G E, Strasser U, M, Zängl and Mauser W. 2007. High resolution modelling of snow transport in complex terrain using simulated wind fields. Berchtesgaden National Park Research Report (special issue Alpine*Snow*Workshop). 2007.

Bernhardt, M, Liston G E, Strasser U. and Mauser W. 2008 a. Using wind fields from a high resolution atmospheric model for simulating snow dynamics in mountainous terrain. Hydrological Processes. 2008, accepted.

Bernhardt, M, Liston G E, Strasser U. and Mauser W. 2008 b. High resolution modelling of snow transport in complex terrain using simulated wind fields. The Cryosphere. 2008, submitted.

Blösch, G and Sivapalan, M. 1995. Scale issues in hydrological modeling. A review. Hydrological Processes. 9, 251-290. 
Blöschl, G. 1999: Scaling issues in snow hydrology. Hydrological Processes, 13, pp. 21492175.

Bowling, L C, Pomeroy, J W and Lettenmaier, D P. 2004. Parameterization of BlowingSnow Sublimation in a Macroscale Hydrology Model. Journal of Hydrometeorology, 5. 2004, pp. 745-762.

Bruland, O, Liston G E, Vonk, J, and Killingtveit, A, 2004. Modelling the snow distribution at two high arctic sites at Svalbard, Norway, and at an Alpine site in central Norway. Nordic Hydrology, 35, pp. 191-208.

Brun E, Martin E, Simon V, Gendre C, Coleou C. 1989. An energy and mass model of snow cover suitable for operational avalanche forecasting, J. of Glaciol., 35, pp. 333-342.

Brun E, David P, Sudul M, Brunot G. 1992. A numerical model to simulate snow-cover stratigraphy for operational avalanche forecasting. Journal of Glaciology 38: 13-22.

Buck, A L. 1981. New equations for computing vapor pressure and enhancement factor. $J$. Appl. Meteor., 20, 1527-1532.

Burridge, D M and Gadd A J. 1974. The meteorological office operational 10 level numerical weather prediction model. British Met. Office Tech. Notes Nos. 12 and 48 London R., Bracknell, Berkshire, RG12 2SZ, England

De Quervain, M and Meister, R. 1987. 50 years of snow profiles on the Weissfluhjoch and relations to the surrounding avalanche activity (1936/37-1985/86). IAHS Publ. No. 162. 1987, pp. 161-181.

Déry, S J and Yau, M K. 1999. A Bulk Blowing Snow Model. Boundary-Layer Meteorology, 93. 1999, 2, pp. 237-251.

Doesken, $\mathbf{N} \mathbf{J}$ and Judson, A. 1996. The Snow Booklet: A guide to the science, climatology, and measurement of snow in the United States. Fort Collins: Colorado State University, 1996.

Doms, G and Schättler, U. 1999. The nonhydrostatic Limited-Area model LM (LokalModell) of DWD. Part I: Scientific Documentation. Offenbach: Deutscher Wetterdienst, 1999.

Doms, G, Steppler, J and Adrian, G. 2002. Das Lokalmodell LM. PROMET, 27. 2002, pp. 123-128.

Donald, J R, Soulis E D, and Kouwen N. 1995. A land coverbased snow cover representation for distributed hydrologic models. Water Resour. Res., 31, pp. 995-1009.

Doorschot, J. 2002. Mass transport of drifting snow in high alpine environments. http://ecollection.ethbib.ethz.ch/show?type $=$ diss\&nr=14515. 2002.

Dozier, J. 1984. Snow reflectance from Landsat-4 thematic mapper. I.E.E.E. Trans. Geosci. Remote Sens. 22, pp.323-328. 
Durand, Y, Guyomarc'h G, Mérindol L, and Corripio J G, 2005. Improvement of a numerical snow drift model and field validation. Cold Regions Science and Technology 43, pp. 93-103.

Durand, M. and Margulis S. 2005. Large-scale SWE Estimation: Optimal Use of Remote Sensing and Snow Modeling, Southwest Hydrology, 4(2), pp.20-21, 32.

Eidsvik, K J, et al. 2004. A Prediction System for Local Wind Variations in Mountainous Terrain. Boundary-Layer Meteorology, 112. 2004, pp. 557-586.

Ellis, A W and Leathers D J. 1999. Analysis of cold airmass temperature modification across the U.S. Great Plains as a consequence of snow depth and albedo. J. Appl. Meteor., 38, pp. 696-711.

Enders, G. 1979. Theoretische Topoklimatologie. Forschungsbericht 1 des Nationalparks Berchtesgaden. Berchtesgaden.

Essery, R L, Li, L and Pomeroy, J W. 1999. A Distributed Model of Blowing Snow over Complex Terrain. Hydrological Processes, 13. 1999, pp. 2423-2438.

Essery, R L. 2001. Spatial statistics of windflow and blowing-snow fluxes over complex terrain. Boundary-Layer Meteorology, 100. 2001, pp. 131-147.

Essery, R L, et al. 2003. Sublimation of snow from boreal forests in a climate model. Journal of Climate, 16. 2003, pp. 1855-1864.

Essery, R L H, and Pomeroy J W. 2004. Vegetation and topographic control of wind-blown snow distributions in distributed and aggregated simulations for an Arctic tundra basin. Journal of Hydrometeorology 5, pp. 734-744.

Etchevers P, Martin E, Brown R, Fierz C, Lejeune Y, Bazile E, Boone A, Dai Y J, Essery R, Fernandez A, Gusev Y, Jordan R, Koren V, Kowalczyk E, Pyles R D, Schlosser A., Shmakin A B, Smirnova T G, Strasser U, Verseghy D, Yamazaki T, Yang Z L. 2002. SnowMIP, an intercomparison of snow models: first results. Proceedings of the International Snow Science Workshop (ISSW 2002), October 2002, Penticton, British Columbia, Canada.

Faria, D A, Pomeroy J W, and Essery R L H. 2000. Effect of covariance between ablation and snow water equivalent on depletion of snow-covered area in a forest. Hydrol. Processes, 14, pp. 2683-2695.

Frei, C and Schär, C. 1998. A precipitation climatology of the Alps from high-resolution raingauge observations. Int. J. Climatol., 18, pp. 873-900

Gal-Chen, T and Sommerville, R C. 1975. On the use of a coordinate transformation for the solution of the navier-stokes equations. Journal of Computational Physics; 17. 1975, pp. 209228.

Gauer, P., 2001. Numerical modeling of blowing and drifting snow in Alpine terrain. Journal of Glaciology 47, pp. 97-110.

Gray, D.M, and others 1979. Snow accumulation and distribution. In Proceedings of a Meeting on Modeling of Snow Cover Runoff. Colbeck SC, Ray M (eds); 1978, Hanover, New 
Hampshire. US Army Cold Regions Research and Engineering Laboratory: Hanover, New Hampshire: 3-33.

Greene, E M, Liston, G E and Pielke, R A. 1999. Simulation of above treeline snowdrift formation using a numerical snow-transport model. Cold Regions Science and Technology, 30. 1999, pp. 135-144.

Grell, G A, Dudhia, J and Stauffer, D R. 1995. A description of the fifth generation Penn State/NCAR mesoscale model (MM5). Boulder, Colorado, USA : s.n., 1995. Technical report, National Centre for Atmospheric Research.

Hall D K, Riggs G A, Salomonson V V. 1995. Development of methods for mapping global snow cover using moderate resolution imaging spectroradiometer data. Remote Sens. Environ. 54, pp. $127-140$

Hall, D K, Foster, J L, Salomonson V V, Klein A G, and Chien J Y L. 2001. Development of a Technique to Assess Snow-Cover Mapping Errors from Space, IEEE Transactions on Geoscience and Remote Sensing, 39(2), pp. 432-438.

Hasholt, B, Liston, G E and Knudsen, N T. 2003. Snow-distribution modelling in the Ammassalik region, south east Greenland. Nordic Hydrology, 34. 2003, pp. 1-16.

Hiemstra, C A, Liston, G E and Reiners, W A. 2002. Snow redistribution by wind and interactions with vegetation at upper treeline in the Medicine Bow Mountains, Wyoming, USA. Arctic Antarctic and Alpine Research, 34. 2002, pp. 262-273.

Hiemstra, C A, Liston, G E and Reiners, W A. 2006. Observing, modelling, and validating snow redistribution by wind in a Wyoming upper treeline landscape. Ecological Modelling. 2006.

Hoinkes H. 1967. Glaciology in the international hydrological decade. IAHS Commision on Snow and Ice: Reports and Discussions, 79, pp. 7-16

Hood, E, Williams, $M$ and Cline, D. 1999. Sublimation from a seasonal snowpack at a continental, mid-latitude alpine site. Hydrological Processes, 13. 1999, pp. 1781-1797.

Johansson, B and Chen, D. 2003. The influence of wind and topography on precipitation distribution in Sweden: Statistical analysis and modelling. International Journal of Climatology, 23. 2003, pp. 1523-1535.

Jordan, R. 1991. A one-dimensional temperature model for a snow cover: Technical documentation for SNTHERM.89. U.S. Army Corps of Eng., Cold Reg. Res.and Eng. Lab. Spec. Rep. 91-16, 1991.

Kirnbauer R and Blöschl G. 1994. How similar are snow cover patterns from year to year. Deutsche Gewässerkundliche Mitteilungen 1994

Koch, S E, Desjardins, $M$ and Kocin, $P$ J. 1983. An Interactive Barnes Objective Map Analysis Scheme for Use with Satellite and Conventional Data. Journal of Climate and Applied Meteorology, 22. 1983, pp. 1487-1503. 
Knap, W H, Brock, B W, Oerlemans, J, Willis, I C. 1999. Comparison of Landsat-TM derived and ground-based albedo of Haut Glacier d'Arolla. International Journal of Remote Sensing., 20, pp.3293-3310.

Kneizys, F X, Shettle, E P, Abreu, L W, Chetwynd, J H, Fenn, R W, Gallery, W O, Selby, J E A, and Clough S. 1988. Atmospheric Transmittance/Radiance: Computer Code Lowtran 6, AFGL-TR-83-0187, Air Force Geophysics Laboratory, Hanscom AFB, Massachusetts

Kuhn, M. 1993. Zwei Gletscher im Karwendelgebirge. Zeitschrift für Glaziologie und Gletscherkunde, 29/1, pp. 85-92.

Kuhn, M. 1995. The mass balance of very small glaciers. Zeitschrift für Glaziologie und Gletscherkunde, 31, pp. 171-179.

Kuhn, M. 2003. Redistribution of snow and glacier mass balance from a hydrometeorological model. Journal of Hydrology, 282. 2003, pp. 95-103.

Kunkel, K E. 1989. Simple procedures for extrapolation of humidity variables in the mountainous western United States. J. Climate, 2, pp. 656-669.

Kyle, H L, Curran, R J, Barnes, W L, and Escoe, D. 1978. A cloud physics radiometer, Third Conference on Atmospheric Radiation, Davis, CA, pp. 107-109.

Kyle, H L, Ardanuy, P E, and Harley, E J. 1985. The status of the Nimbus-7 Earth Radiation Budget data set, Bull. Am. Meteorol. Soc., 66, pp. 1378-1388.

Lehning, M, Doorschot, J, Raderschall, N, Bartelt, P. 2000. Combining snow drift and SNOWPACK models to estimate snow loading in avalanche slopes. Snow Engineering. 2000, pp. 113-122.

Lehning, M, Doorsschot, J, Fierz, C and. Radersschall, N. 2002. A 3D model for snow drift and snow cover development in steep alpine terrain. Proceedings International Snow Science Workshop (ISSW). 2002, pp. 579-586.

Lehning, M, Völksch, I, Gustafsson, D, Nguyen, T A, Stähli, M, Zappa, M. 2006. ALPINE3D: A detailed model of mountain surface processes and its application to snow hydrology, 20. Hydrological Processes. 2006, pp. 2111-2128.

Liston, G E. 1995. Local Advection of Momentum, Heat, and Moisture during the Melt of Patchy Snow Covers. Journal of applied meteorology, 34. 1995, pp. 1705-1715.

Liston, G E and Hall D K. 1995. An energy-balance model of lake-ice evolution. Journal of Glaciology, 41, pp. 373-382.

Liston, G E and Sturm, M. 1998. A snow-transport model for complex terrain. Journal of Glaciology, 44. 1998, pp. 498-516.

Liston, G E, Winther, J G, Bruland, O, Elevehøy, H, Sand, K. 1999. Below-surface ice melt on coastal Antarctic ice sheets. Journal of Glaciology, 45, pp.273-285 
Liston, G E, Winther, J G, Bruland, O, Elevehøy, H, Sand, K, Karlöf, H. 2000. Snow and blue-ice distribution patterns on the coastal Antarctic Ice Sheet. Antarctic Science, 12. 2000, pp. 69-79

Liston, G E. 2004. Representing Subgrid Snow Cover Heterogeneities in Regional and Global Models. Journal of Climate, 17. 2004, pp. 1381-1397.

Liston, G E and Sturm, M. 2004. The role of winter sublimation in the Arctic moisture budget. Nordic Hydrology, 35. 2004, pp. 325-334.

Liston, G E and Elder, K. 2006. A meteorological distribution system for high resolution terrestial modelling (MicroMet). Journal of Hydrometeorology, 7. 2006, pp. 217-234 .

Liston, G E and Elder, K. 2006. A Distributed Snow-Evolution Modelling System (SnowModel). Journal of Hydrometeorology, 7. 2006, pp. 1259-1276 .

Liston, G E, Haehnel, R B; Sturm, M, Hiemstra, C A, Berezovskaya, S, Tabler, R D. 2007. Simulating Complex Snow Distributions in Windy Environments using SnowTran-3D. Journal of Glaciology, 53, pp. 241-256

Ludwig, R, et al. 2003. Web-based modelling of energy, water and matter fluxes to support decision making in mesoscale catchments-the integrative perspective of GLOWA-Danube. Physics and Chemistry of the Earth. 2003, pp. 621-634.

Marks D, Domingo J, Susong D, Link T, Garen D. 1999. A spatially distributed energy balance snowmelt model for application in mountain basins. Hydrological Processes 13. pp. 1935-1959.

Marsh, P. 1999. Snowcover formation and melt: recent advances and future prospects. Hydrological Processes. 1999, Vol. 13, pp. 2117-2134.

Mauser W and Bach H. 2008. PROMET - a Physical Hydrological Model to Study the Impact of Climate Change on the Water Flows of Medium Sized, Complex Watersheds. Journal of Hydrology. submitted

Plattner C, Braun L and Brenning A. (2006). The spatial variability of snow accumulation at Vernagtferner, Austrian Alps, in Winter 2003/2004, Zeitschrift für Gletscherkunde und Glazialgeologie, 39, pp. 43-57.

Pohl S and Marsh P. 2006. Small-scale modelling of spatially variable snowmelt in an arctic catchment. Hydrological Processes, 20, 1773-1792.

Pomeroy, J W. 1988. Wind Transport of Snow. PhD Thesis, Division of Hydrology, University of Saskatchewan, Saskatoon.

Pomeroy, J W and Gray, DM. 1990. Saltation of snow. Water Resources Research, 26, pp. 1583-1594.

Pomeroy, J W, Gray, D M and Landine, P G. 1993. The Prairie Blowing Snow Model characteristics, validation, operation. Journal of Hydrology, 144. 1993, pp. 165-192. 
Pomeroy, J W and Essery, R L. 1999. Turbulent fluxes during blowing snow: field tests of model sublimation predictions. Hydrological Processes, 13. 1999, pp. 2963-2975.

Pomeroy, J W, Gray, D M. 1995. Snowcover: Accumulation, Relocation, and Management. National Hydrology Research Institute, Saskatoon, Canada. NHRI Science Report. 7, pp.144

Pomeroy, J W, Marsh P, Gray D M. 1997. Application of a distributed blowing snow model to the arctic. Hydrological Processes 11: 1451-1464.

Pomeroy J W, Gray D M, Shook K R, Toth B, Essery R, Pietroniro A, Hedstrom NR. 1998. An evaluation of snow accumulation and ablation processes for land surface modelling. Hydrological Processes 12: 2339-2367.

Prasad, R, Tarboton D G, Liston G E, Luce C H, and Seyfried M S. 2001. Testing a blowing snow model against distributed snow measurements at Upper Sheep Creek, Idaho, United States of America. Water Resources Research, 37. 2001, pp. 1341-1356.

Prasch, M, et al. 2007. Physically based modelling of snow cover dynamics in Alpine regions. Proceedings of the International Congress 'Managing Alpine Future - strategies for sustainability in times of change'. 2007.

Raderschall, N, Lehning, $M$ und Doorshot, J. 2002. Boundary layer wind field over steep, snow covered, high alpine topography. Proc. 10th Conference Mountain Meteorology. 2002, S. 303-306.

Rees, G W. 2006. Remote Sensing of Snow and Ice. Taylor and Francis. Boca Raton

Rutter, N, and Essery R. 2006. Evaluation of forest snow processes models (SnowMIP2), Geophysical Research Abstracts, Vol. 8, 05921, 2006 SRef-ID: 1607-7962/gra/EGU06-A05921

Ryan, B C. 1977. A mathematical model for diagnosis and prediction of surface winds in mountainous terrain. Journal of Applied Meteorology, 16. 1977, pp. 571-584.

Schmidt, R A. 1972. Sublimation of wind-transported snow - a model. U.S. Forest Service, Rocky Mountain Forest and Range Experiment Station, Research Paper 90. 1972.

Shafran, P C, Seaman, N L and Gayno, G A. 2000. Evaluation of numerical predictions of boundary layer structure during the Lake Michigan Ozone Study. Journal of Applied Meteorology, 39. 2000, pp. 412-426.

Sundsbø, P A, 1997. Numerical modelling and simulation of snow drift. Doctoral Dissertation, Narvik Institute of Technology, Department of Building Science, The Norwegian University of Science and Technology, 112 pp

Strasser, U, et al. 2007. Is snow sublimation important in the alpine water balance? The Cryosphere Discuss., 1. 2007, pp. 303-350.

Sturm, M, Holmgren, $\mathbf{J}$ and Liston, G E. 1995. A seasonal snow coverclassification system for local to global applications. Journal of Climate. 1995, 8, pp. 1261-1283. 
Thornton, P E, Running, S W and White M A. 1997. Generating surfaces of daily meteorological variables over large regions of complex terrain. J. Hydrol., 190, pp. 214-251.

Tucker, C J. 1979. Red and photographic infiared linear combinations (or monitoring vegetation, Remote Sens. Environ.,8, pp.27-150.

Uematsu, T, Nakata T, Takeuchi K, Arisawa Y, and Kaneda Y, 1991. Three-dimensional numerical simulation of snowdrift. Cold Regions Science and Technology 20, 65-73.

UNESCO/IAHS/WMO. 1970. Seasonal snow cover. In: Technical Papers in Hydrology. Paris: UNESCO/IAHS/WMO

Walcek, C. J., 1994. Cloud cover and its relationship to relative humidity during a spring midlatitude cyclone. Mon. Wea. Rev., 122, pp. 1021-1035.

Walter, M T and McCool, D K. 2004. A simple snowdrift model for distributed hydrological modeling. Journal of Hydrologic Engineering, 9. 2004, pp. 280-287 .

Weber, M. 2005. Mikrometeorologische Prozesse bei der Ablation eines Alpengletschers. Institute for Meteorology and Geophysics. University of Innsbruck. : s.n., 2005.

Wergen, W. 2002. Datenassimilation - ein Überblick. PROMET, 27. 2002, pp. 142-149.

Wieser, A, Fiedler, F, and Corsemeier, U. 2001. The influence of the sensor design on wind measurements with sonic anemometer systems. J. Atmos. Oceanic Technol., 18, pp. 15851608.

Winkler, D. 2005. Der Blaueisgletscher in Not. Berchtesgadener Heimatkalender 2006, pp. 45-48.

Winstral, A and Marks, D. 2002. Simulating wind fields and snow redistribution using terrain-based parameters to model snow accumulation and melt over a semi-arid mountain catchment. Hydrological Processes, 16. 2002, pp. 3585-3603.

Winther, J G, and Hall, D K. 1999. Satellite derived snow cover related to hydropower production in Norway: present and future. International Journal of Remote Sensing, 20. pp. 2991-3008

Xiao, J, Bintanja R, Déry S J, Mann G and Taylor, P A.. 2000. An intercomparison among four models of blowing snow. Boundary Layer Meteorology. 2000, 97, pp. 109-135.

Xue, M, Droegemeier, K K and Wong, V. 2000. The Advanced Regional Prediction System The Advanced Regional Prediction System dynamics and verification. Meteorology and Atmospheric Physics. 2000, 75, pp. 161-193.

Xue, M, Droegemeier, K K, Wong, V, Shapiro A, Brewster K, Carr F, Weber D, Liu Y, and Wang, D H. 2001. The Advanced Regional Prediction System (ARPS) - A multiscale nonhydrostatic atmospheric simulation and prediction tool. Part II: Model physics and applications. Meteorology and Atmospheric Physics. 2001, 76, pp. 161-193.

Zängl, G. 2002. An Improved Method for Computing Horizontal Diffusion in a SigmaCoordinate Model and Its Application to Simulations over Mountainous Topography. Monthly Weather Review, 130. 2002, pp. 1423-1432. 
Zängl, G. 2003. Orographic Gravity Waves Close to the Nonhydrostatic Limit of Vertical Propagation. Journal of the Atmospheric Sciences, 60. 2003, pp. 2045-2063. 


\section{Appendix I}

\section{I) Additional Equations of the snow model (the total set of formulations can be found in Liston and Sturm (1998)}

The following Equations are used for describing the sublimation process during transport:

Sublimation during transport is described as:

$$
Q_{v}\left(x^{*}\right)=\psi_{s} \phi_{s} h_{*}+\int_{h_{*}}^{z_{t}} \psi_{t}\left(x^{*}, z\right) \phi_{t}\left(x^{*}, z\right) d z
$$

$\mathrm{Q}_{\mathrm{v}}\left(\mathrm{kg} \mathrm{m}^{-2} \mathrm{~s}^{-1}\right)=$ sublimation rate of transported snow. $\Psi_{\mathrm{s}} / \Psi_{\mathrm{t}}=$ sublimation loss rate coefficient for saltation and turbulent suspension. $\varnothing_{\mathrm{s}}\left(\mathrm{kg} \mathrm{m}^{-3}\right)=$ saltation layer mass concentration. $\varnothing_{\mathrm{t}}\left(\mathrm{kg} \mathrm{m}^{-3}\right)=$ vertical mass concentration within the turbulent suspension layer.

The sublimation loss rate is defined as:

$t(s)=$ time, $\bar{m}(z)(\mathrm{kg})=$ mean particle mass at height $\mathrm{z}$.

$$
\psi\left(x^{*}, z\right)=\frac{d \bar{m}(z) / d t}{\bar{m}(z)}
$$

The average particle mass is simulated with:

$\rho_{\mathrm{i}}\left(\mathrm{kg} \mathrm{m}^{-3}\right)=$ density of ice, $\bar{r}$ mean radius of snow particles.

$$
\bar{m}(z)=\frac{4}{3} \pi \rho_{i} \overline{r_{r}}(z)^{3}\left(1+\frac{3}{\alpha}+\frac{2}{\alpha^{2}}\right)
$$

$$
\bar{r}_{r}(z)=4.6 * 10^{-5} z^{-0-258}
$$

$\mathrm{z}=$ height

Coefficient $\alpha$ is defined by:

$$
\alpha=4.08+12.6 z
$$

Mass loss from an ice sphere is described by the combined influence of humidity gradients between particle and free atmosphere, as wells as intercepted solar radiation, particle size and ventilation influences:

$$
\frac{d \bar{m}}{d t}=\frac{2 \pi \bar{r} \sigma-\frac{S_{p}}{\lambda_{t} T_{a} N u}\left[\frac{h_{S} M}{R T_{a}}-1\right]}{\frac{h_{S}}{\lambda_{t} T_{a} N u}\left[\frac{h_{S} M}{R T_{a}}-1\right]+\frac{1}{D \rho_{v} S h}}
$$

$\mathrm{M}\left(18.01 \mathrm{~kg} \mathrm{kmole}^{-1}\right)=$ molecular weight of water, $\mathrm{R}\left(8313 \mathrm{~J} \mathrm{kmole}^{-1} \mathrm{~K}^{-1}\right)=$ universal gas constant, $\mathrm{T}_{\mathrm{a}}(\mathrm{K})=$ air temperature, $\lambda_{\mathrm{t}}\left(0.024 \mathrm{~J} \mathrm{~m}^{-1} \mathrm{~s}^{-1} \mathrm{~K}^{-1}\right)=$ thermal conductivity of the atmosphere, $\mathrm{h}_{\mathrm{s}}=$ latent heat of sublimation. $\mathrm{D}$ $\left(\mathrm{m}^{2} \mathrm{~s}^{-1}\right)=$ diffusivity or water vapour in the atmosphere, $\rho_{\mathrm{v}}=\left(\mathrm{kg} \mathrm{m}^{-3}\right)=$ saturation density of water vapour. $\mathrm{R}_{\mathrm{d}}$ $\left(287 \mathrm{~J} \mathrm{deg}^{-1} \mathrm{~kg}^{-1}\right)=$ gas constant for dry air, $\mathrm{e}_{\mathrm{s}}=$ vapour pressure over ice. $\mathrm{Nu}=$ Nusselt Number, $\mathrm{Sh}=$ Sherwood Number.

The formulation for the radius of a snow particle $\bar{r}(z)(m)$, of mean particle mass $\bar{m}(z)$ is:

$$
\bar{r}(z)=\left(\frac{3 \bar{m}(z)}{4 \pi \rho_{i}}\right)^{\frac{1}{3}}
$$


Nusselt and Sherwood numbers are related to the Reynolds number:

$$
N u(z)=\operatorname{Sh}(z)=1.79+0.606 \operatorname{Re}(z)^{0.5}
$$

The particle Reynold's number (Re) is defined to be:

$$
R_{e}(z)=\frac{2 \bar{r}(z) V_{V}(z)}{v}
$$

$\mathrm{v}=$ kinematic viscosity of the air, $\mathrm{V}_{\mathrm{V}}=$ ventilation velocity.

The ventilation velocity consists of two components, the mean and the fluctuating velocity component (in the case of turbulent suspension $\mathrm{V}_{\mathrm{t}}$ ).

$$
V_{t}(z)=\bar{w}(z)+3 x_{r}(z) \cos \left(\frac{\pi}{4}\right)
$$

Where the mean terminal fall velocity is given as:

$$
\bar{\omega}(z)=1.1 * 10^{7} \bar{r}(z)^{1.8}
$$

And the fluctuating component:

$$
x_{r}(z)=0.005 u(z)^{1.36}
$$

For the case of saltation the formulation follows Pomeroy and Gray (1995):

$$
V_{s}=0.68 u_{*}+2.3 u_{* t}
$$

The solar radiation absorbed by the snow particle is described by:

$$
S_{p}=\pi \bar{r}_{r}(z)^{2}\left(1-\alpha_{p}\right)\left(1+\alpha_{s}\right) S_{i}
$$

$\alpha_{\mathrm{p}}=$ smow particle albedo (assumed to be 0.5 ) and $\alpha_{\mathrm{s}}=$ is the snow cover albedo (assumed to be 0.8 ).

$\mathrm{S}_{\mathrm{i}}=$ the incoming solar radiation and follows Liston (1995):

$$
S_{i}=S^{*} \Upsilon \sin \omega
$$

$\mathrm{S}^{*}=$ solar irradiance at the top of atmosphere $\left(1370 \mathrm{~W} / \mathrm{m}^{2}\right), \Upsilon=$ net sky transmissivity, $\sin \omega=$ solar elevation angle. 


\section{II) Equations used for the subscale snow model used in chapter 6}

The following section will present the subscale snow distribution model presented by Liston (2004). The model was used in chapter 6 for describing the subscale snow heterogeneity of the snow cover.

If the snow free and the snow covered fractions are known, the per grid cell energy balance can be weighted linearly proportionally to the percentages of snow free and snow covered fractions (eq 38):

$$
Q_{g a}=\Gamma Q_{s c}+(1-\Gamma) Q_{s f}
$$

Estimation of the grid averaged fluxes $\mathrm{Q}_{\mathrm{ga}}=\mathrm{Q}_{\mathrm{sc}}=$ Snow covered flux, $\mathrm{Q}_{\mathrm{sf}}=$ snow free flux, $\Gamma=$ snow covered fraction.

The subscale snow distribution is described with a set of formulas based on the works of Donald et al (1995), Pomeroy et al. (1998), Faria et al. (2000) and Liston (1999 and 2004).

Liston (1999) found that the internal grid cell snow water equivalent distribution, the average melt rate and the snow covered fraction are interrelated. He has also demonstrated that any of the three parameters can be predicted if the other two are known. Equation 38 shows that every model cell includes a snow free and a snow covered fraction under melt conditions. The two fractions sum to 1 for any pixel:

$$
\int_{0}^{D_{m}} f(D) d D+\int_{D_{m}}^{\infty} f(D) d D=1
$$

Sum of the snow free and snow covered fraction of any grid cell. $D_{m}=$ grid cell melt rate, $f(D)=$ SWE depth probability function.

Thus the snow free fraction can be expressed by:

$$
\Gamma\left(D_{m}\right)=1-\int_{0}^{D_{m}} f(D) d D
$$

$\Gamma\left(D_{m}\right)$ snow covered fraction in dependence of the melt rate, $f(D)$ SWE depth probability function.

According to Donald et al. (1995), Pomeroy et al. (1998) and Faria et al. (2000), snow water equivalent depth distributions can be approximated by a two parameter log-normal distribution:

$$
f(D)=\frac{1}{D \xi \sqrt{2 \pi}} \exp \left\{-\frac{1}{2}\left[\frac{\ln (D)-\lambda}{\xi}\right]^{2}\right\}
$$

SWE distribution function $f(\mathrm{D})$ : $\mathrm{D}=$ SWE depth, $\lambda$ and $\zeta$ are distribution parameters (Liston 2004). 
The description of the first distribution parameter $\lambda$ is based on Pomeroy et al. (1995):

$$
\lambda=\ln (\mu)-\frac{1}{2} \xi^{2}
$$

Distribution parameter $\lambda: \mu=$ mean SWE depth, $\xi$ distribution parameter.

The second distribution parameter is mainly characterized by a coefficient of variation. Liston (2004) defined $C V$ as equal to the ratio of the standard deviation to the mean of the SWE depth of a given area. $C V$ modifies the general form of the log-normal distribution (fig. 65a):

$$
\xi^{2}=\ln \left(1+C V^{2}\right)
$$

Distribution parameter $\xi$ : CV = coefficient of variation (Donald et al. 1995)

The average $S W E$ depth of a grid cell $\mathrm{D}_{\mathrm{a}}$ under assumption of a certain melt depth $\mathrm{D}_{\mathrm{m}}$ is given by Donald et al. (1995):

$$
D_{a}\left(D_{m}\right)=\frac{1}{2} e^{\left(\lambda+\xi^{2} / 2\right)} \operatorname{erfc}\left(\frac{z_{D_{m}}-\xi}{\sqrt{2}}\right)-D_{m} \Gamma\left(D_{m}\right)
$$

Average SWE depth of a grid cell $\mathrm{D}_{\mathrm{a}}$ in dependence on the SWE melt depth $\mathrm{D}_{\mathrm{m}}: \lambda$ and $\xi$ = distribution parameters, $\mathrm{z}_{\mathrm{Dm}}=$ eq. $39, \Gamma \mathrm{D}_{\mathrm{m}}=$ snow covered fraction in dependence on $\mathrm{D}_{\mathrm{m}}$

where $z_{D m}$ is defined by:

$$
Z_{D_{m}}=\frac{\ln (\mathrm{D})-\lambda}{\xi}
$$

$\mathrm{z}_{\mathrm{Dm}}$ is the result of a change in the integration variable from $\mathrm{D}$ to $\mathrm{z} . \mathrm{D}=S W E$ depth, $\lambda$ and $\xi=$ distribution parameters.

Figures65a and 66 can be used to explain the operation of the presented routine. Figure 65a shows different log-normal functions which are representative for the sub-scale snow distribution of a grid element of e.g. a SVAT model. The area under the curves is 1 in any case. Figure 66 shows the shift of the curve in the direction of smaller SWE averages. The extent of the shift depends on the melt rates. If the curve intersects the $y$ axis the area below of the curve will be reduced. The remaining proportion represents the snow covered fraction of the respective model grid. 


\section{III) Spatial characteristics of MM5 wind fields in dependency of the wind direction.}

This part of the appendix should give an idea about the spatial heterogeneity of the predicted MM5 wind fields. All of the presented wind fields were calculated under usage of identical input wind speeds (cp. fig 13) of 10 [m/sec] for the 10m MM5 model level and 25[m/sec] for the 100hpa level. The resulting differences are due to wind-topography interactions. An analysis of the wind fields shows that the maximum wind speeds are reached when the input wind direction is around 180 degrees or around 270 degrees respectively. The increased wind speeds when using these input wind directions can be decaled by the fact that the highest wind speeds are reached if the wind direction is near to, or 90 degrees to the crest orientation which is north to south for the main massifs and east to west for the later branches. If this is the case modelled wind speeds can reach up to 25 [m/sec]. This is because of the reduced cross section the air masses have to pass through if they are forced to overflow the mountains massif. Otherwise the wind speed is moderate and only around $6[\mathrm{~m} / \mathrm{sec}]$ in maximum. It could be also seen that the maximum wind speeds are located in the direct environment of the crests. Here, a nonlinear increase of the modelled wind speed can be found. Windward and leeward effects are observable in all of the calculated MM5 wind fields. The presented examples show how heterogeneous the calculated MM5 wind fields can be under a constant input energy. The produced heterogeneity cannot be reproduced by an interpolation routine which was shown on the basis of the comparison to the available station measurements. 

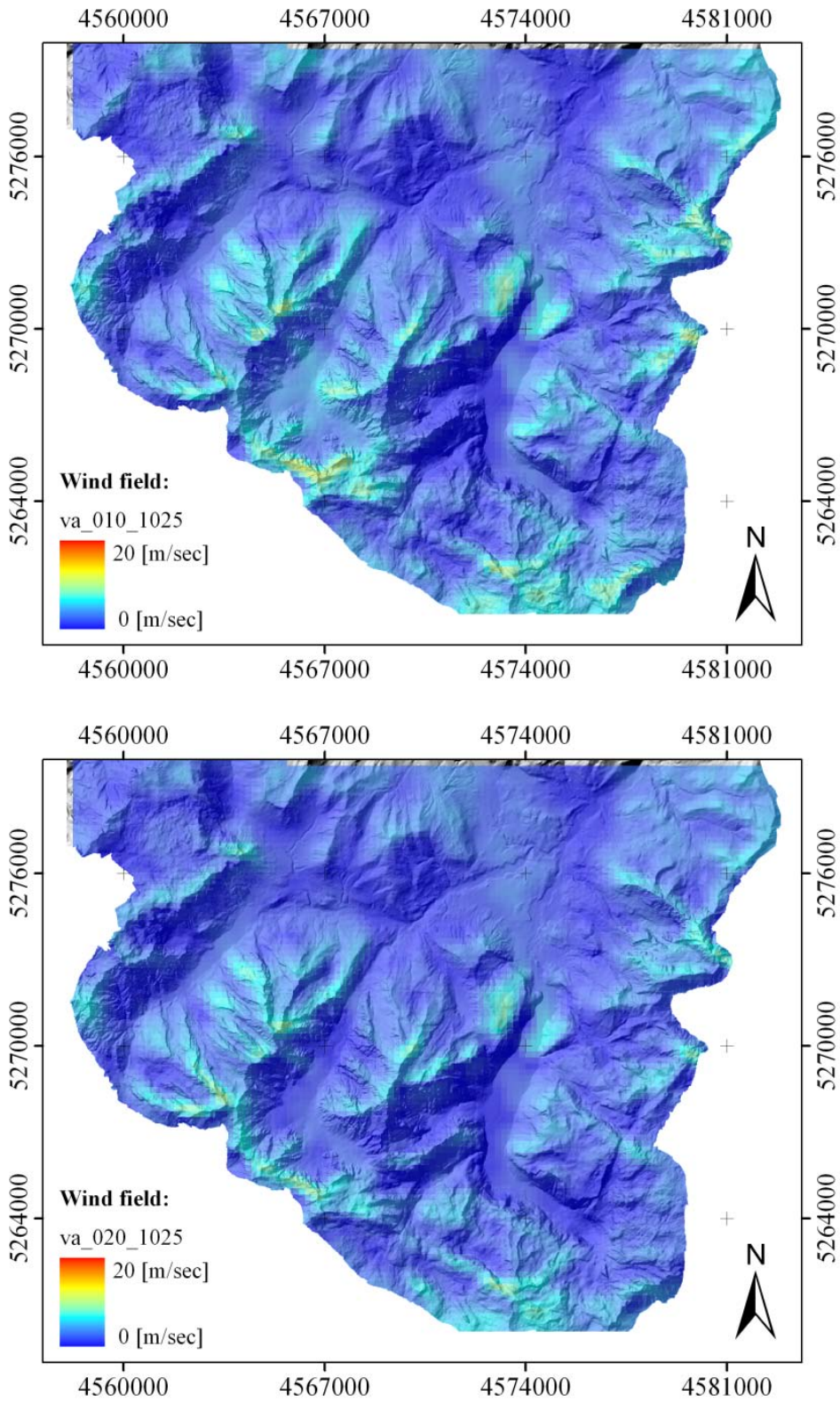

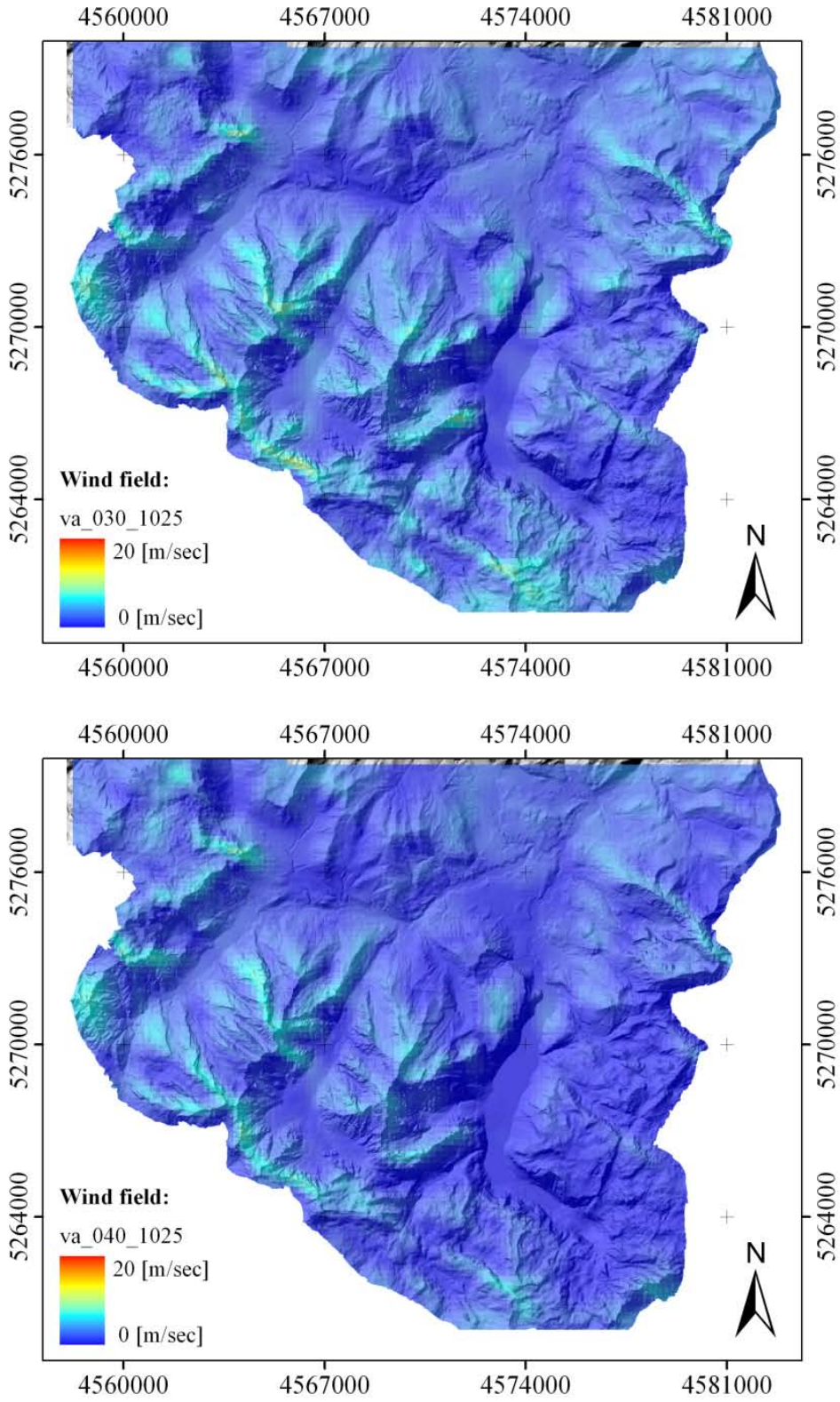

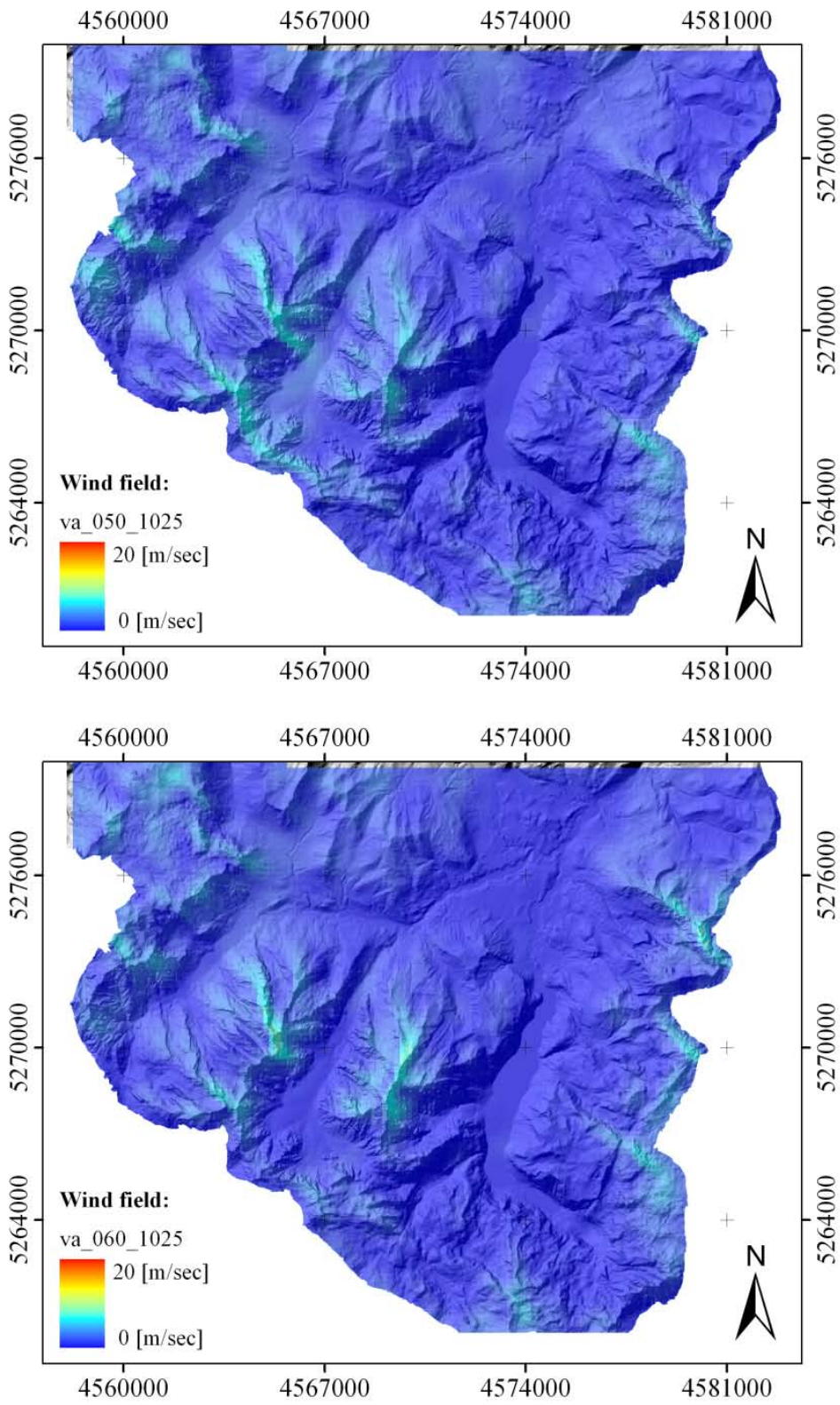

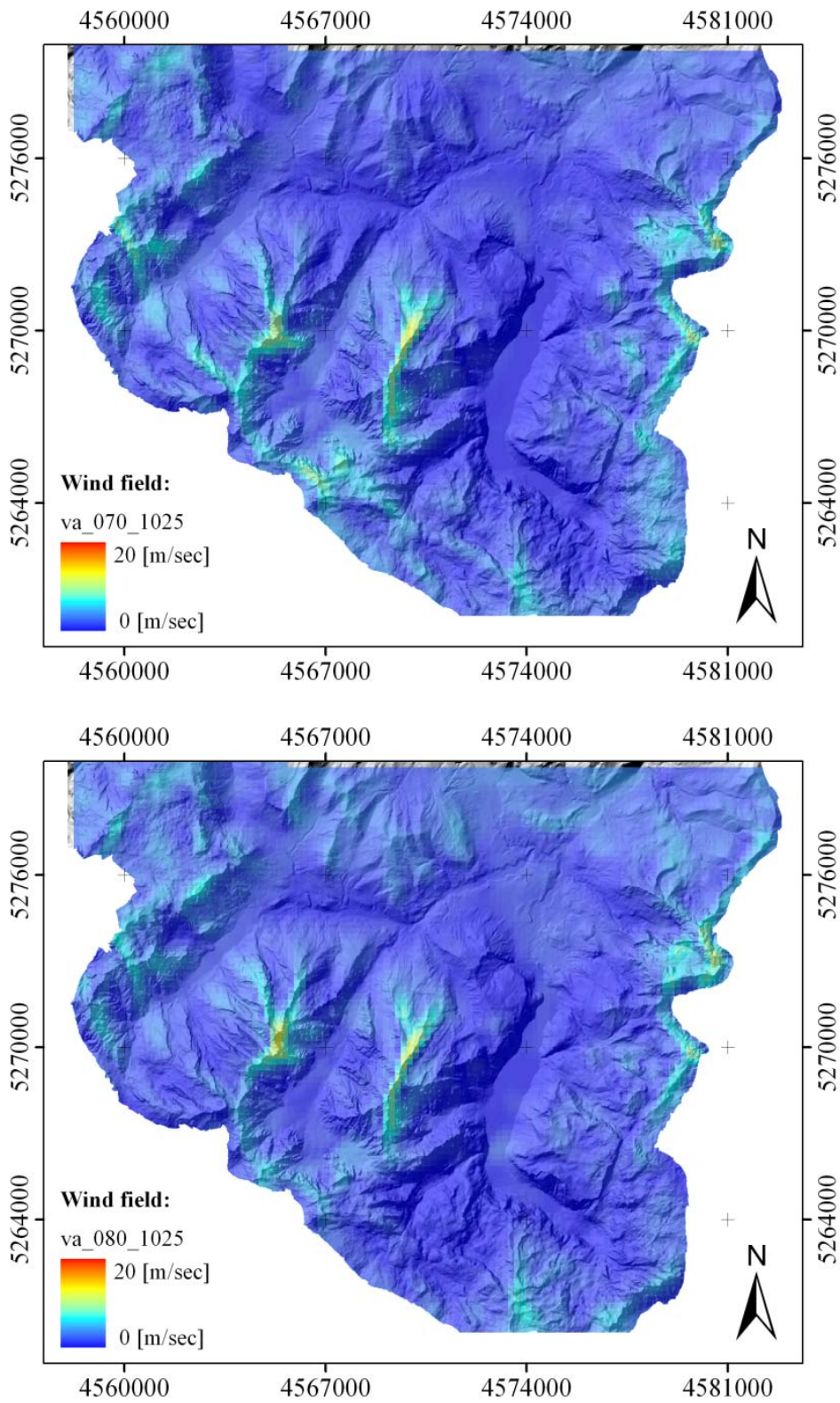

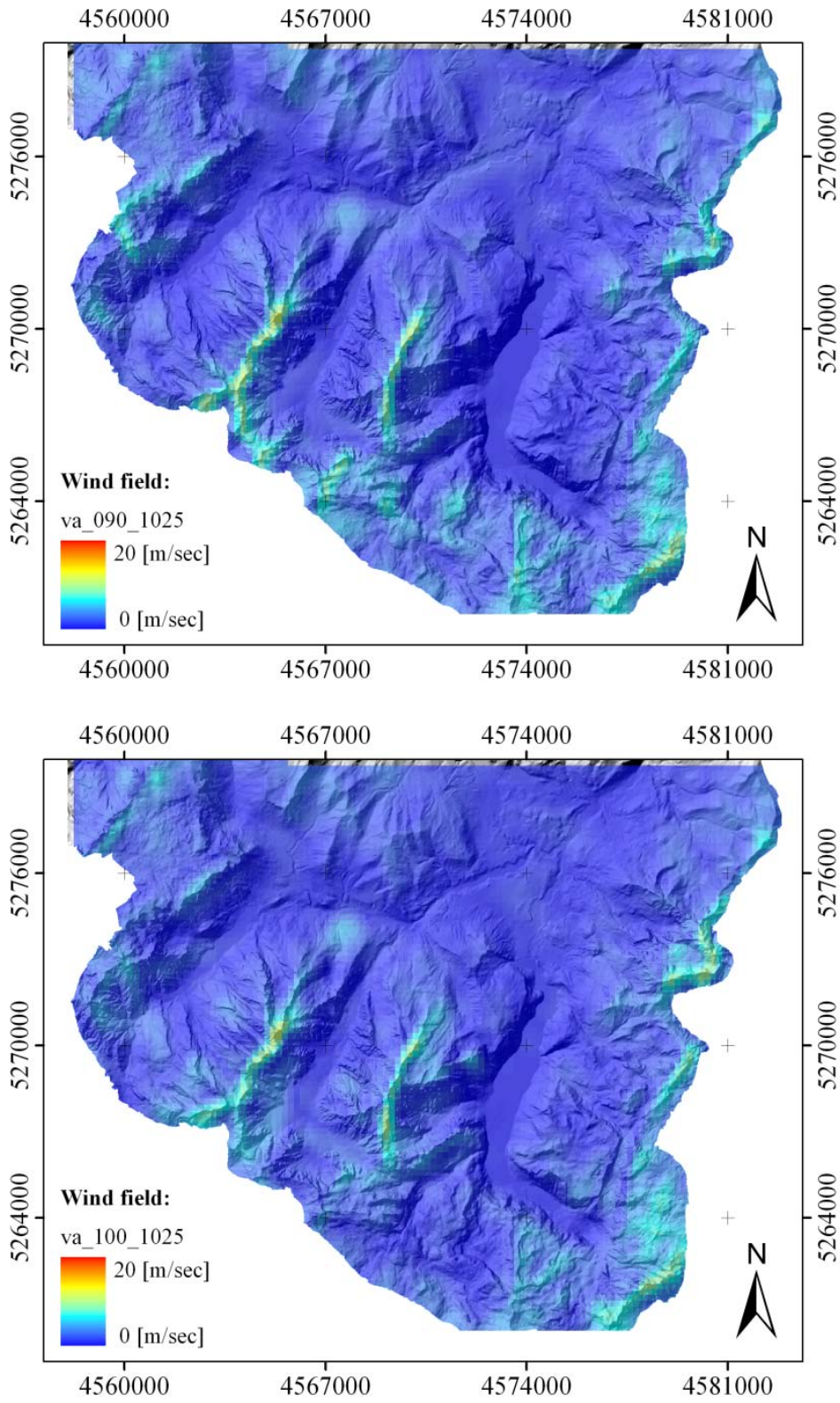

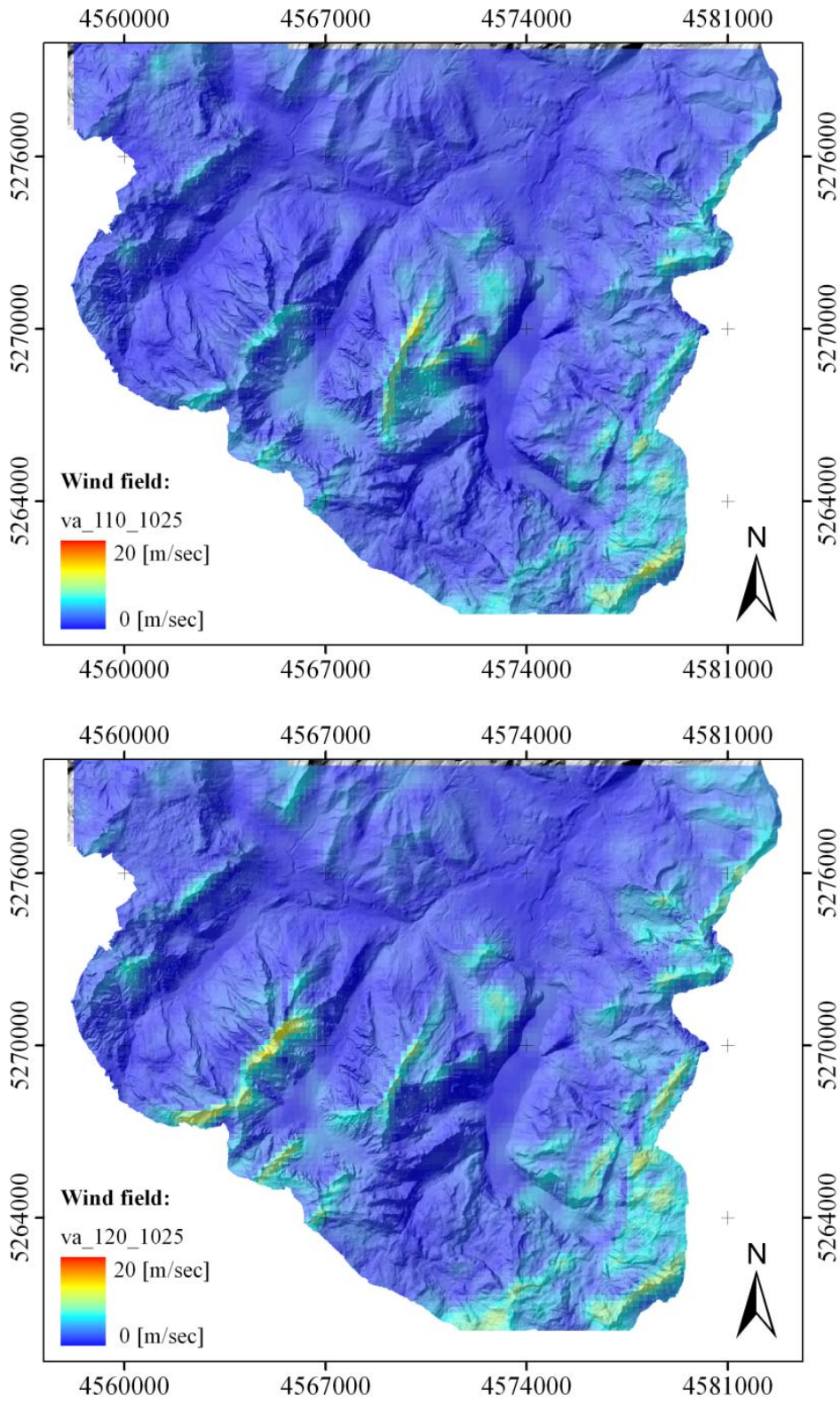

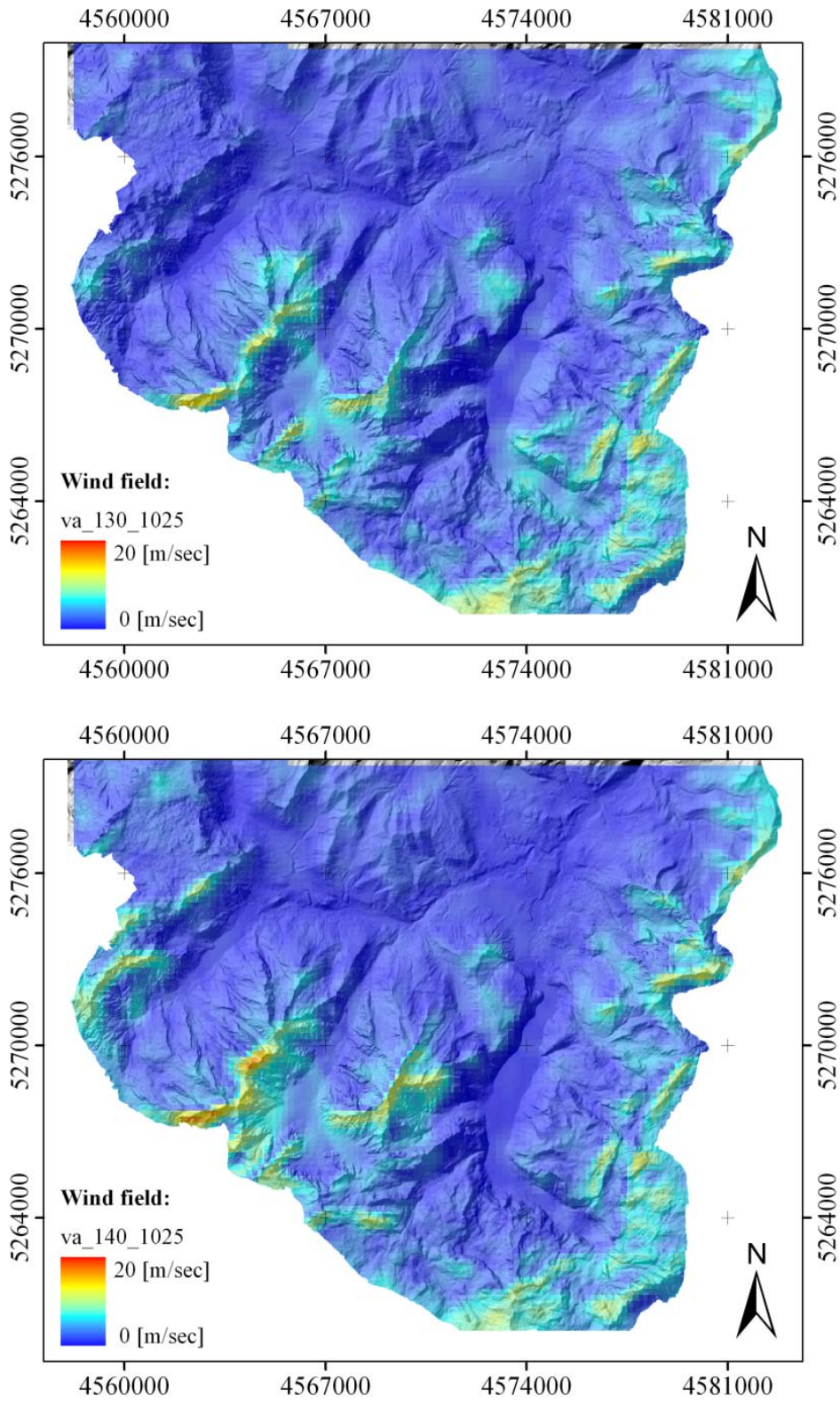

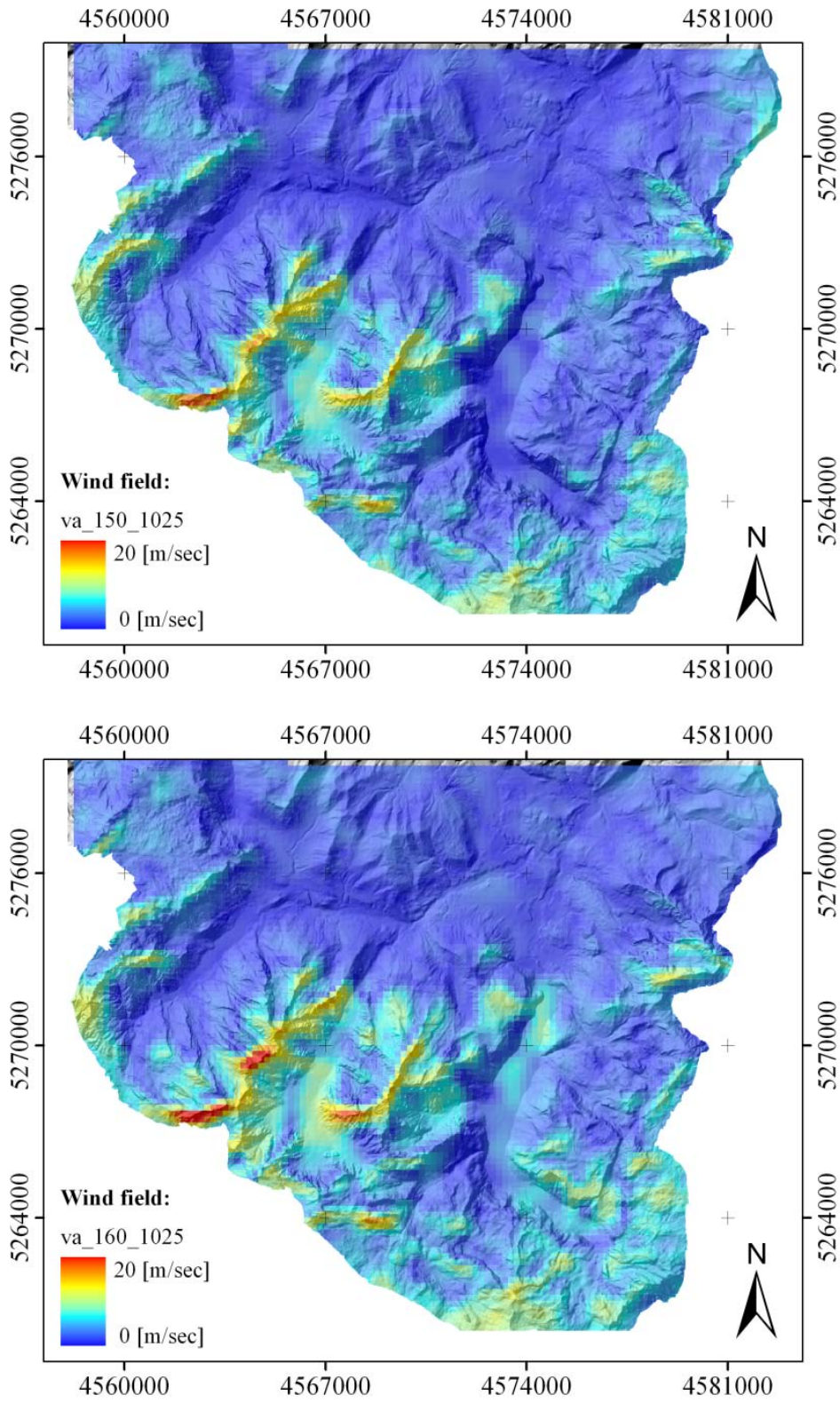

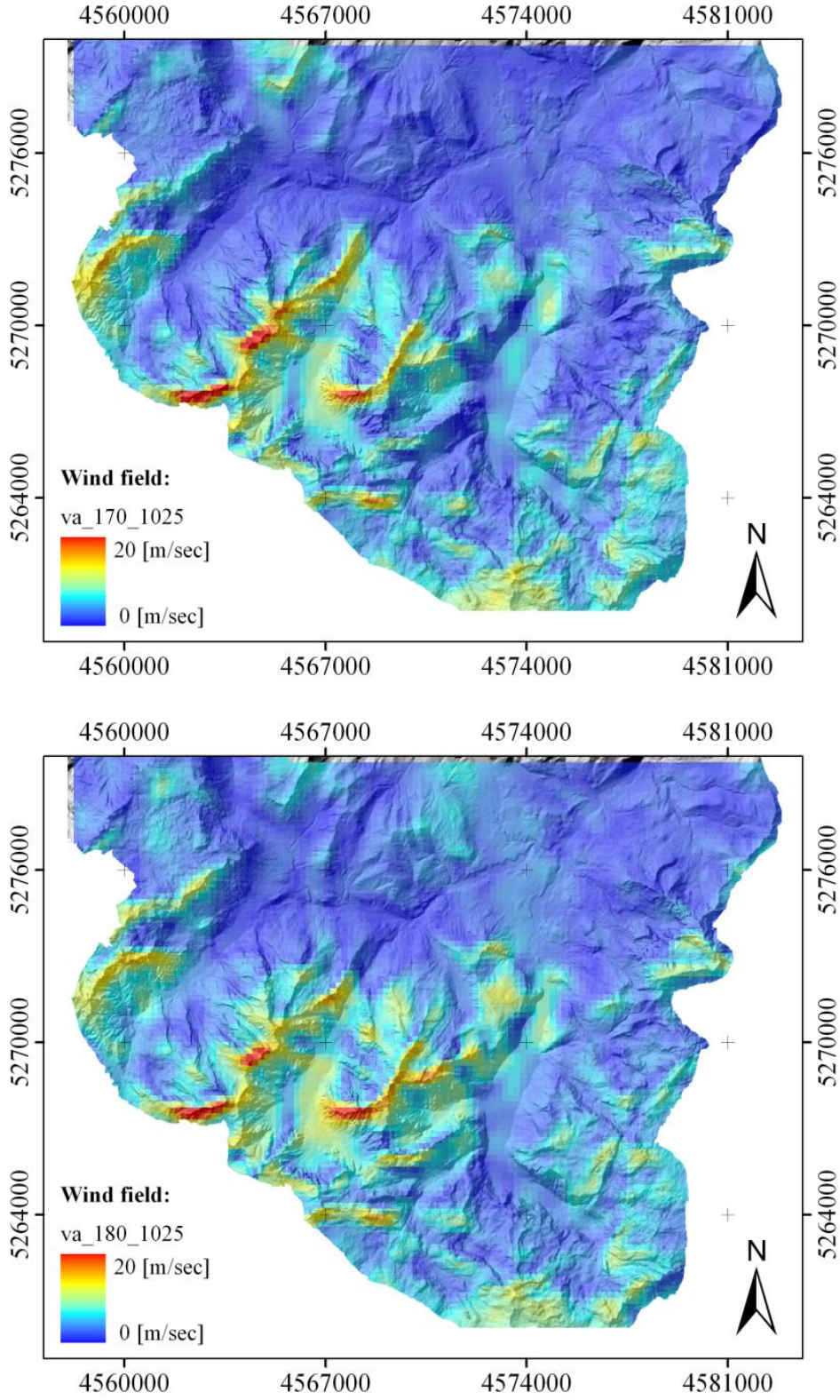

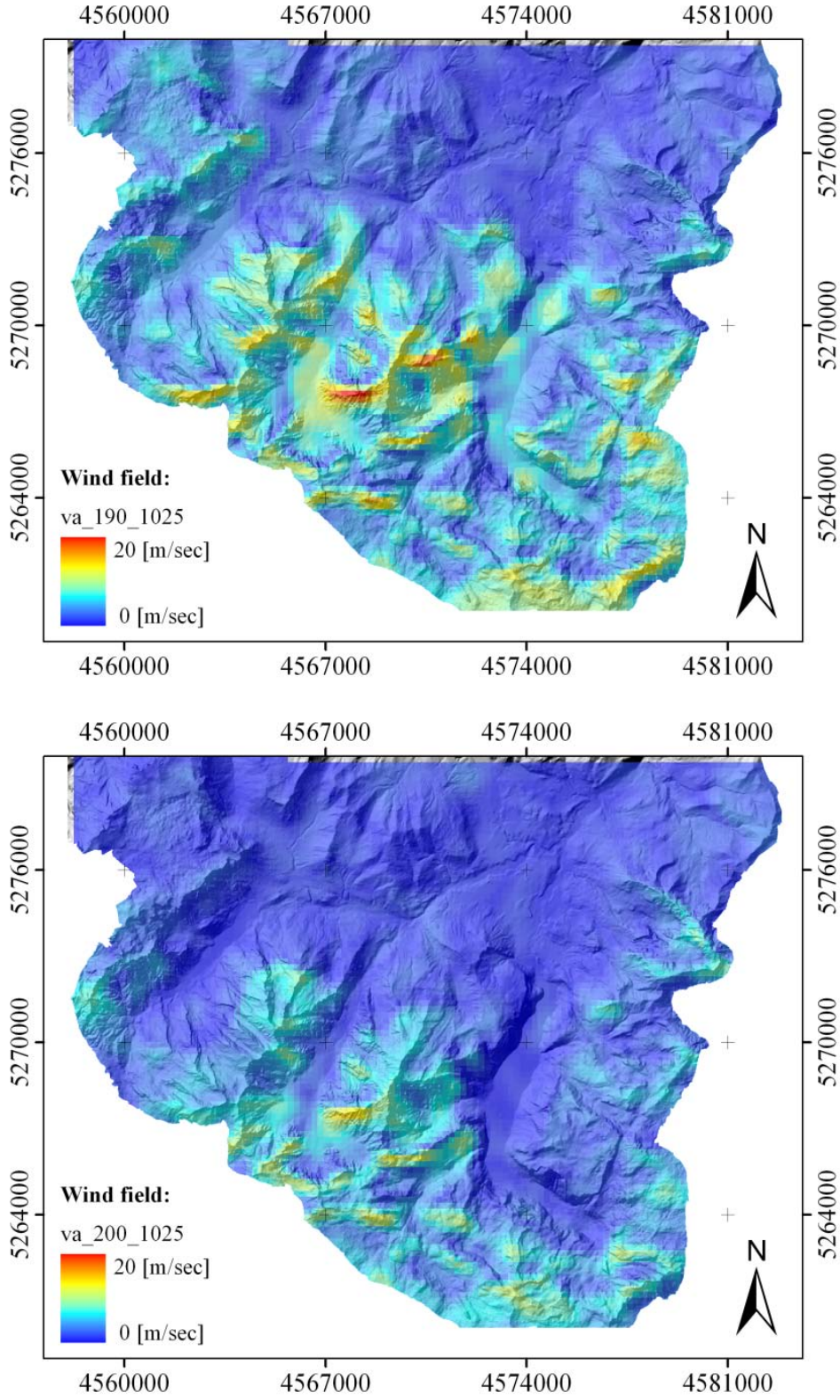

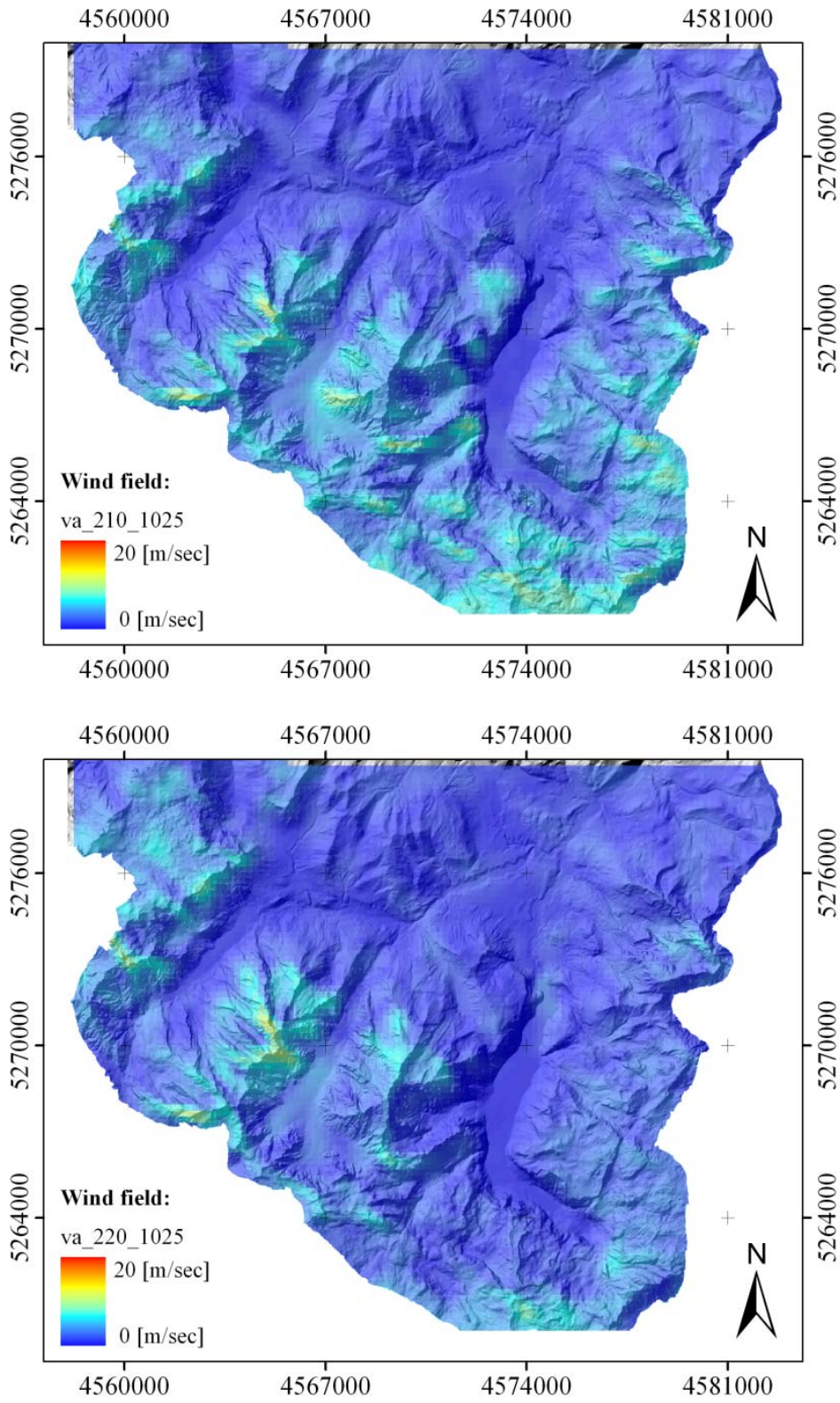

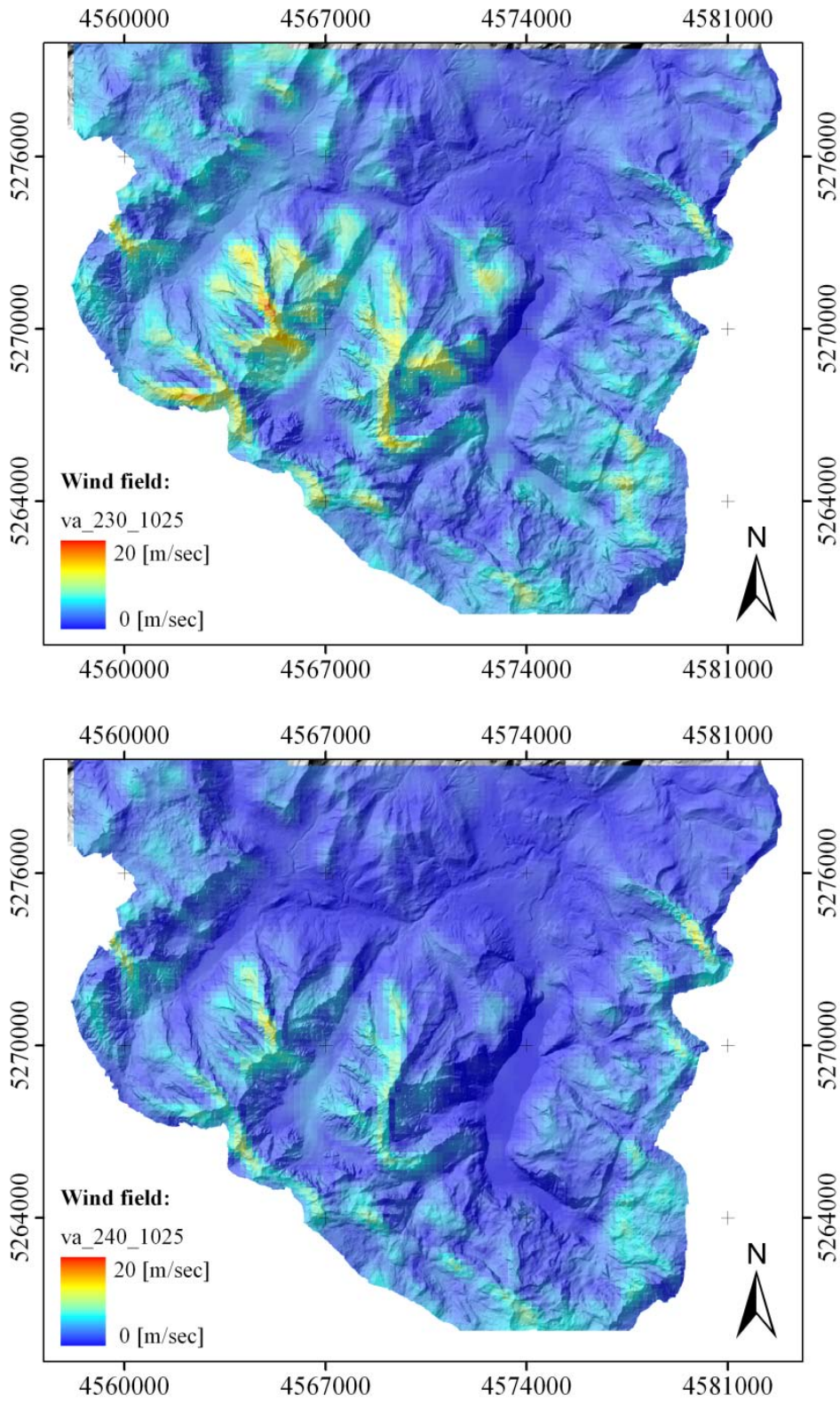

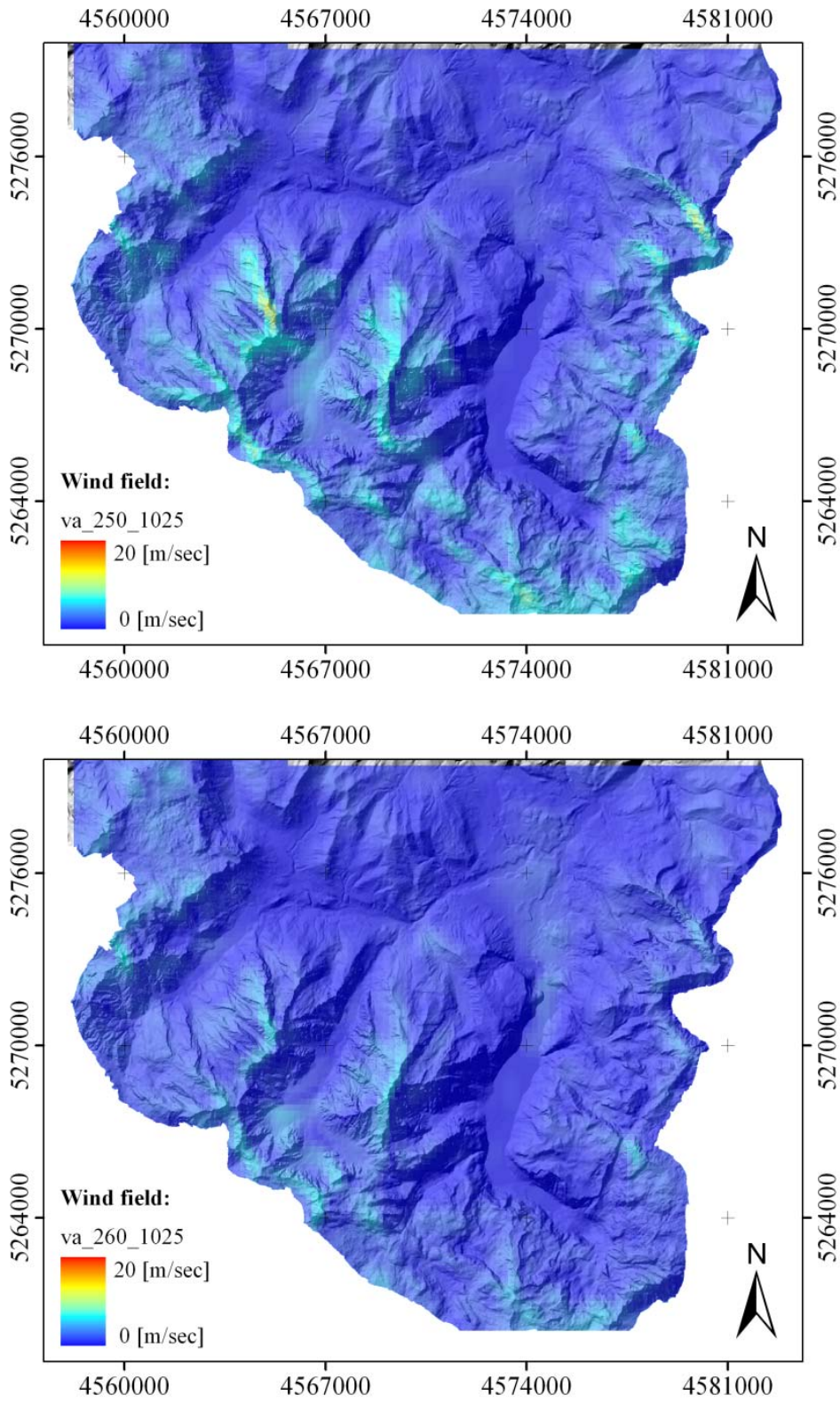

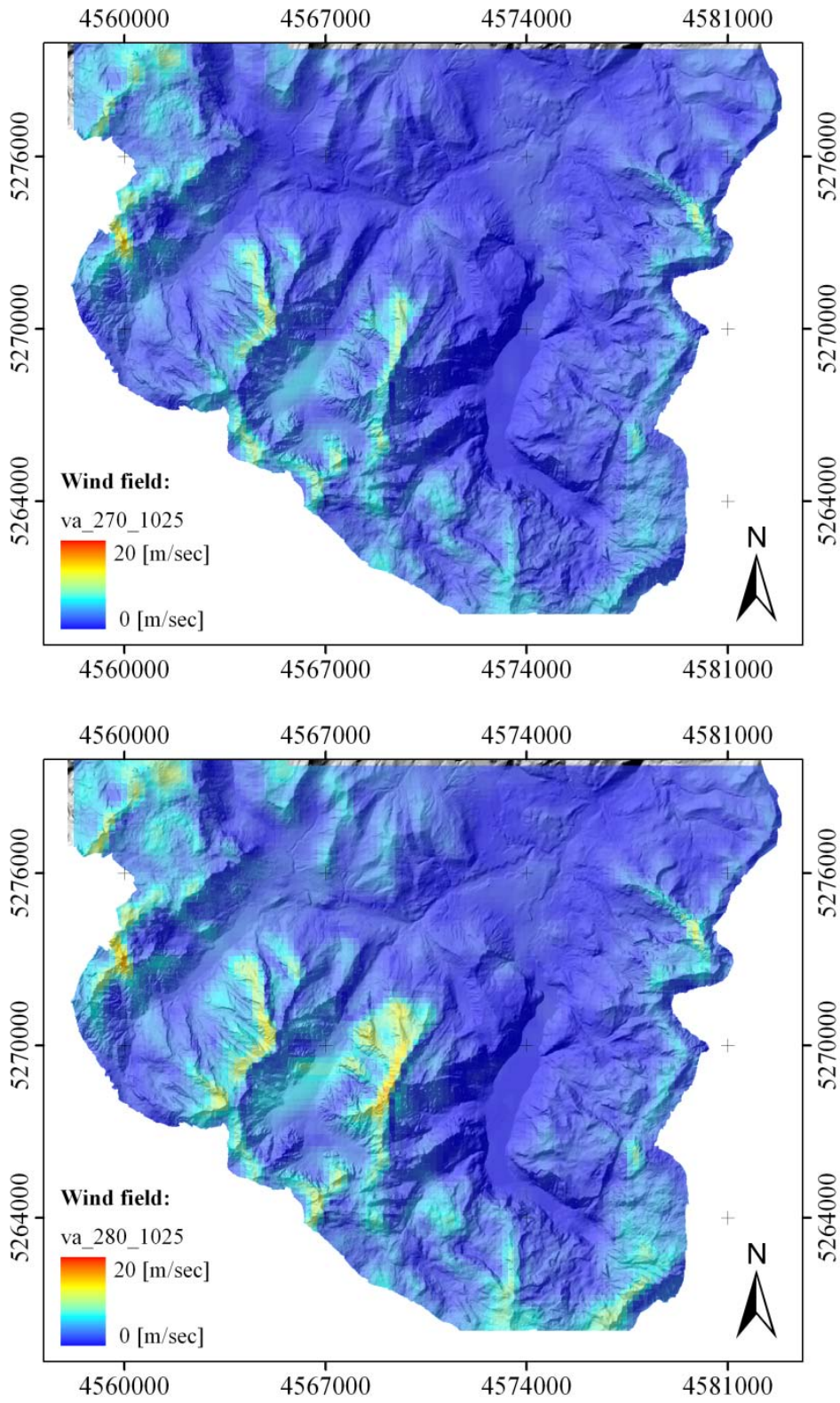

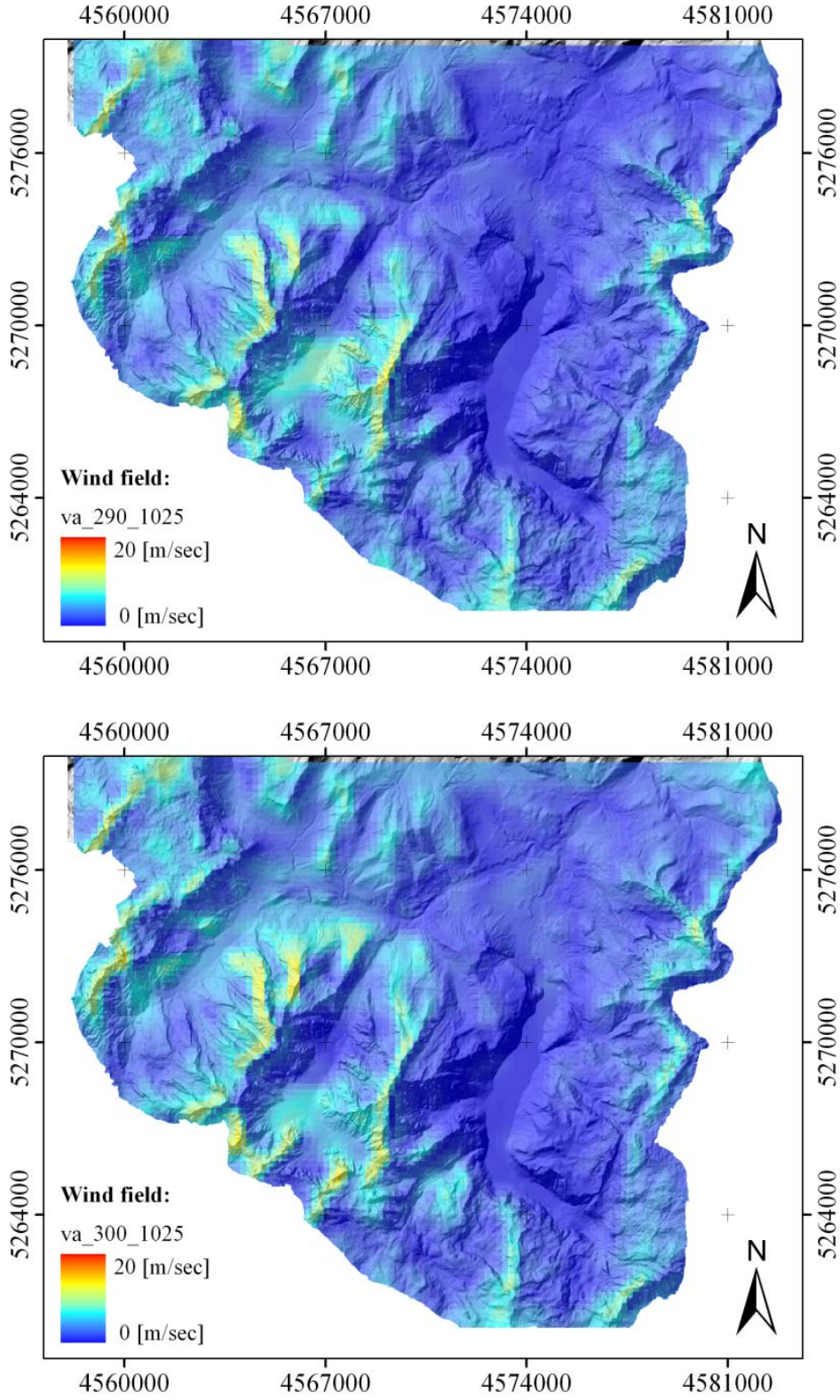

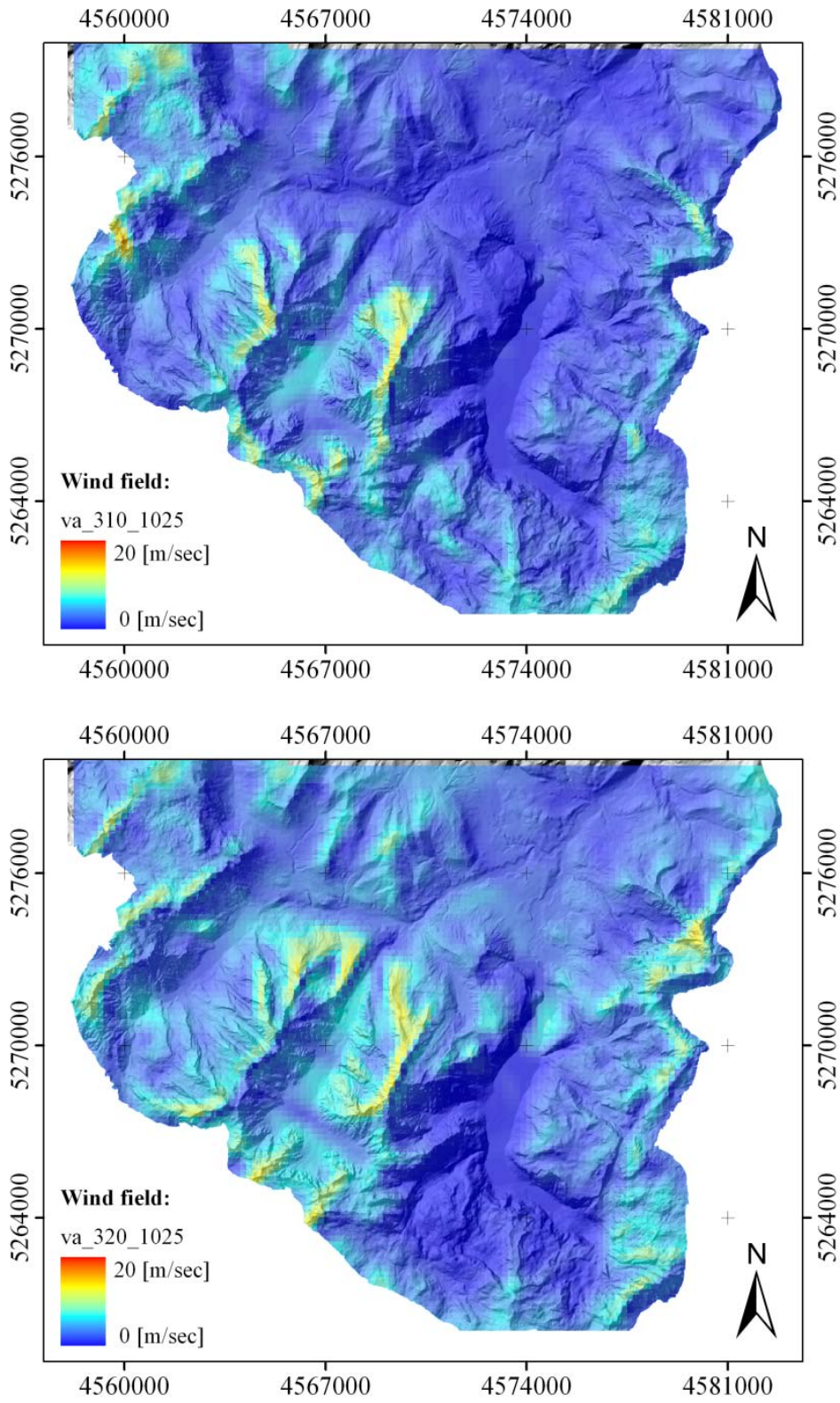

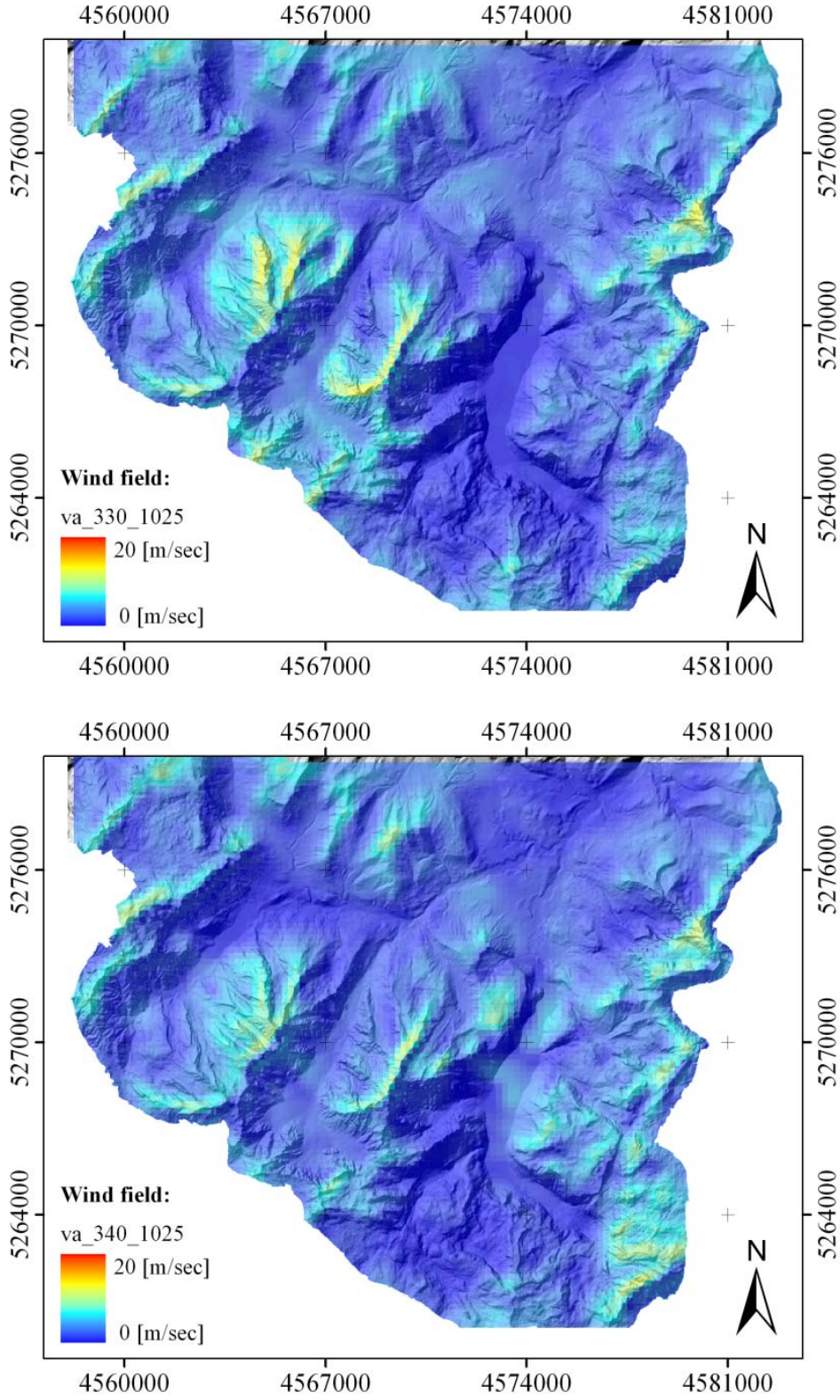

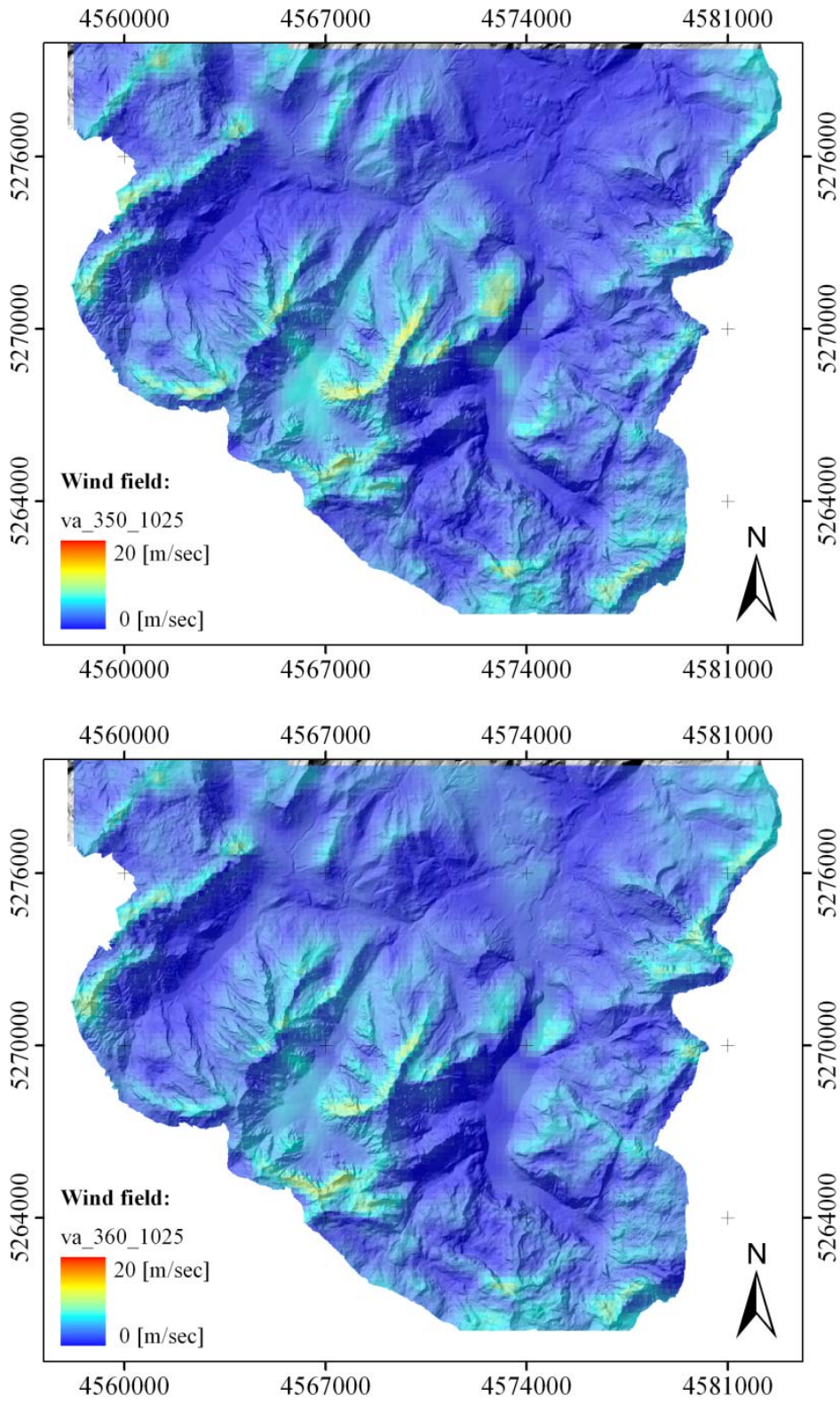
IV) Some impressions of the test-site:

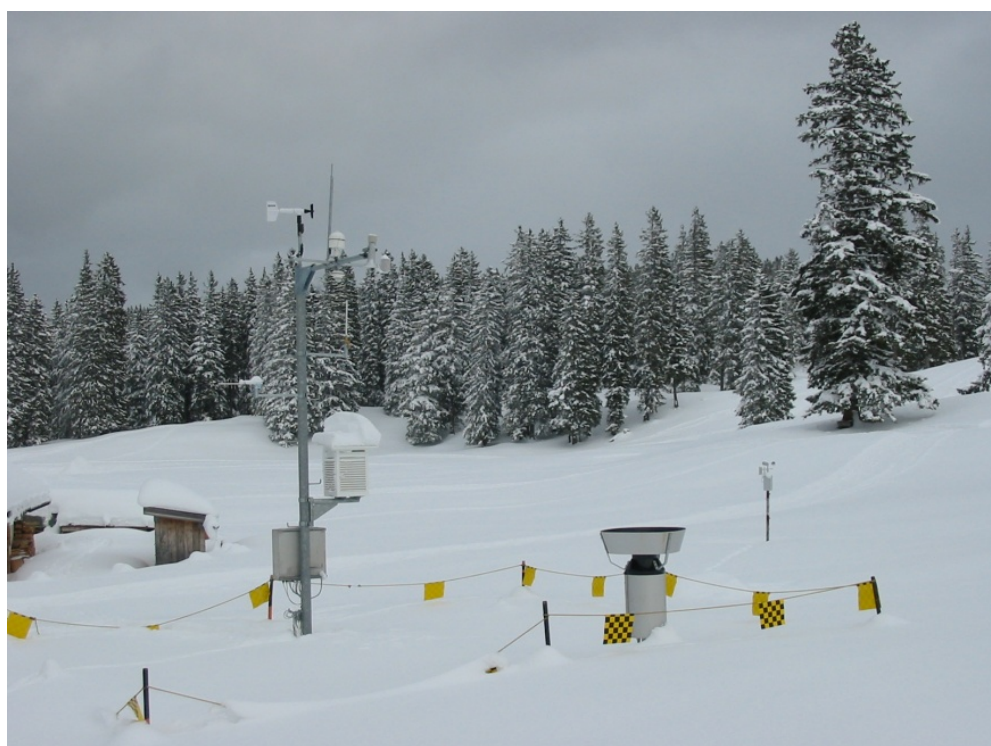

Kühroint

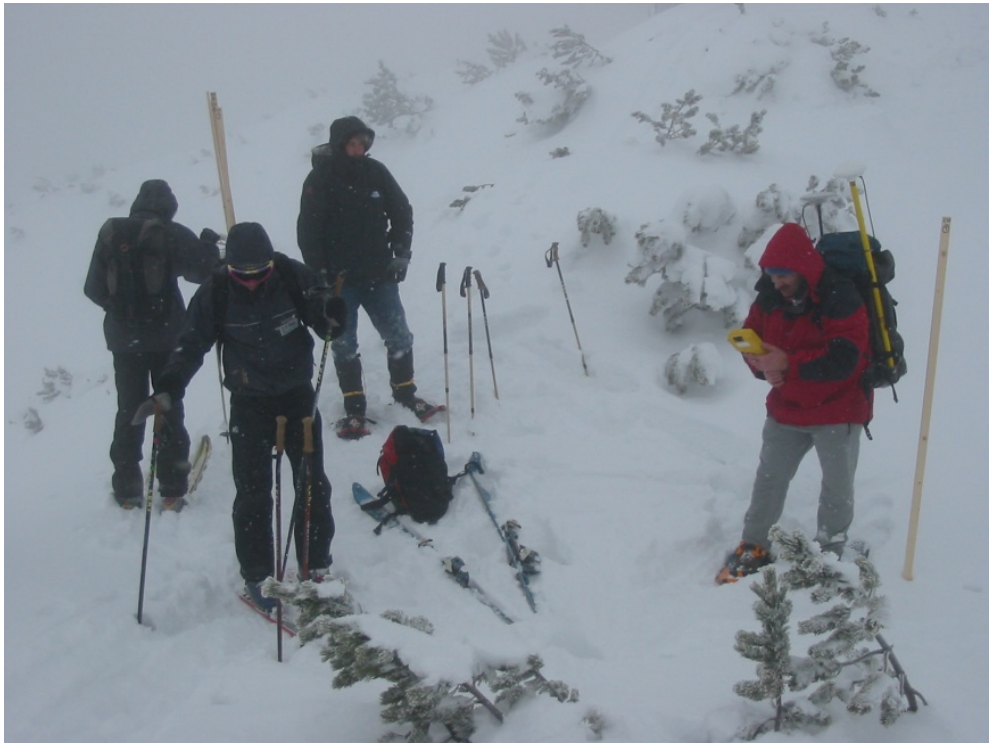

Field campaign 


\section{Personal CV}

Contact Information:

Name: -------------------------------------------- Bernhardt

First Name:------------------------------------------ Matthias

Address: ---------------------------------------------- Ickstattstr.9

80469 München

Telephone:

0049 179/5232822

Email:

m.bernhardt@iggf.geo.uni-muenchen.de

Personal Information:

Date of Birth:

08.08.1977

Place of Birth: Rosenheim

Citizenship: German

Gender: Male

Marital Status: Unmarried

Academic CV:

1998-2004: Study in Geography, Remote Sensing and Zoology, University of Munich 2004: Diploma in Geography (Mark: 1.0).

Diploma thesis: Modelling nitrogen fluxes under wheat stand utilizing the physically based model WHNSIM (Mark: 1.3). 
Since 2004: Scientific Staff member at the Department for

Geography, Ludwig-Maximilians-University.

Scholar CV:

1986-1988:

Primary school Au b. Bad Feilnbach

1988-1990:

Primary school Schloßberg

1990-1997:

Freie Waldorfschule Chiemgau

1997:

"Abitur” certificate at the Ludwig-Thoma

Gymnasium; Prien am Chiemsee. 